Key Words:

Environment

Remediation

Chlorinated Solvents

Retention:

Permanent

\title{
ENHANCED ATTENUATION: A REFERENCE GUIDE ON APPROACHES TO INCREASE THE NATURAL TREATMENT CAPACITY OF A SYSTEM
}

\section{AUGUST 2006}

Washington Savannah River Company Savannah River Site

Aiken, SC 29808
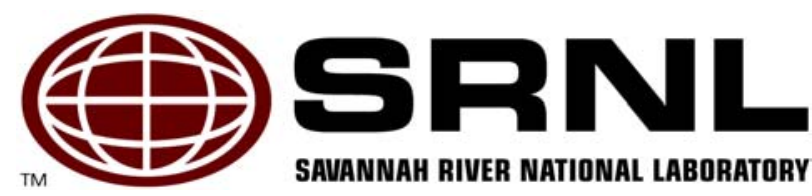


\section{DISCLAIMER}

Preparation of this report was coordinated by Westinghouse Savannah River Company (WSRC) for the United States Department of Energy (US DOE) under Contract No. DE-AC09-96SR18500. Extensive effort was made by the authors to assure the accuracy of the contents and interpretation. However, the USDOE nor WSRC, nor any of their employees makes any warranty, expressed or implied, or assumes any legal liability or responsibility for accuracy, completeness, or usefulness, of any information, apparatus, or product or process disclosed herein or represents that its use will not infringe privately owned rights. Reference herein to any specific commercial product, process, or service by trade name, trademark, name, manufacturer or otherwise does not necessarily constitute or imply endorsement, recommendation, or favoring of same by Westinghouse Savannah River Company or by the United States Government or any agency thereof. The views and opinions of the authors expressed herein do not necessarily state or reflect those of the United States Government or any agency thereof.

Printed in the United States of America

Prepared For

U.S. Department of Energy 
Key Words:

Environment

Remediation

Chlorinated Solvents

Retention:

Permanent

\title{
ENHANCED ATTENUATION: A REFERENCE GUIDE ON APPROACHES TO INCREASE THE NATURAL TREATMENT CAPACITY OF A SYSTEM
}

\author{
Prepared by the Enhancements Subteam \\ Tom Early, Geo Consultants, LLC \\ Bob Borden, North Carolina State University \\ Michael Heitkamp, Savannah River National Laboratory (SRNL) \\ Brian B. Looney, SRNL \\ David Major, GeoSyntec, Inc. \\ W. Jody Waugh, S. M. Stoller \\ Gary Wein, Bechtel Savannah River Inc. \\ Todd Wiedemeier, T.H. Wiedemeier \& Associates, LLC \\ Karen M. Vangelas, SRNL \\ Karen M. Adams, U.S. Department of Energy \\ Claire H. Sink, U.S. Department of Energy
}

AUGUST 2006

Washington Savannah River Company Savannah River Site

Aiken, SC 29808
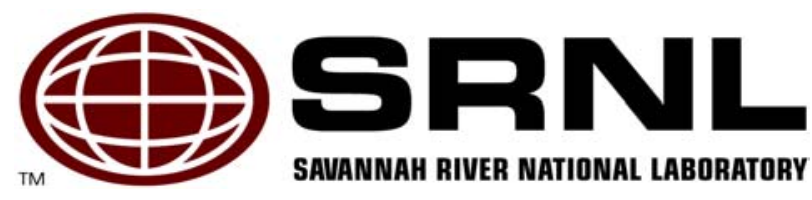
Page 131, second paragraph, second to last line. PCE and TCE were transposed in Rev. 0. Correction made.

References have been updated to reflect revisions to supporting documents.

Page 15. Paragraph 1. Updated Looney et al. reference to reflect publication year. Published in 2006.

Page 16. Paragraph 2. Updated Gilmore et al. reference to reflect revision to document. Now Revision 1.

Page 16 Paragraph 2. Updated Looney et al. reference to reflect publication year. Published in 2006.

Page 80. Paragraph 1. Updated Gilmore et al. reference to reflect revision to document. Now Revision 1.

Page 80. Paragraph 2. Updated Looney et al. reference to reflect publication year. Published in 2006.

Page 86. Provides updated reference for Gilmore et al, 2006.

Page 91. Provides updated reference for Looney et al. 2006. 


\section{FOREWORD}

In 2003 U.S. Department of Energy (DOE) Office of Environmental Management authorized an alternative project at the Savannah River Site designed to develop cost effective and environmentally protective technical solutions for the challenge of large and complex plumes of chlorinated volatile organic compounds (cVOCs) at DOE sites. The project builds upon the current U.S. Environmental Protection Agency (EPA) protocol and directive (EPA, 1998, 1999) for monitored natural attenuation (MNA). The DOE effort focuses on three major technical thrust areas: mass balance, enhanced attenuation (EA), and innovations in characterization/monitoring. Each of these three topics is supported by a broad-based group of recognized technical experts and each group currently is developing an interim report related to the topic area. By introducing the concepts of mass balance and EA, along with the technical basis and documentation for these concepts, the project is working toward a goal of providing new and powerful tools for transitioning from active remediation to a protective long term monitoring state. This project is a departure from classical MNA in that its central theme is to take an active part, as needed, to achieve a favorable balance between the release of contaminants from sources (source loading) and processes that destroy or retard migration of contaminants in resultant plumes (attenuation capacity of the system).

\section{OBJECTIVES}

The objective of this document is to explore the realm of enhancements to natural attenuation processes for cVOCs and review examples that have been proposed, modeled, and implemented. We will identify lessons learned from these case studies to confirm that enhancements are technically feasible and have the potential to achieve a favorable, costeffective contaminant mass balance. Furthermore, we hope to determine if opportunities for further improvement of the enhancements exist and suggest areas where new and innovative types of enhancements might be possible.

\section{TARGET AUDIENCE}

The intended audience for this reference guide includes state and federal regulators, stakeholders, and environmental managers, as well as environmental technology professionals. Although this diverse group is technically astute, not all users of the document will be subject-area experts for the various technologies discussed. This fact poses a significant challenge to achieve an appropriate level of technical detail. To the extent possible, enhancement technologies are covered succinctly in the main body of the document. However, supplemental information on many enhancements has been included in Appendix A so that readers seeking additional information and references can find them easily. 
An overview of the purpose of the document is presented in Section 1. The conceptual framework and organizing principles of enhancements to natural attenuation of cVOCs in the subsurface are presented in Section 2. This section contains a summary discussion of different classes of enhancements and the concept of enhancement zones is introduced. The objective of Section 2 is to establish the technical basis and justification for the premise that enhancements to natural attenuation processes have the potential to reduce the mass flux of contaminants sufficiently to meet regulatory requirements. In addition, questions related to required effectiveness of enhancements and regions where they might be applied for maximum benefit also are discussed in Section 2. Sections 3 through 6 present technical reviews of potential enhancements and many of these are linked to supplemental material in Appendix A that provides more detailed information. A spectrum of enhancements including those applicable to the source zone to reduce source loading as well as methods to improve biological and abiotic degradation of contaminants is provided. A brief summary of relevant case studies for different types of enhancements is presented in tabular form in Appendix B. Section 7 addresses another key factor related to enhancements: how to integrate cost and performance optimization (i.e., decision analysis) into a systems approach to enhancements. Also included in Section 7 is a summary chart of the technical reviews presented in Sections 3 through 6. This chart includes a column titled "Regulatory Acceptance". The Interstate Technology and Regulatory Council through the Enhanced Attenuation: Chlorinated Organics Team was instrumental in rating the potential enhancements for regulatory acceptability.

Throughout the text, case studies that illustrate examples of different potential enhancements are presented in boxes. These case studies generally represent actions that were taken to reduce risk at a site by reducing the flux of contaminants, but they were carried out independent of the Enhanced Attenuation (EA) concept. However, now we are examining them within this context to determine if and how they can be integrated into EA to provide sustainable and quantifiable reductions in contaminant mass flux (i.e., increases in attenuation capacity) in vadose zone and aquifer systems. Some of the case studies reveal technologies that are fully mature now and readily adaptable to EA. However, others may have deficiencies that make their application to EA problematic or will require modifications or further research to become useful. These deficiencies represent targets for further science and engineering improvements.

Current research and future research opportunities that can help resolve these deficiencies are summarized in Section 8. As noted above, summary information for a broader range of case studies is presented in tabular form in the Appendix B.

Conclusions and recommendations are presented in Section 9. 


\section{TABLE OF CONTENTS}

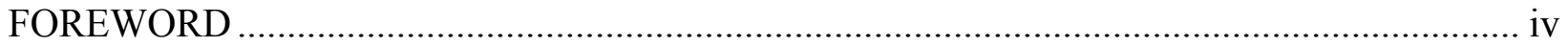

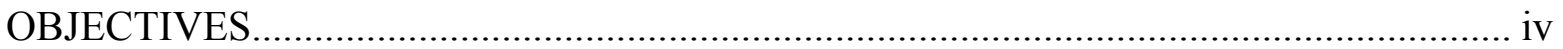

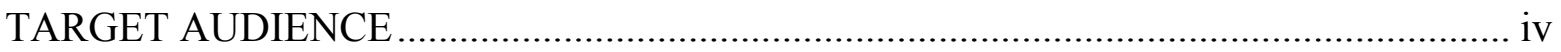

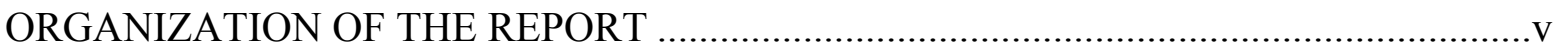

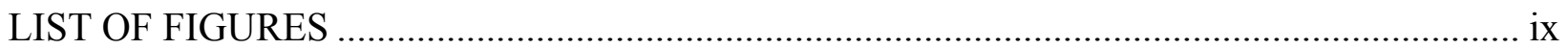

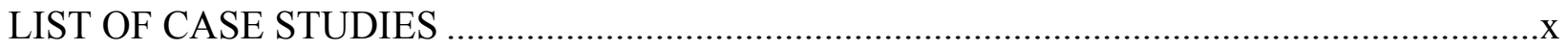

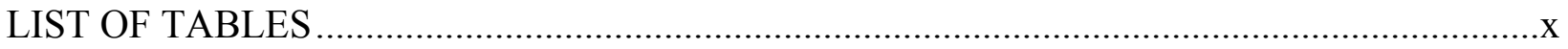

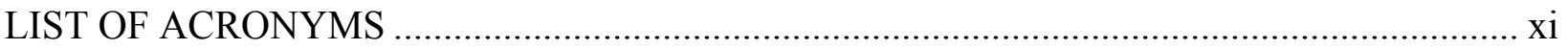

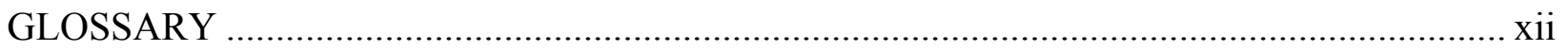

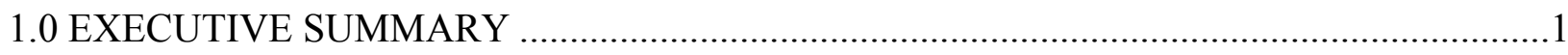

2.0 CONCEPTUAL FRAMEWORK OF ENHANCED ATTENUATION ...................................

2.1 NATURAL ATTENUATION PROCESSES ……………........................................6

2.1.1 Physical Attenuation Processes......................................................................6

2.1.2 Chemical Attenuation Processes.......................................................................

2.1.3 Biological and Abiotic Degradation Attenuation Processes ...............................

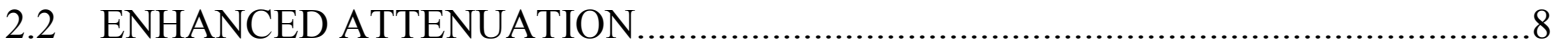

2.2.1 What do we mean by the term "enhancement"? ............................................... 8

2.2.2 How effective do enhancements need to be? ....................................................12

2.2.3 How must enhancements be tailored to current and future environmental settings? ............................................................................. 12

2.2.4 Where can the enhancements be used most effectively? .................................13

2.2.5 How do enhancements interface with mass balance and characterization/ monitoring? ......................................................................14

2.2.6 Organization of Discussions about Enhancements ..........................................16

3.0 ENHANCEMENTS TO REDUCE PLUME LOADING: HYDRAULIC

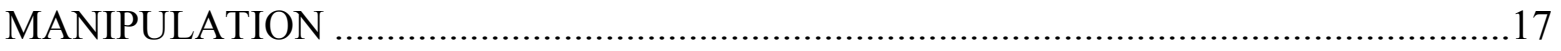

3.1 REDUCE INFILTRATION THROUGH THE SOURCE ZONE ..................................18

3.1.1 Intercept and divert surface runoff and stormflow water ....................................18

3.1.2 Reduce Infiltration with Sustainable Covers.......................................................19

3.1.2.1 Conventional and Alternative Covers .................................................19

3.1.2.2 Vegetation Management for Alternative Covers...................................21

3.1.2.3 Processes Influencing Cover Performance ...........................................22

3.1.2.4 Long-Term Cover Performance Issues..................................................22

3.2 REDUCE MASS TRANSFER OF CONTAMINANTS TO

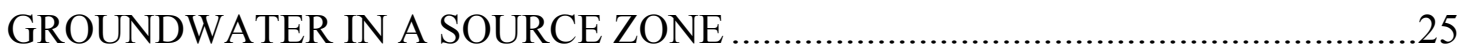

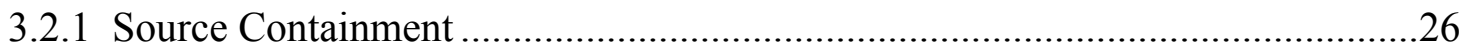


3.2.1.1 Low-permeability barriers to divert groundwater around a source......26

3.2.1.2 Encapsulation of waste in a source ..................................................27

3.2.1.3 Use of diffusion barriers to enhance source containment ....................27

3.2.2 Modifying the Hydraulic Gradient with Drainage Structures ............................28

3.2.3 Modifying the Hydraulic Gradient Through Phytotranspiration........................29

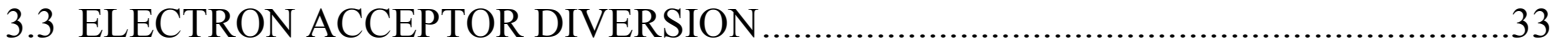

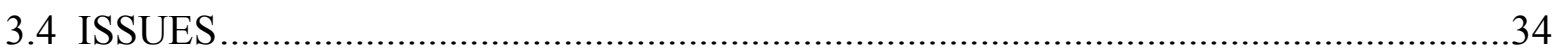

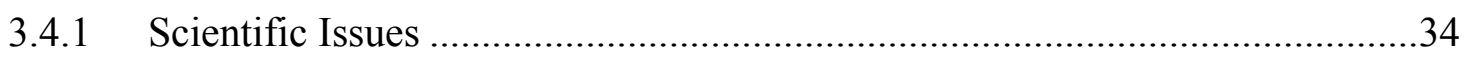

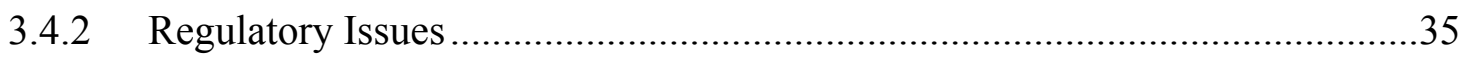

4.0 ENHANCEMENTS TO REDUCE PLUME LOADING: PASSIVE RESIDUAL

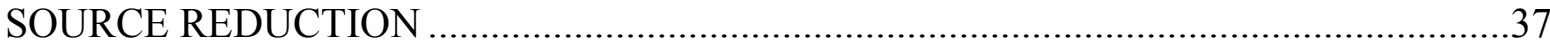

4.1 PASSIVE VAPOR EXTRACTION OF CVOCS FROM THE VADOSE

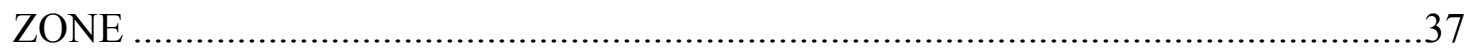

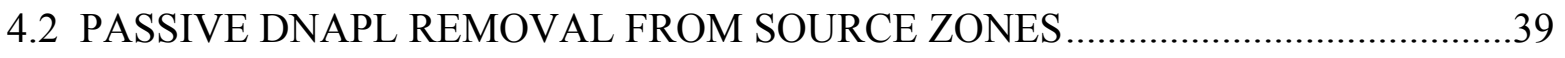

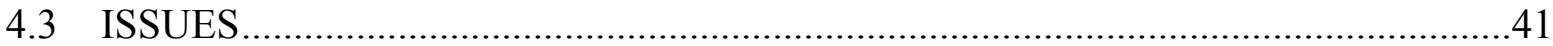

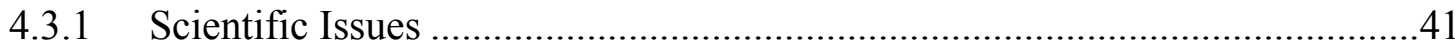

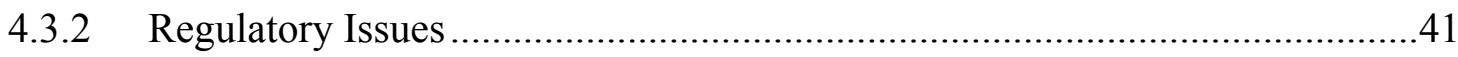

5.0 INCREASE SYSTEM ATTENUATION CAPACITY: BIOLOGICAL

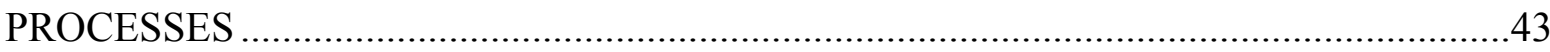

5.1 MICROBIAL DEGRADATION METHODS ...................................................44

5.1.1 Biostimulation using Long-Lived Electron Donors, Electron

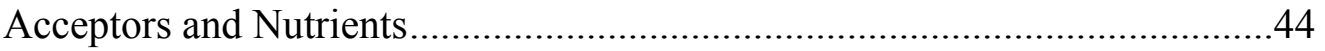

5.1.1.1 Methods for Controlling Reagent Release Rate ...............................45

5.1.1.2 Reagent Delivery Approaches....................................................46

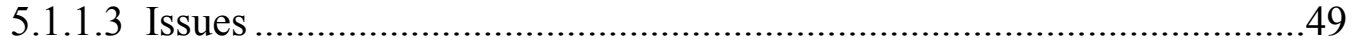

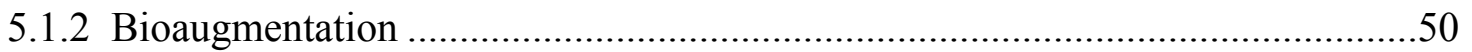

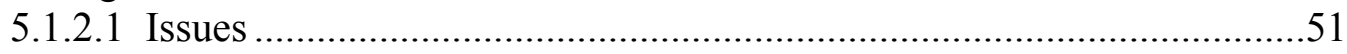

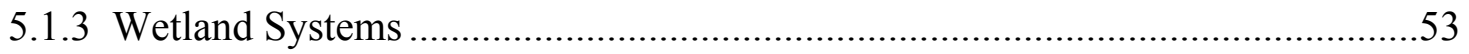

5.1.3.1 The role of plants in wetland systems ..........................................5

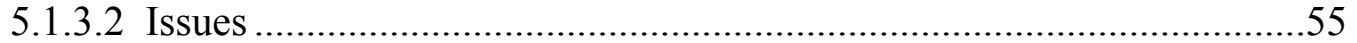

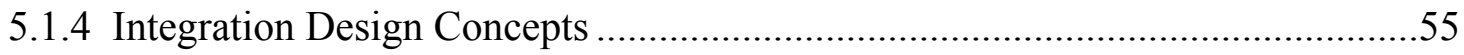

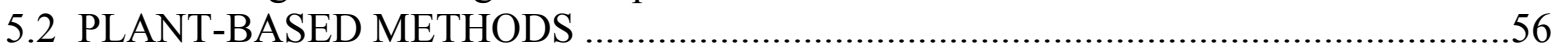

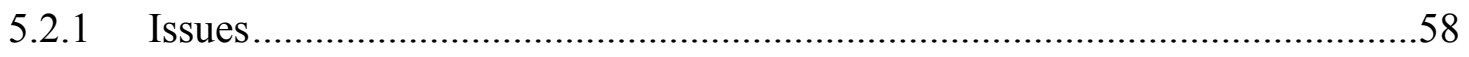

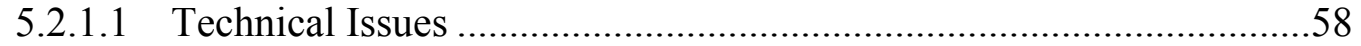

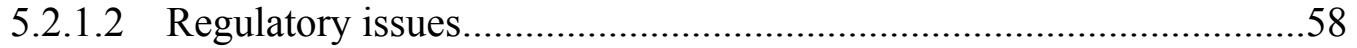

\subsection{ABIOTIC AND BIOLOGICALLY MEDIATED ABIOTIC ATTENUATION} METHODS

6.1 ABIOTIC REACTIONS WITH REDUCED IRON AND SULFUR PHASES WITH OR WITHOUT BIOLOGICAL MEDIATION ..............................59

6.1.1 Abiotic Reactions with Reduced Mineral Phases.............................................59

6.1.2 Biologically Mediated Abiotic Reactions ................................................60

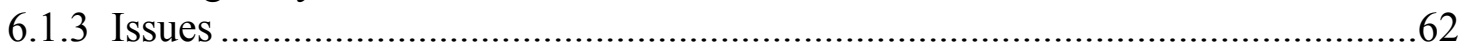

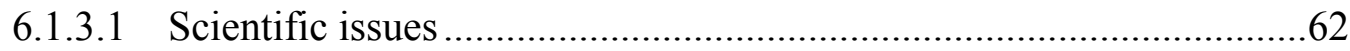

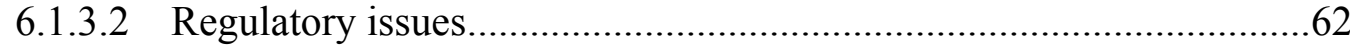


6.2.1 Issues ..... .63

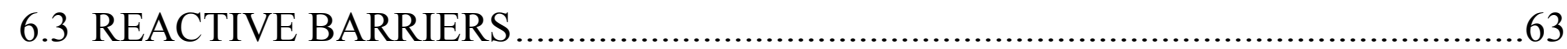

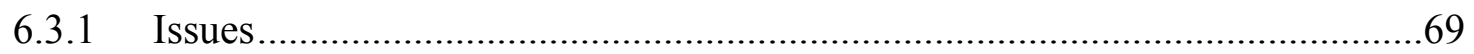

6.3.1.1 Technical Issues ...................................................................69

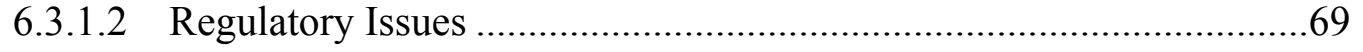

7.0 STRATEGY FOR APPLYING ENHANCEMENTS …..........................................

8.0 RESEARCH ON ENHANCEMENTS TO ATTENUATION PROCESSES ......................75

8.1 SUMMARY OF PROJECT RESEARCH STUDIES ............................................75

8.2 OTHER RESEARCH OPPORTUNITIES FOR ENHANCEMENTS ..........................76

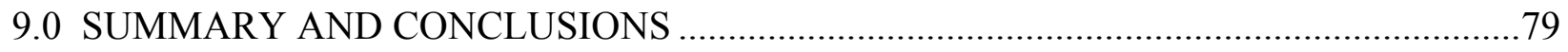

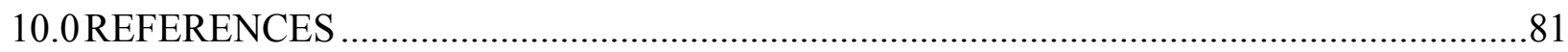

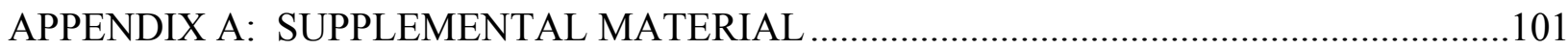

APPENDIX B: CASE STUDY SUMMARY TABLES......................................................134 


\section{LIST OF FIGURES}

Figure 2-1. Natural attenuation processes decrease the mass flux of contaminants..................6

Figure 2-2. Flow diagram illustrating the distinction between MNA and EA............................9

Figure 2-3. Enhancements to natural attenuation processes increase the attenuation

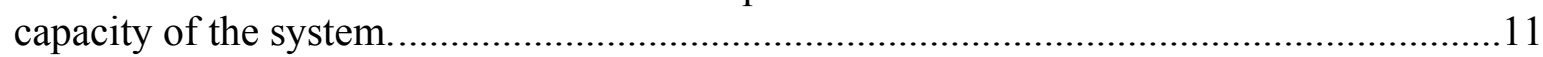

Figure 2-4. Natural attenuation enhancement zones in a plume ..........................................14

Figure 3-1. Relationship among precipitation, runoff, stormflow, and infiltration ...................19

Figure 3-2. Constant Head Moat Concept (from M. Ankeny, pers. comm.) ............................31

Figure 3-3. Seasonal Depression of the Water Table Underlying a Hybrid Poplar

Plantation (after Hansen, 1991) .....................................................................................32

Figure 3-4. Electron Acceptor Diversion Concept. Other types of diversion concepts

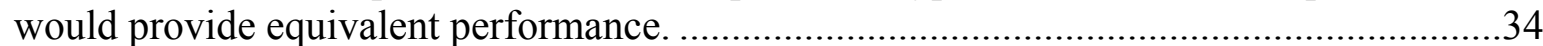

Figure 4-1. Illustration of the BERT Treatment System (from DOE, 2000a) ..........................39

Figure 6-1. Permeable Reactive Barrier to Remediate Contaminated Groundwater..................65 


\section{LIST OF CASE STUDIES}

Case Study 3-1. Surface and Stormflow Water Control at Oak Ridge National

Laboratory.......................................................................................................... 20

Case Study 3-2. EPA's Alternative Cover Assessment Project (ACAP) ............................. 24

Case Study 3-3. Use of French Drains at ORNL to Suppress the Water Table..................... 30

Case Study 4-1. Passive Soil Vapor Extraction (SVE) at the Savannah River Site

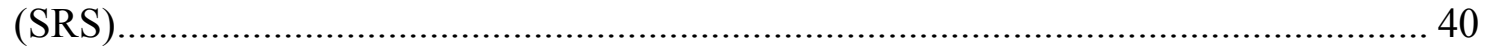

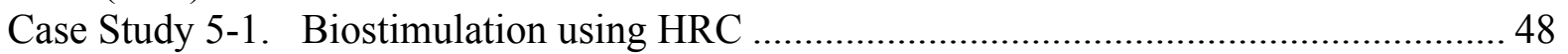

Case Study 5-2. Bioaugmentation at former Kelly AFB, Texas......................................... 52

Case Study 5-3. Wetlands Treatment at Aberdeen Proving Ground, MD ............................ 54

Case Study 6-1. Enhanced Biogeochemical Reductive Dechlorination (BiRD) ................... 64

Case Study 6-2. Reactions in Two PRBs with Contrasting Groundwater

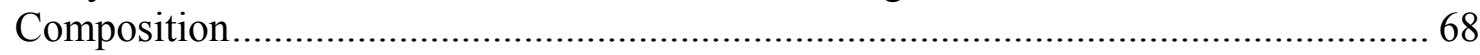

\section{LIST OF TABLES}

Table 5-1. Application Strategy of Processes to Achieve EA ………….....................................56

Table 6-1. Examples of Precipitated Minerals Found in Fe(0) Field-Installed PRBs and Column Studies. (Liang, et al. 2003) .........................................................................67

Table 7-1. Summary of Criteria Affecting the Choice of Enhancement ......................................73

Table 8-1. Examples of Potential Research Opportunities for Enhancements …………..............78 


\section{LIST OF ACRONYMS}

$\begin{array}{ll}\text { ACAP } & \text { Alternative Cover Assessment Project } \\ \text { BERT } & \text { Barometrically enhanced remediation technology } \\ \text { BiRD } & \text { Biogeochemical reductive dechlorination } \\ \text { CFB } & \text { Canadian Forces Base } \\ \text { cVOC } & \text { Chlorinated volatile organic compound } \\ \text { DCE } & \text { Dichloroethene } \\ \text { Dhc } & \text { Dehalococoides } \\ \text { DNAPL } & \text { Dense non-aqueous phase liquid } \\ \text { DoD } & \text { Department of Defense } \\ \text { DOE } & \text { Department of Energy } \\ \text { EA } & \text { Enhanced attenuation } \\ \text { EPA } & \text { Environmental Protection Agency } \\ \text { ESTCP } & \text { Environmental Security Technology Verification Program } \\ \text { ET } & \text { Evapotranspiration } \\ \text { GEMs } & \text { Genetically engineered microorganisms } \\ \text { GRAS } & \text { Generally recognized as safe } \\ \text { HRC } & \text { Hydrogen release compound } \\ \text { KH } & \text { Saturated hydraulic conductivity } \\ \text { MCL } & \text { Maximum concentration limit } \\ \text { MNA } & \text { Monitored natural attenuation } \\ \text { NAPL } & \text { Non-aqueous phase liquid } \\ \text { NAS } & \text { Naval Air Station } \\ \text { NOM } & \text { Natural organic matter } \\ \text { O\&M } & \text { Operations and maintenance } \\ \text { PCA } & \text { 1,1,2,2-tetrachloroethane } \\ \text { PCB } & \text { Polychlorinated biphenyl } \\ \text { PCE } & \text { Perchloroethene or tetrachloroethene } \\ \text { PGDP } & \text { Paducah Gaseous Diffusion Plant } \\ \text { PRB } & \text { Permeable reactive barrier } \\ \text { R\&D } & \text { Research and development } \\ \text { RFID } & \text { Radio frequency identification } \\ \text { SDRI } & \text { Sealed double-ring infiltrometer } \\ \text { TCA } & \text { Trichloroethane } \\ \text { TCE } & \text { Trichloroethene } \\ \text { TSB } & \text { Two-stage borehole permeameter } \\ \text { WAG } & \text { Waste Area Group } \\ \text { VOC } & \text { Volatile organic compound } \\ \text { VC } & \text { Vinyl chloride } \\ \text { ZVI } & \text { Zero valent iron } \\ & \end{array}$




\section{GLOSSARY}

\section{Bioaugmentation}

Application of bioaugmentation to EA involves seeding aquifers with requisite microorganisms depending on the mix of chlorinated solvents and prevailing environment where conventional microbial analyses, microcosm studies, extended field trials, and molecular probes of indigenous microbial communities show that chlorinated solventdegrading microorganisms are not present or are so poorly distributed or at low population densities that their activity does not provide adequate biodegradation capacity.

\section{Biostimulation}

A variety of biologically mediated processes that can be used to enhance the degradation of chlorinated solvents in the subsurface including cometabolic reductive dechlorination, halorespiration, anaerobic oxidation, and direct oxidation. All of these processes require the presence of: (a) microorganisms with the required metabolic capabilities; (b) a biologically available electron acceptor or donor; and (c) nutrients for cell growth. Biostimulation typically involves continuous delivery of a slow, steady supply of one or more chemical reagents including electron acceptors (oxygen, nitrate, sulfate), electron donors (carbohydrates, fatty acids, and $\mathrm{H}_{2}$ ), and nutrients (nitrogen, phosphorus, trace minerals and vitamins).

\section{Enhanced attenuation; enhancement}

An enhancement is any type of intervention that we might implement in a source-plume system that increases the magnitude of attenuation by natural processes beyond that which occurs without our intervention. Enhanced attenuation is the result of applying an enhancement that sustainably manipulates a natural attenuation process leading to an increased reduction in mass flux of contaminants.

\section{"Irreversible" sorption}

Irreversible sorption refers to a hysteresis effect in which a chemical species is more strongly bound to the sorbing medium during desorption than during initial sorption. The term sometimes appears to be used to describe a situation where once sorbed, the contaminant is essentially permanently removed from the plume and remains associated with the sorbing aquifer (or vadose zone) material.

\section{Monitored Natural Attenuation}

"The term 'monitored natural attenuation' ...refers to the reliance on natural attenuation processes (within the context of a carefully controlled and monitored clean-up approach) to achieve site-specific remedial objectives within a time frame that is reasonable compared to that offered by other more active methods. The 'natural attenuation processes' that are at work in such a remediation approach include a variety of physical, chemical, or biological processes that, under favorable conditions, act without human intervention to reduce mass, toxicity, mobility, volume, or concentration of contaminants in soil or groundwater." (EPA, 1999; pg. 3) 


\section{Phytodegradation}

The process in which some plant species can metabolize cVOC contaminants. The resulting metabolic products include trichloroethanol, trichloroacetic acid, and dichloracetic acid. Mineralization products are probably incorporated into insoluble products such as components of plant cell walls.

\section{Phytovolatilization}

The process in which cVOCs are taken up by plants and discharged into the atmosphere during transpiration.

\section{Propagule}

Any part of a plant (e.g. bud) that facilitates dispersal of the species and from which a new plant may form.

\section{Rhizodegradation}

The process whereby plants modify the environment of the root zone soil by releasing root exudates and secondary plant metabolites. Root exudates are typically photosynthetic carbon, low molecular weight molecules, and high molecular weight organic acids. This complex mixture modifies and promotes the development of a microbial community in the rhizosphere. These secondary metabolites have a potential role in the development of naturally occurring contaminant-degrading enzymes.

\section{Rhizosphere}

The soil environment encompassing the root zone of the plant.

\section{Sustainable enhancement}

A sustainable enhancement is an intervention action that continues until such time that the enhancement is no longer required to reduce contaminant concentrations or fluxes. 


\subsection{EXECUTIVE SUMMARY}

Monitored natural attenuation (MNA) and enhanced attenuation (EA) are two environmental management strategies that rely on a variety of attenuation processes to degrade or immobilize contaminants and are implemented at appropriate sites by demonstrating that contaminant plumes have low risk and are stable or shrinking. There will be instances when the natural attenuation capacity of the system may not be sufficient to allow MNA to be included in the remediation train and "active" treatments alone will not allow the remediation goal to be met.

Enhanced attenuation is a new remediation class that allows an enhancement to be introduced as part of a remedy to increase the system attenuation capacity. The basis for identifying this new remediation class is that the US Environmental Protection Agency (EPA) directive on monitored natural attenuation (EPA, 1999) includes the following statement: “...by definition, a remedy that includes the introduction of an enhancer of any type is no longer considered to be 'natural' attenuation." Sustainable EA processes, when added to the remediation treatment train, may result in an increase in attenuation capacity sufficient for meeting the remediation goal.

Enhanced attenuation processes fall into two classes: a) those that reduce mass loading from the source to the plume, and b) those that augment existing attenuation processes occurring within the plume and at the compliance point. For an existing source or active treatment to be classified as an EA technology, the treatment process must have the ability to reduce flux to the point that the natural processes can meet remedial goals at the compliance point within a reasonable timeframe. In addition, the enhancements must be sustainable. Our definition of sustainability is: A sustainable enhancement is an intervention that continues until such time that the enhancement is no longer required to reduce contaminant concentrations or fluxes. Ideally, a single phase of intervention will be sufficient to produce a sustainable enhancement, but some flexibility in this guideline is appropriate.

Enhancements discussed in this reference guide specifically address chlorinated volatile organic contaminants such as TCE and PCE, although some approaches (e.g. those that rely on engineered structures) frequently are equally applicable to other classes of contaminants. Enhancements that can meet or have potential for meeting the requirements of sustainability and reducing contaminmant mass flux include the following:

Reduce mass loading from a source

- Engineered structures to intercept and divert surface runoff, stormflow, and groundwater flow (also including diversion of competing electron acceptors)

- Methods for reducing infilitration in source areas (e.g. engineered covers; plantbased methods)

- Waste encapsulation (e.g. grouting; diffusion barriers using non-toxic vegetable oil)

- Techniques for lowering the hydraulic gradient in source areas (e.g. french drains, plant-based methods)

- Passive reduction of source mass (e.g. soil vapor extraction by barometric pumping) 
Reduce mass flux within a plume

- Biological processes

$\circ$ Biostimulation

- Bioaugmentation

- Wetlands (natural and constructed)

- Plant-based methods

- Abiotic processes

- Contaminant degradation by biologically-enhanced abiotic reactions

- Permeable reactive barriers

Many of these enhancements represent mature technologies that enjoy a firm theoretical basis, an extensive history of full-scale field deployment, and long-term performance data under a variety of site conditions (e.g. engineered diversion structures and covers). In contrast, some enhancements are more conceptual in nature or still under development with few or no examples of field implementation (e.g. diffusion barriers, biologically-enhanced abiotic processes). The report includes a variety of case studies that illustrate examples where enhancements have been used and their impact on the physical properties of the system (e.g. hydraulic gradient) or the concentration of contaminants.

Each category of enhancement is discussed in the report along with an assessment of any technical and regulatory issues that might be involved. Technical issues frequently include concern about the sustainability of the enhancement. Regulatory issues tend to focus on acceptability. Supplemental material that provides a more in-depth discussion of many enhancements is included in Appendix A.

The decision process by which enhancements are chosen for application at a site is important and depends on site conditions (e.g. geology, hydrology, depth of contaminants), potential locations for deploying an enhancement (source, plume, receptor), and cost factors. Section 7 contains a matrix (Table 7-1) that lists the major classes of enhancements discussed in the report and provides summary-level information for some of the key criteria that will affect the selection of enhancements for a site. It is useful for comparing the features of different types of enhancements and to what part of the source-plume system they are applicable.

Finally, this reference guide includes a discussion of areas of research on enhancements including both on-going research projects as well as a spectrum of potential research opportunities. Current research activities include the following projects:

- Use of electron shuttles to biologically enhance abiotic dechlorination

- Enhanced passive remediation using bioaugmentation with aerobic bacteria for cis1,2-DCE

- Developing an MNA modeling tool based on RT3D

A wide range of research opportunities are identified and these focus on obtaining a refined understanding of the science behind enhancements, improved deployment strategies, better methods to address subsurface heterogeneities, sustainability issues, and cost-effectiveness. 
WSRC-STI-2006-00083, Rev. 1

August 1, 2006

Page 3 of 147

In summary, development of enhanced attenuation as a new remediation class will assist in the accelerated development of cost effective and environmentally protective technical solutions to address the real-world chlorinated solvent plumes at DOE sites through out the nation. 
WSRC-STI-2006-00083, Rev. 1

August 1, 2006

Page 4 of 147

This page intentionally left blank. 


\subsection{CONCEPTUAL FRAMEWORK OF ENHANCED ATTENUATION}

At the very heart of the EA paradigm are features that draw a clear distinction between EA and MNA. MNA as originally defined in the EPA's Office of Solid Waste and Emergency Response directive states:

The term 'monitored natural attenuation' ... refers to the reliance on natural attenuation processes (within the context of a carefully controlled and monitored clean-up approach) to achieve site-specific remedial objectives within a time frame that is reasonable compared to that offered by other more active methods. The 'natural attenuation processes' that are at work in such a remediation approach include a variety of physical, chemical, or biological processes that, under favorable conditions, act without human intervention to reduce mass, toxicity, mobility, volume, or concentration of contaminants in soil or groundwater. (EPA, 1999; pg. 3)

Elsewhere in this directive the following statements appear:

- "EPA prefers those processes that degrade or destroy contaminants." (pg. 3)

- "EPA expects that source control and long-term performance monitoring will be fundamental components of any MNA remedy." (pg. 3)

- "While MNA is often dubbed 'passive' remediation..., its use at a site does not preclude the use of 'active' remediation..." (pg. 4)

- "...by definition, a remedy that includes the introduction of an enhancer of any type is no longer considered to be 'natural' attenuation." (pg. 4)

The important initial step in MNA includes some form of primary source treatment to reduce source mass (and mass flux). Both modeling and field investigations indicate that reducing source mass leads to decreases in the mass flux feeding a plume. However, the magnitude of reduction in mass flux attained by source treatment depends on a combination of site specific factors including source contaminant architecture and site specific hydrogeologic conditions.

Rao (2001) addressed the question of the value of dense non-aqueous phase liquid (DNAPL) source reduction and offered a concept that is relevant to this discussion:

It is proposed that not exceeding a threshold contaminant flux across a control plane, rather than contaminant concentration at a monitoring point or contaminant mass reduction, should be used as the basis for evaluating the effectiveness of source-zone remediation. The threshold contaminant flux should be set equal to the natural attenuation capacity within the dissolved plume.

This statement makes the important connection among source treatment, mass flux reduction, and the goal of achieving a balance between flux and natural attenuation capacity. Attaining this objective ensures a stable plume (i.e. one that does not expand over time). 
The impact of MNA on a cVOC plume can be illustrated in Figure 2-1. As indicated, the resultant flux at the control plane exceeds the regulatory limit showing that the attenuation capacity of the system is insufficient for MNA to be a viable treatment alternative.

\subsection{NATURAL ATTENUATION PROCESSES}

The natural attenuation capacity of a hydrogeologic system results from the combined impact of several natural processes. Examples include physical, chemical, and biological mechanisms operating within hydrogeologic systems by which contaminants are either diluted, degraded to innocuous byproducts, or their rate of migration is retarded. All of these processes operate without human intervention.

\subsubsection{Physical Attenuation Processes}

Mass transfer of contaminants to groundwater in the source area creates a dissolved phase plume that transports contaminants by advection. In addition, a vapor phase plume will develop for cVOC contaminants in the vadose zone. Vapor phase contaminants can outgas to the atmosphere and be transferred to groundwater by entrainment in infiltrating precipitation or by diffusion. These are important physical attenuation mechanisms for cVOCs that operate in the vadose zone.

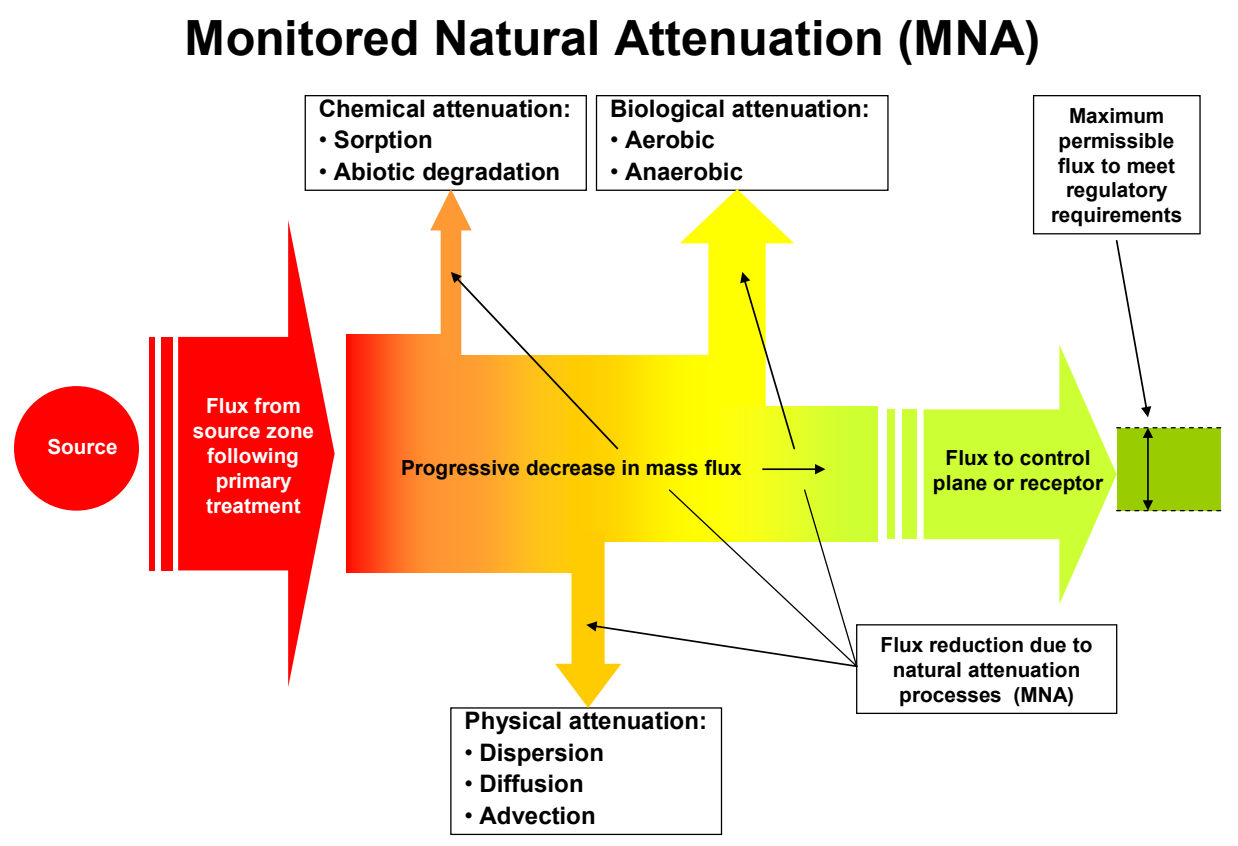

Figure 2-1. Natural attenuation processes decrease the mass flux of contaminants. 
As shown in Figure 2-1, as the contaminant plume migrates it will be influenced by various attenuation processes. Each process contributes to the overall attenuation of contaminants. In fact, what happens is a reduction of the amount of contaminant mass passing through a control plane per unit time (mass flux). The location of the control plane may be defined by a compliance agreement (cf. point of compliance) or may be associated with discharges to the receptor.

Dispersion and diffusion are examples of physical attenuation mechanisms that occur in groundwater. Hydrodynamic dispersion leads to physical dilution of contaminants in groundwater resulting in an increase in the size (volume) of the plume. Diffusion results in contaminants migrating into low permeability parts of the aquifer where they are sequestered in the small pores present in clay-rich material and porous bedrock and only released slowly into groundwater by back-diffusion. Eventually a steady state condition will exist for diffusion and dispersion. The combination of processes reduces both the concentration and mass flux of contaminants.

\subsubsection{Chemical Attenuation Processes}

Sorption includes both physical (absorption) and chemical (adsorption) attenuation processes by which cVOCs are partitioned into the sorbing medium (e.g., soil organic material) or attach to the surfaces of certain solid phases, respectively. Sorption of cVOCs can occur in both the vadose and saturated zones. Sorption causes a reduction in the rate of migration of contaminants in aquifers resulting in a reduction in mass flux. For convenience, both mechanisms are treated in this section.

In equilibrium sorption a steady state will be reached in which the rate of sorption becomes equal to the rate of re-release resulting in no further changes in mass flux. For some contaminants under certain conditions sorption is sometimes referred to as "irreversible". Irreversible sorption refers to a hysteresis effect in which a chemical species is more strongly bound to the sorbing medium during desorption than during initial sorption. The term sometimes appears to be used to describe a situation where once sorbed, the contaminant is essentially permanently removed from the plume and remains associated with the sorbing aquifer (or vadose zone) material.

The net result of sorption is to reduce the mass flux of contaminants crossing the control plane.

\subsubsection{Biological and Abiotic Degradation Attenuation Processes}

Both biological and abiotic processes degrade contaminants into a variety of byproducts. Aerobic and anaerobic bacteria may metabolize the contaminants or may reduce sulfate into sulfide, which, in turn, can combine with Fe(II) to form sulfide minerals having the capability of reductively dechlorinating cVOCs to innocuous byproducts. Plant-based processes can result in in situ destruction of cVOCs in the root zone, uptake, storage, metabolism, or translocation to the atmosphere. In every case, contaminants are removed from the plume leading to a reduction of mass flux. 


\subsection{ENHANCED ATTENUATION}

The basic premise of EA is that for some sites flux reductions achievable by natural attenuation processes may not be sufficient to meet regulatory approval as protective of human health and the environment such that MNA would not be a viable treatment option (see Figure 2-1). This gives rise to the distinction between MNA and EA as illustrated by the flow diagram in Figure 2-2. As shown, both plume management options typically require an initial step of aggressive, primary treatment for sources and, possibly, for associated plumes. This is an important measure to reduce the source size and plume loading.

Following primary treatment a comparison of plume loading from the residual source and natural attenuation capacity within the plume will determine if the plume is expanding, stable, or shrinking. A stable or shrinking plume raises the possibility that MNA is a potentially appropriate plume management strategy. However, if the plume is expanding (or the natural attenuation processes are not sustainable for a stable or shrinking plume) the option exists for considering introduction of enhancements to reduce plume loading and/or increase the attenuation capacity of the system. If sustainable enhancements can be implemented, then EA becomes a viable treatment approach. If not, an additional phase of aggressive source/plume treatment probably will be required. Figure 2-2 illustrates the decision process by which these different alternatives can be evaluated.

Consequently, the concept of enhanced attenuation essentially asks the question: Is it possible through intervention to sustainably manipulate natural attenuation processes so that they operate more effectively than without intervention and thereby result in an increased reduction in mass flux of contaminants sufficient to meet regulatory release requirements?

The remainder of Section 2 systematically explores the concept of enhancements in more depth.

\subsubsection{What do we mean by the term "enhancement"?}

An enhancement is anything we might do to a source-plume system that increases the magnitude of contaminant degradation or sequestration beyond that which occurs naturally without our intervention.

Examples of enhancements to physical attenuation processes include:

- Hydraulic manipulation to reduce advective transport

○ Reduction of infiltrating precipitation that will carry dissolved contaminants downward to the aquifer (e.g., caps, plants, etc.)

$\circ$ Interception and diversion of up-gradient groundwater before it can reach the source (e.g., french drains)

- Source containment to reduce mass loading

○ Physical source containment strategies (e.g., slurry walls; sheet piling)

- Introduction of vegetable oil into the source area to create a diffusion barrier to the contaminants

- Enhanced source removal by barometric pumping 


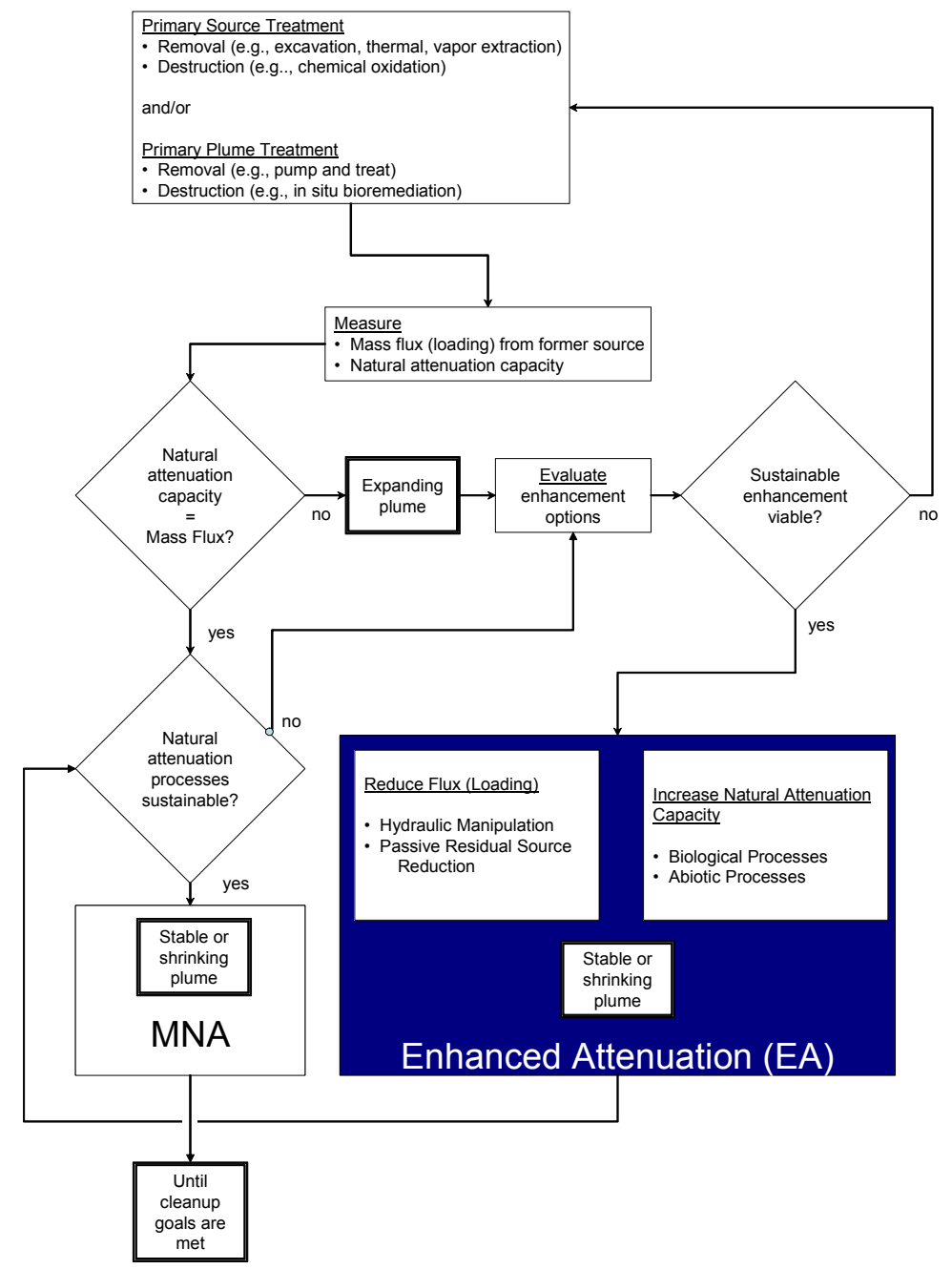

Figure 2-2. Flow diagram illustrating the distinction between MNA and EA.

Example of enhancements to chemical attenuation processes that degrade contaminants include:

- Addition of amendments that result in increased in situ production of reduced iron and sulfur phases (e.g. FeS) that can abiotically degrade cVOCs

- Installation of a reactive zone (permeable reactive barrier with zero-valent iron or other reactive media, biobarrier, etc.)

Examples of enhancements to biological attenuation processes include:

- Addition of an amendment that stimulates a naturally occurring consortium of bacteria to increase the rate of degradation or the overall extent of degradation over that which occurs without the amendment

- Augmenting the natural consortia of microbes with additional species that can function in the plume environment and will increase the overall degradation of contaminants 
- Construction of a wetland at the groundwater-surface water interface that can take advantage of a suite of attenuation mechanisms including microbial degradation and plant-based degradation/extraction processes to increase attenuation in this region

There is at least one example where an aggressive, primary source treatment is a causal factor in generating an enhancement and represents a unique form of symbiosis. Rowland and Golden (2003) and ITRC (2005) cite a relationship between application of in situ chemical oxidation and the creation of a subsequent environment of enhanced biological treatment. This relationship is termed microbial benefits of in situ oxidation (MBISO) and field evidence supporting its potential importance has been reported.

The enhancements discussed in Sections 3 through 6 represent a spectrum in terms of the maturity of the technologies as well as our experience with their deployment. For example, vertical source containment barriers (e.g., sheet piling, slurry walls, etc.) have been in use for decades. Likewise, barometric pumping is a mature technology. Permeable reactive barriers and some areas of biotechnology have been studied extensively over the past 10 or more years, but continue to evolve with additional R\&D and field deployments. Other potential enhancement technologies such as constant head moats and use of diffusion barriers are more conceptual in nature or at a relatively early stage of development and may require significant additional work before their application in EA can be contemplated.

Some natural attenuation mechanisms may not be good candidates for enhancement. For example, it is probably unrealistic to attempt to enhance diffusion and dispersion. Sorption is another attenuation process that may not be practical to enhance, although it might be possible to increase sorption by augmenting the stable fraction of organic carbon in an aquifer matrix.

Figure 2-3 illustrates how enhancements have an additive or supplemental effect on the natural attenuation processes operating on a plume to reduce the mass flux beyond that generated without intervention. Our objective is for the cumulative impact of these enhancements to reduce the mass flux to a level that is less than the attenuation capacity within the aquifer. Note that the effect of introducing enhancements in the source zone following completion of primary source mass reduction treatment is to reduce the mass flux coming from the source in comparison to that resulting from primary treatment alone (the red patterned region illustrates the magnitude of flux reduction). The impact of other enhancements to natural attenuation processes operating outside of the source zone also decreases the resultant mass flux of the plume by increasing the effectiveness of attenuation (shown by the cross-hatched pattern associated with each type of attenuation). The cumulative result of all of these enhancements is a reduction of mass flux at the control plane or receptor sufficient to meet regulatory requirements (compare Figure 2-1 and Figure 2-3).

Many potential enhancements can reduce mass flux temporarily. However, for enhancements to have a place in EA requires a distinction between active remediation (where the intervention may need to be repeated or modified over time to remain effective) versus enhancements that are sustainable. This approach results in enhanced passive treatment. Our definition of sustainability is: 


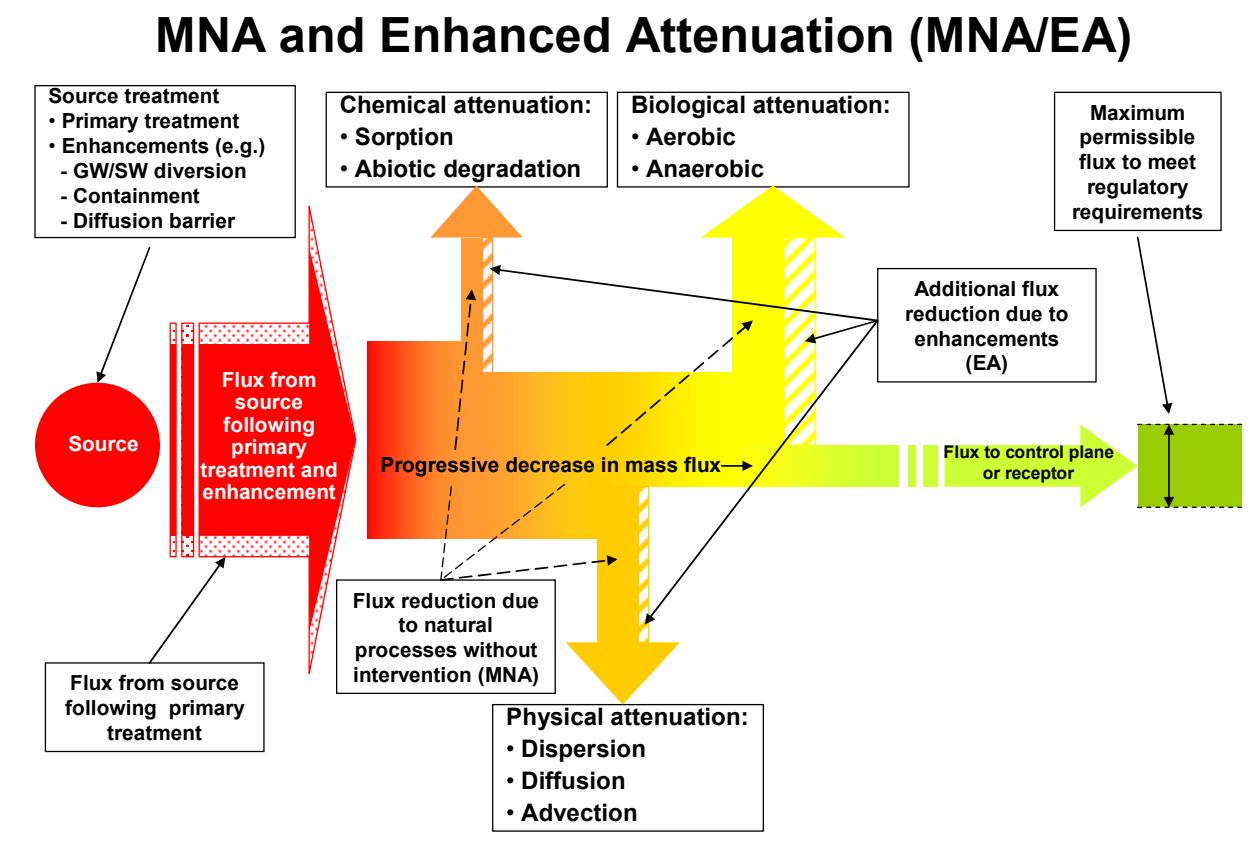

Figure 2-3. Enhancements to natural attenuation processes increase the attenuation capacity of the system.

A sustainable enhancement is an intervention that continues until such time that the enhancement is no longer required to reduce contaminant concentrations or fluxes.

Ideally, enhancements will be deployed with a single phase of intervention sufficient to maintain its effectiveness. However, for some enhancements infrequent, but periodic, intervention may be desirable. For example, if trees are planted as a plantation to improve evapotranspiration (ET) in a source area, periodic (e.g., annual) fertilization of the trees might be desirable, especially if the trees are to be harvested every few years as a short rotation crop with commercial applications.

An equally important consideration embodied in the definition of sustainability is that an enhancement does not have to remain effective indefinitely. Rather, it only must operate as long as necessary to maintain a favorable balance between mass flux and system attenuation capacity. For example, a constructed wetland might be an important enhancement for achieving mass balance early in the treatment cycle of a plume. However, as the source term progressively decreases due to gradual depletion, the necessity for the wetland to operate at peak efficiency also declines, so that at some point in time (perhaps 10 or 20 years later) the treatment capacity of the wetland is no longer required as a supplement to the plume attenuation capacity. Within the context of this example the sustainability of the wetland is measured in terms of several decades. Carrying this example one step further, during its active life the treatment efficiency of the wetland can decline over time as long as it keeps pace with the declining mass flux and provides sufficient attenuation capacity. 
Consequently, the concept of sustainability permits a gradual decrease in efficiency of enhancements over time and a finite lifetime for them consistent with the mass balance paradigm. These are non-conventional concepts compared to the traditional way we tend to think of groundwater treatment and offer the opportunity for a relaxation in the design and performance criteria for the enhancements.

\subsubsection{How effective do enhancements need to be?}

For EA we do not require absolute perfection. Rather, an enhancement only must improve the attenuation of contaminants to reduce mass flux. Therefore, a containment barrier need not be verifiably leak-proof; something less than that will be sufficient. Likewise, a biostimulation enhancement need not achieve complete degradation of trichloroethene (TCE) and byproducts to $<$ maximum concentration limits (MCLs). It is only necessary that the enhancements selected for application at a site are able collectively to reduce the contaminant flux to a level below the natural attenuation capacity of the system (i.e. the condition of a shrinking plume) and can meet regulatory requirements at the point of compliance.

However, it is important to recognize that enhancements that involve contaminant degradation usually proceed through a set of dechlorination reactions. For example, microbial reductive dechlorination of tetrachloroethene (PCE) results in the sequential production of TCE, cis-1,2-dichloroethene (cis-1,2-DCE), vinyl chloride (VC), and ethene. Each of these byproducts, other than ethene, is toxic. Therefore, when designing an enhancement based on microbial dechlorination reactions it is important to consider the overall effectiveness of the process. While the goal of enhancements is to improve the attenuation of contaminants (not necessarily resulting in their complete elimination), one must be mindful of the potential for unintended consequences associated with application of some enhancements.

At some waste disposal sites contaminants have been buried in containers (e.g., drums of solvents) and are prone to episodic releases as the containers gradually deteriorate and begin discharging their contents. Such releases are unpredictable and the resultant source flux profile over time may fluctuate significantly. Where removal of the waste containers is infeasible, the challenge for EA is to design enhancements that are robust enough to accommodate such variations or to take steps during active source treatment to create an environment where releases are better controlled. Encapsulating waste through trench grouting is an example of how contaminant release rates might be buffered (see Section 3.2.1.2).

\subsubsection{How must enhancements be tailored to current and future environmental settings?}

The environmental setting of a site and changes over time of those properties that define the setting, exert a significant influence over the types of enhancements that can be utilized and how they might be deployed. Most importantly, enhancements should be tailored to current site environmental conditions. Then, assessment of potential future changes of these conditions is required. Although evaluation of some future environmental conditions is subject to uncertainty, it is important to consider realistic projections of these conditions to aid in the design and deployment of enhancements. 
Some examples of relevant environmental factors that ought to be considered when implementation of enhancements is contemplated include the following:

- Climate: some types of enhancements are better suited to humid sites with greater rainfall, relatively shallow depths to groundwater and generally short flow paths to points of discharge in comparison to what is typically found at arid sites

- Hydrogeology: aquifer heterogeneities lead to the potential for matrix diffusion, which will extend the lifetime of a plume and may require enhancements to be effective for a longer period of time

- Changes in environmental factors that can occur over time:

○ Short-term, natural weather phenomena such as flooding and off-normal precipitation events

- Changes in the plume footprint and plume discharge locations due to seasonal variations in precipitation-infiltration or stream stage of a receptor

- Gradual or episodic changes in the groundwater balance and gradient due to nearby development activities (i.e. future land use)

- Gradual changes in soil hydraulic properties and plant ecology that may impact the performance of engineered covers (see also Section 3.1.2.4)

A more detailed discussion of these and other environmental factors and how they might influence the choice of enhancements for a site is provided in the supplemental material in Appendix A.

\subsubsection{Where can the enhancements be used most effectively?}

Determining the optimal spatial application of enhancements is as important to the success of EA as identifying the enhancements themselves. A useful context for the discussion on enhancements in this report is provided in Figure 2-4 in which a plume is divided into three enhancement zones:

- Source enhancement zone

- Plume enhancement zone

- Discharge enhancement zone

In general, the source zone is the most effective region in which to apply enhancements because:

- Size of the source usually is relatively small

- Source depth frequently is not great

- Many options for enhancements to the source exist that collectively can be very effective

- Many source enhancement technologies have a long track record of success

Of course there are exceptions to general observations. Source size is variable and site specific; very large sources may be costly targets for application of enhancements. Likewise, source depth may range to values of several hundred feet or more making access particularly expensive. Sources within fractured bedrock are likely to be both difficult and expensive to address with enhancements. 


\section{Natural Attenuation Enhancement Zones}

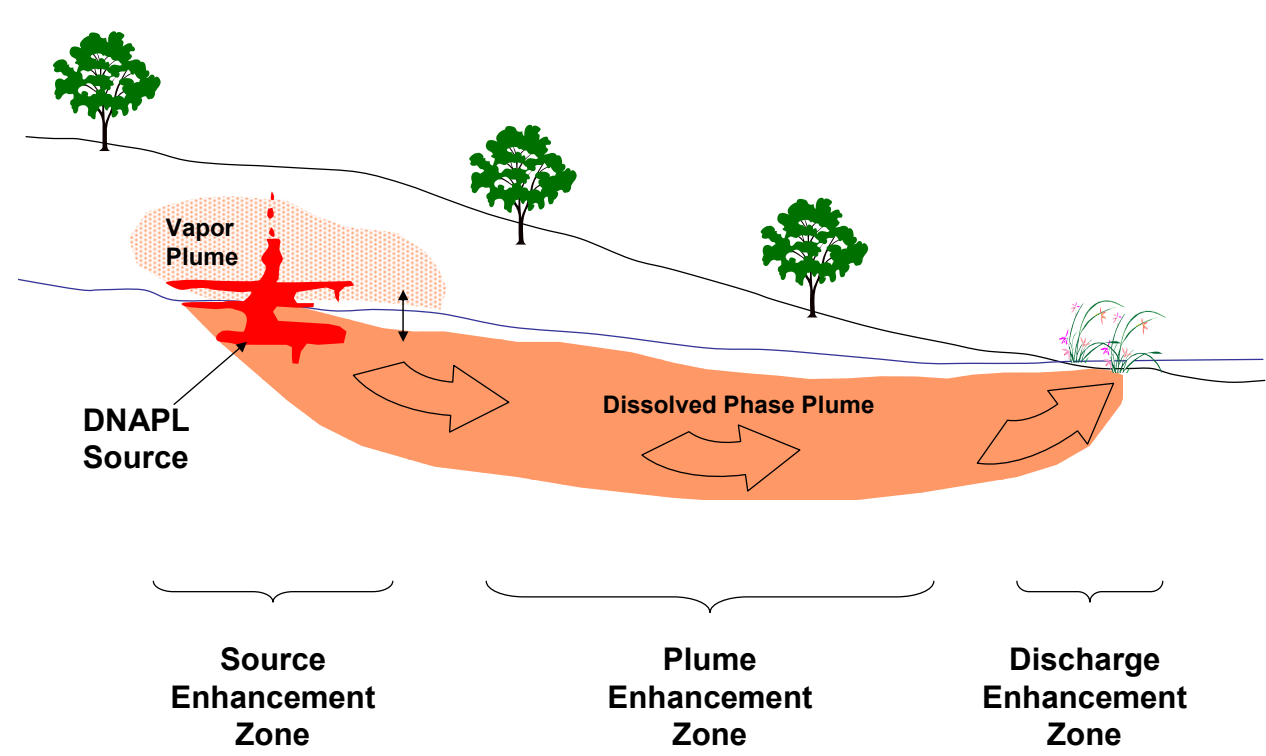

Figure 2-4. Natural attenuation enhancement zones in a plume

The discharge zone is another area where enhancements can be cost-effective because:

- Contamination releases occur in a relatively restricted region

- Contaminants are delivered to the surface

Both of these factors make access to the contaminants relatively simple. However, because of the proximity to the receptor it is important that the enhancement is carefully designed and implemented to ensure that it works as intended and is protective of human health and the environment. These requirements should not preclude using the discharge zone for enhancements, but increases the need for added redundancy and effective monitoring.

In many ways the main body of the plume is the most challenging zone in which to apply enhancements because:

- The scale of the plume (areal extent) is greater than for source and discharge zones

- The depth tends to be greater than for the other zones

However, there are potential enhancements and site specific plumes where enhancements in this region may make great sense.

\subsubsection{How do enhancements interface with mass balance and characterization/ monitoring?}

The mass flux of contaminants emanating from a source zone is the mass of contaminants crossing through a unit area of a plane (e.g. per $\mathrm{m}^{2}$ ) oriented normal to the plume axis per unit time (e.g. per sec.). The integrated mass flux can be thought of as the total mass of 
contaminant passing through the plane per unit time (i.e. encompassing the entire cross sectional area of the plume). It is the basic foundation of this report that application of one or more enhancements to a cVOC source - plume system will result in a decrease in the integrated contaminant mass flux. A further important premise is that the longevity of the enhancement(s) must be sufficient to ensure a sustainable reduction in flux for as long as necessary to achieve regulatory requirements. The objective of such a reduction in flux is to achieve a sustainable balance between source loading (the integrated mass flux from the source) and plume attenuation capacity (the integrated reduction of mass flux due to all natural and enhanced attenuation mechanisms).

The theoretical underpinning of the mass balance approach is a valuable component to EA because it demonstrates that we have the opportunity to use enhancements to manipulate a source - plume system to achieve a desired balance between integrated mass flux and attenuation capacity. The mass balance approach is fully developed in Looney et al. (2006).

It is important to have the ability to reduce mass flux, but our ability to quantify the reduction is equally important. Because the mass flux is the result of the integration of many individual attenuation processes (see Sections 3 to 6) we have two fundamentally different approaches for assessing it. First, we can make a direct measurement of systems-scale mass flux along several transects within the plume to establish that down-gradient reduction in flux is occurring (the empirical approach). Recent and ongoing research is providing practical methodologies for determining mass flux (e.g., Teutsch, 2001; Annable et al, 2001; Hatfield et al, 2004; Wood, 2003; Kavanaugh, 2004) and support the assumption that assessing mass balance is an achievable objective. Alternatively, we can attempt to measure the fundamental parameters that control the impact of individual attenuation processes and numerically integrate them by appropriate computer codes (the deterministic approach).

Although field measurement techniques for mass flux still are a subject of intensive research, this approach is conceptually simple to apply and has the advantage of being a direct measure of mass flux from which the mass balance can be determined and the overall impact of enhancements can be measured unambiguously.

The deterministic approach is indirect and requires a more intensive characterization and monitoring effort. However, it yields specific information about individual attenuation processes and their impact to the system as a whole. The advantages of this approach include its predictive capability and the ability to take basic information about the process and possible enhancements and project future impacts to the system. It gives one the ability to assess the potential value of an enhancement and suggest modifications to make it more effective. This is particularly important when the impact of an enhancement will not be manifested by the source - plume system for a period of time - perhaps years as in the case of plant-based enhancements where it may take several years for trees to mature before the system can respond to them and one can expect to measure the effects.

Likewise, if at some point in the future the mass balance within a plume being treated by EA changes (as determined by mass flux measurements), one may not know why that has occurred. Under these circumstances the ability to reassess individual attenuation processes and the effectiveness of specific enhancements deterministically may permit one to reconcile 
changing mass flux measurements, refine future mass balance projections, and possibly suggest ways to improve the enhancements.

As noted, there will be a time lag between the implementation of an enhancement and our ability to measure the full impact of that enhancement on mass flux. The time scale of this delay is dependant on the type of enhancement and site specific conditions. Some of the measures taken to manipulate hydrology (e.g., caps/covers, French drains, GeoSiphons) will begin to have at least some impact rather quickly. Enhancements such as biostimulation and bioaugmentation will ramp up over a period of time and the full influence of them may not be observed for a period of months. Plant-based enhancements designed to limit infiltration and provide hydraulic control may take several years to become fully functional in affecting mass balance. Characterization and monitoring strategies need to be tailored to the specific enhancements and take into account their variable time-scales.

In summary, the success of enhancements to EA is supported by developing a firm theoretical basis of mass balance (Looney et al., 2006) and the availability of effective characterization and monitoring tools and strategies (Gilmore et al., 2006). Moreover, it is clear that the empirical and deterministic methodologies described above each offer unique, but complementary, capabilities with which to assess the effectiveness of enhancements and EA. Both simple and complex assessment strategies have an important place in EA.

\subsubsection{Organization of Discussions about Enhancements}

As was noted in Section 2.0, the EPA guidance on MNA emphasizes the role of active source control as an essential part of MNA. Likewise, in EA active source treatment is viewed as a necessary precursor before application of enhancements should be considered. Figure 2-2 illustrates the role of source (and plume) treatment as primary treatment actions that are an integral part of EA. It is beyond the scope of this reference guide to address these primary treatment methods, but a wealth of information on technologies appropriate to these components of remediation are available from the ITRC (www.itrcweb.org), EPA (www.cluin.org), and DoD environmental R\&D programs (e.g. SERDP: www.serdp.org; ESTCP: www.estcp.org).

Once primary treatment methods have been deployed and their impact in reducing mass flux has been assessed, it is appropriate to consider EA as a residual source-plume management option. Figure 2-2 illustrates how enhancements can be organized into two major categories: a) reduce loading and $b$ ) increase attenuation capacity. The following four sections of this document address enhancements within this structure as follows:

- Actions that reduce source loading:

○ Hydraulic manipulation (Sect. 3)

- Passive residual source reduction (Sect. 4)

- Actions that increase the attenuation capacity of the system:

- Biological degradation of contaminants (Sect. 5)

- Abiotic degradation of contaminants (Sect. 6) 


\subsection{ENHANCEMENTS TO REDUCE PLUME LOADING: HYDRAULIC MANIPULATION}

Many of the concepts for EA rely on sustainably increasing the attenuation capacity of the system so that it exceeds contaminant loading from the source. An alternative concept is to apply enhancements to reduce contaminant loading so that the natural attenuation capacity of the site is sufficient to achieve a balance between mass flux and attenuation. A variety of different approaches are possible to achieve this goal. Most of these concepts rely on reconfiguring the site to permanently modify the large-scale hydrology in the vicinity of the source. Hydraulic controls alone are often not considered in evaluating options because they do not destroy or immobilize contaminants. However, when considered in the context of MNA and EA where the goal is to maximize capacity and minimize loading, this concept appears promising.

Because "loading" is the product of concentration and flow, this term can be directly modified by altering and reducing the flow of water into or through the contaminant source zone. Modifications to the source area that intercept and divert surface runoff and shallow stormflow from up-slope areas from passing through the source represent one approach to reduce the rate of source dissolution and resultant mass flux. Likewise, under favorable hydraulic conditions, a variety of methods, such as the use of passive drains or siphoning wells, can be used to intercept groundwater upgradient from the source. The resulting decrease of the hydraulic gradient in the source area reduces the flow of contaminants from the source. Preventing infiltration through capping or reducing its impact through increased ET with trees and grasses also can be effective hydraulic control options.

Implementation can take many forms including the obvious variants that have been periodically considered and implemented (O'Donnell et al., 1995): "capping near the source," "cutoff walls," and "building a dam." Other, often overlooked, traditional methods of large-scale hydrologic control include eliminating anthropogenic sources of water (leaking process, domestic and fire lines, storage basins, etc.). Attempts to wall off contaminant plumes may not provide the sustainable performance desired. A dam installed on a gaining stream, for example, provides a transient benefit, but over time, the plume discharge shifts to a location just below the dam. After a new steady state is established, the loading, the flow rates and total flow times are often similar to the pre-dam conditions. The subsurface slurry wall installed at DOE's Portsmouth facility in 1994 is an example of the limitations of such barriers. Although it delayed the advance of a TCE plume at the southern boundary of the plant for approximately ten years, it is now suspected that migration has begun to progress around one margin of the barrier.

Setting up permanent, sustainable, and easily documented changes in large-scale hydrology is relatively straightforward. Properly designed and implemented, these traditional concepts provide hydrologic control. Flow controls will be in place as long as the hydraulic controls are in place. Moreover, large-scale hydrology modification is relatively easy to model and monitoring is likely to be inexpensive. Simply stated, differences in hydraulic head are robust and will operate without detailed knowledge of underlying processes. 
In addition to traditional methods of hydraulic manipulation to reduce source loading, more innovative techniques that make use of the ability for DNAPLs and cVOCs to preferentially partition into vegetable or other nontoxic non-aqueous phase liquid (NAPL) oils raise the possibility of creating barriers at the top of the water table to greatly reduce downward migration of contaminants from the vadose zone. Likewise, such oils injected directly into a DNAPL source in an aquifer can dissolve the contaminants and significantly reduce mass transfer rates of cVOCs to groundwater.

\subsection{REDUCE INFILTRATION THROUGH THE SOURCE ZONE}

\subsubsection{Intercept and divert surface runoff and stormflow water}

A major way to reduce the mass loading to a plume is by reducing the infiltration of precipitation. Infiltration can be fed by: (a) direct precipitation on the surface overlying the source, (b) sheet runoff advancing down-slope to the source area, and

(c) stormflow traveling down-gradient in the top $\sim 1-2$ meter of the soil column where permeability is greatest. Not all of these processes are important at every site. Interception and diversion of these contributors to infiltration can have a significant impact on the amount of water that passes through a source zone, the rate of mass transfer of contaminants to groundwater, and the mass flux feeding a plume.

Precipitation ponding on relatively flat surfaces has an increased potential to infiltrate. However, even in areas where the land surface is sloping, sheet runoff from up-slope regions can bring large quantities of water to down-slope regions and provide opportunities for infiltration. Simply recontouring topography and lining drainageways to maximize runoff will minimize infiltration.

Similarly, in regions of relatively high topographic relief, stormflow can be an effective mechanism of transporting storm-event water in the upper 1-2 meters of the subsurface and can have an impact on infiltration. This soil interval has greatly enhanced permeability because it represents the principal root zone of vegetation and location of burrowing animals, both of which tend to loosen the soil. For example, in the hilly regions of the Oak Ridge Reservation it is estimated that as much as $90 \%$ of subsurface flow is stormflow (Solomon, et al., 1992). Figure 3-1 illustrates these hydrologic features that can impact the amount of infiltration in source areas and help facilitate the mobilization of contaminants to the water table.

Both of these phenomena have been significant factors in the mobilization of contaminants from waste disposal trenches at Oak Ridge and have led to various design strategies to control their impact (see Case Study 3-1). These measures were just implemented in 2004 in association with a massive trench capping program, so their effectiveness has not yet been ascertained. However, water control measures such as these have been used for many years and, if properly designed and constructed, work well.

Another important impact of surface runoff is its erosion potential. If not controlled, erosional processes may be able to deeply dissect and expose waste disposal trenches or compromise containment structures such as caps. 


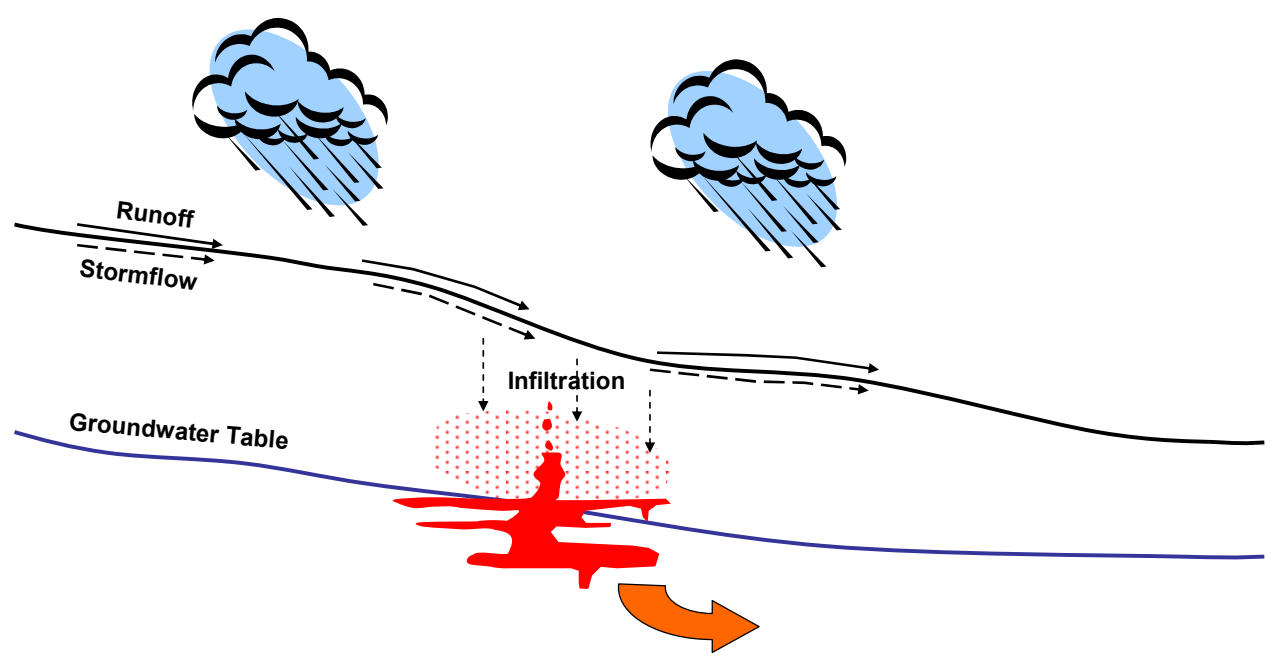

Figure 3-1. Relationship among precipitation, runoff, stormflow, and infiltration

\subsubsection{Reduce Infiltration with Sustainable Covers}

Sustainable covers are central to the long-term success of source containment at many sites. Covers either reduce the permeability of soils overlying a source zone, or favorably manipulate the soil water balance so as to limit percolation through a source zone. Among practitioners there is a widely held misconception that cover technologies are well developed and that prescribed, engineered cover designs, once constructed, will work as projected for $10 \mathrm{~s}$ to $100 \mathrm{~s}$ of years. In reality, most short-term performance data are largely experimental and long-term performance data are virtually non-existent. The limited amount of monitoring data suggest that after a few years, many existing covers have fallen short of design and performance targets (Daniel 1994, Melchoir 1997, Benson et al. 1999), largely because of unanticipated ecological consequences (Suter et al. 1993, Bowerman and Redente 1998, Clarke et al. 2004, Waugh 2004).

\subsubsection{Conventional and Alternative Covers}

Conventional engineered cover designs are based on guidance developed to comply with the Resource Conservation and Recovery Act of 1976. These designs rely on the low permeability of a compacted soil layer to limit percolation (EPA 1989). However, conventional covers often fall short of permeability requirements. Some designs inadvertently create habitat for deep-rooted plants and burrowing animals. Biological intrusion and soil development can increase the saturated hydraulic conductivity of compacted soil layers several orders of magnitude above design targets. Hence, the lowpermeability requirements for conventional covers may not always be achievable. 


\section{Case Study 3-1. Surface and Stormflow Water Control at Oak Ridge National Laboratory}

Waste Area Grouping 4 (WAG 4) at Oak Ridge National Laboratory is a location where hundreds of waste trenches occur that contain a large inventory of low-level radioactive waste. WAG 4 lies within a sloping terrain and down-gradient migration of surface water, storm flow, and shallow groundwater occurs into and through the trench area. Monitoring data for ${ }^{90} \mathrm{Sr}$ releases extends back to the early 1960 s and shows the impact of several mitigation activities designed to reduce ${ }^{90} \mathrm{Sr}$ discharges. These included surface water diversion ditches that were lined in the mid-1970s, addition of further runoff diversion structures in 1983, and grouting of four trenches in 1996. Of particular interest is the interpreted evidence of releases from new sources, presumably as waste containers periodically rupture (e.g., see Huff, 2000).

In 2003, in order to fulfill the terms of an interim record of decision, an extensive program of capping and surface recontouring was initiated for WAG 4 that incorporated surface water and storm flow interception and diversion design features. The figure below is a photograph of WAG 4 during cap construction (July 2004) and illustrates the control structures that have been integrated into the remedy.

As an enhancement, control of surface and stormflow water is a viable option for reducing source loading by minimizing water entering the source zone.

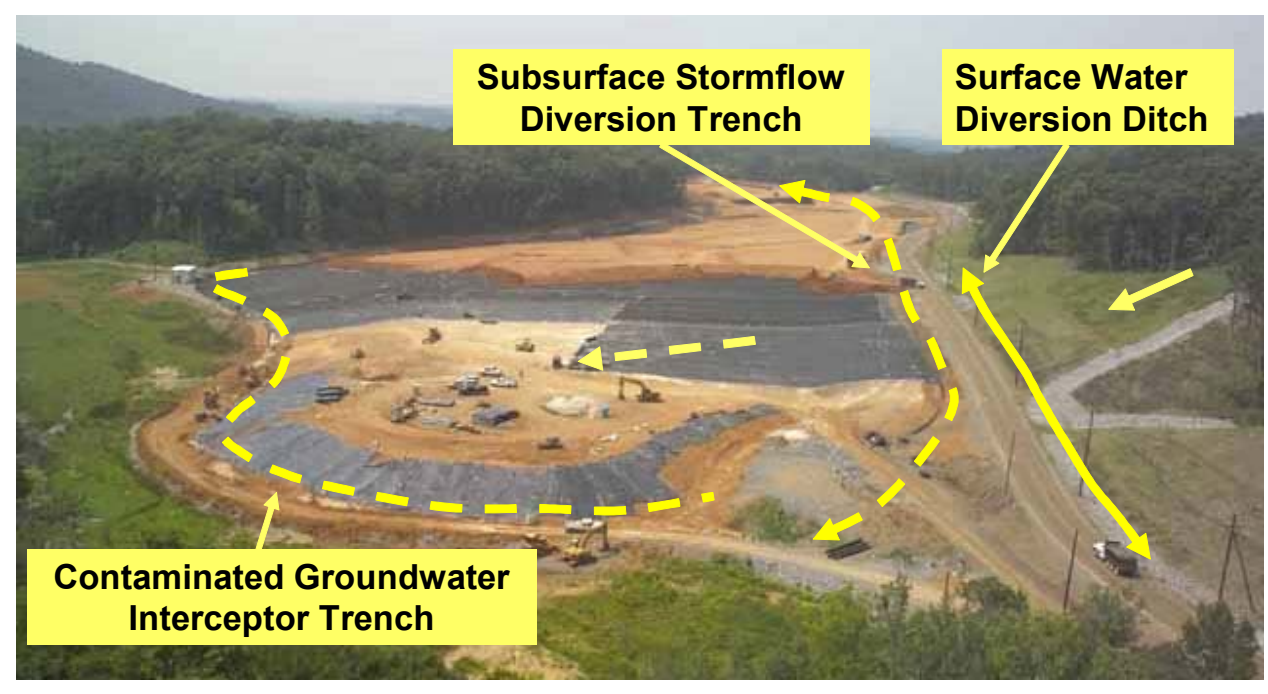


In general, low-permeability covers attempt to resist natural processes, rather than working with them, and will likely require increasing levels of maintenance or retrofitting in the future (Clarke et al. 2004). The goal of alternative cover designs is to accommodate and enhance beneficial natural processes. For example, in many arid and semiarid ecosystems, relatively low precipitation, high potential ET, and thick unsaturated soils limit recharge (Gee and Tyler, 1994). Alternative covers that mimic this natural water conservation may provide long-term hydrologic isolation of subsurface contaminants (Winograd, 1981; Reith and Thompson, 1992). Alternative covers, sometimes called vegetative or ET covers, generally consist of thick, fine-textured soil layers that store precipitation in the root zone where ET seasonally removes it (Anderson et al., 1993; Link et al., 1994; Hauser and Shaw, 1994; Ward and Gee, 1997; Hauser et al., 2001; Hauser and Gimon, 2001; Anderson and Forman, 2002; EPA, 2003a; ITRC, 2003a, 2003b). Capillary barriers consisting of coarsetextured sand and gravel placed below this soil "sponge" can enhance water storage and limit unsaturated flow (Stormont and Anderson, 1998; Khire et al. 2000).

Alternative covers for humid sites also can be designed to favorably manipulate the soil water balance. At humid sites, where precipitation exceeds ET, recharge can be managed by shedding rainfall to the perimeter of the cover, so that ET can remove the lesser amounts of water that infiltrate the soil. This concept has been demonstrated using roofing panels and corrugated sheets of fiberglass and metal (O’Donnell, 1997; NFESC 1999). A sustainable water-shedding design might be achieved using durable materials such as slate rock or slabs of concrete.

\subsubsection{Vegetation Management for Alternative Covers}

Revegetation goals for alternative covers include establishment of plant communities that 1) are well-adapted to the engineered soil habitat, 2) are capable of high transpiration rates, 3) limit soil erosion, and 4) are structurally and functionally resilient. Seeding of monocultures or low-diversity mixtures on covers is common. The revegetation goal for alternative cover designs should be to emulate the structure, function, diversity, and dynamics of native plant communities in the area.

A diverse mixture of native plants on a cover will maximize water removal by ET (Link et al. 1994) and remain more resilient to catastrophes and fluctuations in the environment. Diverse plant communities consist of a mosaic of many species that structurally and functionally change in response to disturbances and environmental fluctuations. Diverse mixtures of native and naturalized plants will maximize water removal and remain more resilient given variable and unpredictable changes in the environment resulting from pathogen and pest outbreaks, disturbances (overgrazing, fire, etc.), and climatic fluctuations. Local indigenous ecotypes that have been selected over thousands of years are usually best adapted to climatic changes and biological perturbations. In contrast, the exotic grass plantings common on covers are genetically and structurally rigid and, thus, are more vulnerable to disturbance or eradication by single factors. In some cases, naturalized non-native species have broader ecological tolerances, are more readily established in disturbed soils, grow more rapidly, and transpire more water in the first few years after planting, than local ecotypes. 
Grasses are frequently planted on ET covers in the humid east, however, several designs have included the use of trees such as the hybrid poplar to take advantage of their deeper root system and superior water uptake. One of the limiting factors in using plants is that many plant species undergo a period of dormancy. During periods of dormancy, rates of evaporation/transpiration are greatly reduced. The response to periods of dormancy are species specific. For example Kramer and Kozlowski (1979) showed that yellow-poplar, a deciduous-leaved tree in North Carolina, does not have any ET between mid-November and late May, while Loblolly pine, an evergreen tree, continued to exhibit ET year round. For example, in the winter months the rate of ET in Loblolly pine was observed to drop to $16 \%$ of that observed in the early fall. A strategy that might aid in continuing ET during the winter months in hybrid poplar stands would be to interplant evergreen tree species such as native pines or laurel cherry.

As an alternative approach, Mathews et al. (2003) suggests that if ET plantations are correctly sized they can create a water table deficit during the summer months that would be carried through the winter months and not allow contaminant movement. A note of caution: if a barrier is used over a waste unit and combined with a vegetated ET cover, sufficient soil reservoir capacity must be present. Otherwise, the plant's ET capacity can exceed their water supply and they will die (Hauser and Shaw, 1994; Anderson and Forman, 2002).

\subsubsection{Processes Influencing Cover Performance}

Cover systems are designed to contain and control releases of subsurface contaminants. Many factors can compromise the ability of covers to function properly and the potential magnitude of their impact on performance must be evaluated at each site. Relevant processes that should be considered include:

- Water infiltration

- Erosion

- Frost penetration

- Animal intrusion

- Plant encroachment and succession

More detail about each of these processes is provided in the supplemental material in Appendix A.

Case Study 3-2 provides a summary of EPA's Alternative Cover Assessment Project (ACAP) which is a testing program to compare conventional and alternative cover designs under a variety of climatic conditions (Albright et al. 2004).

\subsubsection{Long-Term Cover Performance Issues}

A goal of designing and building sustainable covers that accommodates natural processes is to reduce long-term risks and maintenance costs. Current design guidelines (EPA 1989) are prescriptive and do not address long-term changes in the environmental setting that may contribute to risk. Designing sustainable covers requires consideration of long-term processes and episodic events associated with climate change, ecological succession, geomorphology, and soil development (see also Section 2.2.3). 


\section{Climate Change}

The long-term performance of covers will be influenced by changes in climate. Controlled experiments of design performance, field demonstrations, and soil water balance all require input of meteorological data. Performance evaluations may require data on annual and decadal variability in climate, extreme events, and shifts in climate states.

Current design approaches implicitly assume that instrumental climate records and statistics adequately bound reasonable ranges of future climate. However, instrumental climate records are too short to encompass long-term climate shifts or climate-related events that will likely influence cover performance. Climatologists generally agree that during the next decades and centuries, global climatic variation and extremes will likely exceed the historical record (e.g., Thompson et al. 1998, Hulme and Sheard 1999, US Global Change Research Program, www.usgcrp.gov). This may happen as has occurred naturally in the past (e.g., Houghton et al. 1990, Crowley and North 1991) and/or as the lower atmosphere warms in response to increasing concentrations of anthropogenic carbon dioxide and other greenhouse gases (e.g., Mahlman 1997, Ledley et al. 1999).

\section{Pedogenesis}

Pedogenic (soil development) processes will change soil physical and hydraulic properties that are fundamental to the performance of covers. Although rates and magnitudes of change vary, pedogenesis takes place to some degree in all soils. Pedogenesis includes processes such as (1) formation of macropores for preferential flow associated with root growth, animal holes, and soil structural development; (2) secondary mineralization, deposition, and illuviation of fines, colloids, soluble salts, and oxides that can alter water storage and movement; (3) soil mixing caused by freeze-thaw activity, animal burrows, and the shrinkswell action of expansive clays (Chadwick and Graham, 2000), and (4) formation of lag layers by winnowing, frost heaving, movement of soil gases during and after rain, and the shrink-swell action of expansive clays (e.g. McFadden et al. 1998, McDonald et al. 1996).

\section{Ecological Change}

Ecological change is inevitable and may alter the functional performance of all cover designs in ways not initially anticipated. Plant communities develop and change in response to several interacting factors: propagule accessibility, climatic variability, change in soil characteristics, disturbances such as fire, and species interactions such as herbivory, competition, or fluctuations in soil microbe populations. Even in the absence of large-scale disturbances, shifts in species composition, vegetation abundance, and species diversity, may be accompanied by changes in rates of nutrient cycling, energy exchange, and water extraction (Anderson et al. 1993, Link et al. 1994).

In the long term, changes in the waste-site ecology will occur in ways that cannot be captured by predictive models or short-term field tests. For example, successional changes in the vegetation can create small-scale topographic patterns that foster greater heterogeneity in the soil water balance. At arid sites, desert shrub communities that are likely to develop on covers tend to trap windborne sediments causing a hummock-swale relief with variable soil physical and hydraulic properties (Link et al. 1994). Similarly, at humid sites, blowdown of 
The EPA's Alternative Cover Assessment Project (ACAP) is a noteworthy comparison of conventional and alternative cover designs (Albright et al. 2004). ACAP tested prototype covers at 11 landfill sites across the country in climates ranging from arid to humid and from hot to cold. Both conventional low-permeability and alternative ET cover designs were monitored in side-by-side comparisons using 10-by-20 meter drainage lysimeters instrumented for direct measurement of runoff, soil water storage, lateral drainage, and percolation flux for a full-depth cover profile, and mass-balance calculation of ET.

In the ACAP tests, conventional covers designed with compacted soil layers as percolation barriers generally were not effective. Average percolation rates for conventional covers ranged between 52 and 195 $\mathrm{mm} / \mathrm{yr}$ (6.0 to $17 \%$ of precipitation). Preferential flow through cracks or other defects in the soil barrier was likely the primary contributor to percolation at these sites (Benson et al. 2004). The ET covers in humid climates also appeared ineffective in achieving low percolation rates. Average percolation rates between 123 and $160 \mathrm{~mm} / \mathrm{yr}$ ( 10 to $18 \%$ of precipitation) were recorded for monolithic soil covers with trees, whereas capillary barrier ET covers with grasses transmitted percolation at rates ranging between

33 and $57 \mathrm{~mm} / \mathrm{yr}$ ( 6 to $10 \%$ of precipitation). In contrast, the ET covers in the arid, semi-arid, and subhumid sites were generally effective with performance comparable to that attained from conventional covers with composite plastic barriers. Percolation rates for these ET covers generally were less than $1.5 \mathrm{~mm} / \mathrm{yr}$ ( $0.4 \%$ of precipitation).

The data from alternative covers indicate that these covers are not always successful in drier climates. At two sub-humid sites in California, relatively high percolation rates were recorded. The high percolation rates at these sites appeared to be related to inadequate plant transpiration capacity and soil water storage capacity. These unexpected conditions illustrate the need to carefully examine the attributes of vegetation and the storage capacity of cover soils at locations where greater precipitation needs to be managed. Analysis of the data from the ACAP sites suggests that the effective soil water storage capacity in the field can be conservatively estimated as $70 \%$ of the storage capacity as computed based on soil water characteristic curves measured in the laboratory.

As an enhancement, sustainable covers are promising options for reducting source loading by minimizing water infiltrating into the source zone. This results in a decreased transfer of contaminants to the groundwater and a smaller mass flux feeding a plume. 
mature trees growing on covers will create depressions for water accumulation (Suter et al., 1993).

\subsection{REDUCE MASS TRANSFER OF CONTAMINANTS TO GROUNDWATER IN A SOURCE ZONE}

Recently, there has been a great deal of interest in understanding the relationship between the amount and distribution of DNAPL in a source zone, mass transfer of contaminants from DNAPL to groundwater, and the resultant mass flux that feeds a plume. Much of the focus of these studies has been on evaluating the impact of source mass reduction following aggressive source treatment. The research includes numerical modeling of mass transfer processes as well as field evaluation of several different methods for measuring mass flux coupled with source mass reduction assessment.

Development of the theoretical basis for mass transfer from DNAPL source to groundwater is especially relevant to EA for those enhancements that modify the flow of groundwater through a source zone. Consequently, it is helpful initially to summarize some of the important results emerging from modeling studies that will provide the theoretical justification for application of the enhancements.

Investigations by Sale and McWhorter (2001), Falta (2003), Parker and Park (2004), Park and Parker (2004), and Soga, et al. (2004) address different approaches to evaluating mass flux in terms of hydraulic properties of the system and DNAPL architecture. Parker and Park (2004) show that at the field-scale contaminant mass flux is proportional to water flux (i.e. groundwater velocity). Therefore, reducing groundwater flow velocity through a DNAPL source zone has a direct effect on the resultant mass flux. Sale and McWhorter (2001) and Soga, et al. (2004) emphasize the importance of DNAPL distribution within the source on the resultant mass flux, with pools contributing proportionately less to mass flux than residual DNAPL saturation. Results from some of these investigations form the basis for many of the enhancements discussed in the following subsections.

Reduction of flow can be accomplished by two primary methods:

- Deployment of an engineered structure up-gradient of or surrounding the source to intercept and divert groundwater flow around the source, methods of source encapsulation, and diffusion barriers

- Use of passive groundwater collection and bypass methods that effectively lower the hydraulic gradient in the vicinity of the source (e.g., french drains; horizontal drainage wells; GeoSiphon wells)

Alternatively, a highly innovative enhancement involves adding an amendment (e.g., vegetable oil) to the source zone to reduce mass transfer by dissolving the DNAPL and modifying its subsequent release behavior. 


\subsubsection{Source Containment}

\subsubsection{Low-permeability barriers to divert groundwater around a source}

Subsurface engineered structures can be designed to modify the flow of groundwater so that it partially or completely bypasses the source. Slurry walls (cement/bentonite) and sheet piling represent two of the most common forms of barrier materials. More recently, a wide variety of other types of barriers have been proposed or tested. These include installation of impermeable membranes (e.g., Envirowall, Inc. Gretna, LA), injection of colloidal silica or polysiloxane (Moridis et al., 1996), and methods for catalyzing in situ reactions to form minerals such as clays (Nagy and Fredrich, 2000; Fredrich, et al. 2004) or carbonates (Waring and Taylor, 2001) that fill pore spaces to prevent water penetration. Another method involves the localized stimulation of microbial activity to create a biobarrier that physically clogs the aquifer with biofilm (e.g. Hiebert et al., 2001; Komlos et al., 2004). The longevity of biobarriers has not been established. Temporary barriers constructed by freezing technology also have been demonstrated, but are not sustainable within the context of EA except in very cold climates (e.g. see DOE, 1999). Each of these methods has been either proposed or used to effect isolation of contaminant sources.

Permeable reactive barriers represent a unique type of source containment method and they are discussed in Section 6.3.

Just as the types of barriers are varied, so, too, are the installation methods. Conventional installation methods include excavation followed by backfilling with grout slurry or placement of an impermeable membrane. Sheet piling is driven into place with hydraulically operated equipment. These deployment methods generally are useful for shallow $(<100 \mathrm{ft})$ applications. More innovative deployment methods that increase the potential depth of installation include jetting and hydrofracture techniques. However, injection methods may be limited in their application in heterogeneous and low permeability media and little work has been done to explore physical containment with barriers in bedrock.

Containment of a source is one available option and may include a surface cover (to limit infiltration) and some provision for sealing the bottom of the source area. Much less costly alternatives include simple barrier walls placed up-gradient of or only partially enclosing the source that are intended to divert groundwater flow around the source.

It is important to recognize that large-scale hydrologic modifications of the types discussed in this section reduce, but do not eliminate, the loading term. As such they are not total isolation methods - as a general rule complete isolation, especially of source zones, is not feasible. Even in highly controlled situations, such as the sealed sheet pile cells used in DNAPL research at the Canadian Forces Base (CFB) Borden site in Canada, chlorinated solvents contaminated surrounding groundwater. Nonetheless, both innovative and traditional isolation methods, when viewed as an approach to reduce loading to enable the transition to MNA/EA appear reasonable. O'Donnell et al. (1995) provide detailed documentation of traditional isolation methods, including caps, walls and floors. Their compendium addresses construction issues, uncertainties, and approximate costs.

Few of these systems have been selected and implemented, so the practicality and utility within the framework of disciplined and documentable MNA is uncertain. Most of the 
efforts to date have been qualitative rather than quantitative. Additional quantitative evaluation of the potential of such systems will be needed to support inclusion of this class of enhancement in the next generation MNA/EA protocols.

\subsubsection{Encapsulation of waste in a source}

An alternative option to using impermeable barrier structures to contain a source involves injection of materials into the source region that fill pore spaces, reduce permeability and thereby result in partial flow diversion around the source. An example of grouting of lowlevel waste trenches at Oak Ridge National Laboratory (ORNL) is discussed by Long, et al. (1997) and Huff (2000). Significant, near-term reduction in mass flux occurred as a result of the grouting, but questions remain about long-term effects. In addition, because many waste trenches at this site were not grouted, it is possible that future releases from some of them will increase as waste containers deteriorate. However, WAG 4 has been completely capped, so future options for monitoring or other remedial measures are limited.

Although partial or complete containment of the source will result in a reduction of mass flux, such remedies result in an increased longevity of the source in comparison to the no action alternative. Consequently, there will be an increased reliance on establishing the sustainability of these types of enhancement and a greater burden placed on performance monitoring to ensure that a favorable mass balance is maintained.

\subsubsection{Use of diffusion barriers to enhance source containment}

Research on potential roles for nontoxic oils in assisting remediation of cVOCs has been promising and is an important example of the concept of EA. Typically, the nontoxic oils studied to date have been food grade oils, such as soybean oil. There is no specific theoretical limitation to these oils, however, and other oils may be desirable to optimize the desired objective or to increase longevity and make a system more sustainable. Oils that have been considered by Borden and Rodriguez (2004, in prep.) and other researchers include other food grade oils/additives such as animal oils (lard oil and the like), petroleum jelly, white mineral oil, and paraffin, and non-food grade oils such as silicone oils and polymers. Characteristically, these oils have low water solubility, are less dense than water, and can support environmental cleanup of cVOCs when deployed in the subsurface. In general, these oils reduce cVOC concentrations through two mechanisms by providing:

- Slow release forms of carbon source/electron donor for microbially mediated anaerobic degradation, and

- Barriers to physically isolate and mitigate TCE transport due to preferential partitioning into the oil phase.

Past environmental studies of soybean oil and related natural oils have focused primarily on promoting biodegradation, with limited emphasis on the benefits associated with partitioning. A more balanced technical approach, also emphasizing partitioning and the associate flux reduction/elimination may accelerate and improve the implementation of soybean oil based remediation. The use of these oils as an electron donor to support biological breakdown of cVOCs is presented in Section 5.1.1. The following discussion focuses on the non-biological application of vegetable oils for EA. 
Separate phase organics such as soybean oil provide a medium into which chlorinated solvents (e.g. TCE) preferentially partition. Where deployed in the subsurface, nontoxic oil results in the depression of TCE concentrations in nearby groundwater (and soil gas). The actual concentrations can be calculated using partition coefficients and/or Raoult's Law. Because of the simple conceptual basis of this approach, the deployment can be designed to physically isolate the source material from the plume and greatly reduce the flux of contaminants from the source. The oil will provide TCE isolation for an extended period of time. However, since it is inevitable that the oil barrier will deteriorate or degrade over time, there is concern that trapped contaminants may remobilize.

The slow dissolution of the oil provides a long-term source of electron donor for indigenous microbial activity and allows field-scale verification of bioremediation using cost-effective techniques such as in situ respirometry. As in traditional in situ bioremediation, confirmation and quantification of the rate of biological contaminant destruction is the long-term basis for no further action. This confirmation/quantification is accelerated and made possible by the initial deployment of oil for stabilization of the site. If field evaluation indicates that bioaugmentation is needed, the site will have developed appropriate conditions for the follow-on activity.

There are several different deployment scenarios for diffusion barriers that deserve mention. These include: (a) NAPL oil injection into a source area, (b) deep vadose NAPL oil injection, and (c) NAPL oil injection after aggressive source removal activity. Although the primary objective of these scenarios can be customized for partitioning, blending of this objective with microbial degradation may be the optimal approach. A more detailed summary of these scenarios is provided in the supplemental material in Appendix A.

\subsubsection{Modifying the Hydraulic Gradient with Drainage Structures}

One of the simplest methods for reducing source loading is by lowering the hydraulic gradient $(\mathrm{dh} / \mathrm{dl})$ in the contaminant source region. This action has the effect of reducing groundwater velocity according to Darcy's law $\left(\mathrm{V}=-\mathrm{K}_{\mathrm{H}}[\mathrm{dh} / \mathrm{dl}] /\right.$ porosity) and, as discussed earlier, leads to decreased source dissolution and a proportional reduction in mass flux of contaminants.

A conventional, passive method for lowering the hydraulic gradient is by use of a french drain located on the up-gradient side of the source. This type of drainage structure is simply a trench excavated to a depth consistent with the desired level of the water table with a perforated drain pipe placed in the bottom that is backfilled with permeable (e.g., sand/ gravel) material. In a completely passive system, any groundwater entering the trench flows through the drainpipe by gravity and discharges to a stream or surface drainageway downgradient of the source. Because the influent groundwater is up-gradient from the source it is uncontaminated and can be disposed at any convenient point. Case Study 3-3 illustrates an example at WAG 6 at ORNL where a french drain was used successfully to manipulate the shape of the potentiometric surface (Davis et al., 1985; Davis and Marshall, 1988). However, a companion measure taken at this site to control infiltration was installation of a clay cap. Subsequent monitoring revealed that the cap was leaky, which partially negated the benefits of the french drain. 
As DOE sites across the complex accelerate their plans for closure of waste areas, there appears to be an increased reliance on remediation methods that leave waste in place. Consequently, groundwater interception and diversion strategies involving changing the hydraulic gradient will become more commonly used. While not yet widely implemented, these approaches are receiving increasing attention for sites that are contaminated with chlorinated and radioactive contaminants.

DOE's Kansas City Plant represents another example where implementation of engineering controls to lower the hydraulic gradient of groundwater is under consideration. The site is underlain by a low permeability material characterized by low groundwater flow rates and a stable plume of chlorinated solvent and polychlorinated biphenyls (PCBs). It also is bounded by rivers that receive the relatively limited quantity of groundwater flow and which are subject to periodic flooding from stormwater surges.

One of the potential long-term actions recommended by an independent technical team was up-gradient water collection and control. In a manner analogous to the french drain implemented at Oak Ridge, this simple concept collects clean water up-gradient of the source and sends it down-gradient using an engineered system. Every gallon of water that is bypassed is a gallon of water that is not available to leach and move the chlorinated solvent. Up-gradient water control management, especially if the water is clean, is low cost, moderately low risk and easily implemented.

An innovative and conceptual approach for reducing head gradients that integrates both engineering controls and plant-based methods (see Section 3.2.3) is termed a constant head moat (M. Ankeny, pers. comm..; U.S. Patent \# 6,139,221). In principle, constant head moats might be used to contain source areas to greatly reduce plume loading. Their applicability is limited to those sites where groundwater is shallow enough to permit access by cost-effective excavation techniques and is within the depth-range of the roots of phreatophyte plants (e.g., hybrid poplars or willows) that can uptake groundwater and other plants that can intercept infiltration.

The basic concept is to excavate a trench (i.e., moat) to the level of the permanent water table and install a closed-loop perforated drain pipe. The trench is then backfilled. The unique feature of the closed-loop drain is that it imposes an essentially constant head throughout the area enclosed by the drain (i.e., a moat). This can significantly decrease the mass flux of contaminants feeding a plume. Planting trees within the perimeter of the moat will result in ET during the growing season and actually promote an inward head gradient to further supplement the impact of the moat on the groundwater hydraulics of the system. Figure 3-2 illustrates the moat/ET concept.

Additional passive methods for reducing the hydraulic gradient in the vicinity of the source zone are discussed in the supplemental material in Appendix A.

\subsubsection{Modifying the Hydraulic Gradient Through Phytotranspiration}

Plant-based enhancement systems where high rates of water uptake and ET (i.e. evapotranspiration) are utilized represent another strategy for modifying the gradient of the 
WAG 6 at ORNL contains 28 ha of gently to moderately sloping land divided into several smaller sections by natural gullies and seasonal streams. A small ( $0.44 \mathrm{ha})$ portion of this area contains a series of low-level waste disposal trenches. Following trench closure in 1973-74, intra-trench monitoring wells confirmed that the trenches were collecting and holding water, especially during the wetter winter and spring seasons. The impact of direct contact between buried waste and groundwater was high dissolved concentrations of ${ }^{90} \mathrm{Sr}$ within the trenches and down-gradient discharges of elevated ${ }^{90} \mathrm{Sr}$ concentrations in seeps to receiving tributaries of White Oak Creek.

In 1983 a French drain system was constructed to intercept and divert subsurface flow from up-gradient recharge areas to prevent it from entering the trench area and mobilizing ${ }^{90} \mathrm{Sr}$ contamination. The entire French drain system extended to a length of approximately $250 \mathrm{~m}$ along the northern and eastern sides of the trench area and involved excavation to a depth of up to $9 \mathrm{~m}$. Post-construction monitoring illustrated that significant modification to the water table configuration and elevation occurred (see the cross section). The groundwater levels were shown to slope toward the bottom of the French drain indicating a lowering of the water table by as much as $4 \mathrm{~m}$ in some places. In addition, post-construction monitoring revealed that approximately $50 \%$ of the trench area maintained a suppressed water table such that the trenches no longer collected groundwater during the wet season (see shaded region on map). Results of this project confirm that a passive French drain can be successful in lowering the water table in waste disposal areas by intercepting subsurface flow from up-gradient and by direct flow into the drain from the trench area.
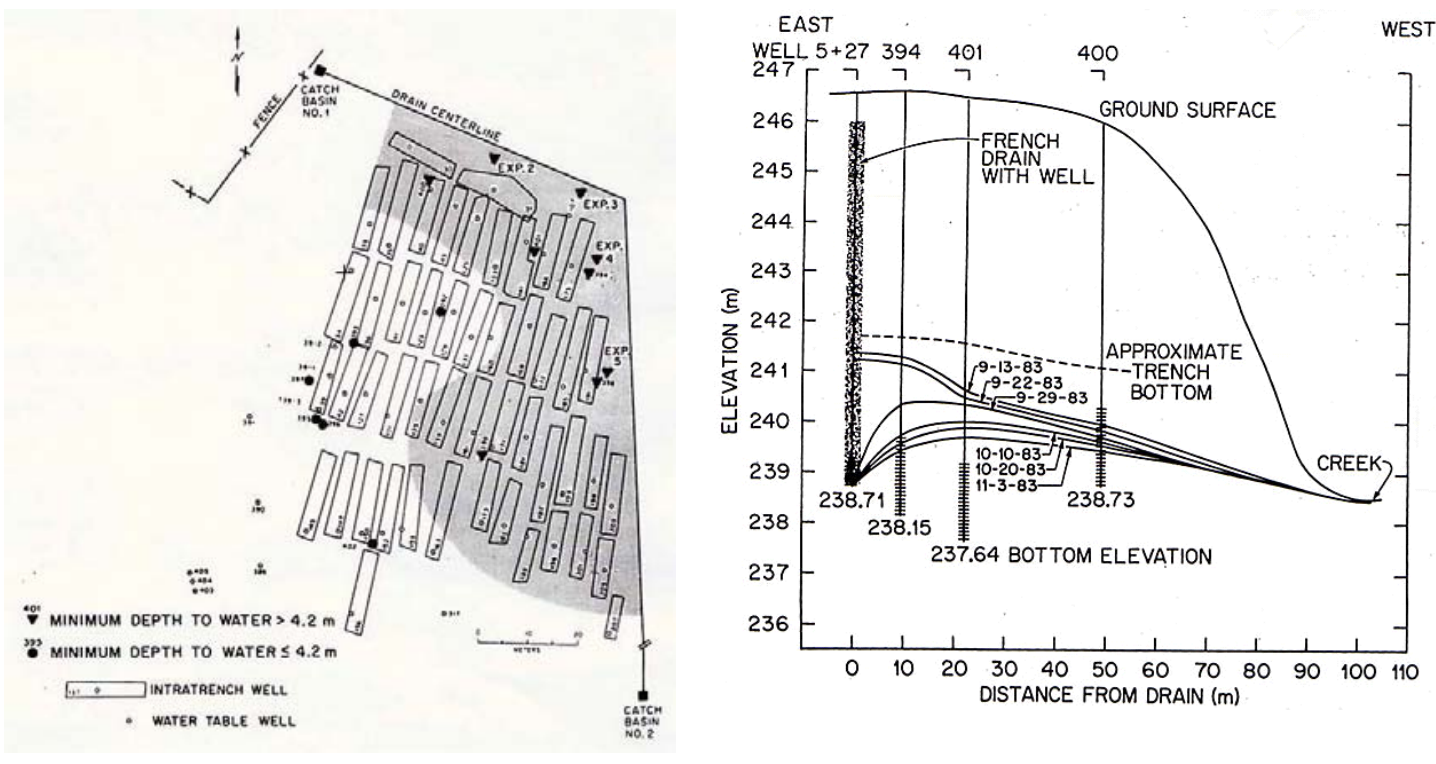

(Figures from Davis and Marshall, 1988)

As an enhancement, manipulating the hydraulic gradient using drainage structures can be an effective, simple and inexpensive method to minimize water infiltration and reduce source loading. 

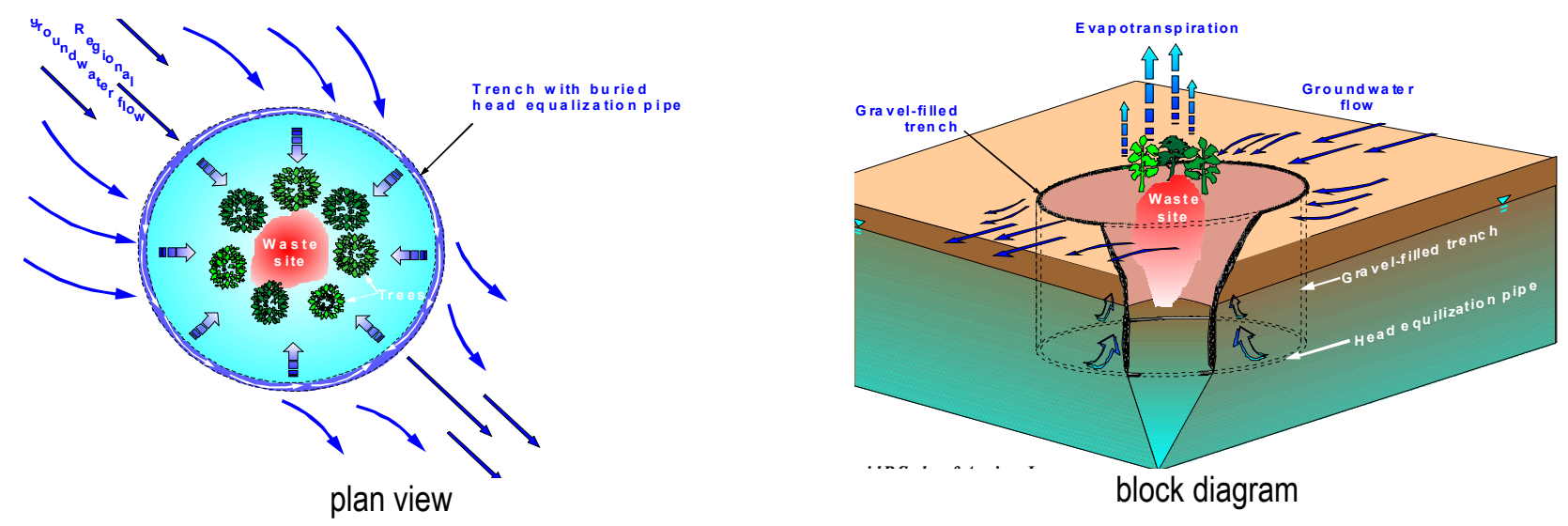

Figure 3-2. Constant Head Moat Concept (from M. Ankeny, pers. comm.)

potentiometric surface in the vicinity of a source zone. This use of trees and/or grasses in this context is different than phytoremediation where plant-based methods are used to degrade contaminants or transfer them to the atmosphere through phytovolatilization (see Section 5.2 for further discussion). The goal of plant-based water harvesting is to remove infiltration or groundwater at a rate that exceeds its replenishment to achieve a locally depressed water table.

Figure 3-3 depicts how a 5-yr old plantation of hybrid poplar trees at a site in Minnesota impacted the shallow water table during one growing season (Hansen, 1991). The results show that in mid-May 1991 the water table was at or slightly above ground surface. Depression of the water table on the order of 1.5 meters occurred over a time period of less than five months. Groundwater flow gradually became inward during the growing season. Had this been a contaminated source zone tree-based water harvesting would have reduced or eliminated plume loading during this time period. Others have demonstrated similar uptake rates. For example, Gordon et al. (1997) reported that a stand of 5 year old poplars could cause a $140 \mathrm{~cm} /$ year draw-down in the water table when grown at a density of 1,750 trees/ha in the warm, arid conditions of eastern Washington state.

Water withdrawal by plants is not uniform throughout the year and there will be recovery of the potentiometric surface during the dormancy period for the trees. However, as noted in Section 3.1.2, some trees do not become fully dormant during the winter. These effects need to be accounted for in modeling efforts and assessment of the value of trees as a method for hydraulic control. In addition, the impact of variations in the annual amount of precipitation (e.g., prolonged drought; unusually wet year) will influence the amount of ET and overall effectiveness of plants in modifying contaminant flux. Finally, it takes a period of years for trees to mature and fully develop their ability to evapotranspire groundwater.

Shallow rooted plants can be used in concert with deep rooted trees in order to maximize the impact of ET as a means of modifying the hydraulic gradient. Shallow rooted plants intercept infiltrating precipitation, denying this source of water for deep rooted trees that 
must preferentially draw groundwater from within the contaminated aquifer. Deep rooted trees such as poplar are not obligate phreatophytes and will use surface water rather than the

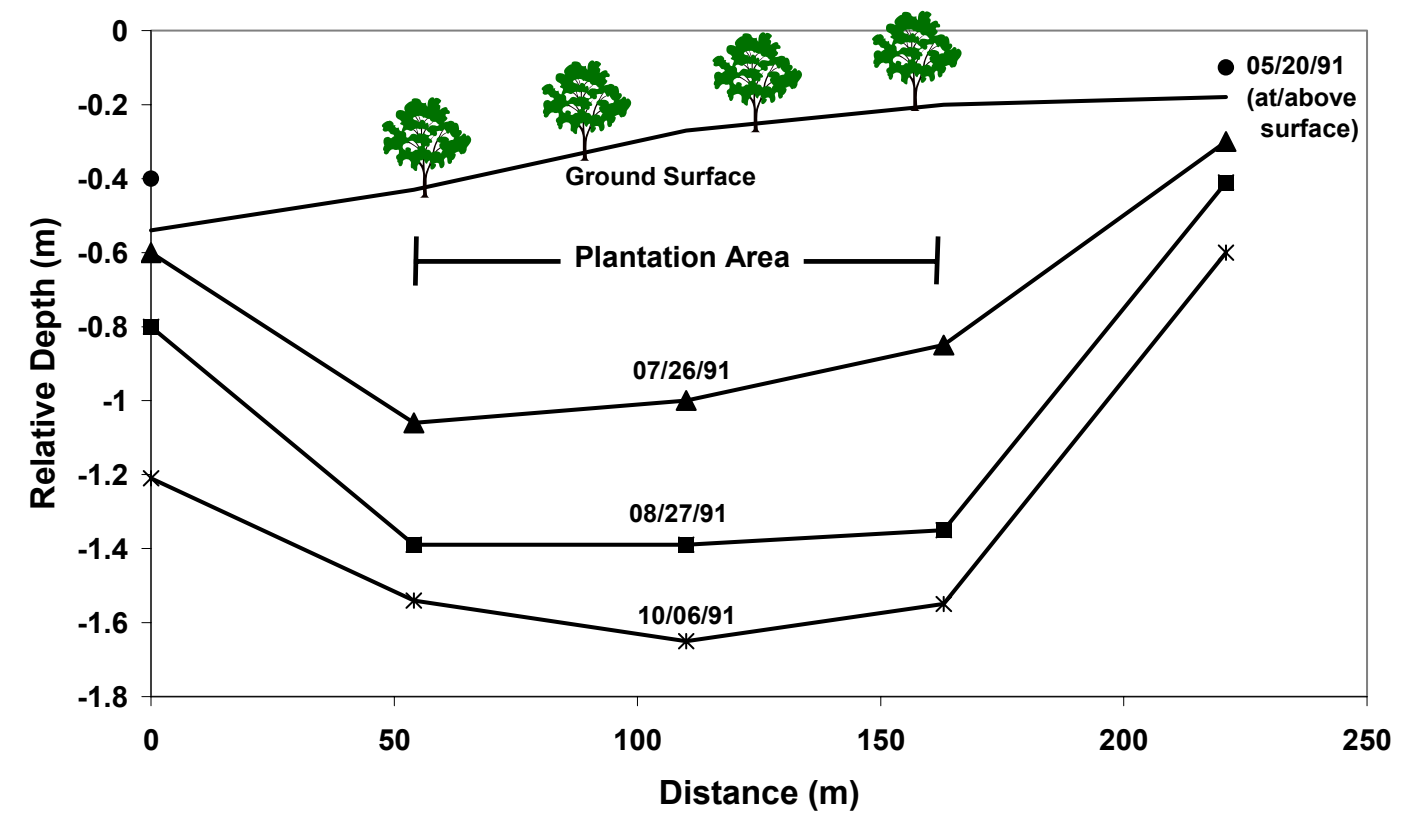

Figure 3-3. Seasonal Depression of the Water Table Underlying a Hybrid Poplar Plantation (after Hansen, 1991)

deeper groundwater if it is accessible. A similar strategy can be employed when phytoextraction, phytovolatilization, or rhizodegradation is the objective (see Section 5.2).

At some sites the contaminated aquifer lies at a depth greater than the maximum depth of penetration of tree roots. However, if the potentiometric surface for the aquifer is at a depth within the range of the root elevation then an innovative approach to phytoremediation/ hydraulic control may be possible. The most successful method to emerge in the past few years to bring plant roots in contact with contaminated groundwater has been by deep rooting using methods such as the patented process of "treemediation" (Ed Gatliffe, Applied Natural Sciences, Inc. - http://www.treemediation.com/; Negri et al., 2000). The concept involves boring a hole into the contaminated aquifer, planting a tree using a porous and permeable backfill material into which groundwater can flow. The borehole is capped at the surface to eliminate surface water infiltration. This forces the tree to grow roots towards the only source of water, groundwater from the aquifer. The boreholes may or may not be lined. The backfill material is homogeneous, porous, permeable, and with a favorable inventory of nutrients to stimulate root growth to much greater depths than would occur in normal soil profiles. It has been estimated that contaminated groundwater can be accessed by deep rooting up to a depth of 20 to $30 \mathrm{ft}$.

In addition to stimulating deeper root growth, the use of backfilled boreholes or trenches that penetrate into a contaminated aquifer can serve another function. If the aquifer is confined or semi-confined, penetrating the confining layer will permit groundwater to rise in the borehole 
or trench to the level of the potentiometric surface. This will make the groundwater more accessible to the tree roots even without additional root growth.

There are several examples where deep-rooting of trees has been implemented. These include the Edward Sears site in New Gretna, New Jersey, two sites at the U.S. Department of Energy's Portsmouth Gaseous Diffusion Plant, and a location at Argonne National Laboratory in Illinois. More information about these applications is provided in the supplemental material in Appendix A.

\subsection{ELECTRON ACCEPTOR DIVERSION}

As discussed previously, large-scale hydrologic modifications have the potential to enhance natural processes by reducing flow and minimizing contaminant loading to groundwater. At some sites, however, a second benefit, electron acceptor diversion, might be realized by one form of large-scale hydrologic modification. Electron acceptor diversion may be at least as important as the reduced loading effect at some chlorinated solvent sites. As for constant head moats, electron acceptor diversion is in the conceptual phase of development and has not yet been implemented at a site.

To accelerate the natural dechlorination process for the purpose of bioremediation, numerous research groups have focused on methods to increase the supply of electron donors to dechlorinating bacteria. Most researchers and technology developers add complex electron donors (such as lactate, molasses, mulch, etc.) that ferment in-situ to release hydrogen. An evaluation of the electron donor mass balance at sites where reductive dechlorination occurs naturally indicates there is another approach to increasing the net electron donor supply to the dechlorinators.

The presence of electron acceptors (primarily dissolved oxygen, nitrate, and sulfate) in a source zone will result in biodegradation reactions that compete with beneficial dechlorination reactions for electron donor. This competition occurs in cases where the electron donor is present in the source zone prior to remediation (a Type I or Type II chlorinated solvent site; Wiedemeier et al., 1999) or if the electron donor supply is enhanced by adding fermentation substrates or hydrogen directly.

By employing large-scale hydrologic controls, it should be possible to permanently divert the transport of competing electron acceptors (oxygen, nitrate, and sulfate) away from chlorinated solvent plumes so that more electron donor (i.e., organic substrates and/or dissolved hydrogen) is preserved for beneficial reductive dechlorination reactions (Newell et. al, 2001a, 2001b). This diversion can be achieved by constructing a physical barrier upgradient of a chlorinated solvent source zone to reduce the transport of competing electron acceptors into the source zone, or alternatively, using other conventional hydraulic containment techniques (Figure 3-4; see also Section 3.2.1). The result will be a zone where the geochemical conditions have been changed to enhance beneficial reductive dechlorination reactions that destroy chlorinated solvents. 
Preliminary calculations indicate that natural attenuation rates could be increased by a factor of hundreds of pounds of solvent per year at some sites, a significant amount compared to the typical mass flux that is observed leaving chlorinated solvent sites.
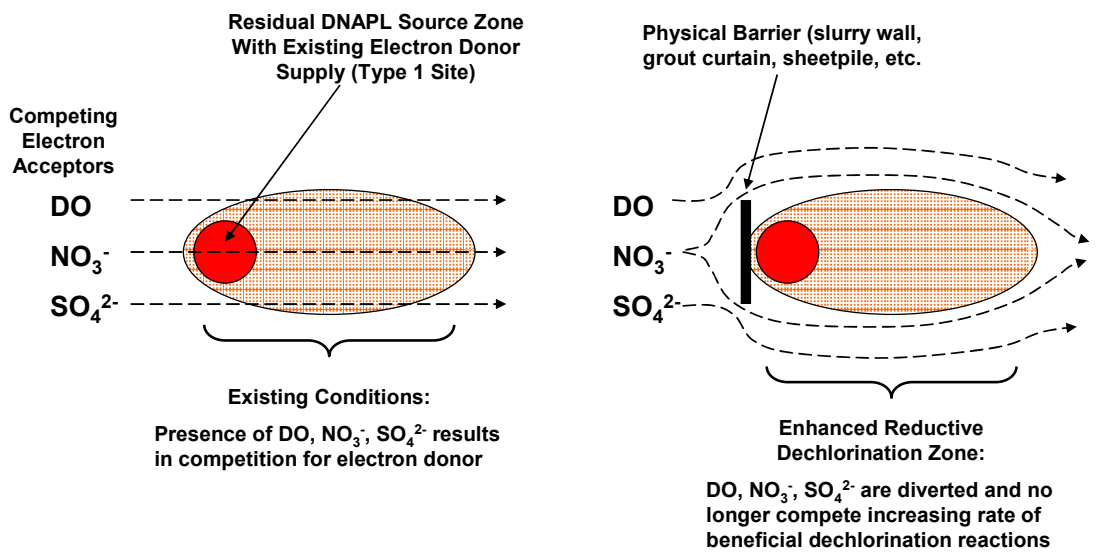

Figure 3-4. Electron Acceptor Diversion Concept. Other types of diversion concepts would provide equivalent performance.

In summary, by employing a hydrologic diversion system up-gradient of a Type I or Type II chlorinated solvent source zone, two benefits may be realized: 1) competing electron acceptors will be diverted away from the source zone, thereby increasing the rate of naturally-occurring bioremediation and increasing mass destruction of chlorinated solvents; 2 ) the loading to the plume will be reduced, thereby shortening the plume and cutting longterm monitoring costs. Such a hydrologic diversion system would be inexpensive, have the potential to significantly enhance natural attenuation processes in a passive manner, and might result in the collapse of the dissolved plume down-gradient of a source zone.

\subsection{ISSUES}

\subsubsection{Scientific Issues}

Many of the enhancements discussed in Section 3 are mature technologies that have been used for decades to control surface and subsurface water, although some represent recent, innovative approaches with limited deployment history (e.g., GeoSiphons). Interception and diversion structures for surface water, stormflow, and groundwater are examples of such technologies where the design, materials, and construction details are well understood and tested. At the time this reference guide was prepared, the use of groundwater diversion structures to limit flow of electron acceptors into a DNAPL source zone has not been attempted in the field. However, it is based on hydrologic principles that are known to be valid.

Engineered covers are another example of a technology that has been available for decades, although it is an active area for research to develop covers for different climatic conditions and ones that continue to perform reliably for much more than the few tens of years commonly encountered with RCRA caps. The use of plant-based methods to limit 
infiltration or modify the hydraulic gradient within an aquifer has a firm theoretical basis, but relatively little direct experience from field applications.

\subsubsection{Regulatory Issues}

The enhancements in Section 3 are designed to control the flow of water into and contaminant flux out of a source zone. They are part of a contaminant containment strategy. EPA tends to favor actions that destroy or removes contaminants, so this approach may encounter some regulatory resistance. It is also likely that regulators will closely scrutinize enhancements that do not have an extensive track record of successful implementation. Plant-based enhancements, engineered covers with limited longevity, and diversion of electron acceptors may require more extensive testing and verification to be acceptable. 
WSRC-STI-2006-00083, Rev. 1

August 1, 2006

Page 36 of 147

This page intentionally left blank. 


\subsection{ENHANCEMENTS TO REDUCE PLUME LOADING: PASSIVE RESIDUAL SOURCE REDUCTION}

Another potential method for reducing plume loading involves source mass reduction. The objective of this approach is to reduce the amount of source mass so that there is a concomitant reduction in mass transfer of contaminants to groundwater. Although the linkage between source mass reduction and resultant mass flux is a subject of intense investigation (e.g., Wood, 2003), it is useful to examine potentially sustainable and passive mass reduction enhancements that might become a part of EA.

The following subsections examine several different types of sustainable and passive source removal options that can have a beneficial impact on source loading and reducing mass flux of a plume.

\subsection{PASSIVE VAPOR EXTRACTION OF CVOCS FROM THE VADOSE ZONE}

The central principle in barometric pumping is the beneficial utilization of natural variations in pressure between the subsurface soil gas and the atmosphere. This technology is a welldocumented example of the class of technologies that might also include methods that rely on tidal oscillations, spatial and temporal temperature or geochemical variations. Barometric pumping can either be used to inject air to stimulate aerobic processes in the subsurface, or to extract air and thus passively provide an enhanced rate of contaminant removal. This is an example of a simple and low-cost EA method that would be potentially applicable to small sources, low risk sites, or as a transition technology to address low levels of residual contaminant after active treatment has removed the bulk of the contaminant.

Barometric pumping in wells has been recognized for many years, dating back to weather forecasting in native cultures and early geological papers (e.g., Fairbanks, 1896; Weeks, 1978). Case studies related to beneficial uses for environmental remediation, however, are more recent and were initiated by DOE laboratories (e.g., Pirkle et al., 1992; Rohay and Cameron, 1992; Rossabi et al., 1994; Rossabi, 1999; Riha et al., 1994) with field work primarily at the DOE Savannah River, Hanford, Idaho, and Nevada sites and by scientist studying bioventing for the DoD (e.g., Zachary, 1993; Zwick et al., 1994). These, and similar case studies, documented the performance potential and limitations for barometric pumping and provide a foundation for modeling and cost estimation. More recently, DoD has supported more comprehensive bioventing technology assessment of barometric pumping (e.g., ESTCP, 2004).

The results to date from various case studies are consistent and provide a relatively clear idea of advantages and disadvantages of the concept, desirable and undesirable site conditions, and implementation issues.

Natural atmospheric pressure fluctuations are transmitted through the unsaturated subsurface. These pressure waves are damped and delayed in phase to degrees dependent on the effective vertical permeability of the formation. As a result, at a given time the atmospheric pressure at the surface and the soil gas pressure in the subsurface are different. If these two zones are 
connected by a vadose zone well, the pressure differential will result in flow either into or out of the well. Wells screened in the unsaturated zone have been observed to inhale ambient air and exhale soil gas. These natural air flows in wells are determined by barometric pressure fluctuations, permeability of the subsurface, and depth of the well screen. The difference between surface and subsurface pressures is the driving force for these flows. Barometric pumping technology is improved by allowing flow in only one direction. Several commercially available devices are available for this purpose, including the Baroball, which is described in more detail in the supplemental material in Appendix A.

The primary advantage of barometric pumping over active systems is the elimination of an electrically powered blower and reduced operating and maintenance costs. Use of a check valve system typically improves the performance of contaminant extraction systems (or air injection systems) by approximately a factor of 2 . One DoD report (ESTCP, 2004) noted that at "facilities such as ranges, training, and proving grounds, electrical power is either unavailable or would be expensive to obtain." It was further concluded in this report that in the case of bioventing, passive systems "can be used to deliver oxygen at a rate equal to the biological demand" and with minimal potential to spread contamination. A cost comparison of passive and conventional bioventing systems at a former USAF base in California presented in the report suggests that a cost savings of $10 \%$ or more is possible with the passive technology. Solar powered microblowers to assist with vapor extraction represent an intermediate technology between traditional electric and barometric pumped systems (see supplemental material in Appendix A for more information).

The primary disadvantage of barometric pumping is that it is viable only at sites with suitable subsurface conditions that lead to a sustained difference between atmospheric and subsurface gas pressure (deep sites, sites with large caps or buildings, sites with strongly layered geologic materials). The passively-induced airflow rate is generally lower in magnitude than the airflow produced by electrically powered blowers. A lower rate of airflow may result in a smaller radius of influence and the need for more wells. Also, in some cases, passive systems may require significant additional remediation time.

Case Study 4-1 illustrates an example of passive soil vapor extraction that was applied at DOE's Savannah River Site as reported by Riha et al.(2000). As can be seen, there has been a remarkable improvement in subsurface contamination in the vadose zone at this site using passive controls. It is unknown if these improvements have resulted in complementary reduction in the rate of transport of contaminants to the underlying groundwater.

Barometric pumping for removal of contaminants can be implemented in several different ways. A series of wells configured with Baroballs or similar one-way valves may be utilized. Alternatively, an impermeable fabric plenum with a check valve has been tested at Idaho National Laboratory in a technology called Barometrically Enhanced Remediation Technology (BERT) that is described in DOE (2000a). Figure 4-1 illustrates how it is deployed.

Case studies to date suggest barometric pumping is a promising concept for EA. Under limited conditions, barometric pumping can be used as all or part of a remediation system or can be viewed as a transition technology to implement following active treatment. More 

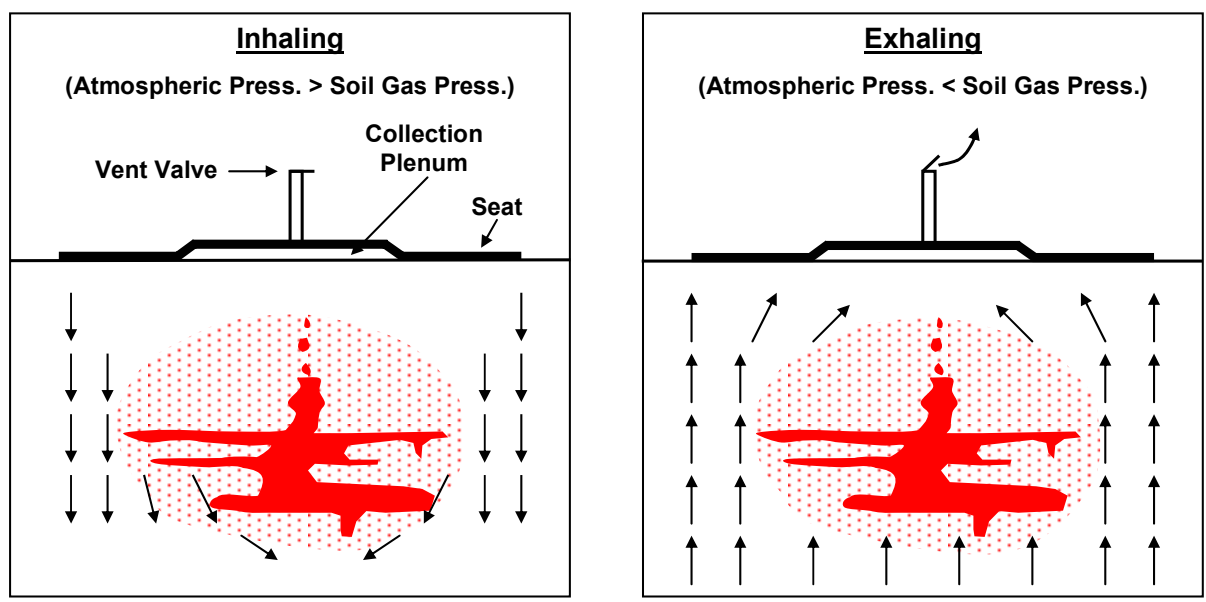

Figure 4-1. Illustration of the BERT Treatment System (from DOE, 2000a)

importantly, barometric pumping is an example of the general class of passive methods that beneficially utilize environmental conditions as a part of a cleanup. Optimal and energy efficient site cleanup may be best supported by considering site specific conditions/needs and matching them using a portfolio of related techniques that grade one to another in how they utilize natural and anthropogenic power.

The distributed nature of any potential implementation will provide monitoring challenges How much monitoring is needed for such a system? Perhaps a distributed radio frequency identification (RFID) type of monitor would be appropriate for this technology. A key to selection and implementation of this method, and other long term - low energy concepts, is that the performance will maintain the mass balance in a desired state.

\subsection{PASSIVE DNAPL REMOVAL FROM SOURCE ZONES}

The architecture of contaminant distribution in DNAPL sources generally is very complex, which greatly increases the difficulty of site characterization where the objective is determining the distribution of contaminants. Even subtle heterogeneities in unconsolidated media lead to a complicated pattern of DNAPL invasion from the release point that depends upon the physical properties of the NAPL, pore throat dimensions of the media, and relative wettability of the NAPL on mineral grains in comparison to air (vadose zone) or water (saturated zone). In fractured media, NAPL advances along transmissive pathways in a network of fractures that range in terms of length, transmissivity, and connectivity.

One method for passive removal of potentially mobile DNAPL from sources involves the placement of screened wells in the source region that intercept mobile zones of DNAPL (i.e., pools). Mobile DNAPL can drain through the screen into the well casing and descend to a sump at the base of a well where it can collect prior to periodic removal. Conceptually, such an approach is applicable to both unconsolidated and fractured media. Such approaches 
In May 1998, a passive SVE treatability study was initiated at the Metallurgical Laboratory on the SRS (Riha, et al, 2000) where solvents such as TCE and PCE were used in degreasing operations from the 1950 s to 1980 s. Nineteen wells were installed as a SVE network, each fitted with a Baroball one-way valve to permit only outflow of contaminated vapors. The well casings were screened from 20-80 ft. BGS in the vadose zone. Natural variations in barometric pressure resulted in low flows (1-10 SCFM). The minimum pressure differential requirement of the Baroball is about $1 \mathrm{mbar}$ in order to permit air flow.

During the two years covered by this investigation approximately $270 \mathrm{lbs}$ of cVOCs have been removed. The graph shows the cumulative recovery of both TCE and PCE over this period of time. The two map figures present the PCE soil gas concentration contours (ppmv) for June 1998 (left) and June 2000 (right) and illustrate significant clean up of vadose zone contamination at the site. Investigators projected that concentrations in all wells in the vapor extraction network will be below 5 ppmv by 2005 .
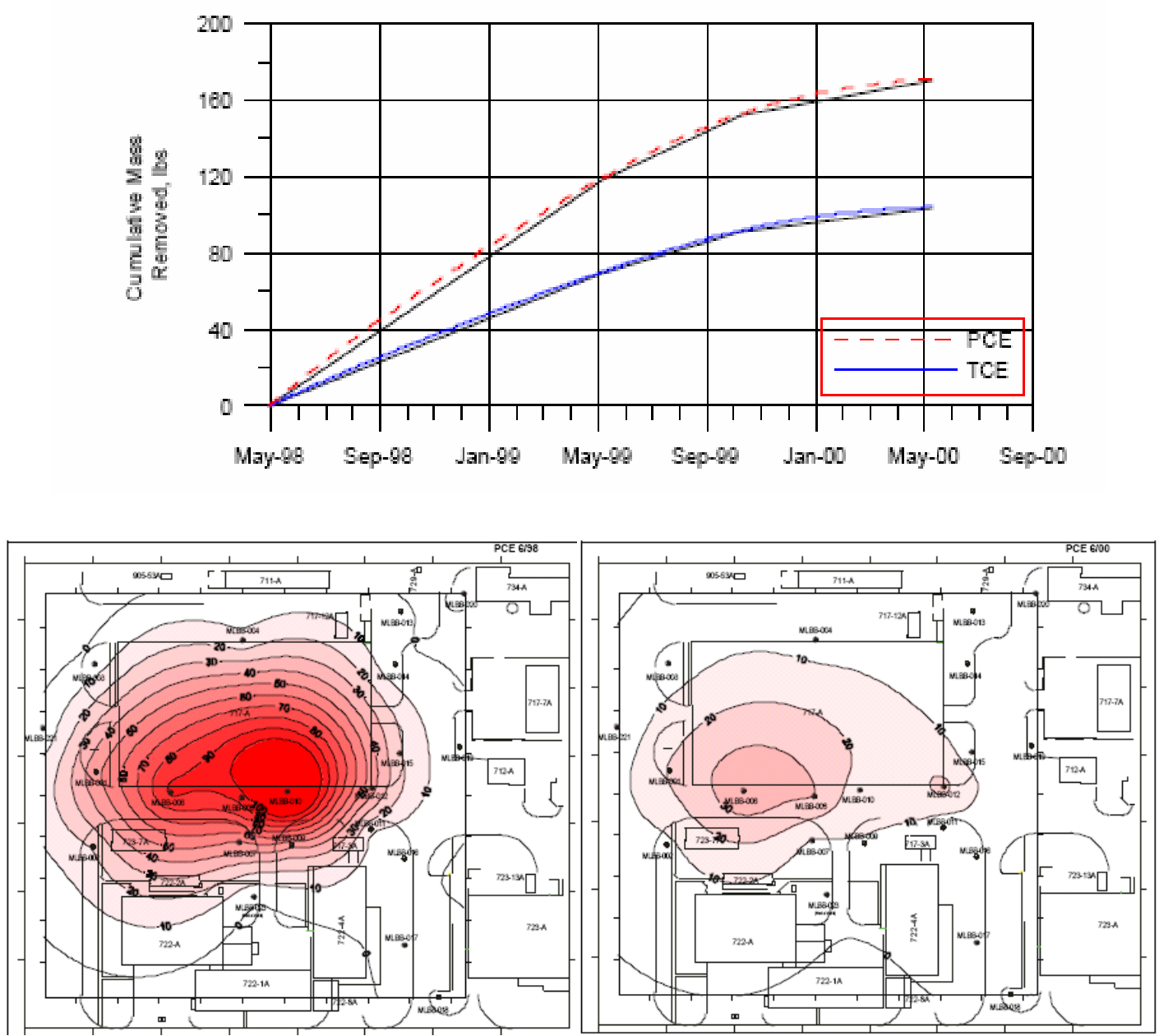

Passive methods for removing source contaminants are viable enhancements for sites where residual contaminants remain upon completion of aggressive source treatments. These methods tend to be low cost, low maintenance, and require no external power source. 
have been considered in past technical brainstorming sessions (see Looney, 2002).

Installing wells directly into a DNAPL source zone is technically challenging in order to ensure that contamination is not mobilized along new pathways created by well installation that will worsen the situation. Indeed, this approach may be considered controversial by some practitioners because of the potential for migration in uncontrolled ways. These constraints may prove to make this approach too risky, not cost effective, or both.

However, sometimes wells are installed that inadvertently intercept mobile DNAPL and this represents a passive way of removing source mass. For example, DOE's Portsmouth Gaseous Diffusion Plant in south-central Ohio is a facility where extensive DNAPL (TCE) contamination occurs underlying the $\mathrm{X} 701 \mathrm{~B}$ site. Several monitoring wells placed in the presumed source region intercept DNAPL within the silt-sand Gallia Formation. For many years a small, but steady, flow of TCE DNAPL has accumulated in the bottom of these wells and is periodically removed (C. Rightmire, pers. comm.).

An important consideration for applying this approach to fractured media is the recognition that diffusion of DNAPL out of fractures into the rock matrix can occur relatively rapidly such that after a sufficient period of time no separate NAPL phase exists in the fracture. Parker et al. (1997) present an analysis of this potential and found that the rate of DNAPL loss to matrix can occur in a matter of days to approximately ten years depending upon the storage capacity (i.e. porosity) of the matrix for the conditions investigated. This time range typically is short in comparison to the length of time that the DNAPL has resided in the subsurface at many sites. Consequently, the probability of success of this approach for passive DNAPL removal needs to be evaluated before being implemented.

\subsection{ISSUES}

\subsubsection{Scientific Issues}

There are no significant technical issues with the enhancements discussed in Section 4. However, DNAPL removal by drainage into well sumps (Section 4.2) only will occur when a continuous pool of DNAPL is encountered. The impact to the waste site of the drainage into the well sump on total mass removed and mass flux probably will be very limited.

\subsubsection{Regulatory Issues}

There are no significant regulatory issues with the enhancements discussed in Section 4. 
WSRC-STI-2006-00083, Rev. 1

August 1, 2006

Page 42 of 147

This page intentionally left blank. 


\subsection{INCREASE SYSTEM ATTENUATION CAPACITY: BIOLOGICAL PROCESSES}

Methods for manipulating biological processes to increase the natural attenuation capacity of systems for cVOCs are critically important to EA. In the past decade an enormous amount of research effort has been put forth to understand and exploit the ability of certain consortia of bacteria to degrade the common chlorinated ethenes (e.g., TCE, PCE, DCE, VC) and other contaminants in the subsurface. Section 5.1 examines some of the key processes where microbial degradation is important.

Likewise, there has been an important, but somewhat lesser, effort directed toward understanding how plants can be utilized to degrade cVOC contaminants or facilitate translocation of them from the subsurface to the atmosphere. Some of these processes are discussed in Section 5.2.

Microbial and plant-based processes also converge to aid in contaminant destruction. For example, plants play an important role in constructed wetlands by promoting stability of the wetland against erosion and being a sustainable source of organic matter to feed the bacteria responsible for $\mathrm{cVOC}$ degradation. A second example involves the synergistic effects of microbial and plant-based processes in the rhizosphere. Complex organic compounds exuded by plants in the root zone can serve as catalysts for microbial degradation of contaminants. These linkages between microbial and plant-based processes are discussed in Sections 5.1.3 and 5.2, respectively.

Recently, it has become obvious that advances in biotechnology are presenting us with the potential for genetically altering certain plants and bacteria to improve their ability to degrade contaminants. Indeed, there are numerous examples of genetically altered food crops (corn, soybeans, etc.) that have increased resistance to disease or certain herbicides. However, the lengthy and expensive regulatory approval process and public concerns for safety jointly have acted to slow the expansion and acceptance of new genetically altered food products in the US and Europe (Weise, 2005).

Concerns also exist for release of genetically altered bacteria. Genetically engineered bacteria that are developed for one class of compounds, such as chlorinated ethenes, must show a low potential to further evolve degradative pathways resulting in production and accumulation of toxic metabolites even as they degrade the target compounds (Velicer, 1999). This issue and other potential deleterious effects, such as unwanted gene transfer, need to be addressed if there is a possibility that released organism(s) may persist in the environment (Tiedje et al. 1989).

As the genetic mapping and associated research of an increased number of plants and bacteria advances it is realistic to assume that "designer" plants and bacteria can be produced that have special capabilities to enhance the degradation of cVOC contaminants. At the present time, however, for the reasons cited above, there is great concern among the regulatory and stakeholder communities about the potential deleterious impacts that might be associated with release of these new species into the environment. Future research may 
eventually lessen these concerns, but for the present there is no compelling reason to incorporate genetically altered plants and bacteria into the framework of EA.

\subsection{MICROBIAL DEGRADATION METHODS}

Biological processes are a significant component of the assimilative capacity within a natural system. The question becomes how this component can be enhanced to increase or augment the natural assimilative capacity to remove chlorinated solvents with minimal intervention (i.e., EA). The biological capacity is a function of the mechanisms that directly or indirectly remove chlorinated compounds and the factors that affect the rate or activity of these mechanisms. If the primary mechanism is biodegradation, then the capacity of the system can be enhanced by removing metabolic limitations, which could be as simple as providing limiting nutrients, or by the addition of metabolic capacity that is missing. Indirect mechanisms can entail the creation of environments that favor abiotic reactions, or that sequester chlorinated compounds.

The purpose of Sections 5.1.1 and 5.1.2 is to examine briefly how these biologically- based mechanisms can be enhanced with minimal intervention. Section 5.1.1 discusses the use of long-lived electron donors or acceptors to enhance and maintain biological degradation processes. Section 5.1.2 discusses the use of bioaugmentation to supplement the biological metabolic capacity within the system. A unique form of enhancement where biological degradation occurs in a wetland environment is discussed in Section 5.1.3. Section 5.1.4 presents an overview of how these ideas might be integrated to improve capacity. Although Section 6 discusses abiotic enhancements, some of these processes involve biological components. These are addressed in Section 6.1.

\subsubsection{Biostimulation using Long-Lived Electron Donors, Electron Acceptors and Nutrients}

A variety of biologically mediated processes are available that can be used to enhance the degradation of chlorinated solvents in the subsurface including cometabolic reductive dechlorination, halorespiration, anaerobic oxidation, and direct oxidation. All of these processes require the presence of: (a) microorganisms with the required metabolic capabilities; (b) a biologically available electron acceptor or donor; and (c) nutrients for cell growth. This section focuses on methods for sustained addition of electron donors, electron acceptors and/or nutrients.

Traditional approaches for enhancing the in-situ biodegradation processes rely on the continuous or periodic addition of one or more chemical reagents including electron acceptors (oxygen, nitrate, sulfate), electron donors (carbohydrates, fatty acids, and $\mathrm{H}_{2}$ ), and nutrients (nitrogen, phosphorus, trace minerals and vitamins). Typically, these reagents are dissolved in water and flushed through the treatment zone. However, traditional dissolved reagents may be less appropriate for EA as these chemicals can be transported quickly out of the target treatment zone by flowing groundwater.

One of the major challenges for long-term enhancement of in-situ biodegradation processes is to develop methods to continuously deliver a slow, steady supply of the required reagent 
without frequent human intervention. Important characteristics of this reagent and/or delivery method include the following.

- The treatment reagent should be a nontoxic, relatively innocuous material to minimize adverse impacts on down-gradient receptors and aid in gaining regulatory approval for in-situ application.

- Once distributed, the treatment reagent should be relatively immobile to prevent it from being washed out of the treatment zone by flowing groundwater.

- The treatment reagent should be relatively resistant to biological or chemical attack so that it will persist for several years between applications.

- The treatment reagent should be sufficiently reactive to support the desired chemical or biological reaction at rates that meet treatment objectives.

Identification of nontoxic, innocuous reagents is relatively straightforward. The carbon source/electron donors are often organic amendments delivered as aqueous solutions (containing lactate, molasses, or similar compounds), proprietary polymerized organics (such as Hydrogen Release Compound - HRC), nontoxic oils (such as soybean oil, lard oil, etc.), and blended amendments (such as water-oil emulsions).

It is a much greater challenge to develop methods for cost-effectively distributing and immobilizing one or more reagents that: (a) react quickly enough to support the desired chemical or biological reaction; and (b) react slowly enough to last for several years in the subsurface.

\subsubsection{Methods for Controlling Reagent Release Rate}

A variety of different approaches and/or processes can be used to control the reagent delivery rate. The primary approaches used to date are described in the following sections.

\section{Release Rate Limited by Surface Mass Transfer.}

This approach relies on the release rate of dissolved reagent being controlled by surface arealimited mass transfer processes. A hypothetical example would be burial of a high solubility reagent (e.g., sodium nitrate or lactic acid) in a semi-permeable membrane. A constant supply of reagent would be delivered to the aquifer based on the physical properties of the membrane and the zone of impact will depend on the rate of advection and the influence of factors such as dispersion and diffusion coupled with the rate of reagent consumption. Previous applications of this approach for groundwater bioremediation include diffusionlimited release of electron acceptors from passive emitters (Wilson and MacKay, 2002) and nutrient briquettes (Kao and Borden, 1997).

\section{Release Rate Limited by Abiotic Reactions.}

In this approach, the rate of reagent supply is controlled by an initial abiotic reaction. Ideally, the reagent supply rate would be relatively constant throughout the treatment period. Previous applications of this approach for groundwater bioremediation include: (1) hydrolysis of $\mathrm{MgO}_{2}$ and $\mathrm{CaO}_{2}$ releasing dissolved oxygen; (2) hydrolysis of HRC releasing dissolved lactate; and (3) hydrolysis of silicon-based organic compounds (Yu and Semprini, 2002). 


\section{Supply of partitioning reactants.}

This concept involves the addition of reactants (e.g., isopropanol) that will partition into the DNAPL phase in a source zone and then repartition into the aqueous phase based on diffusion at a rate that will sustain biodegradation near the DNAPL:water interface. Conversely the DNAPL could partition into the reactant (e.g., oil). Regardless, the rate of reactant/DNAPL dissolution and diffusion would be balanced to allow complete degradation of the chlorinated solvent. Compounds like isopropanol can cause DNAPLs to swell, reducing their density and increasing their effective surface area (Lunn and Kueper, 1997).

\section{Release Rate Limited by Slow Biotic Reaction Kinetics.}

This approach is based upon slow consumption rates, which are an intrinsic characteristic of the treatment reagent. A hypothetical example would be the synthesis of a chemical that is very slowly consumed by naturally occurring bacteria. An example of this approach involves certain highly crystalline iron oxides (naturally occurring) that are used very slowly by indigenous microorganisms. Another application of this approach for enhanced bioremediation includes use of designer substrates for controlled release of hydrogen and acetate (Borden and Rodriguez, 2004, in prep.).

\section{Supply of an external reactant limits release rate.}

In this approach, the rate of reagent consumption is controlled by the supply of an external reactant (either the contaminant to be degraded or another solute dissolved in groundwater). Previous applications of this approach include dissolution of a phosphate buffer that is controlled by the hydroxide ion supply (Liu et al. 2004).

\section{Increase reaeration rate.}

This concept involves physical alteration of the site to increase the rate of oxygen exchange between the atmosphere and the subsurface. To date, the most commonly applied approach has been use of barometric pumping to increase oxygen exchange with the vadose zone (ESTCP, 2004). In Section 4.1 it was noted that the Baroball and similar one-way valve systems can be configured to aerate the subsurface. However, there are a number of passive approaches that could be used to increase oxygen exchange with the saturated zone through increased mixing and/or increasing the surface area for oxygen exchange.

In practice, electron acceptor or donor release rates will be controlled by the simultaneous occurrence of a variety of different processes such as those described in this section.

\subsubsection{Reagent Delivery Approaches}

Successful application of in-situ treatment technologies is often limited by effective delivery of reagents to the treatment zone. The most appropriate application approach often depends on both the physical characteristics of the reagent and site specific conditions (e.g. media type, heterogeneitites, groundwater flow rates, etc.). Examples of typical reagents that might be used include solids (e.g. peat; wood chips) and both aqueous solutions (e.g. lactate, HRC, $\mathrm{ORC}$ ) and non-aqueous oils (vegetable oil or oil emulsions). 
Reagent delivery methods include the following:

- Solids (e.g. peat, wood chips)

$\circ$ Trenching

○ Soil mixing

○ Jetting

- Hydraulic fracturing

- Low solubility liquids (e.g. vegetable oil)

- Injection of NAPL

O Injection of emulsion

- High solubility liquids (e.g. lactate, HRC)

- Injection as aqueous solution

Further detail on these approaches is provided in Appendix A.

The effectiveness of all injection-based approaches within the saturated zone will be influenced by spatial variations in aquifer physical and chemical properties. For example, NAPLs will migrate preferentially through coarse grained layers, bypassing finer grain zones. Emulsions, dispersion, and dissolved reagents will migrate farther through higher permeability zones due to the higher groundwater flow velocities and lower retention by sediment surfaces. The only application technologies that do not suffer from this limitation are trenching and soil mixing which physically removes or disrupts the existing soil heterogeneity.

Case Study 5-1 presents a summary of a biostimulation case study provided by Regenesis (A. Willett, pers. comm.) in which HRC was used to accelerate microbial degradation of TCE and facilitate complete dechlorination of contaminants. Although two applications of HRC were used in this example, significant degradation of cVOCs took place after the first phase of injection. This case study is not presented as a formal example of EA, but encouraging results suggest that such an approach has potential for leading to significant degradation of contaminants with minimal intervention. The question of treatment sustainability is not fully answered at this time and depends on evaluation of a more extensive monitoring record to reveal signs of contaminant rebound. Contaminant breakdown following the addition of an amendment must be sufficiently sustained before biostimulation can become a viable EA approach.

References to other case histories describing sites where one or more of these approaches have been used to provide a slow-release source of electron acceptor or electron donor are provided in Appendix B, Table B-5. 
Case Study 5-1. Biostimulation using HRC

The former FMC Corporation (FMC) site, located in San Jose, California, was used for heavy industrial manufacturing from 1966 to 1988 . Volatile organic compounds were detected in shallow groundwater at concentrations of up to $5,000 \mu \mathrm{g} / \mathrm{L} \mathrm{TCE}$, and in soil at concentrations of up to $10,000 \mu \mathrm{g} / \mathrm{Kg} \mathrm{TCE}$. Daughter products observed included cis-1,2-DCE and VC. FMC voluntarily initiated the clean up project for the site, and routine monitoring and reporting has been conducted since 1990.

An investigation performed at the site in 1998 indicated that limited biodegradation of VOCs had occurred in the past, but at a slow rate. Bench- and pilot-scale studies using various electron donor additives and techniques were performed at the site during the spring of 1999, and HRC application was selected as the optimal treatment to stimulate in situ anaerobic degradation of cVOCs given site conditions. HRC injection locations were at nodes of: a) a 5' X 5' grid in the high concentration zone and b) a 5' X 10' grid in lower concentration areas. This close spacing was chosen to address the site's low permeability silty clay soil. Full-scale treatment was initiated at the site in May 2000, with a second application of HRC in November 2001. Following the first HRC treatment, concentrations of VOCs were reduced by at least one order of magnitude at all treated wells. Following the second HRC application in November 2001, concentrations of TCE have been reduced more than three orders of magnitude at wells in the center of the treatment area, and daughter-product cVOC concentrations have also decreased (see figure). Microbial analyses indicate that dechlorinating bacteria populations have increased in the treatment area.

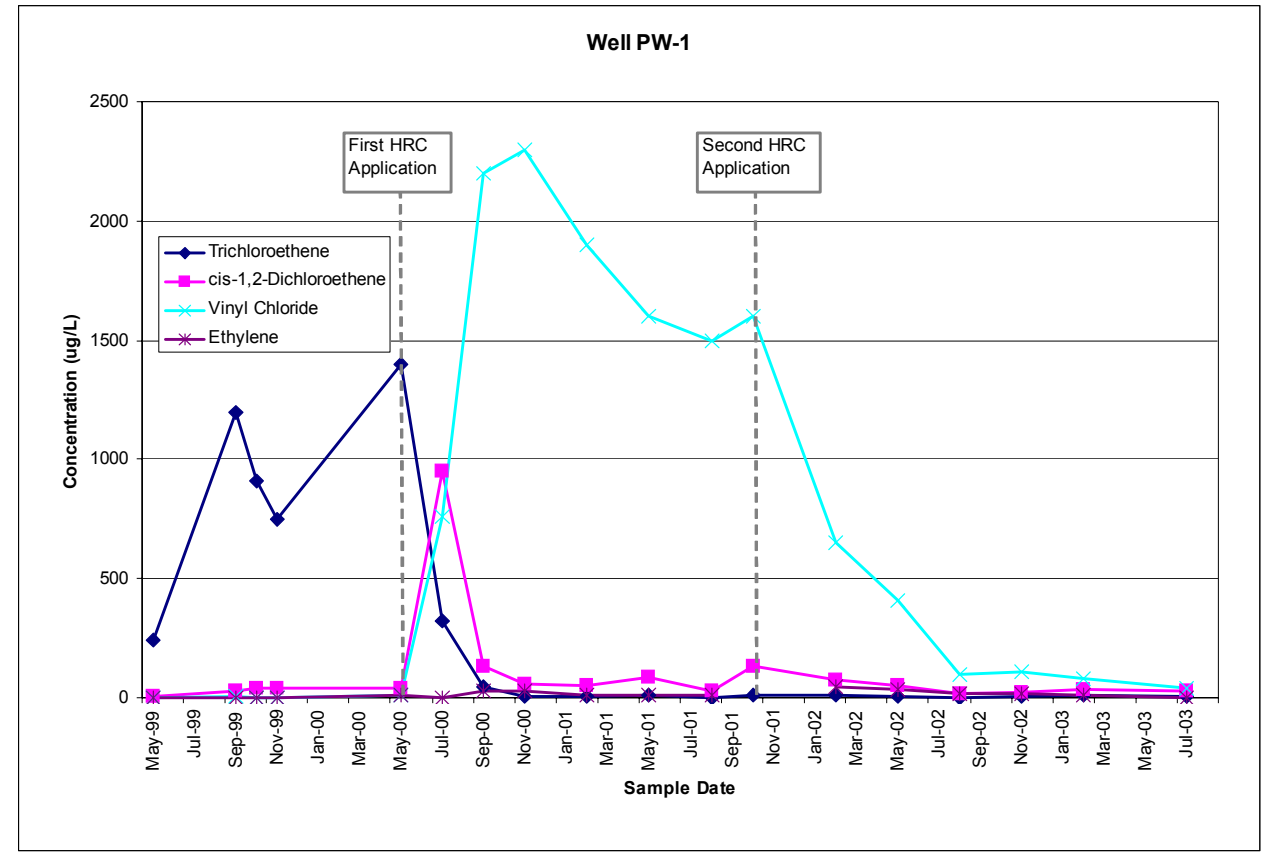




\subsubsection{Issues}

\section{Scientific issues}

A number of important scientific unknowns are related to the application of long-live reagents for EA. It is clear, that addition of chemical reagents to the subsurface will result in gradual changes in the physical, chemical and microbiological characteristics of aquifer sediments. However, it is not yet clear how these changes will affect the long-term performance of an EA remedy or the long-term impact on the ecosystem as a whole. For example, buildup of inorganic precipitates, gas bubbles, and/or biomass around reagenttreated zones could cause dissolved contaminants to flow around the target zone, reducing treatment efficiency. Gradual changes in microbial community structure and/or total size may affect both treatment efficiency and reagent life.

Other deficiencies in our knowledge and experience include:

- We have a very poor understanding of how microorganisms use immobile, nonaqueous reagents or substrates and how to monitor this process. Do the microorganisms have to be in direct contact with both the immobile reagent and the dissolved contaminant?

- There is no reliable method for estimating long-term performance of a reagent injected into the subsurface based on short-term laboratory data.

- There is essentially no practical experience in the design of bioremediation systems that are intended to operate without human intervention for decades or more. However, there are a number of natural and anthropogenic analogues that can be studied to help understand how these systems may perform over extended time periods. For example, we may be able to use information on the degradation of organic materials in landfills to predict the performance of mulch trenches for treating chlorinated solvent plumes.

\section{Regulatory Issues}

There are also a number of critical regulatory and policy issues associated with the application of long-lived reagents for EA that need to be addressed. Existing regulatory processes are oriented towards implementation of remedies that can be easily reversed or altered if performance is not as expected, with regular review of the approved remedy. Some concerns include:

- Regulatory officials may be resistant to approve injection of a very long-lived 'reagent' into the subsurface, even if that material is a completely innocuous food-grade material since this material could be considered a 'pollutant' and could somehow impact the long-term use of the aquifer.

- There will be concerns about down-gradient impacts since many of the proposed remediation approaches may have secondary water quality impacts (e.g. dissolved iron, taste and odor, etc.).

- There are also practical concerns about how to evaluate and monitor performance of an EA remedy where the process may not reach steady-state for years. 


\subsubsection{Bioaugmentation}

The in situ biodegradation of chlorinated solvents primarily requires favorable subsurface conditions, relevant microbial biocatalysts, and bioavailable contaminants. It has now been demonstrated at multiple sites that interventions may successfully enhance subsurface conditions to promote biodegradation by providing electron donors, electron acceptors, altering $\mathrm{pH}$, providing macronutrients/trace elements, and implementing other modifications (AFCEE, 2004a). In some cases, these interventions are sufficient to stimulate in situ microorganisms to complete the biodegradation process. However, there are numerous sites where conventional microbial analyses, microcosm studies, extended field trials, and molecular probes of indigenous microbial communities show that chlorinated solventdegrading microorganisms are not present or are so poorly distributed or at low population densities that their activity does not provide adequate biodegradation capacity. In these situations, bioaugmentation is a means to address these deficiencies.

Because of field experience and results from research on the efficacy of bioaugmentation to treat petroleum hydrocarbons, the bioremediation community initially met bioaugmentation with skepticism. In essence, the prevailing wisdom was that the metabolic capacity to degrade chemicals was ubiquitous in every gram of soil. Although this was shown to be true for petroleum hydrocarbons, it was found not to be the case for chlorinated solvents. Field and laboratory work has clearly demonstrated that bioaugmentation is a viable method to establish metabolic capacity where it otherwise did not exist (AFCEE, 2004a).

Advances in methods to identify causative microorganisms, their growth requirements and the recent ability to culture them in large volumes, has enabled the advancement of bioaugmentation for problematic sites contaminated with chlorinated solvents.

Application of bioaugmentation to EA involves seeding aquifers with requisite microorganisms depending on the mix of chlorinated solvents present and the prevailing environment. For example, viable approaches include the addition of halorespiring microorganisms in anaerobic plumes that contain electron donors and chlorinated solvents, or adding microorganisms that can aerobically biodegrade lower chlorinated solvents where these compounds may discharge or mix with aerobic waters. After seeding the microorganisms should spread and grow and thereby enhance the natural attenuation capacity.

Chlorinated solvents can be biodegraded through reductive dechlorination, anaerobic oxidation, aerobic cometabolism, and direct oxidation. Of these processes, bacteria that are associated with the complete reductive dechlorination of PCE/TCE (past cis-1,2-DCE to ethene) and those capable of aerobically degrading cis-1,2-DCE appear to be less widely distributed.

The following observations support this conclusion for reductive dechlorination:

- Only partial dechlorination of PCE and TCE to cis-1,2-DCE is observed at a significant number of sites, even where geochemical conditions are appropriate for reductive dechlorination (e.g., Koenigsberg et al., 2002); 
- Only microorganisms belonging to one group, the Dehalococcoides (Dhc) group, have demonstrated the capacity to reduce cis-1,2-DCE and VC to ethene (e.g., Maymo-Gatell et al., 1997);

- Dhc was present at all sites where dechlorination proceeded beyond cis-1,2-DCE to $\mathrm{VC}$ and ethene, but absent at all sites where dechlorination stalled at cis-1,2-DCE (Hendrickson et al. 2002); and

- At sites where $D h c$ was not detected and dechlorination stalled at $c i s-1,2-\mathrm{DCE}$, the addition of mixed cultures containing $D h c$ microorganisms led to complete dechlorination to ethene and the establishment of $D h c$ organisms in the bioaugmented aquifer (e.g., Ellis et al., 2000; Major et al., 2002).

The isolation of a novel aerobic bacterium, Polaromonas sp. JS666, that uses cis-1,2-DCE as a sole carbon and energy source (Coleman et al., 2002a,b) supports the assertion that aerobic degradation of cis-1,2-DCE is not ubiquitous. This organism was found in only one of 37 sample-types screened for ability to aerobically oxidize cis-1,2-DCE. Although cis-1,2-DCE is the only chloroethene known (thus far) to serve as growth substrate for JS666, the organism transforms several other chloroethenes (TCE, 1,2-dichloroethane, trans-DCE, and $\mathrm{VC}$ ), suggesting that it may be effective in mixed-contaminant systems. The value of this micoorganism is that it does not require any additional nutrients/added reagents as it can grow solely on cis-1,2-DCE in the presence of oxygen.

The use of mixed cultures containing Dhc (e.g., KB-1 ${ }^{\mathrm{TM}}$; Bio-Dechlor Inoculum) or pure cultures containing JS666 are promising bioaugmentation agents for EA.

Case Study 5-2 contains an example of bioaugmentation as applied at a former US Air Force Base that was reported by Major et al. (2002). The results illustrated are for a limited period of time, so that the sustainability of the treatment in degrading contaminants and avoiding rebound cannot be evaluated. It is unknown how long and effectively the system will continue to destroy contaminants, but the results are encouraging and may lead to a useful enhancement for EA.

\subsubsection{Issues}

\section{Scientific Issues}

Scientific uncertainties surround the distribution, migration and competition of microorganism augmented into natural systems. The addition of $D h c$ has been field demonstrated, but there is still the requirement that a suitable electron donor either be naturally present or added (see Section 5.1.1) to support $D h c$ growth and activity. Polaromonas has yet to be field tested, and various critical parameters (eg. minimum oxygen level) have yet to be determined. Other potentially valuable microorganisms associated with anaerobic oxidation have yet to be isolated and characterized and the factors affecting their activity clearly elucidated.

\section{Regulatory Issues}

The use of naturally occurring microorganisms for remediation is not specifically governed under any existing federal or state regulations. However, various states may require permits 
Bioaugmentation with dehalorespiring bacteria was conducted at a PCE contaminated area at Kelly AFB in San Antonio, Texas. The objective of the pilot test was to promote complete transformation of PCE to ethene. Microcosm studies conducted using soil and groundwater from the site had previously indicated that indigenous microbial populations were capable of degrading PCE to cis-1,2,-DCE, but further dechlorination to VC or ethene was not observed. By comparison, site microcosms inoculated with $\mathrm{KB}-1 \mathrm{TM}$, a natural non-pathogenic dehalorespiring microbial consortia, promoted complete dechlorination of cis-1,2DCE via VC to ethene. Dechlorination to ethene was achieved even in microcosms containing TCE at 100 $\mathrm{mg} / \mathrm{L}$.

Following bioaugmentation, the concentrations of cis-1,2-DCE decreased sharply and an increase in VC and ethene was observed. Within 143 days after bioaugmentation, the concentrations of PCE, TCE, total DCE, and VC had declined to below MCLs within the test area (figure). Ethene was observed as the final degradation end-product. Molecular analysis of extracted $16 \mathrm{~S}$ ribosomal RNA from water samples indicated that halo-respiring microorganisms associated with the KB-1 ${ }^{\mathrm{TM}}$ consortium had spread through out the test area, but were not detected outside the area. Once biodegradation was established, calculated half-lives for degradation were on the order of minutes to hours, with the longest observed half-life being in the cis1,2-DCE to VC step. The results of the successful pilot test confirm that bioaugmentation with KB-1 can promote rapid and complete dechlorination of PCE to ethene.

This investigation was included as part of the corrective measures study for Kelly AFB, and indicates that bioaugmentation can be used to assist in meeting remedial objectives for sites contaminated with PCE and TCE. The results of the study are reported in Major et al, (2002).

Bioaugmentation is a promising EA technology. Questions remaining are how long and how effectively the system will continue to destroy contaminants.

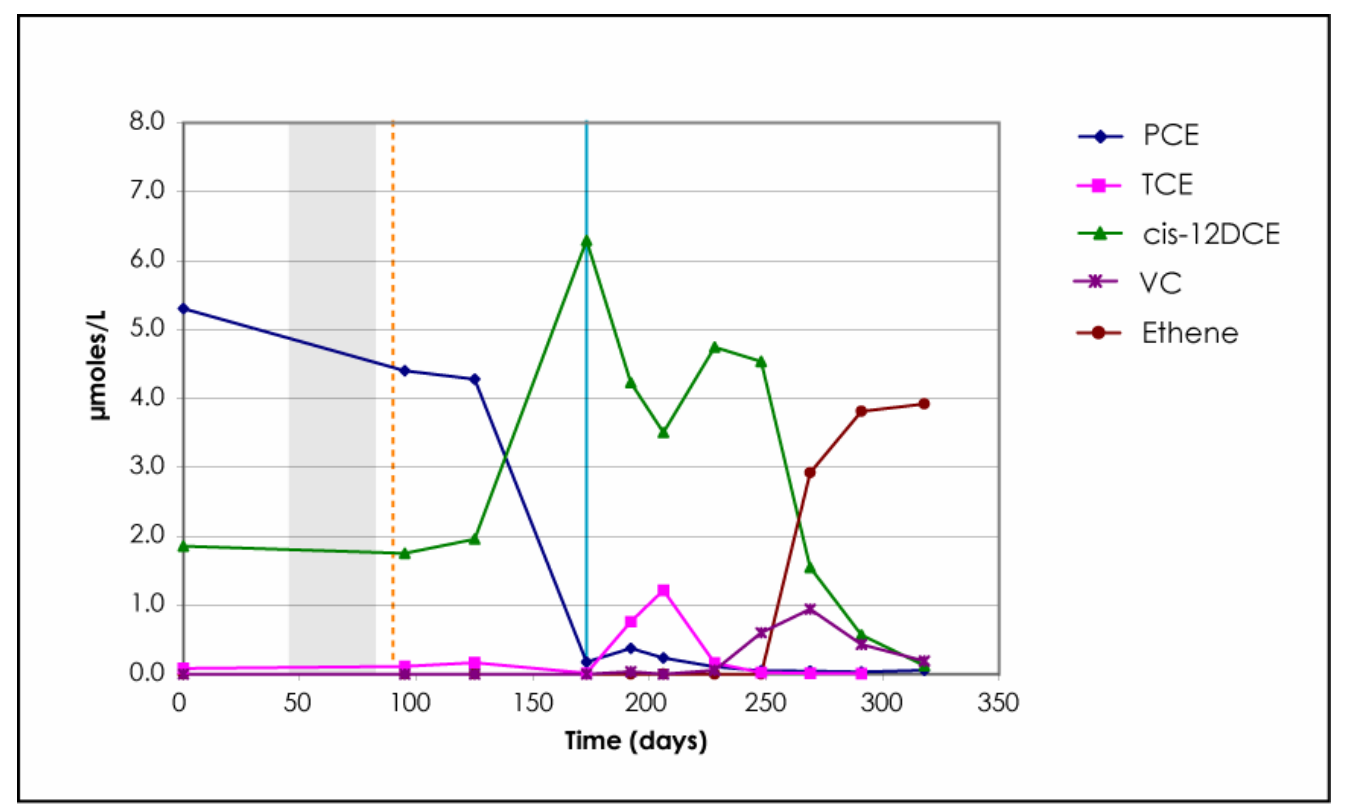


to inject compounds into aquifers. Most states are willing to approve application to inject bacteria as long as they are shown not to contain known human, animal or plant pathogens.

\subsubsection{Wetland Systems}

A unique example of biological treatment of cVOCs can be found in wetland systems. Empirical studies over the past 10 years of natural wetlands into which cVOC-contaminated groundwater discharges provided the first direct evidence that a wide variety of chlorinated compounds can be treated in this type of environment. The Petro-Processors site in Louisiana, Robins AFB in Georgia, and several sites at the Aberdeen Proving Ground, Maryland are examples where natural wetlands have been demonstrated to promote significant degradation of contaminants (Lorah and Olsen, 1999a, 1999b; Pardue et al., 2000a). Case Study 5-3 provides a summary of observations at a natural wetland site at Aberdeen Proving Ground.

Subsequent laboratory research and bench-scale investigations established that artificial (i.e., constructed) wetlands are possible using an organic-rich substrate augmented with appropriate bacteria. In the past several years, pilot- and full-scale constructed wetland projects have been implemented at a small number of sites in the U.S. to treat cVOCcontaminated groundwater.

The supplemental material in Appendix A provides a detailed summary of current information on natural and constructed wetlands. The information is taken from DOE (2005), a report of a DOE-sponsored technical assistance activity at the East Tennessee Technology Park in Oak Ridge, TN that largely was prepared by Michelle Lorah (USGS) and John Pardue (Louisiana State University).

\subsubsection{The role of plants in wetland systems}

The principal benefit from incorporating plants into constructed wetlands is to promote sustainability. Wetland plants such as bulrush (Scirpus cyperinus (Mastin et al, 2001) or Schoenenplecsus californicus (Hawkins et al., 1997; Lehman et al., 2002) not only help to produce an anaerobic zone in the wetland sediment, but also provide a steady supply of organic detritus to that sediment. Both of these actions significantly contribute to the sustainability of the wetland. In addition, plant roots stabilize the sediment and protect it against erosion. Finally, plants establish a habitat that is beneficial to wildlife and create a favorable visual impact that can be of importance to regulators and stakeholders.

However, plants also can contribute more directly to the treatment of cVOCs through phytovolatilization, rhizodegradation, and phytodegradation (see Section 5.2). Native wetland plants have been shown to phytovolatilize and phytodegrade (willows) TCE (Punshon et al., 2003; Nzengung and Jeffers, 2001; Casey et al., 2004). 
Lorah et al. (1997) and Lorah and Olsen (1999a, 1999b) report on the natural attenuation of cVOCs in a freshwater tidal wetland at Aberdeen Proving Ground, MD. The wetland sediment is about 6-12 ft thick and comprised of an upper peat unit and a lower sandy/silty clay or clayey sand unit that overlies the Canal Creek Aquifer. The base of the aquifer rests on a confining unit at a depth of about $40-45 \mathrm{ft}$ thick. There is a strong vertical hydraulic gradient, although tidal cycles create periodic flow reversals. The average upward vertical flow rate is 2-3 ft./yr. Major cVOC contaminants in the aerobic aquifer are TCE, 1,1,2,2tetrachloroethane (PCA), carbon tetrachloride, and chloroform. Concentrations of TCE and PCA range from $100-2000 \mu \mathrm{g} / \mathrm{L}$. Groundwater in the wetland sediments becomes progressively more anaerobic along flow lines. Daughter products are either undetectable or at very low concentrations in the aquifer, but DCE, VC, TCA, and DCA are observed in the wetland with DCE and VC being dominant. Total CVOC concentrations decrease upward in the wetland and are less than $5 \mu \mathrm{g} / \mathrm{L}$ near the surface attesting to the active anaerobic degradation that takes place for both parents and daughter compounds. Microcosm studies using wetland sediments show that the measured half lives for TCE and PCA degradation range from 2-15 days depending on the specific test conditions. Parallel sorption studies show that contaminant velocities in the wetland sediments are retarded by factors of 6-10 as compared to groundwater flow rates, an observation that should enhance the overall opportunity for degradation.

The figure below (from Lorah et al., 1997) shows total cVOC and methane concentrations in groundwater collected in June 1996 at two wetland sites using porous membrane samplers (peepers) inserted in the sediment. The graphs illustrate the progressive decrease of contaminants (and increasing anoxic conditions) within the wetland along the direction of groundwater flow.
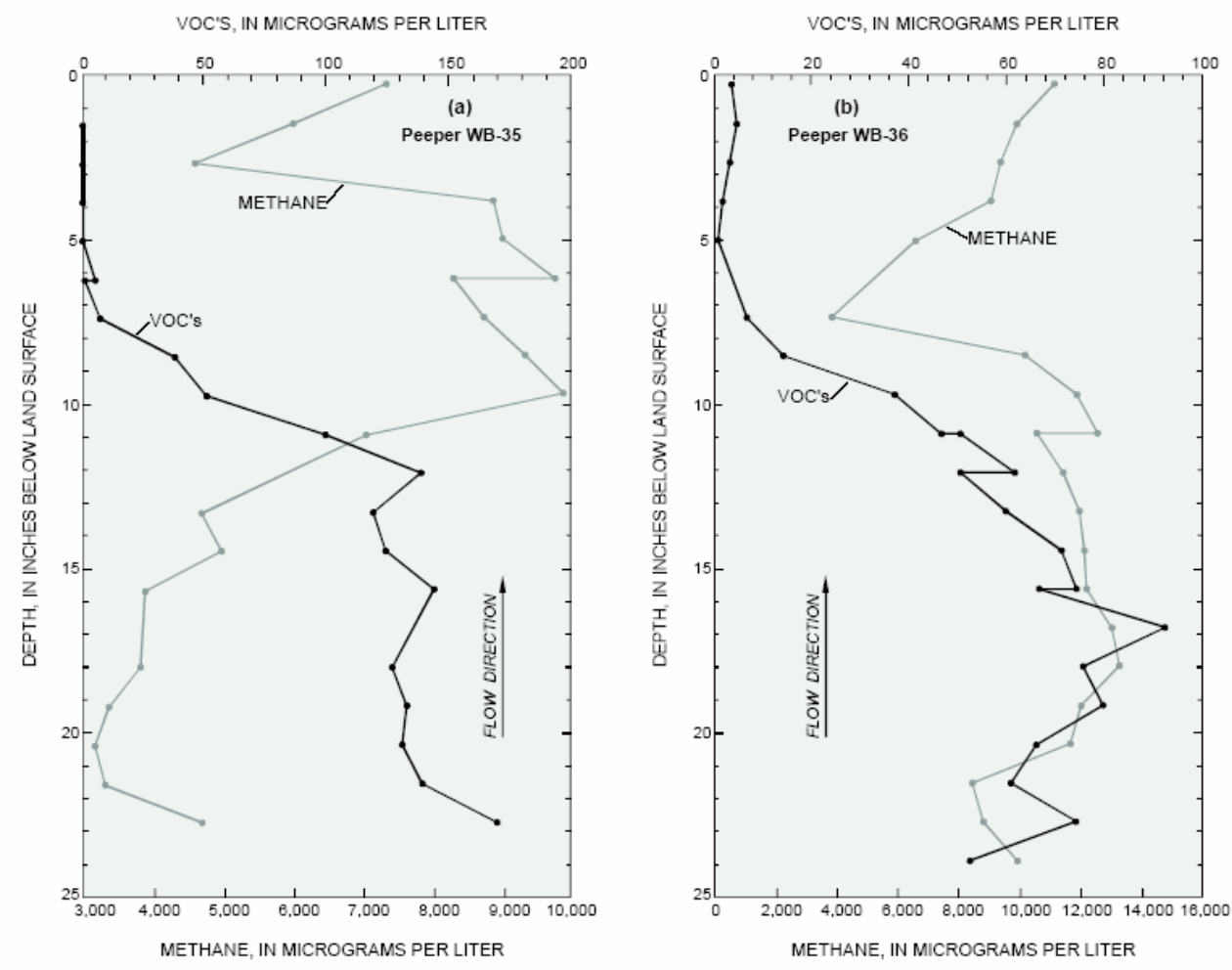


\subsubsection{Issues}

\section{Scientific Issues}

The major scientific issues associated with constructed wetland treatment systems include: a) limited track record, b) efficient hydraulic capture of contaminated groundwater, c) establishing the desired flow of groundwater through the wetland media to ensure sufficient residence time, and d) designing a system that is sustainable through periods of both high and low annual precipitation. Wetlands used to treat storm water and domestic waste have been in existence for many years. The application of wetlands to cVOC treatment is a recent advance. However, laboratory and field investigations have had very successful results where care is taken to select an appropriate organic-rich substrate and microbial consortium for bioaugmentation. The hydraulic factors for the design of constructed wetlands are critically important, although the tools to perform this part of the design are available.

\section{Regulatory Issues}

In general, wetlands are viewed favorably by the regulatory community because they are aesthetically pleasing and create valuable habitat for a variety of fauna. However, the limited maturity of this technology as applied to cVOC treatment may represent a challenge in obtaining regulatory approval until the base of experience increases. The technical/regulatory and guidance documents (ITRC, 2003c) developed by the ITRC should provide a basis for increased familiarity and acceptance by the regulatory community.

There may be some concerns that a wetland represents the "last line of defense" for treatment before discharge of groundwater into receiving bodies of surface water. Within the context of EA it will be necessary to demonstrate that wetland designs are robust and sustainable. This assurance may require a more extensive monitoring program for a few years to establish their long-term performance expectations.

\subsubsection{Integration Design Concepts}

It is important to decide where to apply long-lived reagents or bioaugmentation processes. Table 5-1 presents a matrix of treatment processes, application methods, and locations. The processes include biostimulation, bioaugmentation, and constructed wetlands. Emplacement methods (e.g wells, hydrofracing, trenching, etc.) also are included. Factors that will drive the location are related to practical matters, such as relative ability to distribute reagents and bacteria or the risk of worsening the situation. These elements of the application strategy can be combined at any one site. For example, one might consider the addition of halo-respiring cultures in combination with a partitioning electron donor to enhance the degradation capacity within the source area.

In general, the source area will be more amenable to anaerobic reduction processes and, therefore, the contaminant degradation capacity in the source area will be enhanced by the addition of appropriate long-term electron donors, and bioaugmentation (if required). An exception would be a constructed wetland that typically is applied at the zone of discharge. The emplacement of solid long-term reactants would most likely be immediately downgradient of source areas because emplacement near sources generally requires a smaller footprint/depth to achieve adequate coverage compared to locations within the plume. Similarly, bioaugmentation with cultures that can aerobically or cometabolically degrade chlorinated solvents should be implemented at locations where there is mixing of the 
Table 5-1. Application Strategy of Processes to Achieve EA

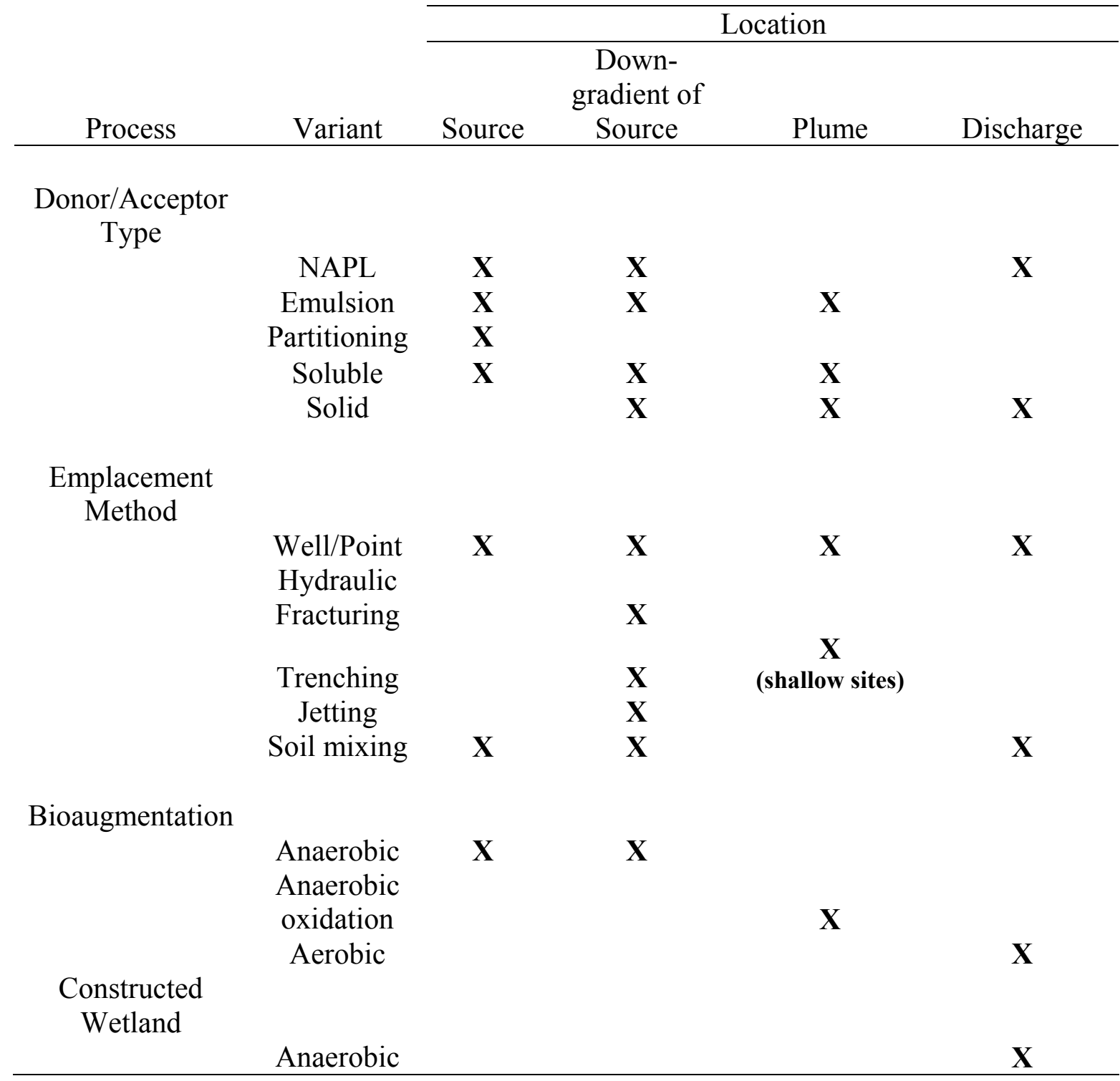

groundwater plume with aerobic surface or ground water. Bioaugmentation with anaerobic oxidation cultures will occur within the plume.

\subsection{PLANT-BASED METHODS}

Since the mid- 1990s there has been increasing interest in the remediation of contaminants using plants - phytoremediation. Mechanistically, plants can potentially remediate soils and groundwater by:

- Phytoextraction - plants extract contaminants from soil and store them in plant tissues

- Rhizodegradation - plants promote a soil environment suitable for microbes that can degrade, or sequester contaminants 
- Phytovolatilization - plants translocate contaminants into the atmosphere via normal transpiration

- Phytodegradation - plants metabolically degrade the contaminant to a nontoxic form in roots, stems or leaves

- Phytostabilization - plants modify the soil environment reducing bioavailability of pollutant

- Rhizofiltration - plant roots filter water by contaminant uptake in an aqueous environment

More detailed information about some of these mechanisms is provided in the supplemental material in Appendix A.

Numerous articles have reviewed the efficacy of using plants to remediate organic contaminants in the environment ( e.g., Macek et al., 2000; Susarla et al., 2002; Alkorta and Garbisu, 2001; Van Den Bos, 2002). Additionally, plants have been used to provide hydraulic control in aquifers by ET (see Section 3.2.3).

Most phytoremediation applications have used hybrid poplar trees, but success with other species such as willows, and pines have been reported. In one project located in Hawaii, Leucaena leucocephala was used (Doty et al., 2003). Herbaceous species (e.g. aquatic macrophytes) have been shown to transpire TCE in wetlands, but sporadically and at a low volume (Punshon et al., 2003). However, they can play an important role in controlling water infiltration in sites that require surface water exclusion

Plant mediated methods do have some advantages over more intrusive methods. Planting trees or other vegetation on a site may be preferable to more expensive alternatives such as soil vapor extraction. Trees can live for long periods; once root systems are established, they can continue to provide relatively inexpensive phytoremediation over the life of the tree. One of the major advantages is the non-intrusive nature of establishing trees/vegetation on a site. Trees are also ecosystem friendly and aesthetically pleasing.

There are some disadvantages to using trees for remediation. For example, soil and groundwater contaminant levels must not exceed plant tolerances for toxicity or they will not survive. Secondly, although trees can live for a long time, the rate at which they remove contaminants may be lower than for more active treatment options. Perhaps one of the greatest limitations to the use of trees for phytoremediation of groundwater occurs where the depth to the contaminated aquifer exceeds the maximum root depth. Consequently, most phytoremediation projects focus on contaminants at depths less than about $8 \mathrm{ft}$ bgs.

However, as discussed in Section 3.2.3, there are methods of installation such as tree wells (Argonne) or trenches (Portsmouth) that can allow trees to reach groundwater plumes at depths of up to $40 \mathrm{ft}$ (Van Den Bos, 2002) if the potentiometric surface of the aquifer is sufficiently shallow. Finally, plants actively transport water (and contaminants) only during the growing season. Most plants that are suitable for phytoremediation are dormant during the winter. 


\subsubsection{Issues}

\subsubsection{Scientific Issues}

There is a growing body of research data on the ability of plants to uptake and metabolize or translocate (to the atmosphere) cVOC contaminants. Likewise, the use of plants to create a biochemical environment in the root zone soil for contaminant degradation also is receiving significant scientific attention. However, with regard to cVOCs, field-based studies still are largely at pilot scale with only a few years of results. Active research in terms of species or clone selection is ongoing. Recent efforts to map the populus genome offers great hope for future progress in phytoremediation, but much basic research work remains to be done.

\subsubsection{Regulatory Issues}

Plant-based methods generally are viewed favorably by the regulatory community because they are perceived as a sustainable, "green" technology. 


\subsection{ABIOTIC AND BIOLOGICALLY MEDIATED ABIOTIC ATTENUATION METHODS}

Abiotic attenuation mechanisms can affect the fate and transport of chlorinated solvents in groundwater. The most common groups of abiotic reactions affecting these compounds include hydrolysis, dehydrohalogenation, and reduction reactions including hydrogenolysis and reductive elimination. Of these, only the reduction reactions can be readily enhanced and, therefore, these reactions are the focus of this section.

For the reductive dehalogenation reactions, hydrogenolysis is the simple replacement of a chlorine atom (or other halogen) by a hydrogen atom. This is a common biologicallymediated reaction, but recently this reaction has been observed to occur abiotically.

Reductive elimination results in the loss of chlorine atoms, the formation of a carbon bond, and possibly the addition of hydrogen atoms. Dihaloelimination is the removal of two chlorines (or other halogens) accompanied by the formation of a double carbon-carbon bond. Butler and Barker (1996) reviewed work by Criddle et al. (1986), Jafvert and Wolfe (1987), Reinhard et al. (1990), and Acton (1990). This review suggests that while these reactions are thermodynamically possible under reducing conditions, they often do not take place in the absence of biological activity, even if such activity is only indirectly responsible for the reaction.

\subsection{ABIOTIC REACTIONS WITH REDUCED IRON AND SULFUR PHASES WITH OR WITHOUT BIOLOGICAL MEDIATION}

\subsubsection{Abiotic Reactions with Reduced Mineral Phases}

In recent years it has become apparent that minerals found in the shallow subsurface can cause the abiotic degradation of chlorinated solvents. According to Lee and Batchelor (2003), some of the most abundant natural reductants are soil minerals that contain reduced forms of iron and sulfur. These minerals can significantly increase the transformation rate of chlorinated organics in heterogeneous suspension with $\mathrm{HS}^{-}$and $\mathrm{Fe}$ (II) and can also reductively transform organic and inorganic contaminants by themselves (Lee and Batchelor, 2003).

Reductive capacities of soil minerals and soil for chlorinated ethylenes have been measured and characterized by Lee and Batchelor (2002a, 2002b, and 2003), Ferrey et al. (2004), Lee and Batchelor (2003), and Danielsen and Hayes (2004). These researchers found that the reductive capacities of iron-bearing sulfide (pyrite), hydroxide (green rust; $\mathrm{GR}_{\mathrm{SO} 4}$ ), and oxide (magnetite) minerals for PCE were 1-3 orders of magnitude greater than those of ironbearing phyllosilicates such as biotite, vermiculite, and montmorillonite (Lee and Batchelor, 2003, 2004). GR $\mathrm{SO}_{4}$ was shown to have the greatest reductive capacity for PCE followed by magnetite, pyrite, biotite, montmorillonite, and vermiculite. Cervini-Silva et al (2001) also studied the abiotic degradation of PCE, TCE, and 1,1,1-TCA on the surfaces of smectite clays and Elsner et al.(2004) have investigated the reductive dehalogenation of carbon tetrachloride by $\mathrm{Fe}(\mathrm{II})$ on goethite. 
Lee and Batchelor (2002a, 2003) show that the reductive capacities of pyrite and $\mathrm{GR}_{\mathrm{SO} 4}$ for chlorinated ethylenes decreased in the order: TCE $>$ PCE $>$ cis-1,2-DCE $>$ VC. They also found that the $\mathrm{Fe}$ (II) content in soil minerals was directly proportional to the reductive capacity for PCE, suggesting that Fe(II) content is an important factor that significantly affects reductive transformations of target contaminants in natural systems. In addition to the work by Lee and Batchelor (2002a, 2002b, and 2003) on pyrite, green rust, and magnetite, recent research has shown that FeS can promote reductive dechlorination (Butler and Hayes, 1999). In contrast to pyrite, green rust, and magnetite, the production of FeS can be stimulated (enhanced) by the addition of iron and/or sulfate to the aquifer. It is not yet clear how significant these reactions are for the natural attenuation of chlorinated compounds.

In some cases, abiotic reductive dechlorination has been observed; however, the conditions that favor such reactions may not occur naturally. For example, Gillham and O'Hannesin (1994) describe reductive dehalogenation of chlorinated aliphatics using zero-valent iron, in which the iron serves as an electron donor in an electrochemical reaction. However, this is not a natural process. Wang and Tan (1990) reported reduction of TCE to ethene and carbon tetrachloride to methane during a platinum-catalyzed reaction between elemental magnesium and water. Given that the metals involved in these reactions are unlikely to occur naturally in the reduced forms used in the aforementioned work, such processes are not likely to contribute to natural attenuation of chlorinated solvents.

\subsubsection{Biologically Mediated Abiotic Reactions}

Biogeochemical reductive dechlorination (BiRD) involves both biological and chemical reactions to effect the abiotic reduction of chlorinated solvents, such as PCE and TCE. While not involved in a manner similar to that for cometabolism, microbes may produce reductants that facilitate such reactions in conjunction with minerals in the aquifer matrix, as has been suggested by work utilizing aquifer material from the Borden test site (Reinhard et al., 1990). Moreover, the reducing conditions necessary to produce such reactions most often are created as a result of microbial activity. It is, therefore, not clear if some of these reactions are truly abiotic, or they should be considered to be a form of biologically-mediated abiotic degradation because of their reliance on microbial activity to produce reducing conditions or reactants.

With the BiRD process, indigenous sulfate-reducing bacteria are stimulated through the addition of a labile organic and sulfate, if not already present at high concentrations. The sulfate reducing bacteria reduce the sulfate, producing sulfide. Sulfide then reacts with ferric iron, typically present in high concentrations (about 1\%) in aquifer sediments, to form iron sulfide (FeS). Iron sulfide then acts to abiotically dechlorinate TCE to acetylene and chloride (Butler and Hayes, 2001; Kennedy et al., 2004a). Acetylene may undergo subsequent hydrogenation to ethylene and/or ethane (Butler and Hayes, 2001). Iron sulfide can also mediate the sequential reductive dechlorination of TCE through cis-1,2-DCE, VC, and ethene, but this pathway appears to be less favorable (Butler and Hayes, 2001).

Laboratory studies using FeS generated through the stimulation of sulfate-reducing bacteria (Kennedy et al., 2004a) or chemically-generated FeS (Butler and Hayes, 1999) have been conducted with a number of halogenated ethenes, ethanes, and methanes, including PCE, TCE, 1,1-DCE, pentachloroethane, 1,1,2,2- and 1,1,1,2-tetrachloroethane, 1,1,1- and 
1,1,2-trichloroethane (TCA), 1,1- and 1,2-dichloroethane, carbon tetrachloride, and tribromomethane. The dichloroethanes and 1,1,2-TCA were not appreciably transformed by FeS. The other compounds were transformed with half-lives ranging from hours to days (Butler and Hayes, 1999; 2000).

Butler and Hayes (1999) studied the transformation of PCE, TCE, and 1,1-DCE by FeS in aqueous solution at $\mathrm{pH} 8.3$ in batch experiments. A $17 \%$ decrease in the concentration of 1,1-DCE was observed over 120 days; however, no reaction products were detected. TCE and PCE transformation data were fit to a first-order rate law assuming transformation of TCE to acetylene via reductive elimination and $c i s-1,2-\mathrm{DCE}$ via hydrogenolysis and transformation of PCE via a parallel reaction pathway to acetylene and TCE. Acetylene was the major reaction product for both TCE and PCE. Determination of rate constants for each reaction pathway indicated that TCE was transformed to acetylene $11.8 \pm 1.1$ times faster than to $c i s-1,2-\mathrm{DCE}$ and that PCE was transformed to acetylene $8.2 \pm 1.8$ times faster than to TCE. Additional minor reaction products were VC (for TCE) and cis-1,2-DCE (for PCE). Detection of acetylene as the major product of both TCE and PCE transformation by FeS contrasts with the sequential hydrogenolysis products typically observed in the microbial transformation of these compounds, making acetylene a potential indicator of abiotic transformation of PCE and TCE by FeS in natural systems.

Although FeS is likely present in the subsurface at many sites where chlorinated compounds are being degraded, its production relies on the coincident occurrence of iron reduction and sulfate reduction, both of which are microbially-mediated reactions. In terrestrial subsurface environments $\mathrm{Fe}^{2+}$ can be produced during dissimilatory iron reduction and $\mathrm{H}_{2} \mathrm{~S}$ is formed by reduction of $\mathrm{SO}_{4}{ }^{2-}$, both of which occur under reducing conditions caused by microbial degradation of organic carbon Thus, even though degradation of solvents can occur abiotically, several biological reactions still are necessary to form the correct environment.

The following equation describes the overall stoichiometry of ferric iron reduction resulting in the production of $\mathrm{Fe}^{2+}$, where organic carbon is represented by the generalized formula, $\mathrm{CH}$ :

$$
10 \mathrm{H}^{+}+5 \mathrm{Fe}(\mathrm{OH})_{3}+\mathrm{CH} \rightarrow \mathrm{CO}_{2}+5 \mathrm{Fe}^{2+}+13 \mathrm{H}_{2} \mathrm{O}
$$

The following equation describes the overall stoichiometry of sulfate reduction (with organic carbon, $\mathrm{CH}$, as a co-reactant) resulting in the production of $\mathrm{H}_{2} \mathrm{~S}$ :

$$
1.25 \mathrm{H}^{+}+0.625 \mathrm{SO}_{4}{ }^{2-}+\mathrm{CH} \rightarrow \mathrm{CO}_{2}+0.625 \mathrm{H}_{2} \mathrm{~S}+0.5 \mathrm{H}_{2} \mathrm{O}
$$

If the system is sulfate reducing or methanogenic and reduced iron is present, then FeS will be produced by the following reaction:

$$
\mathrm{H}_{2} \mathrm{~S}+\mathrm{Fe}^{2+} \rightarrow \mathrm{FeS}+2 \mathrm{H}^{+}
$$

Kennedy, et al. (2004b) suggest the following reaction for degradation of TCE:

$4 / 9 \mathrm{FeS}+\mathrm{TCE}+28 / 9 \mathrm{H}_{2} \mathrm{O} \rightarrow 4 / 9 \mathrm{Fe}(\mathrm{OH})_{3}+4 / 9 \mathrm{SO}_{4}{ }^{2-}+$ Acetelyne $+3 \mathrm{Cl}^{-}+35 / 9 \mathrm{H}^{+}$ 
Aged FeS has been shown to be completely unreactive with respect to TCE (Butler and Hayes, 2001). Because aging appears to decrease the effectiveness of FeS, it is not clear how effective the BiRD process will be in the long-term. Sulfate and/or labile organics may need to be added periodically to regenerate the FeS. However, injection of these amendments into an aquifer may be an issue if state regulatory agencies require permits for their use.

Case Study 6-1 provides a summary of application of the BiRD process at Dover AFB, DE through the addition of $\mathrm{Mg} \mathrm{SO}_{4} \cdot 7 \mathrm{H}_{2} \mathrm{O}$, and Environlac 60 . Envirolac 60 is $40 \%$ Water and $60 \%$ Sodium Lactate $\left(\mathrm{NaC}_{3} \mathrm{H}_{5} \mathrm{O}_{3}\right)$. The results are encouraging, but questions about sustainability and contaminant rebound remain to be resolved before abiotic enhancements can be integrated into EA.

\subsubsection{Issues}

\subsubsection{Scientific Issues}

In Section 6.1.1 it was noted that abiotic reductive dechlorination of cVOCs depends on the presence of suitable iron-phase minerals that can promote the reactions. A major technical issue is the fact that sites with appropriate mineralogy are encountered infrequently. Biologically mediated abiotic reactions (Section 6.1.2) appear to be more feasible. However, sweep efficiency of injected nutrients, and hence the production of the reducing phase, FeS, will be dependent on the heterogeneity of the aquifer. Heterogeneous systems likely will require greater site characterization and a more detailed program of nutrient injection. At this time it is not known if sulfate and/or labile organics need to be added periodically to regenerate the FeS. In summary, abiotic degradation attenuation mechanisms are an active area of research and our understanding of the processes and limitations are not fully mature at present.

\subsubsection{Regulatory Issues}

No specific regulatory barriers are presented by abiotic attenuation processes other than the fact that the technology has a very limited track record based on only a few small-scale field investigations. However, the injection of sulfate and organic nutrients may be an issue if regulatory bodies require permits for their use.

\subsection{SORPTION}

The ability of chlorinated organic compounds such as TCE and PCE to sorb on aquifer materials is well-documented in the technical literature (e.g., Piwoni and Keeley, 1990). The octanol-water partition coefficient $\left(\mathrm{K}_{\mathrm{OW}}\right)$ is an experimentally-derived measure of the extent to which an organic compound will partition into octanol in comparison to water. Octanol is a proxy for natural organic matter (NOM) which is present in soils and aquifer materials and is composed of very large, complex organic compounds related to humic substances. There is a correlation between the amount of NOM in an aquifer and its capacity to sorb compounds with elevated $\mathrm{K}_{\mathrm{OW}}$ values. Hydrophobic substances such as cVOCs have relatively high values of $\mathrm{K}_{\mathrm{OW}}$. For example, log $\mathrm{K}_{\mathrm{Ow}}$ values for TCE, PCE, and carbon tetrachloride are $2.42,3.4$, and 2.83, respectively. In contrast, ethanol, a typical hydrophilic compound, has a log $\mathrm{K}_{\mathrm{OW}}$ value of -0.31 (Yaws, 1999). 
We are unaware of any field investigations that have sought to increase the sorption capacity of soils and aquifers for $\mathrm{cVOC}$ contaminants. However, several options to accomplish this might exist. For example, one strategy might be to inject a hydrophobic organic substance that will become immobilized within the aquifer in pore spaces to which cVOCs can sorb. The concept of a diffusion barrier (Section 3.2.1.3) could be considered an extreme example of this approach.

Another potential approach focuses on the sorptive capacity of inorganic mineral phases. In general, these phases do not appear to be significant sorbers for cVOCs. However, some investigators have explored the use of cationic surfactants that readily attach to the surfaces of certain zeolites and modify their interfacial chemical properties such that cVOCs can tightly sorb to them. Bowman et al (2001) performed pilot-scale work using this approach with PCE-contaminated groundwater. Zeolites are not common phases in most aquifers, but it may be possible to modify the surface of some more common phases (e.g. clay minerals) in a similar manner to increase the retardation of cVOCs. We are unaware if this approach has been pursued.

At present, it appears that the ability to increase the sorption coefficient of soil and aquifer materials for cVOCs is unproven at the field-scale and may prove to be impractical.

However, this may represent an area for future research into new enhancement mechanisms (Section 8.2).

\subsubsection{Issues}

The concept of enhancing the sorptive capacity of aquifer material is rather speculative and there are many scientific issues related to its feasibility and sustainability. Perhaps future research will demonstrate that it has a place in EA, but at present it does not appear to represent a viable enhancement.

\subsection{REACTIVE BARRIERS}

In 1991 a concept for the passive, in situ treatment of groundwater contaminated with cVOCs was initiated by installation of a continuous trench permeable reactive barrier (PRB) at the Canadian Forces Base Borden in Ontario, Canada (Gillham and O'Hannesin, 1992). The treatment process involved reductive dechlorination of contaminants using granular metallic iron (zero valent iron - ZVI) which was placed in the trench to intercept a plume containing TCE and PCE. Figure 6-1 is an illustration of this type of PRB. The term "permeable reactive barrier" can be misleading because PRBs are not intended to be barriers to groundwater flow, only to the contaminants dissolved and transported within a dissolved phase plume.

The feature that makes PRBs such an attractive plume treatment option with possible applications to EA is their potential for sustainable and passive operation. Both of these features are important considerations for EA.

The ability of metals to degrade cVOCs in waste water dates to at least 1981 (Sweeney, 1981a, 1981b) and in situ treatment of groundwater was first described by researchers at the University of Waterloo in association with construction and investigations of the PRB 
Case Study 6-1. Enhanced Biogeochemical Reductive Dechlorination (BiRD)

A BiRD pilot test was performed in Target Area 1 at Dover Air Force Base, DE by Kennedy et al. (2004a) [see map]. The approach facilitates reductive dechlorination of cVOCs by iron sulfides produced by engineered biogeochemical processes. Groundwater was amended with an injectate consisting of lactate and sulfate, which was introduced into five injection wells. A total of 2,650 gallons of injectate was added to each of five injection wells at the site. A total of $14 \mathrm{lbs}$ of $\mathrm{NaBr}$ (tracer), $990 \mathrm{lbs} \mathrm{Mg} \mathrm{SO} \mathrm{I}_{4} \cdot 7 \mathrm{H}_{2} \mathrm{O}$, and $700 \mathrm{lbs}$ of Environlac 60 was added. Envirolac 60 is $40 \%$ water and $60 \%$ sodium lactate $\left(\mathrm{NaC}_{3} \mathrm{H}_{5} \mathrm{O}_{3}\right)$. The $\mathrm{BiRD}$ project has been active since August 2003. This summary presents the results for the first 155 days of the test and includes five monitoring events.

Prior to injection the site was aerobic and sediment contained less than $1 \mathrm{mg} / \mathrm{Kg} \mathrm{FeS.} \mathrm{Sediment} \mathrm{was}$ resampled in April 2004 to observe changes in mineralogy with significant concentrations of FeS observed (up to $112 \mathrm{mg} / \mathrm{Kg}$ ) along a transect. FeS deposition appears to be related to injectate distribution. The test response of generating FeS and with the resulting $\mathrm{CAH}$ removal was successful.

Injectate was directly emplaced in ESM1 and ESM2 during the initial injection. Initial TCE concentrations $(\sim 1,200 \mu \mathrm{g} / \mathrm{L}$ for both wells) were reduced to $138 \mu \mathrm{g} / \mathrm{L}$ and $240 \mu \mathrm{g} / \mathrm{L}$ for ESM1 and ESM2, respectively, immediately after the injection. TCE has been consistently declining in concentration, apparently according to first order kinetics, with a half life of 74 days. Concentrations of TCE were $231 \mu \mathrm{g} / \mathrm{L}$ in ESM1 and 362 $\mu \mathrm{g} / \mathrm{L}$ in ESM2 at 155 days. Thus, about $80 \%$ of the original contaminant mass has been removed in 155 days (see figure for ESM1). Significantly, DCE has decreased in ESM1 and ESM2 from original concentrations of $\sim 2,820 \mathrm{ug} / \mathrm{L}$ (for both wells) to $967 \mathrm{ug} / \mathrm{L}$ ( $66 \%$ decrease) and 1,960 $\mu \mathrm{g} / \mathrm{L}$ (31\% decrease), respectively. The decline in cis-1,2-DCE follows the same general first order decline rate as TCE, especially in ESM1. No VC has been observed.
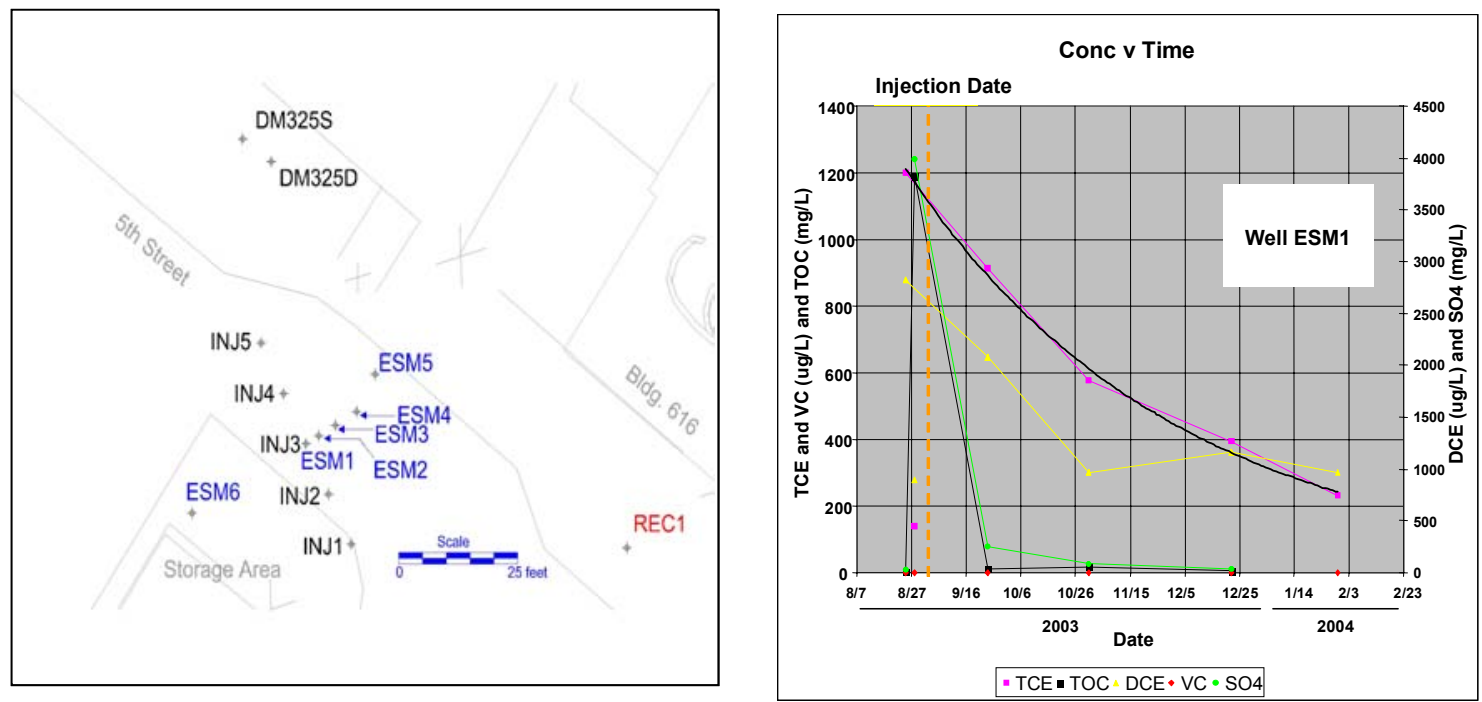


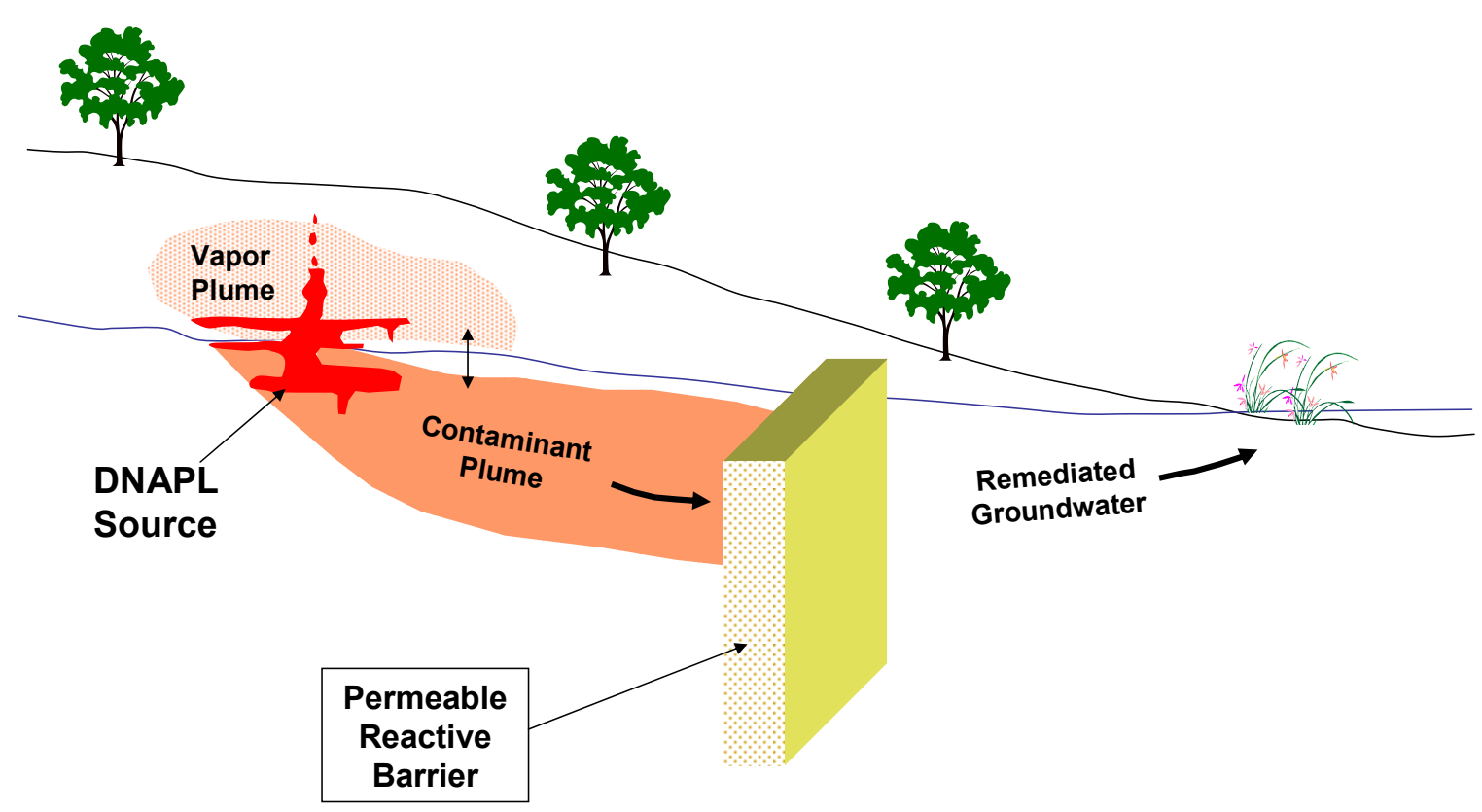

Figure 6-1. Permeable Reactive Barrier to Remediate Contaminated Groundwater

at the Borden site (Reynolds et al., 1990, Gillham and O'Hannesin, 1992, Gillham, 1993).

The reductive dechlorination reactions occurring as $\mathrm{Fe}(0)$ degrades cVOCs appear to follow several different pathways. A simplified summary reaction for TCE destruction is illustrated as follows:

$3 \mathrm{Fe}(0)+\mathrm{C}_{2} \mathrm{HCl}_{3}+3 \mathrm{H}^{+}=3 \mathrm{Fe}(\mathrm{II})+\mathrm{C}_{2} \mathrm{H}_{4}+3 \mathrm{Cl}^{-}$

In reality, small quantities of partially dechlorinated byproducts such as DCE and VC are observed as well as a variety of other compounds. The suite of reaction byproducts may be influenced by the contaminants present, details of groundwater chemistry, and the particular variety of ZVI being used. Numerous researchers have worked to elucidate the possible reaction pathways (e.g. Sivavec and Horney, 1995; Orth and Gillham, 1996; Sivavec, et al., 1997). These and other studies also have investigated the importance of production of various chlorinated byproducts, hydrogen gas, and elevated pH. AFRL (2000) provides a more complete summary of this research and associated references.

Since their first field application at the Borden site, PRBs typically have been employed to treat relatively shallow plumes in unconsolidated media. Most PRBs are created by excavating a trench transverse to the plume axis and filling it with ZVI. The grain size of the ZVI is selected to create a PRB with high enough permeability to permit groundwater to readily pass through the barrier, but with a sufficiently large surface area per gram to be amply reactive. The thickness of the wall needs to be adequate to ensure sufficient residence time of contaminants in the PRB to result in complete dechlorination of the parent 
compounds and any toxic daughter products before the plume exits the down-gradient side of the PRB.

Some permeable reactive systems have adopted a different approach based on favorable site conditions. Rather than design an in situ treatment wall where the installation cost may be high, an ex situ treatment system is utilized. This approach is particularly well suited to sites where groundwater (and contaminant) discharge to receptors is confined to well-defined seeps and springs or the hydrologic characteristics of the site (i.e., configuration of the water table in comparison to land surface) allow one to install passive extraction devices (e.g., GeoSiphons or gravity feed, near-horizontal wells) to bring contaminated groundwater to the surface. The reactive treatment media is contained in drums or canisters and contaminated water is permitted to flow by gravity through the media before discharging to the receptor stream. Several examples of this approach are provided in Appendix A.

As the application of PRBs to treating contaminated groundwater has increased greatly since the early 1990's, there have been many innovations in the design, installation methods, and reactive media that are employed. Continuous wall and funnel and gate configurations are widely used. Emplacement by trench excavation and backfill methods is most common, although techniques using hydrofracture insertion of the media as a proppant (both vertical and horizontal) and direct injection of reactive fluids also are utilized. A wide range of reactive meadia have been investigated including granular metals (e.g. Fe, $\mathrm{Cu}, \mathrm{Al}, \mathrm{Zn}, \mathrm{Pd}-$ used individually or in bimetallic combination), nano-scale iron, oxidizing (e.g. $\mathrm{KMnO}_{4}$ ) and reducing (sodium dithionite) materials, and media that stimulates biologically-mediated reductive dechlorination (e.g. mulch, vegetable oil). The supplemental material in Appendix A contains much more detail about these subjects.

The question of sustainability and long term performance of PRBs has been an issue since their inception. For PRBs employing ZVI it is known that gradual oxidation of the Fe(0) will lead to formation of a variety of solid reaction products such as $\mathrm{Fe}$ oxyhydroxides, green rust, etc.(Table 6-1). The specific gravity of these products is less than that of Fe (0) (i.e., there is an increase in solid phase volume) and eventually probably will lead to clogging of the PRB resulting in some diversion of groundwater around the PRB and reduced levels of contaminant degradation. The chemistry of influent groundwater is one of the important parameters that will determine the types of reactions occurring in PRBs. For example, groundwater rich in dissolved oxygen readily reacts with ZVI to produce hydrous iron oxides in the first few centimeters of the up-gradient side of a PRB and this can lead to diversion of groundwater. Grain size, pore scale, and reaction byproduct attachment processes also help determine how rapidly clogging occurs. Several well-studied PRBs (e.g., CFB Borden; Sunnyvale CA) have been operating successfully for many years and have projected lifetimes of several decades or more. Other examples, however, show where buildup of reaction products in only a few years of operation resulted in significant changes to groundwater flow through the barrier (e.g., at DOE's Y-12 Plant). A report based on research of three agencies (EPA, DoD, and DOE) address many of the long term performance issues with ZVI PRBs (FRTR, 2002).

A comparative example of the behavior of ZVI PRBs at two sites with contrasting groundwater chemistry illustrates some of the issues related to performance (see Case Study 
6-2). These issues are related to the sustainability and longevity of PRBs and a direct concern to their potential viability as an enhancement for EA.

Table 6-1. Examples of Precipitated Minerals Found in Fe(0) Field-Installed PRBs and Column Studies. (Liang, et al. 2003)

\begin{tabular}{|c|c|}
\hline Mineral Precipitate Group & Minerals \\
\hline \multirow{3}{*}{$\begin{array}{l}\text { Iron Oxides and } \\
\text { Oxyhydroxides }\end{array}$} & Goethite $(\alpha-\mathrm{FeOOH})$ \\
\hline & Akaganeite $(\beta-\mathrm{FeOOH})$ \\
\hline & $\begin{array}{l}\text { Lepidocrocite }(\gamma-\mathrm{FeOOH}) \\
\left.\text { (Maghemite }\left(\mathrm{Fe}_{2} \mathrm{O}_{3}\right)\right) \\
\text { Magnetite }\left(\mathrm{Fe}_{3} \mathrm{O}_{4}\right) \\
\text { Amorphous Iron Oxyhydroxides }\end{array}$ \\
\hline Iron sulfides & $\begin{array}{l}\text { Mackinawite }\left(\mathrm{Fe}_{9} \mathrm{~S}_{8}\right) \\
\text { Amorphous Ferrous Sulfide }(\mathrm{FeS})\end{array}$ \\
\hline Carbonates & $\begin{array}{l}\text { Aragonite }\left(\mathrm{CaCO}_{3} \text {, orthorhombic }\right) \\
\text { Calcite }\left(\mathrm{CaCO}_{3} \text {, hexagonal }\right) \\
\text { Siderite }\left(\mathrm{FeCO}_{3}\right)\end{array}$ \\
\hline \multirow[t]{2}{*}{ Green Rusts } & $\begin{array}{l}\text { GR-I }\left(\mathrm{CO}_{3}{ }^{2-}\right)\left(\mathrm{Fe}_{4}{ }^{2+} \mathrm{Fe}_{2}{ }^{3+}(\mathrm{OH})_{12}\right)\left(\mathrm{CO}_{3}{ }^{-} 2 \mathrm{H}_{2} \mathrm{O}\right) \\
\text { GR-I }\left(\mathrm{Cl}^{-}\right)\left(\mathrm{Fe}_{3}{ }^{2+} \mathrm{Fe}^{3+}(\mathrm{OH})_{8} \mathrm{Cl}\right)\end{array}$ \\
\hline & GR-II $\left(\mathrm{SO}_{4}{ }^{2-}\right)\left(\mathrm{Fe}_{4}{ }^{2+} \mathrm{Fe}_{2}{ }^{3+}(\mathrm{OH})_{12}\right)\left(\mathrm{SO}_{4} \cdot 2 \mathrm{H}_{2} \mathrm{O}\right)$ \\
\hline
\end{tabular}

Another concern associated with secondary mineral formation in PRBs is that these phases may passivate the $\mathrm{Fe}(0)$ media, decreasing its reactivity and ability to treat contaminated groundwater. Farrell, et al. (2000), has reported an example of passivation of $\mathrm{Fe}(0)$. They report results of long-term column experiments they have performed in which they observed a $>6$-fold decrease in the reactivity of $\mathrm{Fe}(0)$ to TCE in the two year duration of the experiment. They found that the degree of passivation was related to the ability of secondary phases to adhere to the surface of primary minerals and not the overall mass of these phases formed.

As more work is done on designing, installing, and monitoring PRBs it is apparent that one of the most significant uncertainties impacting the performance and sustainability of PRBs are related to geohydrology. Lithologic heterogeneities leading to preferential flow pathways are properties that impact the details of the groundwater flow system in the vicinity of a PRB and the residence time of contaminants passing through it. These may be significant design considerations for some applications.

Conceptually, PRBs are applicable to any location within a plume. Emplacement of a PRB immediately down-gradient of a source zone, within the main part of a plume, or up-gradient of the compliance point are all options for deployment. However, key considerations to successful deployment include constructability (e.g., the required length and depth of installation as a function of location within a plume), cost-effectiveness, and an assessment 
Case Study 6-2. Reactions in Two PRBs with Contrasting Groundwater Composition

The following table illustrates differences in groundwater chemistry and resultant secondary minerals observed in PRBs at the Canadian Forces Base Borden in Ontario, Canada (O'Hannesin and Gillham, 1998) and the US Department of Energy Y-12 Plant in Oak Ridge, Tennessee (Phillips, et al. 2000). The low dissolved solids groundwater at the Borden site apparently has resulted in little formation of new solid phases over a period of four years and most precipitation appears to be restricted to a very thin zone at the influent face of the PRB. In contrast, the highly mineralized water from Y-12 resulted in much more extensive formation of secondary phases, illustrated by the cementation of reactive media. The presence of $\mathrm{NO}_{3}{ }^{-}$at high concentration in the $\mathrm{Y}-12$ groundwater is an important factor in the degree of reaction occurring in this PRB because $\mathrm{NO}_{3}{ }^{-}$is readily reduced to $\mathrm{NH}_{3}$ as iron is oxidized and, therefore, is very corrosive to the $\mathrm{Fe}(0)$ (Liang, et al., 2003).

\begin{tabular}{|c|c|c|}
\hline \multirow[t]{2}{*}{ Chemical Constituent } & \multicolumn{2}{|c|}{$\begin{array}{c}\text { Concentration (mg/L) } \\
\end{array}$} \\
\hline & $\begin{array}{c}\text { Canadian Forces Base } \\
\text { Borden }\end{array}$ & $\begin{array}{c}\text { US Dept. of Energy Y-12 } \\
\text { Plant }\end{array}$ \\
\hline $\begin{array}{l}\mathrm{Na} \\
\mathrm{K} \\
\mathrm{Ca} \\
\mathrm{Mg} \\
\mathrm{Total} \mathrm{Fe} \\
\mathrm{Cl} \\
\mathrm{SO} 4 \\
\mathrm{SiO} 2 \\
\mathrm{NO} 3 \\
\text { Alkalinity (as CaCO3) } \\
\text { pH (unitless) } \\
\text { Eh (mV) } \\
\text { Dissolved Oxygen }\end{array}$ & $\begin{array}{c}4 \\
0.4 \\
55 \\
4 \\
<0.5 \\
3 \\
5-10 \\
\text { na } \\
\text { na } \\
158 \\
7.9 \\
300 \\
2.5-5\end{array}$ & $\begin{array}{c}8.9 \\
3.6 \\
361 \\
20.5 \\
0.02 \\
55 \\
47 \\
3.8 \\
904 \\
220 \\
6.8 \\
? \\
?\end{array}$ \\
\hline $\begin{array}{l}\text { Secondary minerals } \\
\text { observed: }\end{array}$ & $\begin{array}{l}\text { Traces of iron oxides } \\
\text { CaCO3 } \\
\text { FeCO3 } \\
\text { (after four years of } \\
\text { operation; no } \\
\text { cementation; } \\
\text { mineralization confined } \\
\text { to within several } \mathrm{mm} \text { of } \\
\text { influent face of the } \\
\text { PRB) }\end{array}$ & $\begin{array}{l}\text { CaCO3 (aragonite) } \\
\mathrm{Fe} 2(\mathrm{OH}) 2 \mathrm{CO} 3 \\
\mathrm{FeCO} 3 \\
\text { Goethite } \\
\text { Maghemite } \\
\text { Amorphous iron oxide } \\
\text { green rust } \\
\text { mackinawite } \\
\text { (iron media cemented } \\
\text { extensively at influent } \\
\text { face) }\end{array}$ \\
\hline Source: & $\begin{array}{l}\text { O'Hannesin and } \\
\text { Gillham (1998) }\end{array}$ & Liang, et al. (2003) \\
\hline
\end{tabular}

Longevity of PRBs is a key in determining if these systems will be an acceptable EA technology. Additional study on interactions of different reactive media and subsurface geochemistry will be important in moving this technology forward. 
that adequate, sustainable performance can be achieved. Within the context of EA the measure of performance of a PRB need not be evaluated by its ability to achieve MCLs. Rather, the goal should be a reduction of contaminant flux that helps the system achieve a mass balance. Therefore, less than complete degradation may be acceptable as long as fluxes of unreacted contaminants and degradation products (e.g., TCE, DCE, VC) remain low enough. Reduced residence time in the barrier (e.g., due to a thin wall or high velocity pathway) or partial bypass of contaminated groundwater around or under the wall may not be fatal design flaws. Indeed, relaxing conventional design constraints should result in a more cost-effective approach to implementing such an enhancement.

\subsubsection{Issues}

\subsubsection{Scientific Issues}

Permeable reactive barriers, especially those using ZVI as the reactive medium, have been thoroughly researched in the laboratory and in pilot-scale field applications. There are many full-scale field deployments that have occurred and appear to be working as anticipated. Questions remain about the longevity of PRBs and a recent study (FRTR, 2002) identifies some of the factors that affect it. Some PRBs suffer rapid formation of secondary minerals in the up-gradient face of the barrier that can result in significant flow diversion and bypass. In addition, it is widely recognized that one of the most important performance issues of PRBs is related to aquifer hydrologic conditions resulting in preferential flow paths and partial bypass of the PRB due to periodic or seasonal changes in groundwater flow directions. Finally, PRBs of the types discussed in Section 6.3 are not appropriate for application in bedrock due to the difficulty and cost of emplacement and issues related to highly heterogeneous fracture flow. However, alternative emplacement strategies may be possible.

\subsubsection{Regulatory Issues}

The regulatory community appears to embrace the use of PRBs and few issues concerning their use are encountered. Longevity may be the most important regulatory issue encountered. 
WSRC-STI-2006-00083, Rev. 1

August 1, 2006

Page 70 of 147

This page intentionally left blank. 


\subsection{STRATEGY FOR APPLYING ENHANCEMENTS}

Each of the enhancements discussed in Sections 3 through 6 has the potential to reduce mass flux to some degree and move the overall system in the direction of achieving a balance between source loading and attenuation capacity so the resulting discharge at the compliance point meets the remediation goal. There are many variables to be considered and the problem appears to be challenging. Each enhancement is associated with costs (implementation; operations and maintenance [O\&M]) and benefits (performance; sustainability). Does it make sense to utilize a single enhancement or should several be employed? If only one enhancement is to be used how does one select among the possible options? If more than one enhancement is contemplated how does one decide which ones should be integrated into a system that will minimize cost and maximize benefits? The answers to these questions lie within the province of decision analysis - a formal process whereby project objectives and parameter uncertainties are integrated to arrive at rational decisions. A general decision analysis framework that considers uncertainty in decision variables is described by Schuyler (1996). Gorelick (1988) has applied decision analysis to groundwater systems with parameter uncertainties in conjunction with numerical optimization methods to determine an optimal set of design parameters to meet specific cost and/or performance criteria.

However, an initial consideration in the decision process must be whether or not the site can support specific enhancements. For example, if the source zone is embedded within a densely developed industrial complex it is unlikely that enhancements to limit infiltration will be required or feasible. Likewise, if the source is located at significant depth, some of the passive methods of hydraulic control (e.g. GeoSiphon) or containment (e.g., PRB) may not be practicable to deploy. A plume that has not advanced sufficiently to be discharging into a surface body of water is not a candidate for development of a wetland treatment system.

Another component of this initial evaluation phase is to assess the acceptability of specific types of enhancements to regulators and stakeholders. For example, the introduction of nonindigenous biological material (e.g., plant or bacteria) may not be acceptable at some sites. The use of plants that transfer cVOC contaminants from groundwater to the atmosphere also may not gain regulatory approval. These concerns need to be understood in this first stage of evaluation of potential enhancements.

Consequently, the initial assessment of a site for enhancements must focus on site-specific factors imposed by the geology, hydrology, physical features, and infrastructure of the site as well as constraints imposed by regulatory and stakeholder bodies. Some factors that need to be considered in the initial assessment include:

- When is the appropriate time to transition from active treatment to an EA treatment or MNA?

- Is the enhancement suitable for the site?

- To which enhancement zone(s) is an enhancement applicable? 
- What is the desired target reduction in overall mass flux and the uncertainty in this number?

- What is the expected performance (i.e. predicted magnitude of reduction in mass flux)?

- What is the longevity (i.e., sustainability): how long do we anticipate that we need an enhancement to function?

- What is the cost to implement?

- What is the cost to perform O\&M (including monitoring costs)?

This evaluation process should yield a range of candidate enhancements for further consideration. One might decide to use a formal decision analysis process that incorporates uncertainties and cost/benefit tradeoffs. The challenge is to develop a decision tool that is technically sound and has the support of regulators, end users, and stakeholders.

Table 7-1 is a matrix that lists the major classes of enhancements discussed in Sections 3 through 6 and provides summary-level information for some of the key criteria that will affect the selection of enhancements for a site. It is useful for comparing the features of different types of enhancements and what part of the source-plume system to which they are applicable. For more in-depth information, the reader is referred to the specific parts in Sections 3-6 that are referenced in the table. For more detailed information on the basis for the ratings in the Regulatory Acceptance column, the reader is referred to Summary of Identification of Regulatory Acceptability of Enhanced Attenuation Categories (Vangelas, 2006). 
Table 7-1. Summary of Criteria Affecting the Choice of Enhancement

\begin{tabular}{|c|c|c|c|c|c|c|c|c|c|c|c|c|}
\hline \multirow[b]{2}{*}{ ENHANCEMENT } & \multicolumn{11}{|c|}{ CRITERIA AFFECTING THE CHOICE OF ENHANCEMENT (See Note 1) } & \multirow[b]{2}{*}{$\begin{array}{l}\text { COMMENTS ON LIKELY IMPACT } \\
\text { OF ENHANCEMENT }\end{array}$} \\
\hline & $\begin{array}{l}\text { OBJECTIVE(S) OF } \\
\text { ENHANCEMENT }\end{array}$ & $\begin{array}{l}\text { MAXIMUM DEPTH OF } \\
\text { EMPLACEMENT (FT) }\end{array}$ & $\begin{array}{c}\text { APPLICABLE } \\
\text { SITE GEOLOGY }\end{array}$ & $\begin{array}{l}\text { CONTAMINANTS } \\
\text { TREATED BY } \\
\text { ENHANCEMENT }\end{array}$ & $\begin{array}{l}\text { MATURITY OF } \\
\text { TECHNOLOGY }\end{array}$ & $\begin{array}{l}\text { WORKER } \\
\text { SAFETY }\end{array}$ & $\begin{array}{l}\text { REGULATORY } \\
\text { ACCEPTANCE } \\
\text { (See Note 2) }\end{array}$ & $\begin{array}{l}\text { LIKELLHOOD OF } \\
\text { SUCCESS IN } \\
\text { REDUCING } \\
\text { MASS FLUX }\end{array}$ & SUSTAINABILITY & \begin{tabular}{|c|} 
APPLLCABLE \\
ENHANCMENT \\
ZONES (SOURCE, \\
PULME, \\
DISCHARGE)
\end{tabular} & $\begin{array}{l}\text { COSTS (CAPITAL } \\
\text { AND O\&M) }\end{array}$ & \\
\hline \multicolumn{13}{|c|}{ HYDRAULIC MANIPULATION: VADOSE \& SATURATED ZONES } \\
\hline \multicolumn{13}{|c|}{\begin{tabular}{|l|l} 
REDUCE INFLLTRATION AT SOURCE &
\end{tabular}} \\
\hline $\begin{array}{l}\text { SW/ISTRM FLOW DIVERSION } \\
\text { (see Section 3.1.1) }\end{array}$ & $\begin{array}{l}\text { REDUCE INFLTRATION OF } \\
\text { SURAREC WATER AND STORM } \\
\text { WATER THROUGH SOURCE }\end{array}$ & $<3.6 \mathrm{FT}$. & 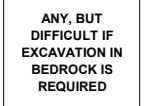 & & & & & & & $\begin{array}{c}\text { SOURCE } \\
\text { ZONE }\end{array}$ & & 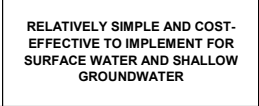 \\
\hline $\begin{array}{l}\text { SUSTAINABLE COVERS } \\
\text { (see Section 3.1.2) }\end{array}$ & $\begin{array}{l}\text { REDUCE INFITRATION OF } \\
\text { PRECIPITATION THROUGH } \\
\text { SOURCE }\end{array}$ & GROUND SURFACE & $\begin{array}{l}\text { ANY WITH } \\
\text { ADEQQATESOIL } \\
\text { AND VEGETATION }\end{array}$ & ANY & & & ? & & & $\begin{array}{l}\text { SOURCE } \\
\text { ZONE }\end{array}$ & & $\begin{array}{l}\text { ALTERNATVE COVERS ARE } \\
\text { PROMISING, BUT SUSTIANABLITYY IS } \\
\text { AN ISSUE }\end{array}$ \\
\hline \multicolumn{13}{|l|}{$\begin{array}{l}\text { REDUCE MASS TRANSFER } \\
\text { SOURCE CONTAINMENT } \\
\end{array}$} \\
\hline $\begin{array}{l}\text { BARRIER WALLS } \\
\text { (see Section 3.2.1.1) }\end{array}$ & 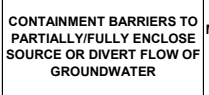 & $\begin{array}{l}\text { MOST COMMONLY <50 FT.; } \\
\text { METHODS EXIST TO } \\
\text { REACH >100 FT. }\end{array}$ & $: \underset{\text { NOT PRACTICAL IN }}{\text { BEDROCK }}$ & ANY & & & & & & $\begin{array}{l}\text { SOURCE } \\
\text { ZONE }\end{array}$ & & $\begin{array}{l}\text { MATURE TECHNOLOGY; MOST COST. } \\
\text { EFFECTIVE IN IRLLATIVEYY SHALLOW } \\
\text { APPLLCATIONS }\end{array}$ \\
\hline $\begin{array}{l}\text { PARTITION BARRIERS (e.g. USING } \\
\text { VEEETABLE OOL) } \\
\text { (see Section 3.2.1.3) }\end{array}$ & 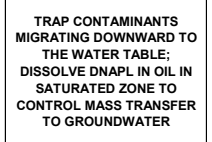 & NO SPECIFCC LMIT & $\begin{array}{l}\text { POROUS MEDAA } \\
\text { NOO PRACTCALL I I } \\
\text { BEDROCK }\end{array}$ & cVOCs (SOLUBLE IN NAPL & & & & UnkNOWn & & $\begin{array}{l}\text { SOURCE } \\
\text { ZONE }\end{array}$ & & 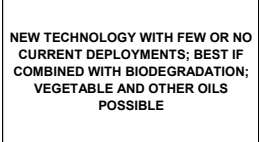 \\
\hline \multicolumn{13}{|l|}{ LOWER HYDRAULIC GRADIENT } \\
\hline $\begin{array}{l}\text { WITH ENGINEERED STRUCTURES } \\
\text { (see Section 3.2.2 and 3.2.4) }\end{array}$ & $\begin{array}{l}\text { INTERCEPT GROUNDWATER } \\
\text { TO CONTROL HVRPAULIC } \\
\text { GRADIENT }\end{array}$ & SHALLOW (-20 FT.) & $\underset{\substack{\text { NOT PRACTICAL IN } \\
\text { BEDROCK }}}{\mid}$ & ANY & & & & & & $\begin{array}{l}\text { SOURCE } \\
\text { ZONE }\end{array}$ & & $\begin{array}{l}\text { MATURE TECHNOLOGY; MOST COST. } \\
\text { EFFECTIVE INRLAATVEYY SHALLO } \\
\text { APPLLCATIONS }\end{array}$ \\
\hline $\begin{array}{l}\text { WITH TREES } \\
\text { (see Section 3.2.3) }\end{array}$ & $\begin{array}{l}\text { PLANT-BASED EXTRACTION } \\
\text { OF GROUNDWATER TO } \\
\text { CONTROL HYRAULLIC } \\
\text { GRADIENT }\end{array}$ & $\begin{array}{l}\text { TREEWELL DEPTH IS } \\
\text { LMITED B COST AND } 25 \\
\text { FT. DEPTH OF } 25 \\
\text { POTENTIOMETRIC } \\
\text { SURFACE }\end{array}$ & \begin{tabular}{|c|c|}
5 & NOT PRACTICAL IF \\
TARGET AQUUFER IS \\
IN BEDROCK
\end{tabular} & ANY & & & & $\because$ & & $\begin{array}{c}\text { SOURCE AND } \\
\text { PLUMEE } \\
\text { ZONE }\end{array}$ & & $\begin{array}{l}\text { INCREASING NUMBER OF } \\
\text { DEPLOYMENTS, BUT STLLL ANEW } \\
\text { APLIIIATAON; MUST CONIDER } \\
\text { IMPACT OF DORMANCY PERIOD }\end{array}$ \\
\hline $\begin{array}{l}\text { ELECTRON ACCEPTOR DIVERSION } \\
\text { (see Section 3.3) }\end{array}$ & $\begin{array}{l}\text { DIVERSION OF COMPETING } \\
\text { ELECTRONACCPTTRS } \\
\text { FROM SOURCE ZONE }\end{array}$ & $\begin{array}{c}\text { MOST COMMONLY <50 FT.; } \\
\text { METHODS EXIST TO } \\
\text { REACH }>100 \text { FT. }\end{array}$ & $\mid \begin{array}{c}\text { NOT PRACTICAL IN } \\
\text { BEDROCK }\end{array}$ & \begin{tabular}{|} 
CVOCS AND OTHER \\
CONTAMINANTS WHERE \\
REDUCTVE PROCESESS \\
ARE REQUIRED
\end{tabular} & & & & UNKNOWN & & $\begin{array}{l}\text { SOURCE } \\
\text { ZONE }\end{array}$ & & \begin{tabular}{|} 
TECHNICALLY SOUND CONCEPT, BUT \\
HAS NOT BEEN TESTED, CANBE \\
LNKED TO METHODS FOR \\
GROUNDWATER DIVERSION
\end{tabular} \\
\hline \multicolumn{13}{|l|}{ PASSIVE REMOVAL OF SOURCE MASS } \\
\hline $\begin{array}{l}\text { VAPOR EXTRACCIION } \\
\text { (see Section 4.1) }\end{array}$ & \begin{tabular}{|} 
PASSIVE REMOVAL OF CVOC \\
VAPPRS FOM VAAOSE EONE \\
(E.G. WITH BAROBALL)
\end{tabular} & NO SPECIFC LMIT & $\begin{array}{c}\text { ANY, BUT } \\
\text { DifFCLLIT IN } \\
\text { BEDROCK }\end{array}$ & VOLATLE COMPOUNDS & & & 3 & 3 & & $\begin{array}{l}\text { SOURCE } \\
\text { ZONE }\end{array}$ & & $\begin{array}{l}\text { A SLOW, BUT SUSTAINABLE AND } \\
\text { COST-EFFECTIVE PROCESS }\end{array}$ \\
\hline $\begin{array}{l}\text { DNAPL REMOVAL: DRAINAGE TO WELLS } \\
\text { (see Section 4.2) }\end{array}$ & $\begin{array}{l}\text { DNAPL COLLECTION IN WELL } \\
\text { SUMPS BY GRAVITY FLOW }\end{array}$ & NO SPECIFIC LMIT & ANY & DNAPL & & & & & & $\begin{array}{c}\text { SOURCE } \\
\text { ZONE }\end{array}$ & & 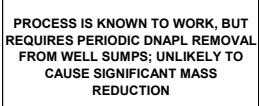 \\
\hline
\end{tabular}


Table 7-1. Summary of Criteria Affecting the Choice of Enhancement - continued

\begin{tabular}{|c|c|c|c|c|c|c|c|c|c|c|c|c|}
\hline \multirow[b]{2}{*}{ ENHANCEMENT } & \multicolumn{11}{|c|}{ CRITERIA AFFECTING THE CHOICE OF ENHANCEMENT (See Note 1) } & \multirow[b]{2}{*}{$\begin{array}{c}\text { COMMENTS ON LIKELY IMPACT } \\
\text { OF ENHANCEMENT }\end{array}$} \\
\hline & $\begin{array}{l}\text { OBJECTIVE(S) OF } \\
\text { ENHANCEMENT }\end{array}$ & $\begin{array}{l}\text { MAXIMUM DEPTH OF } \\
\text { EMPLACEMENT (FT) }\end{array}$ & $\begin{array}{l}\text { APPLICABLE } \\
\text { SITE GEOLOGY }\end{array}$ & $\begin{array}{l}\text { CONTAMINANTS } \\
\text { TREATED BY } \\
\text { ENHANCEMENT }\end{array}$ & $\begin{array}{l}\text { MATURITY OF } \\
\text { TECHNOLOGY }\end{array}$ & $\begin{array}{l}\text { WORKER } \\
\text { SAFETY }\end{array}$ & \begin{tabular}{|l|} 
REGULATORY \\
ACCEPTANCE \\
(See Note 2)
\end{tabular} & $\begin{array}{l}\text { LIKELIHOOD OF } \\
\text { SUCCES IN } \\
\text { REDUCING } \\
\text { MASS FLUX }\end{array}$ & SUSTAINABILITY & \begin{tabular}{|c|} 
APPLICABLE \\
ENHANCEMENT \\
ZONES (SOURCE, \\
PLUME, \\
DISCHARGE)
\end{tabular} & $\begin{array}{l}\text { COSTS (CAPITAL } \\
\text { AND O\&M) }\end{array}$ & \\
\hline \multicolumn{13}{|c|}{ BIOLOGICAL ATTENUATION PROCESSES } \\
\hline $\begin{array}{l}\text { BIOSTIMULATION } \\
\text { (see Section 5.1.1) }\end{array}$ & 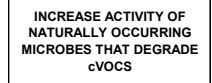 & NO SPECIFIC LIMIT & $\begin{array}{c}\text { ANY, BuT MORE } \\
\text { DifFCLUTTIN } \\
\text { BEDOROCK }\end{array}$ & $\begin{array}{l}\text { cVoc, BTEX, SOME } \\
\text { REDX SENSITIVE } \\
\text { INORGANICS }\end{array}$ & 3 & & & & & $\begin{array}{l}\text { SOURCE, } \\
\text { PLUME, AND } \\
\text { DISCAARE } \\
\text { ZONES }\end{array}$ & & $\begin{array}{l}\text { VERY PROMISING TECHNOLOGY IF } \\
\text { SUSTAINABIITY AND COMPLLTE } \\
\text { DEGRADATION CAN BE ACHIEVEED }\end{array}$ \\
\hline $\begin{array}{l}\text { BIOAUGMENTATION } \\
\text { (see Section 5.12) }\end{array}$ & 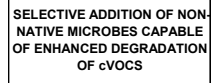 & NO SPECIFIC LIMIT & $\begin{array}{c}\text { ANY, BUT MORE } \\
\text { DIIFCLITITIN } \\
\text { BEDOROCK }\end{array}$ & 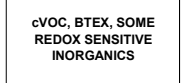 & & & & & & $\begin{array}{l}\text { SOURCE, } \\
\text { PLUMEAND } \\
\text { DISCAAREE } \\
\text { ZONES }\end{array}$ & & $\begin{array}{l}\text { A VERY PROMISING TECHNOLOGY IF } \\
\text { SUSTIANABBLITYN YND RESULATORY } \\
\text { IISUES CAN BE RESOLVED }\end{array}$ \\
\hline $\begin{array}{l}\text { WETLANO SYSTEMS } \\
\text { (see SECTION 5.1.3) }\end{array}$ & 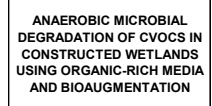 & 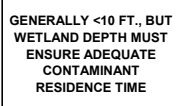 & \begin{tabular}{|c|} 
ANY, IF \\
CONTAMINATE \\
GROUNDATER \\
CAN BE CAPTURED \\
BY WETLAND
\end{tabular} & $\begin{array}{l}\text { cVoc, BTEX, SOME } \\
\text { REDX STENSTIVE } \\
\text { INORGANICS }\end{array}$ & & & & & & DISCHARGE ZONE & & 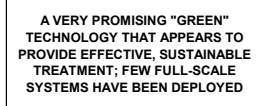 \\
\hline $\begin{array}{l}\text { PLANT-BASED METHODS } \\
\text { (see Section 5.2) }\end{array}$ & 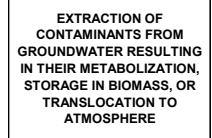 & $\begin{array}{l}\text { TREEWELL DEPTH IS } \\
\text { LIMIED B B COST AND } 25 \\
\text { FT. DEPH OF } 25 \\
\text { POTENTIOMETRRIC } \\
\text { SURFACE }\end{array}$ & $\begin{array}{l}\text { NOT PRACTICAL IF } \\
\text { TARGET AQUUEFR IS } \\
\text { IN BEDROCK }\end{array}$ & $=\begin{array}{c}\text { VARIOUS ORGANIC AND } \\
\text { INORGANC } \\
\text { CONTAMNANTS }\end{array}$ & & & & & & $\begin{array}{l}\text { PLUME AND } \\
\text { DISCHARGE } \\
\text { ZONES }\end{array}$ & & 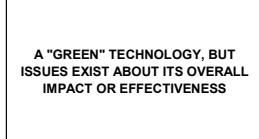 \\
\hline \multicolumn{13}{|c|}{ ABIOTIC AND BIOLOGICALLY-MEDIATED ABIOTIC DEGRADATION } \\
\hline $\begin{array}{l}\text { BIOLOGICALLY MEDIATED ABIOTIC } \\
\text { DERARADTION } \\
\text { (see Section 6.1.2) }\end{array}$ & \begin{tabular}{|l|} 
STIMULATE PRODUCTION OO \\
FE(II)-SPHASES THAT WILL \\
REDUCTIVEY DEERADE \\
cVOOCS
\end{tabular} & NO SPECIFIC LIMIT & $\begin{array}{c}\text { ANY, BUT MORE } \\
\text { DIIFCLITIN } \\
\text { BEDOROCK }\end{array}$ & cvocs & & & & 3 & 3 & $\begin{array}{l}\text { SOURCE, } \\
\text { PLUME, AND } \\
\text { DISCHAREE } \\
\text { ZONES }\end{array}$ & ? & 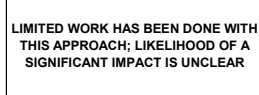 \\
\hline $\begin{array}{l}\text { PERMEABLE REACTIVE BARRIERS } \\
\text { (see Section 6.3) }\end{array}$ & 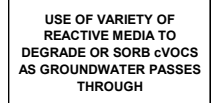 & $\begin{array}{l}\text { MOST COMMONLY <50 FT. } \\
\text { METHODS EXIST TO } \\
\text { REACH >100 FT. }\end{array}$ & $\mid \begin{array}{c}\text { NOT PRACTICAL IN } \\
\text { BEDROCK }\end{array}$ & $\mid \begin{array}{c}\text { CVOCS AND SOME REDOX } \\
\text { SENSITIVE INORGANICS }\end{array}$ & & $\because$ & & & & $\begin{array}{l}\text { SOURCE, } \\
\text { PLUME, AND } \\
\text { DISCHARE } \\
\text { ZONES }\end{array}$ & & 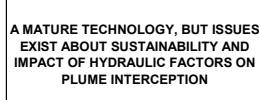 \\
\hline \multicolumn{13}{|c|}{3} \\
\hline
\end{tabular}




\subsection{RESEARCH ON ENHANCEMENTS TO ATTENUATION PROCESSES}

\subsection{SUMMARY OF PROJECT RESEARCH STUDIES}

Fourteen projects are in the research portfolio of the MNA/EA project. Of these, most focus on mass balance and characterization/monitoring investigations. Only three of the projects directly relate to enhancements. The small number of enhancement projects was anticipated because the limited funding and short duration of the studies makes it difficult to design and implement a field-scale enhancement and have sufficient time for it to have an impact that can be objectively evaluated. Nonetheless, these three projects will provide important results to support more extensive future work on enhancements.

One project is investigating an innovative way to create a sustainable environment for enhanced abiotic degradation of cVOCs. The second study will seek to overcome a common problem in aerobic systems, where biodegradation does not proceed past DCE, by augmenting it with a recently identified bacterium that can metabolize this contaminant. The final project involves updating and expansion of a popular reactive flow and transport numerical model (RT3D) to include a suite of attenuation processes.

\section{Use of Electron Shuttles to Biologically Enhance Abiotic Dechlorination (P. McLoughlin, R. Pirkle, B. Wilson, and J. Wilson)}

The objective of this project is to explore a method of enhancing the abiotic dechlorination of cVOCs. The advantage of this process is to avoid the stalling of biological dechlorination that occurs if the system is not sufficiently anaerobic and to modify the system to sustainably support the enhancement. Electron shuttles (e.g., humic acids) have the ability to facilitate the transfer of electrons in groundwater systems. In this project electron shuttle catalysts will be used to oxidize $\mathrm{Fe}(\mathrm{II})$ in solution and reduce $\mathrm{Fe}(\mathrm{III})$ on mineral surfaces making the newly-formed $\mathrm{Fe}(\mathrm{II})$ available for abiotic dechlorination reactions. It is proposed that addition of a carbon substrate and electron shuttle will result in a sustainable system. Part of this project will be to investigate the production and measurement of acetylene as a byproduct of the abiotic degradation of cis1,2-DCE.

\section{EA using bioaugmentation with aerobic bacteria for cis-1,2-DCE (J. Gossett)}

A novel aerobic bacterium (JS666) has been isolated that uses cis-1,2-DCE as its sole carbon and energy source. Apparently it is a rare organism and is a good candidate for bioaugmentation of cVOC plumes under aerobic conditions where complete dechlorination by other pathways will not occur. The project will involve (a) laboratory studies using JS666 to determine conditions under which it is active and can be cultured and (b) the design and testing of a molecular probe for monitoring this organism. 


\section{(M. Truex, C. Johnson, and P. Clement)}

The RT3D modeling software enjoys widespread use as a 3-D, multi-species, reactive transport code that can be applied to evaluating MNA. For this project a comprehensive set of reaction/attenuation modules will be developed and added to the model. In addition, updated documentation and case study examples will be incorporated to help explain the implementation of the modules. These modifications will transform RT3D into a more versatile tool for evaluating MNA. The model also will have application as an EA design tool where the impact of potential enhancements can be evaluated.

\subsection{OTHER RESEARCH OPPORTUNITIES FOR ENHANCEMENTS}

Many of the enhancements discussed in this document have been in use for many years, but with somewhat different objectives and performance expectations. Various strategies for hydraulic manipulation (e.g., caps/covers, french drains, etc.) are good examples of mature technologies that have been widely used. Other potential enhancements have been the subject of significant research and development (R\&D) in the past 10-15 years, but have remaining science questions yet to be answered (e.g., PRBs, biostimulation/ bioaugmentation, etc.). Still others currently are at the cutting edge of scientific inquiry (e.g., abiotic processes, partition barriers, microbial degradation by oxidative pathways, some plant-based methods, etc.) and require further investigation.

It is ironic that some technologies, such as engineered covers, have been in use for decades, but recognized deficiencies in their design and long-term performance under a variety of climatic conditions continue to stimulate extensive R\&D and field studies. The goal is for development of more robust and sustainable cover designs and continued investigations are needed.

Fortunately, this work is in progress through the EPA ACAP program (see Section 3.1.2) and the results should have direct application to EA.

The application of these types of technologies and processes to EA is for the purpose of reducing contaminant mass flux rather than remediating contamination. However, the ability to understand the underlying science, successfully manipulate it sustainably, and be able to reliably predict (and measure) the impact over time of all enhancements are critical objectives. These objectives need to be developed and applied to EA regardless of the level of maturity of the enhancements themselves.

For more mature enhancement technologies the principle remaining science needs are in the areas of performance prediction and monitoring. How long will a cap continue to function satisfactorily? Will the reduction of infiltration it provides result in a sufficient reduction in source loading? What is the simplest and most effective way of monitoring cap performance?

For the immature technologies the science burden shifts to developing a fundamental understanding of processes. Can the information gained by determining the Populus genome be translated into new clones with properties especially favorable to EA (and can regulatory barriers 
for their use be overcome)? Can new consortia of bacteria be isolated, studied, and cultured to improved degradation of cVOCs and still meet the important criterion of sustainability?

In summary, we can identify the kinds of investigations necessary to transform various technologies into viable candidates of enhancements for EA:

- Refine our understanding of the science behind an enhancement

- Design systems to support deployment

- Develop methods to address heterogeneities and preferential flow pathways for enhancements requiring subsurface injection of amendments

- Demonstrate that an enhancement is sustainable with little or no further intervention once deployed

- Ensure that an enhancement can be deployed cost-effectively and will have acceptable O\&M requirements

- Identify simple monitoring technologies to assess the performance of enhancements and provide an early warning of their potential failure

Table 8-1 illustrates some of the science and engineering opportunities that exist for enhancements to various attenuation processes. 
Table 8-1. Examples of Potential Research Opportunities for Enhancements

- Engineered covers

- Better, more sustainable designs for a range of site conditions

- Source containment

- Simple and effective designs for partial source containment

- Field-based confirmation of the efficacy of electron acceptor diversion as an enhancement

- Plant-based processes (e.g. hydraulic control, contaminant extraction, contaminant attenuation in rhizosphere)

- Leveraging Populus genome work; genetic engineering

- Constructed wetlands design

- Sustainability and O\&M issues; seasonality

- Biological attenuation

- Novel microbes

- Novel reaction paths that avoid toxic byproducts

- Improved sustainability of enhancements; long-lasting electron donors

- Issues related to subsurface heterogeneities and injection of amendments

- Abiotic processes

- Better understanding of sorption

- Further elucidation of degradative reactions

- Issues related to subsurface heterogeneities and injection of amendments

- Sustainability of abiotic processes

- Partition barriers

- Novel vegetable oils with special properties

- Sustainability of oils

- Overcoming subsurface heterogeneities

- Permeable reactive barriers (PRBs)

- New reactive media (e.g. nano Fe)

- Sustainability

- Better understanding of hydrology on barrier performance

- Impacts of enhancements

- Develop/adapt advanced monitoring tools to measure enhancement performance

- Probabilistic decision tools and scenario-based approaches to aid in the selection of enhancements

- Enhancements suitable for deployment in fractured bedrock 


\subsection{SUMMARY AND CONCLUSIONS}

The concept of enhanced attenuation essentially asks the question: Is it possible through intervention to sustainably manipulate natural attenuation processes so that they operate more effectively than without intervention and thereby result in an increased reduction in mass flux of contaminants sufficient to meet regulatory release requirements?

This reference guide attempts to present the broad spectrum of enhancement mechanisms (physical, chemical, and biological) that can be applied to natural systems and have potential for sustainably reducing the mass flux of contaminants to achieve a balance between flux and attenuation capacity. Although some enhancements specifically target cVOC contaminants (e.g., biostimulation, bioaugmentation, abiotic processes), others are more generic and apply equally well to any type of contaminant (e.g., large-scale hydrologic controls).

In addition to describing the enhancements, this reference guide also discusses several factors that must be considered relative to their application within the context of EA. The first requirement is sustainability; ideally, once an enhancement is deployed no further intervention is necessary to keep it functioning. Secondly, enhancements must be tailored to the environmental setting in which they will be applied (i.e. work with, not against nature). Third, enhancements must be robust enough to accommodate site specific temporal and spatial factors that may impact their application. Fourth, a methodology must be developed for optimizing the selection of enhancements to be used to ensure cost-effectiveness.

Some potential enhancements involve relatively new technologies or processes where our understanding is still evolving. Examples include constant head moats, diffusion barriers, and electron acceptor diversion. Although the underlying technical concepts for them are firmly grounded, we have limited or no experience with their implementation. They represent opportunities for additional $R \& D$ that can help refine them to explore their applicability to EA.

A second group of potential enhancements includes biotechnology, plant-based, and abiotic approaches that largely have been developed during the past $10-15$ years. Our understanding of the attenuation mechanisms, although significant, continues to evolve through additional R\&D and field applications. Some of these technologies are exceptionally promising in support of EA and will likely become important additions to the EA toolbox in the future.

Finally, many enhancements discussed in Sections 3 -6 are mature technologies that have been deployed at many sites, although not as part of an EA strategy. Many of the methods for hydraulic manipulation (e.g. french drains, barrier walls) fall into this category. Design criteria and performance expectations for these technologies are relatively well-understood.

Enhancements cannot be considered in isolation of the other components of EA: a) monitoring techniques and strategies for evaluating the performance of enhancements, and $b$ ) formal development of the concept that looks at both sides of the mass balance equation - integrated 
mass flux and attenuation capacity. Successful blending of these three components is essential to the viability of EA.

There is a clear and critical linkage between an enhancement and effective monitoring tools to assess the performance of that enhancement. Fortunately, some of the enhancements discussed in this document have evolved to a level of maturity where a suite of cost-effective monitoring tools are available and can be adapted for use within the context of EA. For enhancements that are much newer or still in the development stage one of the challenges will be to identify robust monitoring approaches for them. The monitoring strategy as discussed by Gilmore et al. (2006), provides a road map for how monitoring for EA should be implemented.

Likewise, it must be possible to evaluate the impact of an enhancement as it is integrated into the overall mass balance dynamics of the system. Looney et al. (2006) lay the foundation for a quantitative framework for EA that blends both empirical and deterministic approaches. The ability to make projections of the future performance of enhancements based on their past performance is crucial in establishing confidence in EA as a treatment approach for a site. 


\subsection{REFERENCES}

Acton, D.W., 1990. Enhanced in situ biodegradation of aromatic and chlorinated aliphatic hydrocarbons in anaerobic, leachate-impacted groundwaters: M.Sc. Thesis, University of Waterloo, Waterloo, Ontario.

AFCEE. 2003. Cost and performance summary report. Mulch Biowall at Altus Air Force Base, Landfill 3, Oklahoma. Air Force Center for Environmental Excellence, June 2003.

AFCEE, 2004a. Principals and practices of enhanced anaerobic bioremediation of chlorinated solvents. Prepared by Parsons Corporation under contract to the Air Force Center for Environmental Excellence and Navy Facilities Engineering Service Center.

AFCEE. 2004b .Report for Full-Scale Mulch Wall Treatment of Chlorinated HydrocarbonImpacted Groundwater, Offutt AFB, NE, Building 301. Prepared for AFCEE by Groundwater Services. April 13, 2004.

AFRL, 2000. Design guidance for application of permeable reactive barriers for groundwater remediation. Prepared for the Air Force Research Laboratory, Tyndall AFB, FL, March 31

Albright, W.C., C.H. Benson, G.W. Gee, A.C. Roesler, T. Abichou, P. Apiwantragoon, B.F. Lyles, and S.A. Rock, 2004. "Field water balance of landfill final covers," J. Environmental Quality. 33:2317-2332.

Alkorta, I., and C. Garbisu, 2001. "Phytoremediation of organic contaminants in soils," Bioresource Technology 79:273-276.

Anderson, J.E., R.S. Nowak, T.D. Ratzlaff, and O.D. Markham, 1993. "Managing soil moisture on waste burial sites in arid regions," Journal of Environmental Quality, 22:62-69.

Anderson, J.A. and A. D. Forman, 2002. The Protective Cap/Biobarrier Experiment: A study of Alternative Evapotranspiration Caps for the Idaho National Engineering and Environmental Laboratory. Prepared for U. S. Department of Energy - Idaho Field Office. Environmental Surveillance, Education and Research Program. STOLLER-ESER-46. http://www.stoller-eser.com/PDF/PCBReport.pdf.

Annable, M.D., K. Hatfield, J. Cho, S. Rao, B. Parker, and J. Cherry, 2001. "Quantifying Water Flow and Contaminant Flux in Boreholes," American Geophysical Union, Fall meeting suppl., Abstract H32G-03 in EOS. Trans. AGU, 82(47) pg. F444.

Arthur, W.J. III, and O.D. Markham, 1983. "Small mammal soil burrowing as a radionuclide transport vector at a radioactive waste disposal area in southeastern Idaho," J. Environ. Qual, 12:117-122. 
Benson, C., W. Albright, T. Abichou, S. Rock, E. MacDonald, L. Li, and X. Wang, 2004. "Forensic Evaluation of a Conventional Cover with a Compacted Clay Barrier," in Designing, Building, and Regulating ET Landfill Covers, U.S. Environmental Protection Agency, March 910, 2004, Denver, CO.

Benson, C.H., D.E. Daniel, and G.P. Boutwell, 1999. "Field Performance of Compacted Clay Liners," Journal of Geotechnical and Geoenvironmental Engineering 125:390.

Bjornstad, B.N., and S.S. Teel, 1993. Natural analog study of engineered protective barriers at the Hanford Site. PNL-8840, Pacific Northwest National Laboratory, Richland, Washington.

Borders, A., 2005. "Center Views: Biowall construction begins at Altus," Centerviews 11. http://www.afcee.brooks.as.mil/ms/msp/vol11no1/15.asp.

Boronina, T., K.J. Klabunde, and G. Sergeev, 1995. "Destruction of organohalides in water using metal particles: Carbon tetrachloride/water reactions with magnesium, tin, and zinc," Envir. Sci. Technol. 29:1511-1517.

Bowerman, A.G., and E.F. Redente, 1998. "Biointrusion of protective barriers at hazardous waste sites," J. Envron. Qual., 27:625-632.

Bowman, R.S.,Z. Li, S.J. Roy, T.Burt, T.L.Johnson, and R. L. Johnson, 2001. "Pilot test of a surfactant-modified zeolite permeable barrier for groundwater remediation," in J.A.Smith and S.Burns (eds.) Physical and chemical remediation of contaminated aquifers. Kluwer Academic/Plenum Publ., New York. pp161-185.

Burris, D.R., T.J. Campbell, and V.S. Manoranjan, 1995. "Sorption of trichloroethylene and tetrachloroethylene in a batch reactive metallic iron-water system," Environ. Sci. Technol. 29(11): 2850-2855

Butler, B.J., and Barker, J.F., 1996. "Chemical and microbiological transformation and degradation of chlorinated solvent compounds," in, Pankow, J.F., and Cherry, J.A., eds., Dense Chlorinated Solvents and Other DNAPLs in Ground water: History, Behavior, and Remediation, Waterloo Press, Waterloo, Ontario, p. 267-312.

Butler, E.C. and Hayes, K.F., 1999. "Kinetics of the transformation of trichloroethylene and tetrachloroethene by iron sulfide," Environmental Science and Technology, 33:2021-2027.

Butler, E.C. and K.F. Hayes, 2000. "Kinetics of the Transformation of Halogenated Aliphatic Compounds by Iron Sulfide," Environ. Sci. Technol. 34: 422-429.

Butler, E.C. and K.F. Hayes, 2001. "Factors Influencing Rates and Products in the Transformation of Trichloroethylene by Iron Sulfide and Iron Metal," Environ. Sci. Technol. 35:3884-3891. 
Casey, C. C., A. Sanford, and D.A.Vroblesky, 2004. "Sequential passive treatment processes for mixed chlorinated Aliphatics in groundwater," in Fourth International Conference. Remediation of Chlorinated and Recalcitrant Compounds Conference. Monterey, CA. May 24-27 2004. B9

Cervini-Silva, J. R.A. Larson, J. Wu, and J. W. Stucki, 2001. "Transformation of Chlorinated Aliphatic Compounds by Ferruginous Smectite," Environ. Sci. Technol. 35:805-809.

Chadwick, O.A., and R.C. Graham, 2000. “Pedogenic processes,” in: M.E. Summer (ed.), Handbook of Soil Science, CRC Press.

Chamberlain EJ, A.J. Gow, 1979. "Effects of freezing and thawing on the permeability and structure of soils," Engineering Geology 13:73-92.

Clarke, J.H., M.M. MacDonell, E.D. Smith, R.J Dunn, and W.J. Waugh, 2004. "Engineered Containment and Control Systems: Nurturing Nature," Risk Analysis 24:771-779.

Coleman, N. V., T. E. Mattes, J. M. Gossett, and J. C. Spain, 2002a. "Biodegradation of cis-Dichloroethene as The Sole Carbon Source by a b-Proteobacterium," Applied and Environmental Microbiology, 68:2726-2730.

Coleman, N. V., T. E. Mattes, J. M. Gossett, and J. C. Spain, 2002b. "Phylogenetic and Kinetic Diversity of Aerobic Vinyl-Chloride-Assimilating Bacteria from Chlorinated-EtheneContaminated Sites," Applied and Environmental Microbiology, 68:6162-6172.

Compton, H.R. et al., 2003. "Phytoremediation of Dissolved Phase Organic Compounds: Optimal Site Considerations Relative to Field Case Studies," Remediation, summer 2003.

Criddle, C.S., P.L McCarty, M.C. Elliot, and J.F. Barker, 1986. "Reduction of hexachloroethane to tetrachloroethylene in groundwater," Journal of Contaminant Hydrology, 1:133-142.

Crowley, T. J., and G. R. North, 1991. Paleoclimatology. Oxford Monographs on Geology and Geophysics No. 16. Oxford University Press, New York.

Daniel, D.E., 1994. "Surface Barriers: Problems, Solutions, and Future Needs." pp. 441-487, in G.W. Gee and N.R. Wing (eds.), In-Situ Remediation: Scientific Basis for Current and Future Technologies, Battelle Press, Columbus, Ohio.

Danielsen, K.M., and K.F. Hayes, 2004. " $\mathrm{pH}$ Dependence of Carbon Tetrachloride Reductive Dechlorination by Magnetite," Environ. Sci. Technol. 38:4745-4752.

Davis, E.C., R.G. Stansfield, L.A. Melroy, and D.D. Huff, 1985. "Water diversion at low-level waste disposal sites," Jour. of Envir. Engr. 111(5):714-729

Davis, E.C. and D.S. Marshal, 1988. "Groundwater suppression at a low-level radioactive waste disposal site using a French drain," Radioactive Waste Mgt. and the Nucl. Fuel Cycle 11(2):133159. 
Davrock, B., J. Riedel, J. Bertram, and G. Gottschalk, 1992. "Isopropylbenzene (cumene) - a new substrate for the isolation of trichloroethene degrading bacteria," Arch. Microbiol. 158:9-13.

DOE, 1992. Vegetation growth patterns on six rock-covered UMTRA Project disposal cells, DOE UMTRA Project Office, Albuquerque Operations Office, Albuquerque, New Mexico.

DOE, 1999. Frozen Soil Barrier. Innovative Technology Summary Report, DOE/EM-0483, DOE Office of Science and Technology.

DOE, 2000a. Barometrically enhanced remediation technology $\left(B E R T^{T M}\right)$. Innovative Technology Summary Report, DOE/EM-0516, DOE Office of Science and Technology.

DOE, 2000b. Remediation of DNAPLs in low permeability soils. Innovative Technology Summary Report DOE/EM-0550.

DOE, 2002. Technical Assistance to Kansas City Plant: Mitigation of Polychlorinated Biphenyl Discharges, WSRC-RP-2003-00276, DOE Office of Environmental Management, available from the DOE Office of Science and Technology Information, Oak Ridge TN.

DOE, 2005. Chlorinated hydrocarbon treatment at ETTP - Wetland design. Risk Reduction Report No. 031102-501, DOE Office of Environmental Management.

Doty, S.L., T.Q. Shang, A.M. Wilson, A.L. Moore, L.A. Newman, S.E. Strand, and M.P. Gordon. 2003. "Metabolism of the soil and groundwater contaminants, ethylene dibromide and trichloroethylene, by the tropical leguminous tree, Leucaena leucephal," Water Res. 37:441-449.

Ellis, D. E., E.J. Lutz, J.M. Odom, R.J.J. Buchanan, C.L. Bartlett, M.D. Lee, M.R. Harkness, and K.A. Deweerd, 2000. "Bioaugmentation for accelerated in situ anaerobic bioremediation," Environmental Science \& Technology 34:2254-2260.

Elsner, M., S.B. Haderlein, T. Kellerhals, S. Luzi, L. Awank, W. Angst, and R.P. Schwarzenbach, 2004. "Mechanisms and Products of Surface-Mediated Reductive Dehalogenation of Carbon Tetrachloride by Fe(II) on Goethite," Environ. Sci. Technol. 38:20582066.

EPA, 1989. Technical Guidance Document: Final Covers on Hazardous Waste Landfills and Surface Impoundments, EPA/530-SW-89-047, Washington, D.C.

EPA, 1998. Technical protocol for evaluating natural attenuation of chlorinated solvents in ground water. EPA/600/R-98/128, Washington, D.C. September 1998

EPA, 1999. Use of monitored natural attenuation at Superfund, RCRA Corrective Action, and Underground Storage Tank sites. OSWER Directive 9200.4-17P, Washington, D.C. April 21, 1999. 
EPA, 2000. J-Field Phytoremediation Project Field Events And Activities Through July 31, 2000 Aberdeen Proving Ground, Edgewood, Maryland. Prepared for U.S. EPA/ERTC by REAC Lockhead Martin. August 31, 2000.

EPA, 2002. "Mulch Biowall used to treat TCE-contaminated ground water," Technology News and Trends 1:1.

EPA, 2003a. Evapotranspiration Landfill Cover System Fact Sheet, EPA 542-F-03-015, Solid Waste and Emergency Response (5102G), Washington, D.C.

EPA. 2003b. Phytoremediation of Groundwater at Air Force Plant 4, Carswell, Texas. Innovative Technology Evaluation Report. EPA/540/R-03/506.

ESTCP, 2004. Natural Pressure Driven Passive Bioventing, ESTCP Cost and Performance Report, CU-9715, U. S. Department of Defense Environmental Security Technology Certification Program, Washington DC.

Fairbanks, H. A., 1896. "Notes on a Breathing Gas Well,” Science, 3:693.

Falta, R.W., 2003. "Modeling sub-grid-block-scale dense nonaqueous phase liquid (DNAPL) pool dissolution using a dual-domain approach," Water Resources Res. 39(12):1360-1367.

Farrell, J., M. Kason, N. Melitas, and T. Li, 2000. "Investigation of the long-term performance of zero-valent iron for reductive dechlorination of trichloroethylene," Envir, Sci. Technol. 34:514521

Ferraro, T., S. Blair, A. Rawa, and R.H. Kadlec, 2000. "Treatment wetlands for chlorinated alkenes: concept, benefits, and design process," in 7th International Conference on Wetland Systems for Water Pollution Control, Boca Raton, Florida, p. 1387.

Ferrey, M.L., R.T. Wilkin, R.G. Ford, and J.T. Wilson, 2004. "Nonbiological Removal of cisDichloroethylene and 1,1-Dichloroethylene in Aquifer Sediment Containing Magnetite," Environ. Sci. Technol. 38:1746-1752.

Fredrich, J.T., A.A. DiGiovanni, and K.L. Nagy, 2004. "In situ clay formation: Evaluation of a proposed new technology for stable containment barriers," Sandia National Lab release (abstract), SAND2004-0414.

FRTR, 2002. Evaluation of permeable reactive barrier performance. Prepared for the Federal Remediation Technologies Roundtable by the Tri-agency Permeable Reactive Barrier Initiative. Dec. 9, 2002. Available at: http://www.epa.gov/tio/download/rtdf/2-prbperformance_web.pdf

Fruchter, J.S., C.R. Cole, M.D. Williams, V.R. Vermeul, S.S. Teel, J.E. Amonette, J.E.

Szecsody, and S.B. Yabusaki, 1997. "Creation of a subsurface permeable reactive barrier using in situ redox manipulation," in Proceedings of International Containment Technology

Conference and Exhibition St. Petersburg, FL, Feb. 9-12, pp 704-710. 
Gavaskar, A. and E. Becvar, 2004. Sequestration of DNAPL Source with Vegetable Oil. ESTCP Project Information (01 July 2004), http://www.estcp.org/projects/cleanup/CU0319.cfm.

Gee, G.W., and S.W. Tyler (eds.), 1994. "Symposium: Recharge in arid and semiarid regions," Soil Science Society of America Journal, 58:5-72.

Gerhardson, B., 2002. "Biological substitutes for pesticides,” Trends Biotechnol. 20:338-343.

Gillham, R.W., 1993. Cleaning halogenated contaminants from groundwater. U.S. Patent No. 5,266,213. Nov. 30 .

Gillham, R.R. and S.F. O'Hannesin, 1992. "Metal-catalyzed abiotic degradation of halogenated organic compounds,"in IAH Conference: Modern Trends in Hydrogeology. Hamilton, Ontario, May 10-13. pp 94-103.

Gillham, R.W., and S.F. O’Hannesin, 1994. "Enhanced degradation of halogenated aliphatics by zero-valent iron," Ground Water, 32,(6):958-967.

Gilmore, T., B. B. Looney, N. Cutshall, D. Major, T. Wiedemeier, F. H. Chapelle, M. Truex, T. Early, M. Heitkamp, J. Waugh, D. Peterson, G. Wein, C. Bagwell, M. Ankeny, K. M. Vangleas, K. M. Adams, and C. H. Sink, 2006. Characterization and Monitoring of Natural Attenuation of Chlorinated Solvents in Ground Water: A Systems Approach. WSRC-STI-2006-00084 Rev. 1, U.S. Department of Energy Office of Environmental Management, available from the Office of Scientific and Technology Information Office, Oak Ridge, TN.

Gordon, M., N. Choe, J. Duffy, G. Ekuan, P. Heilman, I. Muiznieks, L. Newman, M. Raszaj, B. Shurtleff, S. Strand, and J. Wilmoth, 1997. "Phytoremediation of trichloroethylene with hybrid poplars," in Phytoremediation of Soil and Water Contaminants. American Chemical Society, Washington, DC.

Gorelick, S.M., 1988. "Incorporating assurance into groundwater quality management models," in Groundwater flow and quality modeling, D. Reidel Publ. Co. Boston, MA. Pp. 135-150.

Green, C. and A. Hoffnagle, 2004. Phytoremediation Field Studies Database For Chlorinated Solvents, Pesticides, Explosives, and Metals, U.S. Environmental Protection Agency Office of Superfund Remediation and Technology Innovation Washington, DC www.clu-in.org.

Haberl, R., S. Grego, G. Langergraber, R. Kadlec, A.-R. Cicalini, S. Dias, J. Novais, S. Aubert, A. Gerth, H.Thomas, and A., 2003. "Constructed Wetlands for the Treatment of Organic Pollutants," Journal of Soils and Sediments 3:109-124.

Hadacek, F., 2002. "Secondary metabolites as plant traits: Current assessment and future perspectives," CRC Critical Review Plant Science 21:273-322. 
Hakonson, T.E., 1986. Evaluation of geologic materials to limit biological intrusion into lowlevel radioactive waste disposal sites, LA-10286-MS, Los Alamos National Laboratory, Los Alamos, New Mexico.

Hakonson, T.E., J.L. Martinez, and G.C. White, 1982. "Disturbance of low-level waste burial site covers by pocket gophers," Health Physics, 42:868-871.

Hakonson, T.E., L.J. Lane, and E.P. Springer, 1992. "Biotic and abiotic processes," in Deserts as Dumps? The Disposal of Hazardous Materials in Arid Ecosystems, C.C. Reith and B.M. Thompson (eds.), Univ. of New Mexico Press, Albuquerque, New Mexico, pp. 101-146.

Hansen, E., 1991. Mid-rotation yields of biomass plantations in the north central United States, USDA, Forest Service, North Central Forest Experiment Station, Research Paper NC-309.

Hatfield, K. J. Cho, D. Bondehagen, M. Annable, L. Wood, and C. Enfield, 2004. "Passive flux meters for remedial performance," Abstract in A.R. Gavaskar and A.S.C. Chen (eds.) Remediation of Chlorinated and Recalcitrant Compounds - 2004. Proceedings of the Fourth International Conference on Remediation of Chlorinated and Recalcitrant Compounds, Monterey CA, May 24-27, 2004.

Hawkins, W., J. H. Rodgers Jr., W. B. Gillespie, Jr. , A. W. Dunn, P. B. Dorn and M. L. Cano, 1997. "Design and Construction of Wetlands for Aqueous Transfers and Transformations of Selected Metals," Ecotoxicology and Environmental Safety 36:238-248.

Hauser, V. L. and M. A. Shaw. 1994. "Climate effects on water movement through soil vegetative landfill covers.” Proc. 17th International Madison Waste Conference, Sept. 21-22, Dep. Engr. Professional Development, Univ. of Wisconsin, Madison, Wisc.

Hauser, V. L., B. L. Weand, and M. D. Gill, 2001. "Natural covers for landfills and buried waste.” Am. Soc. Civil Engineers, J. Environ. Engineering 127(9) 768-75.

Hauser, V. L. and D. M. Gimon, 2001. Vegetated landfill covers and phytostabilization-The potential for Evapotranspiration-based remediation at Air Force bases. 26 pp (also includes 109 base-specific sheets).

Hendrickson, E.R., J.A. Payne, R.M. Young, M.G. Starr, M.P. Perry, S.Fahnstock, D.E. Ellis, and R.C. Ebersole, 2002. "Molecular analysis of Dehalococcoides 16S Ribosomal DNA from chloroethene-contaminated sites throughout North America and Europe," Appl. and Envir. Microbiol., 68(2): 485-495.

Henn, K. and D. Waddill, 2004. "Implementation of a pilot in situ nano iron source remediation," Abstract 2E-11 in A.R. Gavaskar and A.S.C. Chen (eds.) Remediation of Chlorinated and Recalcitrant Compounds - 2004. Proceedings of the Fourth International Conference on Remediation of Chlorinated and Recalcitrant Compounds, Monterey, CA, May 2004. 
Henry, B.M., D.C. Downey, A. M. Love, A. Whallon, S. Moore, J.R. Gonzales, J.Gorden, and E.S.K. Becvar, 2004. "Performance validation of a mulch biowall for remediation of chlorinated ethenes," in A.R. Gavaskar and A.S.C. Chen (eds.) Remediation of Chlorinated and Recalcitrant Compounds - 2004. Proceedings of the Fourth International Conference on Remediation of Chlorinated and Recalcitrant Compounds. Monterey, CA May 24-27 2004.

Hiebert, R., R. Sharp, A. Cunningham, and G. James, 2001. "Development and demonstration of subsurface biofilm barriers using starved bacterial cultures," Soil Sediment \& Water, August.

Hillel, D., 1980. Fundamentals of Soil Physics. Academic Press, San Diego.

Holser, R.A., S.C. McCutcheon, and N.L. Wolfe, 1995. "Mass transfer effects on the dehalogenation of trichloroethene by iron/pyrite mixtures," Extended abstracts from the $209^{\text {th }}$ ACS National Meeting, Anaheim, CA 35(1): 788-791.

Houghton, J. T., G. J. Jenkins, and J. J. Ephraums, eds., 1990. Climate Change: The IPCC Scientific Assessment. Cambridge University Press, Cambridge, United Kingdom.

Huff, D.D., 2000. “A 35-year history of ${ }^{90}$ Sr releases from a radioactive-waste burial ground," Envir. Geology 39(11):1275-1285.

Hulme, M., and N. Sheard, 1999. Climate Change Scenarios for the USA, Climatic Research Unit: Norwich, UK, http://www.cru.uea.ac.uk/ mikeh/research/usa.pdf.

ITRC, 2003a. Technology Overview Using Case Studies of Alternative Landfill Technologies and Associated Regulatory Topics. Prepared by the Alternative Landfill Technologies Team, Interstate Technology \& Regulatory Council. March, 2003.

ITRC, 2003b. Technical and Regulatory Guidance for Design, Installation, and Monitoring of Alternative Final Landfill Covers. Prepared by the Alternative Landfill Technologies Team, Interstate Technology \& Regulatory Council. December, 2003.

ITRC, 2003c. Technical and Regulatory Guidance for Constructed Wetlands. Interstate Technology \& Regulatory Council. December, 2003.

ITRC, 2005. Technical and Regulatory Guidance for In Situ Chemical Oxidation of Contaminated Soils and Groundwater, $2^{\text {nd }}$ edition. January, 2005.

Jafvert, C.T., and N.L. Wolfe, 1987. "Degradation of selected halogenated ethanes in anoxic sediment-water systems," Environ. Toxicol. Chem 6:827-837.

Kao, C. M. and R. C. Borden, 1997. "Enhanced Biodegradation of BTEX in a Nutrient BriquetPeat Barrier System,” Journal of Environmental Engineering, ASCE, 123(1):18-24.

Kao, C.M. and S.E Lei, 2000. "Using a peat biobarrier to remediate PCE/TCE contaminated aquifers," Water Resources 34:835-845. 
Kassenga, G., J.H. Pardue, S. Blair and T. Ferraro, 2003. "Treatment of chlorinated VOCs using treatment wetlands," Ecological Engineering 19(5):305-323.

Kassenga, G., J.H. Pardue, W.A. Moe, and K. Bowman, 2004. "Hydrogen thresholds as indicators of dehalorespiration in constructed treatment wetlands," Environ. Sci. Technol. 38(4):1024-1030.

Kavanaugh, M., 2004. Diagnostic tools for performance evaluation of innovative in-situ remediation technologies a chlorinated solvent-contaminated sites. Project summary for ESTCP project CU-0318, Environmental Security Technology Certification Program.

Kennedy, L.G., J. Everett, J.Haley, L.H. Lhadj, P. Haas, and J. Gonzales, 2004a. "Biogeochemical Reductive Dechlorination," Proceedings of the AFCEE Technology Transfer Workshop. San Antonio, TX. August 16-19, 2004.

Kennedy, L.G., J.W. Everett, and J. Gonzales, 2004b. Biogeochemical treatment for the engineered and natural attenuation of chlorinated solvents. http://www.afcee.brooks.af.mil/products/techtrans/bioremediation/downloads/GeomicPaper128. pdf.

Khire, M.V., C.H. Benson, and P.J. Bossher, 2000. "Capillary barriers: design variables and water balance," Journal of Geotechnical and Geoenvironmental Engineering, 126:695-708.

Kim,W.H., and D.E. Daniel, 1992. "Effects of freezing on the hydraulic conductivity of compacted clay," Journal of Geotechnical Engineering 18:1083-1097.

Kim, D. M.J. Park, S.C. Koh, J.S. So, and E. Kim, 2002. "Three separate pathways for the initial oxidation of limonene, biphenyl, and phenol by Rhodocccus sp strain T-104," J. Microbiol. 40:86-89.

Koenigsberg, S.S., A. Sandefur, K.A. Lapus, and G. Pasrich, 2002. "Facilitated desorption and incomplete dechlorination: observations from 350 applications of HRC," in the Proceedings of the Third International Conference on Remediation of Chlorinated and Recalcitrant Compounds, Monterey,CA, May 2002.

Komlos, J., A.B. Cunningham, A.K. Camper, and R.R. Sharp, 2004. "Biofilm barriers to contain and degrade dissolved trichloroethylene," Environmental Progress 23(1):69-77.

Korte, N.E., L. Liang, and J. Clausen, 1995. "The use of palladized iron as a means of treating chlorinated contaminants," in Emerging Technologies in Hazardous Waste Management VII, Extended abstracts for the special symposium, Atlanta, GA, pp 42-45.

Kramer, P.J. and T.T.Kozlowski, 1979. Physiology of Woody Plants. Academic Press, New York. 
Landeen, D.S., 1994. "The influence of small-mammal burrowing activity on water storage at the Hanford Site," in G.W. Gee and N.R. Wing (eds.), In-Situ Remediation: Scientific Basis for Current and Future Technologies, Battelle Press, Richland, Washington, pp. 523-543.

Ledley, T. S., E. T. Sundquist, S. E. Schwartz, D. K. Hall, J. D. Fellows, and T. L. Killeen, 1999. "Climate Change and Greenhouse Gases," EOS, Transactions of the American Geophysical Union, 80:453.

Lee, W. and Batchelor, B., 2002a, "Abiotic reductive dechlorination of chlorinated ethylenes by iron-bearing soil minerals; 1 - pyrite and magnetite," Environmental Science and Technology 36:5147-5154.

Lee, W. and Batchelor, B., 2002b, "Abiotic reductive dechlorination of chlorinated ethylenes by iron-bearing soil minerals; 2 - green rust," Environmental Science and Technology 36:53485354.

Lee, W. and Batchelor, B., 2003, "Reductive capacity of natural reductants," Environmental Science and Technology 37:535-541.

Lee, W. and B. Batchelor, 2004. "Abiotic reductive dechlorination of chlorinated ethylenes by iron bearing phyllosilicates," Chemosphere. 56(10):999-1009.

Lehman, R. W., F. D. Mooney, J. H Rodgers, Jr., J. B. Gladden, C. Murray-Gulde, and J. F. Bell, 2002. Wetlands for Industrial Wastewater Treatment at the Savannah River Site. Weston Technical Paper 0202.

Li, Z. and R.S. Bowman, 1998. "Sorption of perchloroethylene by surfactant-modified zeolite as controlled by surfactant loading," Environ. Sci. Technol. 32:2278-2282.

Liang, L, A.B. Sullivan, O.R. West, G.R. Moline, and W. Kamolpornwijit, 2003. "Predicting the precipitation of mineral phases in permeable reactive barriers," Jour. of Environ. Eng. Sci. 20(6):635-653.

Ligotke, M.W., 1994. "Control of eolian soil erosion from waste-site surface barriers," pp 545-559, in G.W. Gee and N.R.Wing (eds.), In-Situ Remediation: Scientific Basis for Current and Future Technologies, Battelle Press, Richland, Washington.

Link, S.O., W.J. Waugh, and J.L. Downs, 1994. "The role of plants on isolation barrier systems," in G.W. Gee and N.R. Wing (eds.), In-Situ Remediation: Scientific Basis for Current and Future Technologies, Battelle Press, Columbus, Ohio.

Liu LB, Flora JRV, Aelion CM., 2004. "Theoretical analysis of the influence of process parameters on the use of an encapsulated phosphate buffer to control $\mathrm{pH}$ in a soil column," Journal of Environmental Science and Health Part A-Toxic/Hazardous Substances \& Environmental Engineering 39(1):35-59. 
Long, J.D., D.D. Huff, and A.A. Naudts, 1997. "A case study - using multi-grout barrier to control ${ }^{90} \mathrm{Sr}$ release at ORNL," in the Conference Proceedings, International Containment Technology Conference, February 9-12, 1997, St. Petersburg, FL, USA.

Looney, B. B. (ed.), 2002. Technical Targets - A Tool to Support Strategic Planning in the Subsurface Contaminants Focus Area. WSRC-RP-2002-00077, U.S. Department of Energy Office of Environmental Management, available from the Office of Scientific and Technical Information, Oak Ridge TN.

Looney, B. B., M. A. Phifer and B. D. Riha, 2005. Enhanced Attenuation of Chlorinated Solvents: Deployment Options for Partitioning Barriers in the Vadose Zone and Shallow Groundwater, WSRC-MS-2005-00182, DOE Office of Scientific and Technical Information, Oak Ridge TN. (www.osti.gov).

Looney, B. B., F. H. Chapelle, T. O. Early, K. M. Vangelas, K. Adams, and C. H. Sink, 2006. Mass Balance: A Key to Advancing Monitored and Enhanced Attenuation for Chlorinated Solvents. WSRC-STI-2006-0000082, Rev. 0, U.S. Department of Energy Office of Environmental Management, available from the Office of Scientific and Technical Information, Oak Ridge, TN.

Lorah, M.M., L.D. Olsen, B.L. Smith, M.A. Johnson, and W.B. Fleck, 1997. Natural attenuation of chlorinated volatile organic compounds in a freshwater tidal wetland, Aberdeen Proving Ground, Maryland, U.S. Geological Survey Water-Resources Investigations Report $97-$ 4171, $95 \mathrm{p}$.

Lorah M. and L. Olsen, 1999a. "Degradation of 1,1,2,2-tetrachloroethane in a freshwater tidal wetland: field and laboratory evidence," Environ. Sci. \& Technol 33(2):227-234.

Lorah M. and L. Olsen, 1999b. "Natural attenuation of chlorinated volatile organic compounds in a freshwater tidal wetland: field evidence of anaerobic biodegradation," Water Resources Res. 35:3811-3827.

Lorah, M.M., L.D. Olsen, D.G. Capone, and J.E. Baker, 2001. "Biodegradation of trichloroethylene and its anaerobic daughter products in freshwater wetland sediments," Bioremediation Journal 5(2):101-118.

Lorah, M.M., E.J.P. Jones, S. Husain, M.A. Voytek, and M.M. Mount, 2003a. "Biostimulation and bioaugmentation to enhance degradation of chlorinated solvents in wetland sediments," in In Situ and On-Site Bioremediation, Seventh International Symposium, June 2-5, Orlando, Florida.

Lorah, M.M., M.A. Voytek, J.D. Kirshtein, and E.J.P. Jones, 2003b. Anaerobic degradation of 1,1,2,2-tetrachloroethane and association with microbial communities in a freshwater tidal wetland, Aberdeen Proving Ground, Maryland: Laboratory experiments and comparisons to field data, U.S. Geological Survey Water-Resources Investigations Report 02-4157, 64 p. 
Lorah, M.M., and M.A. Voytek, 2004. "Degradation of 1,1,2,2-tetrachloroethane and accumulation of vinyl chloride in wetland sediment microcosms and in situ porewater: Biogeochemical controls and associations with microbial communities," Journal of Contaminant Hydrology 70:117-145.

Lorah, M.M., E.J.P. Jones, M.A. Voytek, J.H. Pardue, D.J. Green, and J. Wrobel, 2004. "Bioaugmentation of engineered peat mixtures for enhanced bioremediation of chlorinated alkanes, alkenes, and methanes," in Fourth International Conference on Remediation of Chlorinated and Recalcitrant Compounds, May 24-27, Monterey, California, Battelle.

Lunn, S.R.D. and B.H. Kueper, 1997. "Removal of pooled dense, nonaqueous phase liquid from saturated porous media using upward gradient alcohol floods," Water Resources Res. 33(10):2207-2219.

Macek, T., M. Machová, and J. Káš, 2000. "Exploitation of plants for the removal of organics in environmental remediation," Biotechnology Advances 18:23-34.

Mahlman, J. D., 1997. "Uncertainties in projections of human-caused climate warming," Science 278:1416-1417.

Majcher, E.H., M.M. Lorah, M.A. Voytek, D.J. Phelan, and J. Wrobel, 2003. "Characterization of ground-water seeps and implications for design of enhanced bioremediation of chlorinated solvents," in Seventh International In Situ and On-Site Bioremediation Symposium, June 2-5, Orlando, Florida.

Majcher, E.H., M.M. Lorah, M.A. Voytek, D.J. Phelan, J. Wrobel, and D. Green, 2004. "Influences of preferential flow on microbially mediated reductive dechlorination of chlorinated solvents," in Proceedings of Fourth International Conference on Remediation of Chlorinated and Recalcitrant Compounds, May 24-27, Monterey, California.

Major, D.W., M.L. McMaster, E.E. Cox, E.A. Edwards, S.M. Dworatzek, E.R. Hendrickson, M.G. Starr, J.A. Payne, and L.W. Buonamici, 2002. "Field demonstration of successful bioaugmentation to achieve dechlorination of tetrachloroethene to ethane," Environ. Sci. Technol. 36(23):5106-5116.

Mastin, B.J., R.M. Sherrard, J.H. Rodgers, and Y.T. Shah, 2001. "Hybid caviatation/constructed wetland reactors for treatment of chlorinated and non-chlorinated organics," Eng. Life Sci 1:97105.

Matthews, D.W., J. Massmann, and S.E. Strand, 2003. "Influence of aquifer properties on phytoremediation effectiveness," Ground Water 41:41-47.

Maymo-Gatell, X., Y.T. Chien, J.M. Gossett, and S.H. Zinder, 1997. "Isolation of a bacterium that reductively dechlorinates tetrachloroethene to ethene," Science, 276:1568-1571. 
McDonald, E.V., F.B. Pierson, G.N. Flerchinger, and L.D. McFadden, 1996. "Application of a process-based soil-water balance model to evaluate the influence of Late Quaternary climate change on soil-water movement in calcic soils," Geoderma 74:167-192.

McFadden, L.D., E.V. McDonald, S.G. Wells, K. Anderson, J. Quade, and S.L. Forman, 1998. "The vesicular layer of desert soils: Genesis and relationship to climate change and desert pavements based on numerical modeling, carbonate translocation behavior, and stable isotope and optical dating studies," Geomorphology 101-145.

Melchior, S., 1997. "In situ studies on the performance of landfill caps." in Proceedings of the International Containment Technology Conference, St. Petersburg, Florida, pp. 365-373..

Melchior, S., K. Berger, B. Vielhaber, and G. Miehlich, 1994. "Multilayer landfill covers: Field data on the water balance and liner performance," pp. 411-425, in G.W. Gee and N.R. Wing (eds.), In-Situ Remediation: Scientific Basis for Current and Future Technologies, Battelle Press, Columbus, Ohio.

Miller R.,1980. "Freezing phenomena in soils," in: D Hillel, (ed.), Applications in Soil Physic. Academic Press, Inc., San Diego, California, pp 254-259.

Moore, G.K. and J.L. Clausen, 1997. Analysis and interpretation of water levels in observation wells at the Paducah Gaseous Diffusion Plant, 1990-1997. KY/EM-210, Lockheed Martin Energy Systems.

Morgan, R.P.C., and R.J. Rickson (eds.), 1995. Slope stabilization and erosion control: A bioengineering approach, Chapman and Hall, London.

Moridis, G., J. Apps, P. Persoff, L. Myer, S. Muller, K. Preuss, and P. Yen, 1996. "A field test of a waste containment technology using a new generation of injectable barrier liquids," SPECTRUM '96 International Conference, Seattle WA, August 18-23, 1996; 16 pp.

Muftikian, R., Q. Fernando, and N. Korte, 1995. "A method for the rapid dechlorination of low molecular weight chlorinated hydrocarbons in water," Water Res. 29:2434.

Nagy, K. and J. Fredrich, 2000. "In-situ clay formation: A new technology for stable containment barriers," Abstract for Project CU-1093, SERDP.

NATO/CCMS, 2003. Annual Report NATO/CCMS Pilot Study Evaluation of Demonstrated and Emerging Technologies for the Treatment and Clean Up of Contaminated Land and Groundwater (Phase III). Rome, Italy May 5-10, 2002. http://www.cluin.org/download/partner/2002_annual_report.pdf.

NAVFAC, 2004. Naval Weapons Station Charleston, SC: An Innovative Technology Test Site, NWS Charleston, SC, Web Page, 2004. http://www.ert2.org/charleston/toolsB.asp. 
Negri, M. C. R.R. Hinchman, and J. Quinn, 2000. Deployment of phytoremediation at the 317/319 area at Argonne National Laboratory - East, ANL/ES/CP-101048.

Newell, C.J., C.E. Aziz, and G.A. Cox, 2001a. "Novel Method to Enhance Chlorinated Solvent Biodegradation by the Use of Barriers," 2001 Int. Containment \& Rem. Technology Conf., June 10-13, 2001, Orlando, Florida.

Newell, C.J., C.E. Aziz, P.E. Haas, J. B. Hughes, and T.A. Khan, 2001b. "Two Novel Methods for Enhancing Source Zone Bioremediation: Direct Hydrogen Addition and Electron Acceptor Diversion", Proceedings of the Battelle Sixth International In Situ and On-Site. Bioremediation Symposium, June 4-7, 2001. San Diego, CA, Battelle Press, Columbus, Ohio.

Newman, L.A., S.E. Strand, N. Choe, J. Duffy, G. Ekuan, M. Ruszaj, B.P. Shurtleff, J. Wilmoth, P. Heilman, and M.P. Gordon, 1997. "Uptake and biotransformation of trichloroethylene by hybrid poplars," Environ. Sci. Technol 31:1062-1067.

Newman, L.A., and C. R. Reynolds, 2004. "Phytodegradation of organic compounds," Current Opinion in Biotechnology 15:225-230.

NFESC, 1999. Infiltration Control Landfill Cover Demonstration at Marine Base, Hawaii. Technical Report TR-2108-ENV, Naval Facilities Engineering Service Center, Port Hueneme, California.

Nzengung, V.A. and P. Jeffers, 2001. "Sequestration, phytoreduction, and phyooxidation of halogenated orgaic chemicals by aquatic and terrestrial plants," International J. of Phytoremediation 3:12-40.

Nzengung, V.A., and S. Ramaley, 2001. "Coupling Natural Attenuation and Phytoremediation to Clean Up a Shallow Chlorinated Solvent Plume at the Former Naval Training Center in Orlando, Florida," in Proceedings of the 2001 International Containment \& Remediation Technology Conference and Exhibition, June 10-13, 2001, Orlando, FL, DOE/EM-0620, Institute for International Cooperative Environmental Research, Florida State University.

O’Donnell, S.A., Rumer, R. R. and J. K. Mitchell, 1995. Assessment of Barrier Containment Technologies: A Comprehensive Treatment for Environmental Remediation Applications, Publication No. PB96-180583, Proceedings of the International Containment Technology Workshop, Baltimore, MD, August 29-31, 1995. A publication prepared by the U.S. DOE, the U. S. EPA and the Dupont Company; available from the National Technical Information Service, Springfield VA.

O’Donnell, E., 1997. “Controlling Water Infiltration through Radioactive Waste and Landfill Covers-A Field Demonstration at Beltsville, MD," in: Reynolds, T., and R. Morris (eds.), Landfill Capping in the Semi-Arid West: Problems, Perspectives, and Solutions. ESRF-019, Environmental Science and Research Foundation, Idaho Falls, ID. 
O'Hannesin, S.F. and R.W. Gillham, 1998. "Long-term performance of an in situ 'iron wall' for remediation of VOCs," Ground Water 36(1):164-170.

O’Hara, S., T. Krug, D. Major, J. Quinn, C. Geiger, C. Clausen, and S. Yoon, 2004.

"Performance evaluation of dehalogenation of DNAPLs using emulsified zero valent iron," Paper 2E-05 in, A.R. Gavaskar and A.S.C. Chen (eds.) Remediation of Chlorinated and Recalcitrant Compounds - 2004. Proceedings of the Fourth International Conference on Remediation of Chlorinated and Recalcitrant Compounds, Monterey, CA, May 2004.

Orth, R. G. and D.E. McKenzie, 1995. "Reductive dechlorination of chlorinate alkanes and alkenes by iron metal and metal mixtures," Emerging Technologies in Hazardous Waste Management VII, Extended abstracts for the special symposium, Atlanta, GA, p. 50.

Orth, W.S. and R.W. Gillham, 1996. "Dechlorination of trichloroethene in aqueous solution using Fe(0)," Envir. Sci. Technol. 30(1):66-71.

Pardue, J.H., C.R. Yuen, L. Martino, D. McInnis and J. Wrobel, 2000a. "Enhanced natural attenuation of chlorinated solvents in upland and adjacent wetland groundwater," International Conference on Remediation of Chlorinated and Recalcitrant Compounds, Platform Presentation, Monterey, CA.

Pardue, J.H., G. R. Kassenga, and W.S. Shin, 2000b. "Design approaches for chlorinated VOC treatment wetlands," in J.L. Means and R.E. Hinchee (eds.), Wetlands and Remediation, An International Conference, Salt Lake City, Utah, November 1999: Battelle Press, pp. 301-308.

Pardue, J.H., 2002. "Remediating chlorinated solvents in wetlands: active processes or a natural approach?" (Keynote Address) Wetlands and Remediation II, Second International Conference, Burlington, Vermont, September 5-6, 2001: Battelle Press.

Park, E. and J.C. Parker, 2004. "Effect of partial flow reductions on DNAPL source dissolution rate," Abstract for fourth international conference, Remediation of Chlorinated and Recalcitrant Compounds, Monterey CA, May 24-27, 2004.

Parker, B.L., D.B. McWhorter, and J.A. Cherry, 1997. "Diffusive loss of non-aqueous phase organic solvents from idealized fracture networks in geologic media," Ground Water 35(6):1077-1088.

Parker, J.C. and E. Park, 2004. "Modeling field-scale dense nonaqueous phase liquid dissolution kinetics in heterogeneous aquifers," Waste Resources Res. 40(5): 12 pp.

Parson Corp. 2004. Principles and Practices of Enhanced Anaerobic Bioremediation of Chlorinated Solvents, Report prepared for Air Force Center for Environmental Excellence Brooks City-Base, Texas, Naval Facilities Engineering Service Center Port Hueneme, California, and Environmental Security Technology Certification Program Arlington, Virginia. August 2004. http://www.afcee.brooks.af.mil/products/techtrans/Bioremediation/downloads/PrinciplesandPractices.pdf. 
Phillips, D.H., B.Gu, D.B.Watson, Y.Roh, L.Liang, and S.Y.Lee, 2000. "Performance evaluation of a zerovalent iron reactive barrier: Mineralogical characteristics," Env. Sci Technol. 34(1):4169-4176.

Pirkle, R. J., D. E. Wyatt, V. Price and B. B. Looney, 1992. "Barometric Pumping, the Connection Between the Vadose Zone and Atmosphere," Proceedings, Focus on Eastern Regional Groundwater Issues, 1992.

Piwoni, M.D. and J.W. Keeley, 1990. Basic concepts of contaminant sorption at hazardous waste sites. EPA/540/4-90/053, Environmental Protection Agency, Washington, D.C., October 1990.

Pro2Serve, 2003a. Five-year Evaluation Report for the X-740 Phytoremediation Project at the Portsmouth Gaseous Diffusion Plant, Piketon, Ohio. DOE/OR/11-3135\&D1. Prepared by Pro2Serve Technical Solutions.

Pro2Serve, 2003b. Addendum to the Five-Year Evaluation Report for the X-740 Phytoremediation Project at the Portsmouth Gaseous Diffusion Plant, Piketon, Ohio. DOE/OR/11-3135\&D1/A1. Prepared by Pro2Serve Technical Solutions.

Punshon, T., G. Mills, and D.C. Adriano, 2003. Enhanced Monitored Natural Attenuation: Plant Assisted Remediation of the C-Area Burning Rubble Pits (CBRP) - Twin Lakes Wetland Ecosystem. ERD-EN-2003-0111. Westinghouse Savannah River Company, Aiken. SC.

Rao, P.S.C., 2001. “DNAPL Source Zone Reduction: Utility or Futility?” American Geophysical Union, Fall meeting suppl., Abstract H32G-01 in EOS Transactions, American Geophysical Union, 82(47) pg. F444.

Reinhard, M., G.P. Curtis, and M.R. Kriegman, 1990. Abiotic reductive dechlorination of carbon tetrachloride and hexachloroethane by environmental reductants: Project Summary, EPA/600/S2-90/040, September 1990.

Reith, C.C., and B.M. Thompson (eds.), 1992. Deserts as dumps? The disposal of hazardous materials in arid ecosystems, University of New Mexico Press, Albuquerque, New Mexico.

Reynolds, G.W., J.T. Hoff, and R.W. Gillham, 1990. "Sampling bias caused by materials used to monitor halocarbons in groundwater," Environ. Sci. Technol. 24(1):135-142.

Riha, B. D., J. Rossabi and B. B. Looney, 1994. "VOC Removal Rates Using Barometric Pumping," EOS Transactions, American Geophysical Union 1994 Spring Meeting, 75(16):151.

Riha, B.D., J. Rossabi, and W.K. Hyde, 2000. Metallurgical Laboratory (MetLab) treatability study: An analysis of passive soil vapor extraction wells (PSVE), June 2000 Update(U). WSRCTR-2000-00182; Westinghouse Savannah River Co.

Robertson, W.D., D.W. Blowes, C.J. Ptacek, and J.A. Cherry, 2000. “Long-Term 
Performance of In Situ Reactive Barriers for Nitrate Remediation," Ground Water 38(5):689695.

Rohay, V. J. and R. J. Cameron, 1992. "Field Measurement of Natural Soil Gas Venting Cycles in Boreholes at the Hanford Site, Washington," EOS Transactions, American Geophysical Union 1992 Spring Meeting, 73(43):238.

Rossabi, J., B. B. Looney, C. A. Eddy-Dilek, B. D. Riha and V. J. Rohay, 1994. "Passive Remediation of Chlorinated Volatile Compounds Using Barometric Pumping," Proceedings of Water and Environment Federations: Innovative Solutions for Contaminated Site Management, Miami FL, March 6-9.

Rossabi, J., 1999. The Influence of Atmospheric Pressure Variation on Subsurface Soil Gas and the Implications for Environmental Characterization and Remediation, $\mathrm{PhD}$ Dissertation, Environmental Engineering and Science, Clemson University, Clemson SC.

Rowland, M. and K. Golden, 2003. "Microbial benefits from in situ oxidation conceptual model," Poster at Sixth Battelle Bio conference, Orlando, FL.

http://www.thirdlegconsultants.com/ers/2003_poster.html

RPM, 2004. "Sequential Passive Cleanup Processes Lower Costs and Preserve Natural Resources, Naval Weapons Station Charleston," RPM NEWS Remedial Project Manager News Published By NFESC Spring 2004. http://enviro.nfesc.navy.mil/erb/erb_a/outreach/newsltr/rpmnews/2004sp.pdf.

Sachin D.S. and C.L. Braun, 2004. Demonstration-Site Development and Phytoremediation Processes Associated With Trichloroethene (TCE) in Ground Water, Naval Air Station-Joint Reserve Base Carswell Field, Fort Worth, Texas. USGS Fact Sheet. http://pubs.usgs.gov/fs/2004/3087/pdf/FS_2004-3087.pdf.

Sale, T.C. and D.B. McWhorter, 2001. "Steady state mass transfer from single-component dense nonaqueous phase liquids in uniform flow fields," Water Resources Res. 37(2):393-404.

Schuyler, J.R., 1996. Decision analysis in projects, Project Management Institute, Upper Darby PA.

Shang, T.Q., S.L. Doty, A.M. Wilson, W.N. Howald, and M.P. Gordon, 2001.

"Trichloroethylene oxidative metabolism in plants: the trichloroethanol pathway," Phytochem. 58:1055-1065.

Siegrist, R.L., K.S. Lowe, L.D. Murdock, W.W. Slack, and T.C. Houk, 1998. X-231A demonstration of in situ remediation of DNAPL compounds in low permeability media by soil fracturing with thermally enhanced mass recovery or reactive barrier destruction. ORNL/TM13534, Oak Ridge National Laboratory, Oak Ridge TN. 
Singer, A. C., D. E. Crowley and I. P. Thompson, 2003. "Secondary plant metabolites in phytoremediation and biotransformation," TRENDS in Biotechnology 21:123-130.

Sivavec, T.M. and D.P. Horney, 1995. "Reductive dechlorination of chlorinated ethenes by iron metal," Presented at the $209^{\text {th }}$ ACS National Meeting, Anaheim CA, April 2-6.

Sivavec, T.M., P.D. Mackenzie, D.P. Horney, and S.S. Baghel, 1997. "Redox-active media for permeable reactive barriers," Proceedings of the 1997 International Containment Conference and Exhibition, St. Petersburg, FL.

Soga, K., J.W.E. Page, and T.H. Illangasekare, 2004. "A review of NAPL source zone remediation efficiency and the mass flux approach," J. of Hazardous Mat. 110:13-27.

Solomon, D.K., G.K. Moore, L.E. Toran, R.B. Dreier, and W.M. McMaster, 1992. Status report: A hydrologic framework for the Oak Ridge Reservation. ORNL/TM-12026 ESD-3815, Oak Ridge National Laboratory.

Starr, R.C. and J.A. Cherry, 1994. "In situ remediation of contaminated ground water: The funnel-and-gate system," Ground Water 32(3): 465-476.

Stormont, J., and C. Anderson, 1998. "Method to estimate water storage capacity of capillary barriers," Journal of Geotechnical and Geoenvironmental Engineering, 124:297-302.

Susarla, S.,V.F. Medina, S.C. McCutcheon, 2002. "Phytoremediation: An ecological solution to organic chemical contamination," Ecological Engineering 18:647-658.

Suter, G.W., II, R.J. Luxmoore, and E.D. Smith, 1993. "Compacted soil barriers at abandoned landfill sites are likely to fail in the long term," J. Environ. Qual., pp. 217-226.

Sweeny, K.H., 1981a. The reductive treatment of industrial wastewaters: I. Process description. In G.F. Bennett (ed.), American Institute of Chemical Engineers, Symposium Series, Water1980, 77(209): 67-71.

Sweeny, K.H., 1981b. The reductive treatment of industrial wastewaters: II. Process description. In G.F. Bennett (ed.), American Institute of Chemical Engineers, Symposium Series, Water-1980, 77(209):72-88.

Teutsch, G., 2001. "Mass Flux Measurements at Field Scale: Principles and Applications," American Geophysical Union, Fall Meeting suppl., Abstract H32G-02 in EOS. Trans. AGU, 82(47) pg. F444.

Tiedje, J.M., R.K. Colwell, Y.L. Grossman, R. Hodson, R.E. Lenski, R.N. Mack, and P.J. Regal, 1989. "The planned introduction of genetically engineered organisms: ecological considerations and recommendations," Ecology 70:298-315. 
Thompson, R.S., S.W. Hostetler, P.J. Bartlein, and K.H. Anderson, 1998. A Strategy for Assessing Potential Future Changes in Climate, Hydrology, and Vegetation in the Western United States, U.S. Geological Circular 1153.

Van Den Bos, A., 2002. Phytoremediation of Volatile Organic Compounds in Groundwater: Case Studies in Plume Control. USEPA, Technology Innovation Office, Washington, D.C.

Vangelas, K.M., 2006. Summary of Identification of Regulatory Acceptability of Enhanced Attenuation Categories. U.S. Department of Energy Office of Environmental Management, available from the Office of Scientific and Technical Information.

Velicer, G.J., 1999. "Pleiotropic effects of adaptation to a single carbon source for growth on alternative substrates," Appl. Environ. Microbiol. 65:264-269.

Walters, W.H., and R.L. Skaggs, 1986. The Protection of Uranium Mill Tailings Impoundments Against Overland Erosion. NUREG/CR-4323, U.S. Nuclear Regulatory Commission, Washington, D.C.

Wang, T.C., and C.K. Tan, 1990. "Reduction of halogenated hydrocarbons with magnesium hydrolysis process,” Bull. Environ. Contam. Toxic. 45:149-156.

Ward, A., and G. Gee, 1997. "Performance evaluation of a field-scale surface barrier," J. Environ. Qual., 26:694-705.

Waring, C. and J. Taylor, 2001. "A new technique for building in situ sub-surface hydrologic barriers: NBT," Abstract for the 2001 International Containment and Remediation Technology Conference and Exhibition, Orlando, FL, June 10-13, 2001, 3 pp.

Waugh, W.J., 2004. "Designing Sustainable Covers for Uranium Mill Tailings," in Proceedings $16^{\text {th }}$ High Altitude Revegetation Workshop, Colorado State University, Fort Collins, CO.

Weeks, E. P., 1978. Field Determination of Vertical Permeability to Air in the Unsaturated Zone, U. S. Geological Survey Professional Paper 1051. U. S. Geological Survey, Reston VA.

Weise, E., 2005. "Biotechnology appears to be withering as a food source," USA Today, February 3, 2005, pg. 8D.

West, O.R., R.L. Siegrist, T.C. Houk, L. Liang, S.Y. Lee, A. Laase, D.A. Pickering, M.J. Dickey, X. Yin, and B. Gu, 1997. The X-625 Treatment Facility: Assessment of reactive barrier technology at PORTS. POEF-LMES-174, Piketon OH.

Wiedemeier, T.H., H.S. Rifai, C.J. Newell, and J.T. Wilson, 1999. Natural Attenuation of Fuel Hydrocarbons and Chlorinated Solvents, John Wiley and Sons, New York, New York.

Wilson RD, Mackay DM, 2002. "Diffusive oxygen emitters for enhancement of aerobic in situ treatment," Ground Water Monitoring and Remediation 22(2):88-98. 
Winograd, I.J., 1981. "Radioactive waste storage in thick unsaturated zones," Science, 212:1457-1464.

Winsor, T.F., and F.W. Whicker, 1980. "Pocket gophers and redistribution of plutonium in soil," Health Physics, 39:257-262.

Wood, A.L., 2003. Impacts of DNAPL source zone treatment: Experimental and modeling assessment of benefits of partial source removal. Project summary for SERDP project CU-1295, Strategic Environmental Research and Development Program.

Yaws, C.L. (ed.), 1999. Chemical Properties Handbook. McGraw-Hill Publishers.

Yu SH, Semprini L, 2002. "Comparison of trichloroethylene reductive dehalogenation by microbial communities stimulated on silicon-based organic compounds as slow-release anaerobic substrates," Water Research 36(20):4985-4996.

Zachary, S. P., 1993. "In Situ Active/Passive Bioreclaimation of Vadose Zone Soils Contaminated with Gasoline and Waste Oil Using Soil Vapor Extraction/Bioventing," Proceedings of Petroleum Hydrocarbons and Organic Chemicals in Groundwater: Prevention, Detection, and Restoration, Houston TX, Nov 10-12.

Zwick, T. R., R. E. Hinchee, R. Hoeppel, C. Kyburg and L. Bowling, 1994. "Passive Venting Driven By Natural Air Exchange," Proceedings of Petroleum Hydrocarbons and Organic Chemicals in Groundwater, Houston TX, Nov 2-4. 


\section{APPENDIX A: SUPPLEMENTAL MATERIAL}

Figure A-1. Slow diffusion of DNAPL contamination into the rock matrix.

Figure A-2. Seasonal changes in the potentiometric surface for the Regional Gravel

Aquifer at PGDP. The two major contaminant plumes at the site are overlayed on

the figures. From Moore and Claussen (1997)

Figure A-3. Concept of Diffusion Barriers using Vegetable Oils

Figure A-4. Partitioning Barriers in the Vadose Zone

Figure A-5. Partitioning Barriers Applied to the Vadose Zone after Source Treatment

Figure A-6. Simplified Diagram of GeoSiphon Concept as Evaluated for Kansas City

Plant a) shows baseline conditions and b) illustrates layout for hydraulic control....

Figure A-7. Control Well System to Reduce Flow of Groundwater. Controls reduce the

hydraulic driving force for plume migration and contaminant loading. Various

designs for the well control system have been evaluated.

Figure A-8. Simplified Schematic Diagrams of Options Developed for the Waste

Management Unit at the DOE Ashtabula Closure Plant a) baseline conditions, b)

cross section with controls, c) site configuration options.

Figure A-9. Diagram of Engineered Phytotranspiration System as Implemented by the

DOE Portsmouth Site

Figure A-10. Baroball Passive Vapor Extraction System

Figure A-11. Microblower Used to Enhance Soil Vapor Extraction

(http://www.srs.gov/general/enviro/erd/technology/Pages/h10p.html

Figure A-12. Different Configurations of the Funnel and Gate Technology. (a). Lowry

AFB, CO. (b). NAS Moffet Field, CA. (c). Dover AFB, DE

Figure A-13. Concept of a Reactive Barrier Using Emulsified Oil 


\section{SUPPLEMENT TO SECTION 2.2.3}

Page 102 of 147

The environmental setting exerts a significant influence over the types of enhancements that can be utilized and how they might be deployed. Enhancements should be tailored to both current and future environmental conditions. Evaluations of future settings are needed to develop scenarios for performance assessment. One major constraint is climate. For example, humid sites that are typically located in the eastern US tend to have greater rainfall, relatively shallow depth to groundwater, and generally short flow paths from sources to points of discharge to the surface in comparison to what is observed in more arid sites of the western US. These distinctions suggest that enhancements such as groundwater diversion structures and various source containment options may be easier and less costly to implement (i.e., shallower deployment) in the eastern regions of the US. However, the more extensive vadose zone thickness commonly found in the arid western US could favor deployment of a cost effective barometrically enhanced vapor extraction system that may not be feasible in many sites in the humid eastern US.

A second major consideration related to environmental setting involves characteristics of the geologic media for source areas and aquifers containing contaminant plumes. Geologic media can range from nearly homogeneous unconsolidated sediments (from fine- to coarse-grain) to fractured bedrock. Unconsolidated media typically is somewhat heterogeneous and contains preferential flow paths characterized by relatively high saturated hydraulic conductivity $\left(\mathrm{K}_{\mathrm{H}}\right)$ values that transmit the bulk of groundwater and contaminants. Lower $\mathrm{K}_{\mathrm{H}}$ zones (e.g., clay lenses) do not transmit much water, but may be locations where some contaminants enter mesoscale pores by diffusion and are slowly released back to groundwater. This back-diffusion process extends the lifetime of the plume, but does not necessarily mean that treatment cannot be achieved.

Fractured bedrock represents an extreme end-member in terms of heterogeneous media. Here the preferential flow pathways are transmissive fractures where groundwater flow and contaminant transport rates can have velocities of many meters per day. In addition, the microand meso-scale pores of the matrix surrounding fractures can receive significant quantities of contaminants through diffusion from the fractures (matrix diffusion) and become long-term secondary sources of contaminants that greatly extends the longevity of plumes (see Figure A-1). Once the concentration gradient between fracture and matrix reverses after the source DNAPL is removed or contained, slow, diffusion-controlled release of contaminants from the matrix leads to a reduced contaminant flux. This could mean that enhancements may not need to reduce mass flux very much once the diffusion-dominated phase of contaminant release occurs. However, as the matrix will be a long-term secondary source those enhancements selected for implementation may need to operate sustainably for an extended period of time in comparison to an unconsolidated media site where diffusion has a more limited impact on contaminant flux.

Fast flow and transport in fractures may not permit sufficient residence time for enhancements such as biological and abiotic treatment processes to be effective in these zones. However, options such as selective grouting of fracture zones or other groundwater control measures (e.g., interception and diversion) may greatly reduce the flux of contaminants associated with 
fractures. Likewise, fracture-dominated discharge to surface streams may permit spatially targeted deployment of certain types of enhancements (e.g., wetlands).

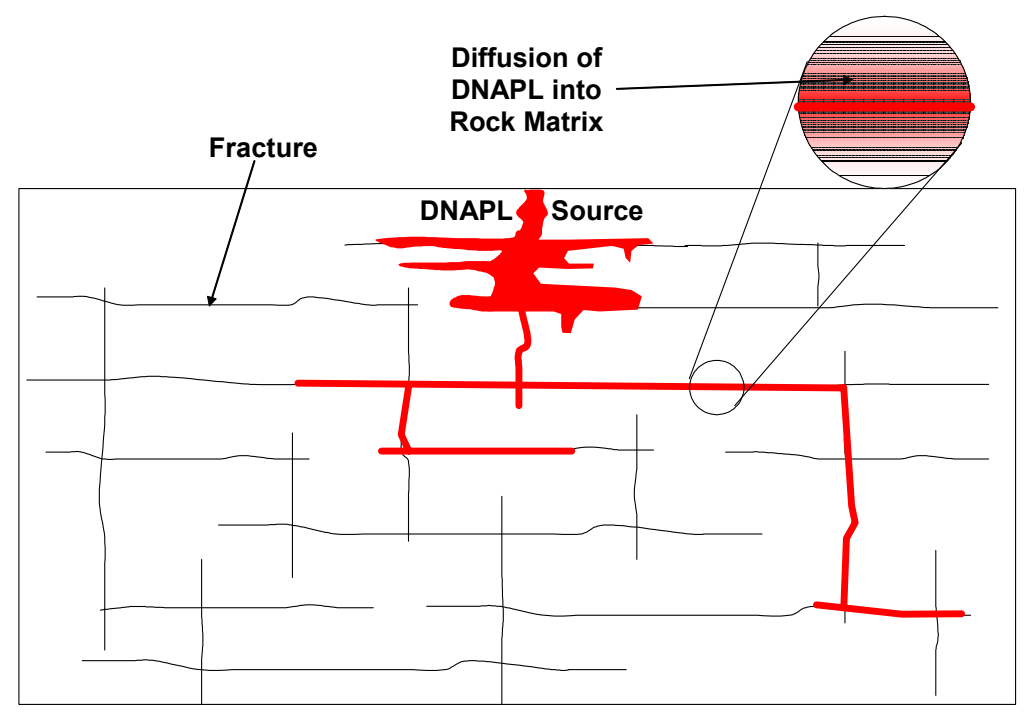

Figure A-1. Slow diffusion of DNAPL contamination into the rock matrix.

A factor that often is under-appreciated in remediation investigations is the impact of timedependant changes to the hydrologic system on the effectiveness of the remediation measures. Short-term, natural weather phenomena such as off-normal precipitation events, and seasonal changes can impact the performance of enhancements. Long-term climatic changes occur on a time scale that is much longer than EA and, therefore, are generally of limited concern. For EA, where enhancements must be designed to operate for many years, some of these factors are of increased (perhaps even critical) importance. The sustainable effectiveness of enhancements depends on proper placement in relation to the contaminant plume as well as maintenance of process operational factors. For example, the fundamental processes associated with a constructed wetland may be designed to function satisfactorily for degrading discharging cVOC contamination for many years, but if the zone of discharge shifts over time the wetland may no longer completely capture the contaminants and its usefulness may be diminished.

Off-normal precipitation events can result in increased erosion and can compromise the integrity of engineered structures. For example, surface water diversion structures, caps/covers, and related facilities may be vulnerable to increased erosion. Likewise, constructed wetlands can be ravaged by the impact of flooding. One can anticipate such events and implement design strategies to mitigate against the more probable ones among them, but it is impractical to imagine being able to guard against all such events. Choices must be made regarding using more robust designs and the cost of implementing them. These factors can be integrated into the decision analysis process described in Section 7.

A good example of the potential for seasonal changes in plume location can be found at the Paducah Gaseous Diffusion Plant (PGDP) in Kentucky (Moore and Clausen, 1997). PGDP is 
located approximately 3 miles from the Ohio River and several contaminant plumes originating at the site are migrating toward the river. Until recently, when construction of a new dam was completed downstream from the site, the river stage could vary over a range of more than 50 feet annually between a high in late spring and a low in autumn. Seasonal changes in bank storage accompanying river stage variations resulted in significant modification of the water table configuration (Figure A-2) that appears to have caused seasonal migration of the plume (not shown). The potentiometric surface for October, 1995 (left) and May, 1996 (right) show significant differences for the dry and wet periods of the year. The monthly average Ohio River stage was at $294 \mathrm{ft}$ in October and $328 \mathrm{ft}$ in May. It is clear that the design and placement of enhancements within a plume under similar circumstances need to be mindful of seasonal variations.
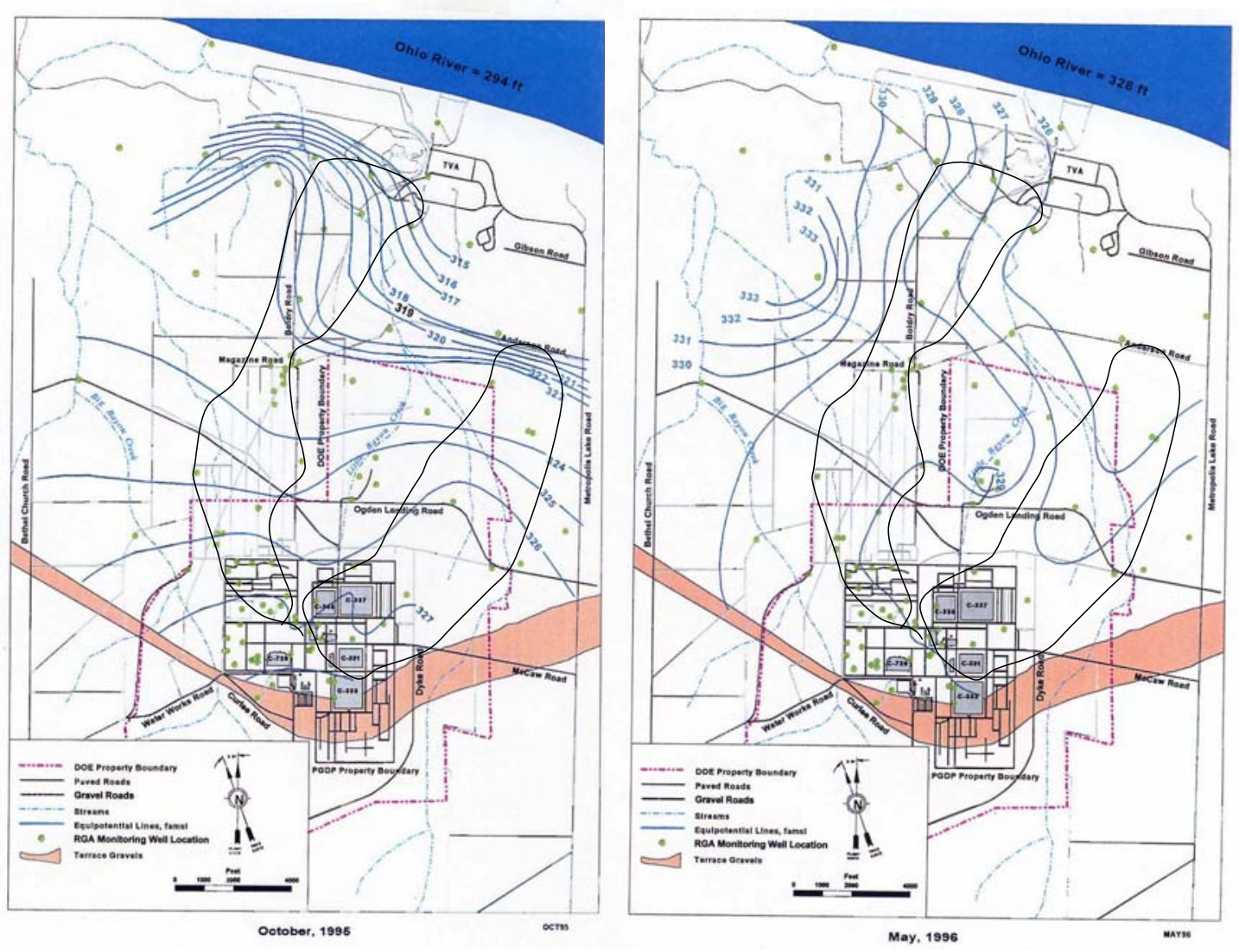

Figure A-2. Seasonal changes in the potentiometric surface for the Regional Gravel Aquifer at PGDP. The two major contaminant plumes at the site are overlayed on the figures. From Moore and Claussen (1997)

Hydrologic changes resulting from manmade development activities are more problematic because they frequently are not predictable on a time-scale exceeding a few years. One needs to ensure that future land use alternatives do not compromise the integrity of enhancements during the time when they are required to function. Recontouring the land surface to support construction activities is an example that may change the infiltration water balance and result in 
mass flux changes. Construction of a water impoundment might lead to undesirable modification of the hydrologic system. Sites surrounded by heavily developed regions where extensive use of groundwater currently exists also may experience future changes in the hydrologic system if businesses shut down or a piped water supply is provided to the area. Consequently, future land use planning both at the site and in neighboring land must be an integral part of the EA remedy.

Several environmental factors influence applications of enhancements designed to control source loading. For example, initial and long-term changes in soil hydraulic properties, plant ecology, and land use are important factors influencing the performance of covers. The properties of soils overlying a source influence water storage and percolation flux rates. Over time, soil development processes that create preferential flow may reduce storage and increase percolation flux. Soil properties also influence plant ecology including habitat characteristics, succession, and spatial patterns. Plants growing on covers may either enhance or degrade the performance of covers, depending on the cover design. Hence, post-installation land use and management must be carefully factored into the design and stewardship of source control enhancements. 
Contaminants are vulnerable to transport through covers primarily via infiltration and percolation of rainwater. Erosion, frost penetration, and intrusion by plant roots and burrowing animals can degrade covers and increase contaminant loading. The magnitude of these processes will vary and thus must be evaluated at each site.

Water Infiltration. Rainwater and snowmelt not lost by runoff and evaporation will enter the rock and soil layers overlying a source and become distributed in these materials in response to various water potential gradients (e.g., Hillel 1980). Depending on the properties and thickness of the cover layers, soil water could evaporate from the cover surface, be extracted by plants and returned to the atmosphere as transpiration, remain stored in the soil, pass into and remain stored in the underlying source material, or drain from source zone and potentially mobilize and release contaminants.

Erosion. Removal of fine-grained material by sheet-flow erosion, rilling, gullying, and wind deflation could expose and disperse contaminants under extreme conditions or, more likely, reduce the thickness of overlying cover layers leading to contaminant transport by water infiltration and other pathways. Soil loss by sheet-flow erosion involves the detachment of soil particles from the cover by raindrop splash and overland flow. If storm runoff is intense, flow may concentrate and cut rills and gullies deep into the cover (Walters and Skaggs 1986). Wind transports soil particles by surface creep, saltation, and resuspension and may be particularly rapid leeward of mounded covers in arid regions (Ligotke 1994).

Frost penetration. As temperatures drop and soil layers within the cover freeze, water drawn toward the freezing front can cause desiccation cracking (Chamberlain and Gow 1979), freeze/thaw cracking, and frost heaving (Miller 1980). Desiccation and frost cracking may lead to increased permeability and gas diffusion in compacted soil layers within the frost zone (Kim and Daniel 1992). Frost heaving also may cause distinct engineered soil layers to become mixed, thereby disrupting the integrity of critical layer interfaces (Bjornstad and Teel 1993).

Animal intrusion. Burrowing animals can mobilize contaminants by vertical displacement of tailings or by altering erosion, water balance, and radon-release processes (Hakonson et al. 1992). Vertical displacement results as animals excavate burrows and ingest or transport contamination on skin and fur (Hakonson et al. 1982). Once in the surface environment, contaminants may then be transferred through higher trophic levels and carried off site (Arthur and Markham 1983). Loose soil cast to the surface by burrowing animals is vulnerable to wind and water erosion (Winsor and Whicker 1980). Burrowing influences the soil-water balance by decreasing runoff, increasing rates of water infiltration and gas diffusion, and increasing evaporation because of natural drafts (Landeen 1994).

Plant Encroachment and Succession. Root intrusion can physically degrade covers. Macropores left by decomposing plant roots can act as channels for water and gases to rapidly bypass the soil mass in compacted soil layers. Plant roots also tend to concentrate in and extract water from compacted clay layers, causing desiccation and cracking. This can occur even when overlying soils are nearly saturated (Hakonson, 1986), indicating that the rate of water extraction 
by plants may exceed the rehydration rate of the compacted clay. In addition, roots may clog lateral drainage layers (DOE 1992), potentially increasing rates of infiltration through the underlying compacted soil.

Conversely, extraction of soil water from the cover by plants (transpiration) may significantly decrease recharge. Even in humid climates, where precipitation exceeds potential ET, water extraction by plants may account for more than half the soil water loss from engineered covers (Melchior et al., 1994). Vegetation also improves slope stability, although the complexity of vegetation and soil interactions has hampered quantification (Morgan and Rickson, 1995). 


\section{SUPPLEMENT TO SECTION 3.2.1}

The following sections describe three archetypical scenarios.

NAPL Oil Injection into the Source Area. Injection of oil into a source zone has several potential benefits and presents several research opportunities. Many of these are highlighted in the summary of the ongoing Environmental Security Technology Certification Program (ESTCP) project - Sequestration of a DNAPL Source with Vegetable Oil. According to Gavaskar and Becvar (2004),

Vegetable oil is a light, viscous liquid that is sparingly soluble in water. It acts as a slow-release electron donor source in the long-term, and vegetable oil injection has been used primarily for this purpose. However, there are additional benefits from injecting the oil into a DNAPL source zone .... When enough oil is injected in the soil, the oil can sequester the DNAPL by physically diverting groundwater flow around the source and thus weakening the plume emanating from the source. Additional sequestration occurs as the DNAPL is solubilized in the oil. These physical-chemical features of the oil injection play an important role in controlling the DNAPL source. The challenge often is in obtaining sufficient distribution of the oil in the subsurface to realize these benefits. Use of emulsifiers and cosolvents can enhance distribution of the oil, but it may be difficult to retain the oil in this form in the source zone as it may migrate out with the groundwater flow. Bench-scale tests have shown that heating the oil temporarily reduces its viscosity, allowing it to travel into the soil pores surrounding the injection point. In the soil, the oil cools quickly, its viscosity rebounds, and it remains trapped in the source zone.

Vegetable oil injection has the potential to be an environmentally benign and relatively low-cost treatment for DNAPL sources, both in the short- and longterm. In the short-term, the physical-chemical aspects of the oil distribution play a major role. In the long-term, its ability to act as a slow-release electron donor will enhance biodegradation of any residual plume.

The general concept is presented in Figure A-3. 


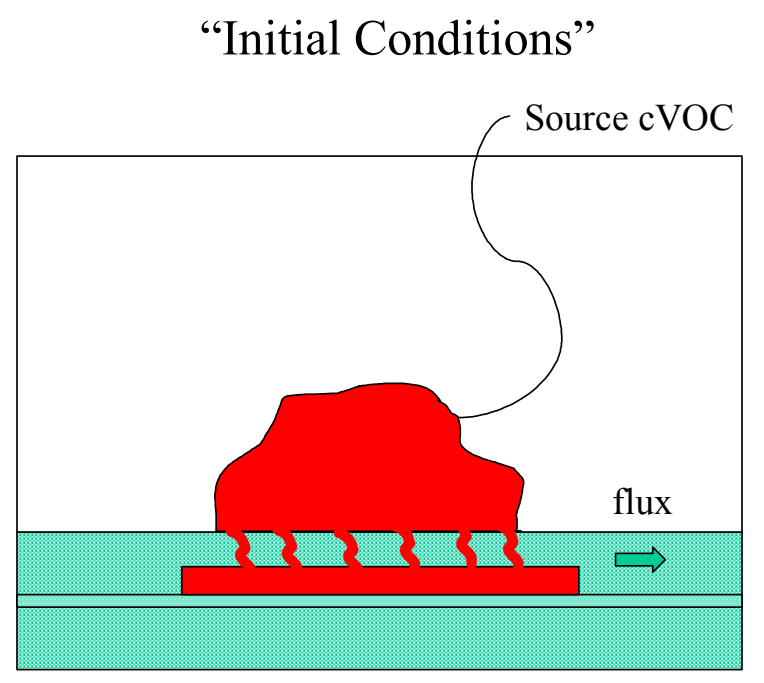

Baseline
“Oil Deployment Conditions"

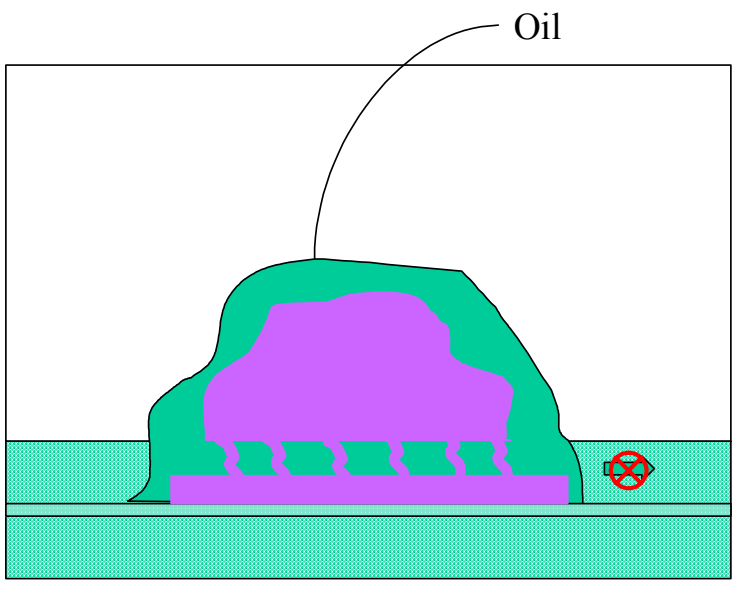

-Oil Barrier deployed source zone

- "eliminates" contaminant transfer from source to vadose zone and groundwater

-physical performance can be calculated using partitioning and Raoult's Law

- sets up conditions that promote contaminant

biodegradation

- allows time for field confirmation and estimation

of contaminant degradation

-For partitioning alone, requires large amount of oil

if significant source remains

Figure A-3. Concept of Diffusion Barriers using Vegetable Oils

When injecting nontoxic NAPL oils, such as vegetable oil, into DNAPL source zones, the potential of forming a mobile vegetable oil-DNAPL phase must be considered. Factors such as viscosity and pore entry pressures for the new NAPL phase in the subsurface media will need to be evaluated when designing an injection program. Uncontrolled migration of the oil-DNAPL phase would not be a desirable outcome. Injection of an emulsified oil may lessen the probability of mobilization. However, careful evaluation of potential problems associated with post-injection mobilization must be considered during the design process.

Deep Vadose NAPL Oil Injection. Figure A-4 outlines the concept for a simple vadosegroundwater barrier (Looney et al., 2005). Note that the diagram shown is highly simplified and variations are possible based on local conditions. A key aspect of this scenario is the spreading of the oil on the water table to optimize the geometry of the interception and partitioning barrier. If implementation of a partitioning barrier is contemplated, prior partial source removal (e.g., by soil vapor extraction) to reduce the bulk of the mass would be advantageous. The partitioning barrier approach generally requires NAPL oils with long lifetimes and low solubility. Because this is conceptualized as an interception system, the partitioning behaviors and the impacts of the barrier on water phase permeability need to be considered. 


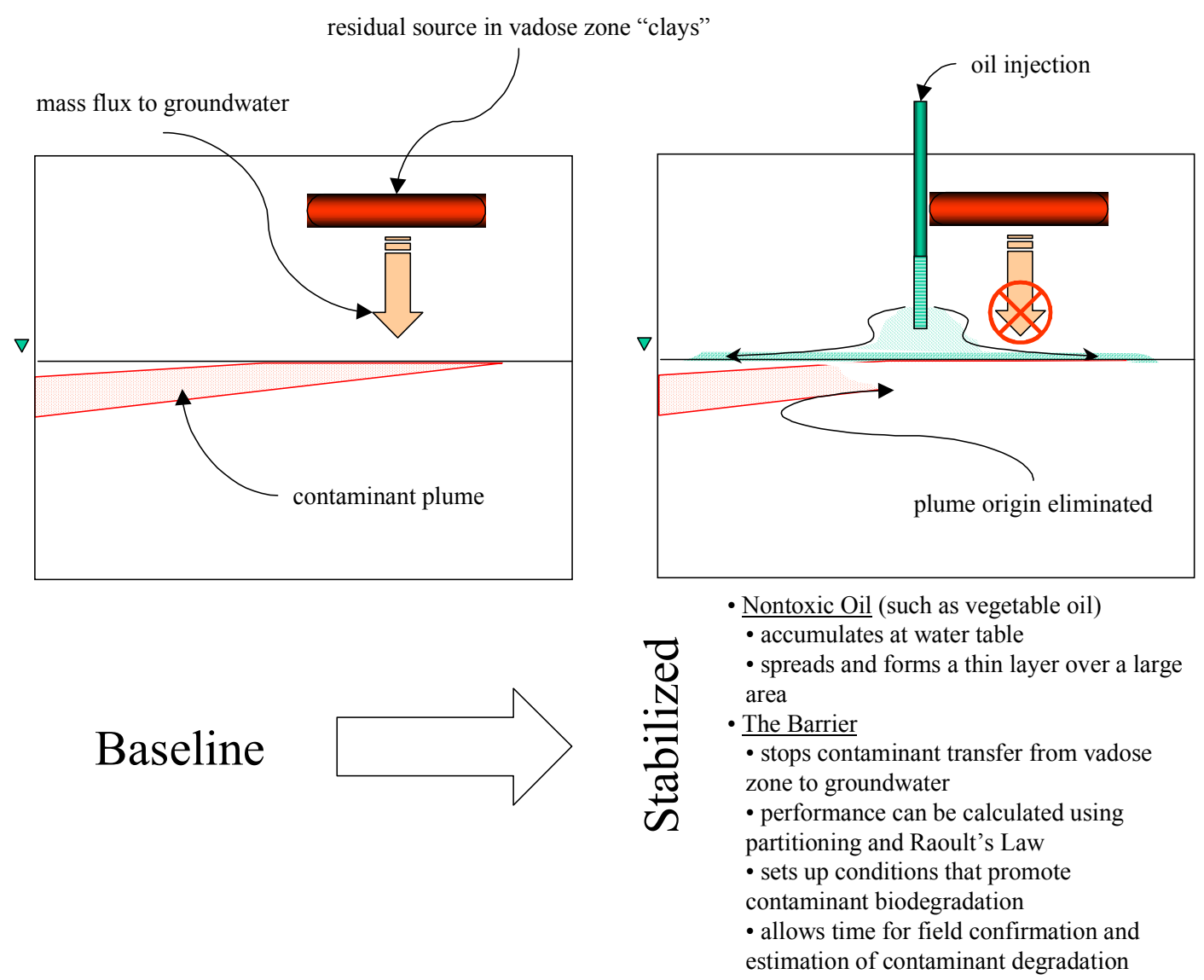

\section{Figure A-4. Partitioning Barriers in the Vadose Zone}

NAPL Oil Injection after Aggressive Source Removal. Deployment of nontoxic oil within the vadose zone as a follow up to aggressive source removal actions, such as steam or electrical resistance heating, may provide viable EA. The source removal action removes much of the source mass and flux. The oil can be deployed to address the residual source mass by limiting subsequent release of NAPL constituents. As shown in the baseline figure

(Figure A-5), the primary reservoir of residual cVOC at such sites is often in a shallow silty or clayey zone. This zone continues to release contaminant slowly to the surrounding "clean" soil or sediments. A technology that mitigates or eliminates this flux represents a defensible final closure action. NAPL oil infusion in this case can be performed in shallow low-cost geoprobe wellpoints in an upper or middle vadose zone sand. The underlying vadose clays will provide additional control on the infused oil and provide a controlled volume for the deployment. This scenario presents many research opportunities including examination of the potential viability of longer chained hydrocarbons. Residual heat will not adversely impact the process and may, in fact, enhance any biological degradation of PCE. 
WSRC-STI-2006-00083, Rev. 1

August 1, 2006

Page 111 of 147

"Post Source Removal"Conditions"

(e.g., residual cVOC source in fine grained sediments after thermal treatment)

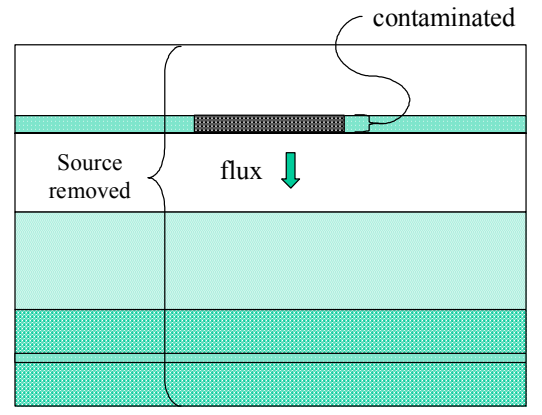

silty clay

sand

clay

sand

clayey sand

water table aquifer

(interbedded sands and clays)

"Oil Deployment" Conditions

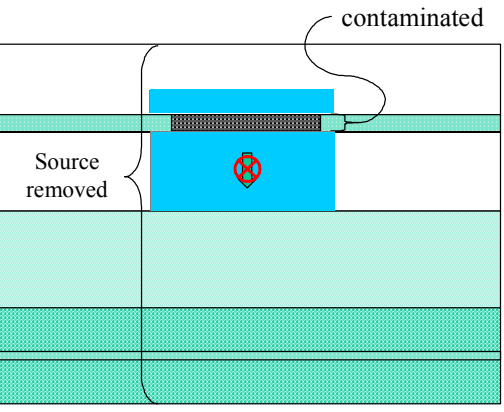

- Oil Barrier deployed in upper vadose zone

7. "eliminates" contaminant transfer from source to

. vadose zone and groundwater

- physical performance can be calculated using

Baseline

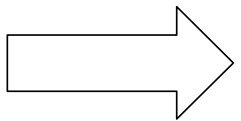

鬲 $\cdot$ sets up conditions that promote contaminant

biodegradation

- allows time for field confirmation and estimation

of contaminant degradation

Figure A-5. Partitioning Barriers Applied to the Vadose Zone after Source Treatment 


\section{SUPPLEMENT TO SECTION 3.2.2}

Plant managers at DOE's Kansas City Plant are developing a comprehensive strategy to address both short term issues, such as trace contamination appearing in storm sewers that traverse the plume, and long-term issues, such as implementing technically based and protective actions for the whole site. The independent team that evaluated hydrologic control options for the site concluded:

...if data and risk assessment show that the residual sources are relatively stable and only limited supplementary methods would assure risk reduction performance, a passive version of this technology might be applied. In this configuration, up-gradient "GeoSiphon" wells (such as those developed at the Savannah River Site) or high ET plantings (such as have been applied at Portsmouth and other sites) would extract water. The system would target clean water entering the system from the bluffs to the north along with infiltration north of the major site plume(s). For the GeoSiphon, the difference in elevation between the water level in the wells and the receiving Blue River provides the motive force for water flow from the wells via a siphon. The result would be a reduction in the driving force through the groundwater system minimizing flow through PCB and VOC source zones. The system would need to be carefully designed to pump an appropriate quantity of water to flatten the gradient without inducing flow toward the siphon. More modeling (or addition of appropriate scenarios to existing models) would be useful to properly design and document a GeoSiphon system.... A GeoSiphon/phytoextraction may be viable at this site. (DOE 2002)

Figure A-6 is a schematic illustration of the GeoSiphon alternative proposed for this site.

Creative systems have been proposed for reducing plume loading that connect two aquifers with different hydraulic heads with engineered wells. Conceptually, this approach can allow clean, up-gradient groundwater to bypass contamination sources (Figure A-7). Systems that combine hydrologic control with creation of a sustainable reaction zone also have been proposed (Figure A-8. 
A.

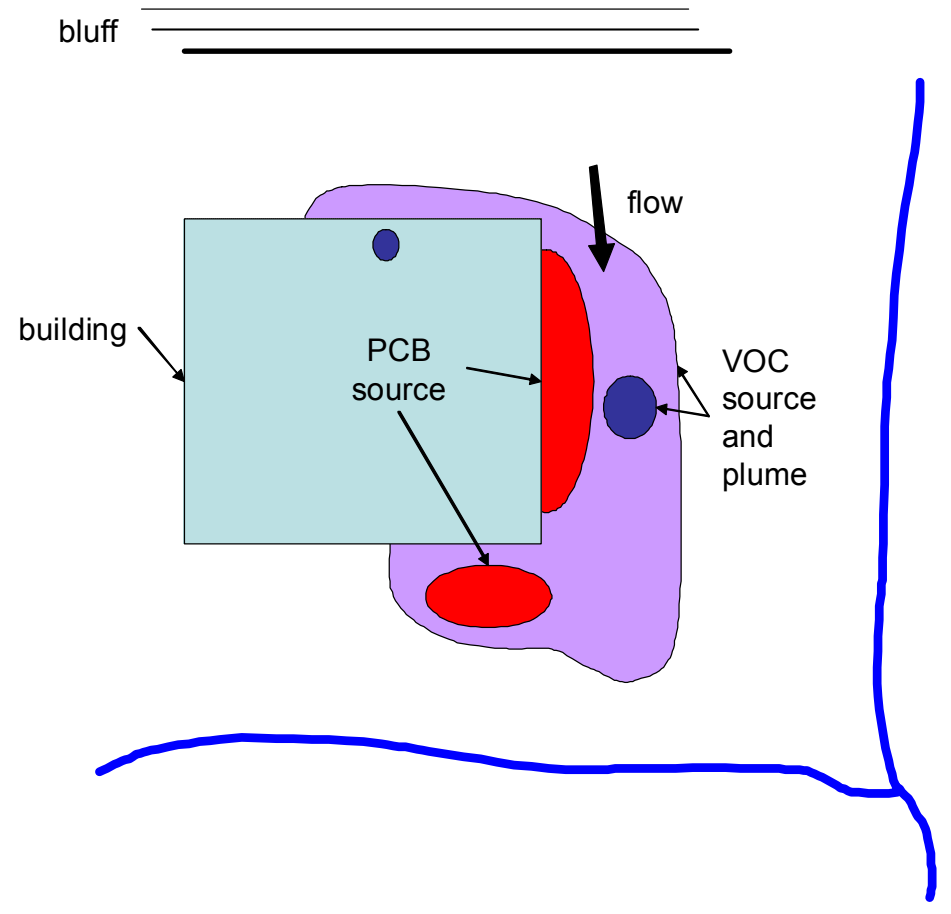

B.

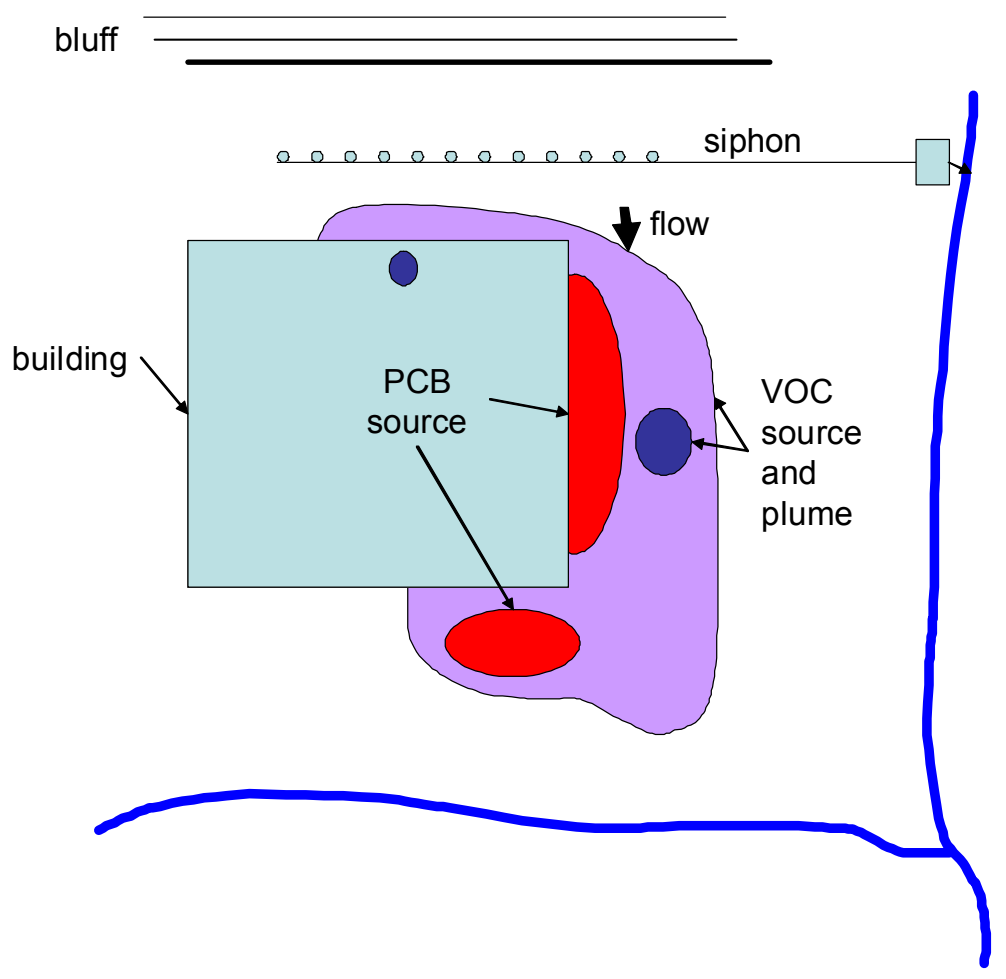

Figure A-6. Simplified Diagram of GeoSiphon Concept as Evaluated for Kansas City Plant a) shows baseline conditions and b) illustrates layout for hydraulic control. 


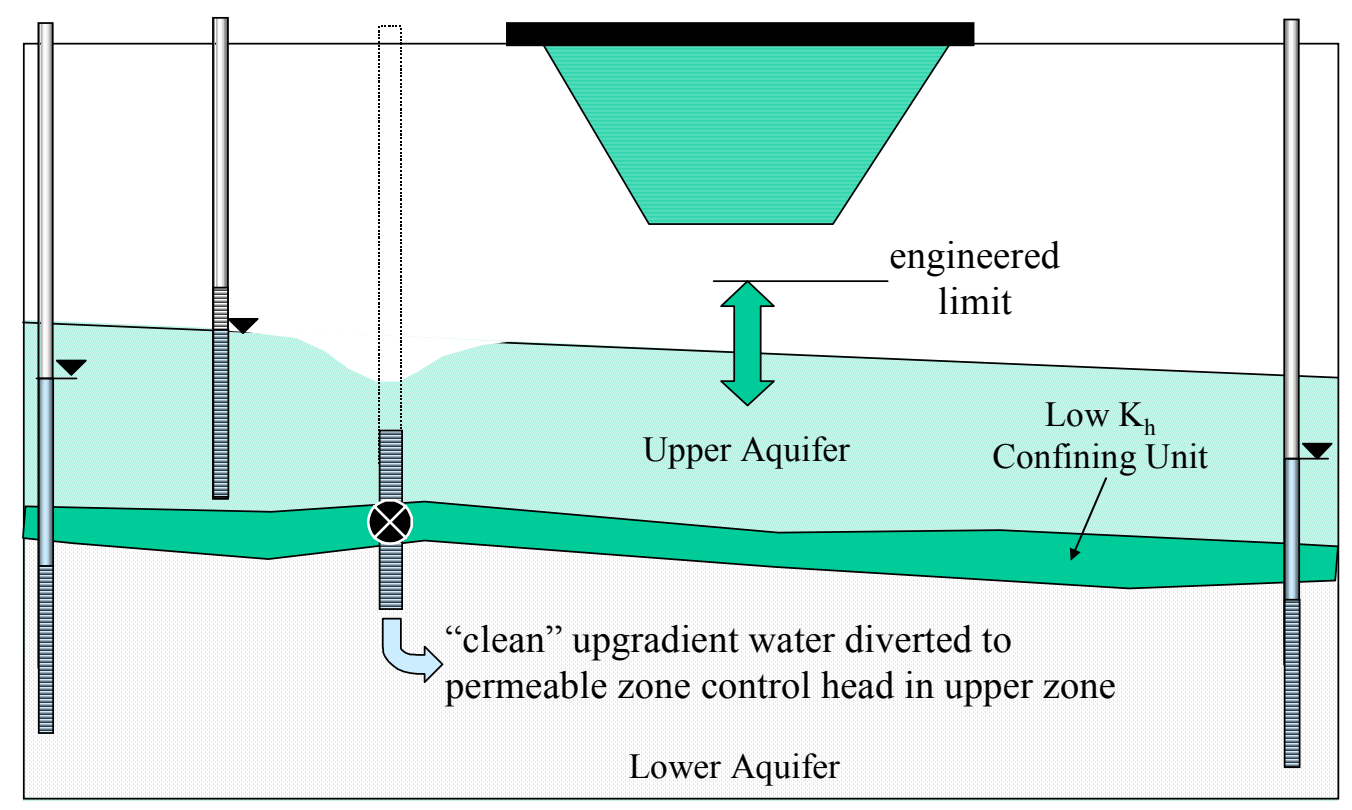

Figure A-7. Control Well System to Reduce Flow of Groundwater. Controls reduce the hydraulic driving force for plume migration and contaminant loading. Various designs for the well control system have been evaluated. 
a)

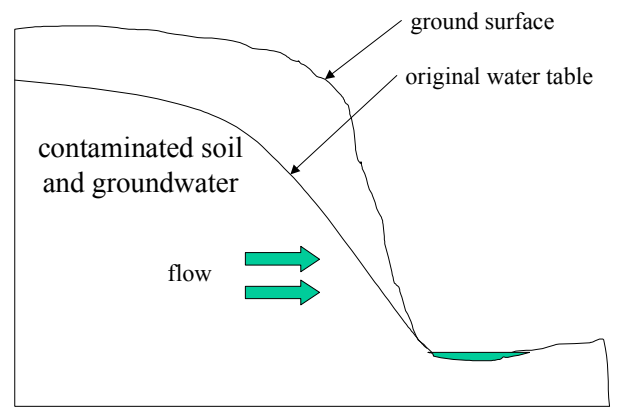

Baseline Conditions

b)

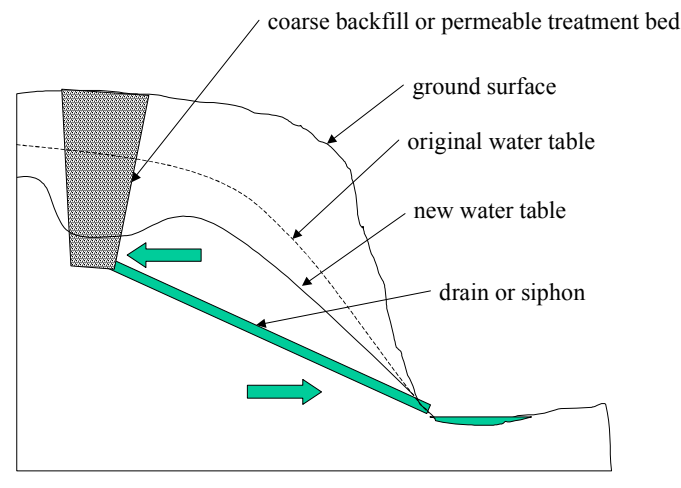

Basic GeoDrain

(see text for description of options)

c)

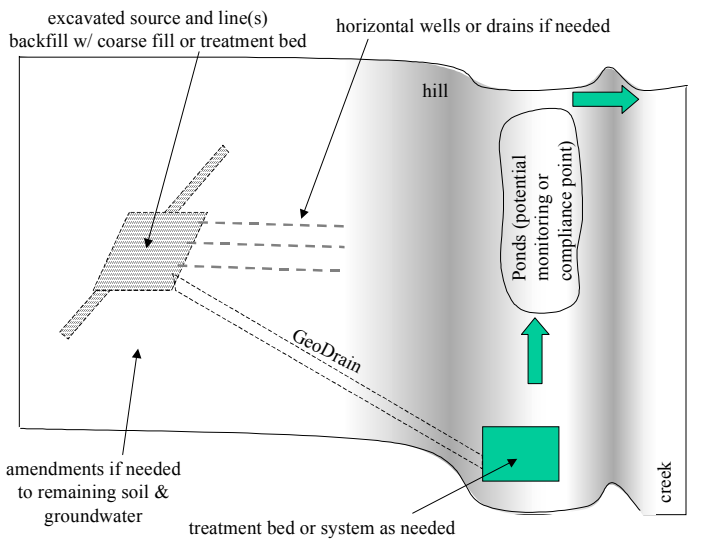

Figure A-8. Simplified Schematic Diagrams of Options Developed for the Waste Management Unit at the DOE Ashtabula Closure Plant a) baseline conditions, b) cross section with controls, c) site configuration options. 


\section{SUPPLEMENT TO SECTION 3.2.3}

Several examples listed in the last paragraph of Section 3.2.3 are presented here in greater detail and provide a continuum of approaches to deep rooting trees for modifying the shape of the water table. For example, an engineered system for groundwater and contaminant extraction using high transpiration rate trees was installed at a former oil handling facility at the U.S. Department of Energy's Portsmouth Gaseous Diffusion Plant at two sites in 1999 and 2002, respectively. Hybrid poplars were planted in trenches ( $2 \mathrm{ft}$ wide and $10 \mathrm{ft}$ deep) filled with planting medium. The bottom of the trenches were connected to the contaminated groundwater by up to 30-ft-long, 8-inch-diameter, boreholes that were backfilled with fine sand (sand pipes or "sand stacks"). Trees were planted within the trenches (Figure A-9). After several seasons of growth, a significant impact was seen in the water balance and water levels declined (Pro2Serve, $2003 a, b)$. The promising results suggest that additional deployments of this type are worthwhile in the appropriate settings.

For the system to be successful, the engineered connection must serve to allow both upward flow of groundwater to the tree roots and to deliver it at a rate faster than that from the low permeability surrounding soil. If the backfill is too coarse, it will not have sufficient capillarity to wick the water upward and the connection will be broken. If the backfill is too fine grained, the permeability may be too low for adequate delivery. This project was successful in demonstrating groundwater control but little movement of TCE up the 8 inch boreholes was noted. Some TCE has been detected in the transpiration stream. Because the trenches were not sealed from surface water, trees preferentially developed root systems in the trenches rather than into the 8-inch boreholes.

Perhaps the best example of deep rooting of trees is at Argonne National Laboratory in Illinois (East Argonne Area 317/319). Hybrid poplars were deep rooted in Treewells, plastic lined holes bored to a depth of 30 feet. Boreholes were filled with topsoil and then surface capped. The surface capping isolates the tree from surface water and forces the roots to utilize contaminated groundwater. Root extension of 10 feet has been observed.

This type of system extends the applicability of phytotranspiration approaches to aquifers that are somewhat deeper than the root zone. Importantly, the system is limited by fundamental principles and pressure relationships that govern the ability of trees to transfer water upward. Water can not be wicked and delivered vertically more than about 20 feet - thus, the potentiometric surface must be within ten or twenty feet of the bottom of the root mass for this system to be viable. 


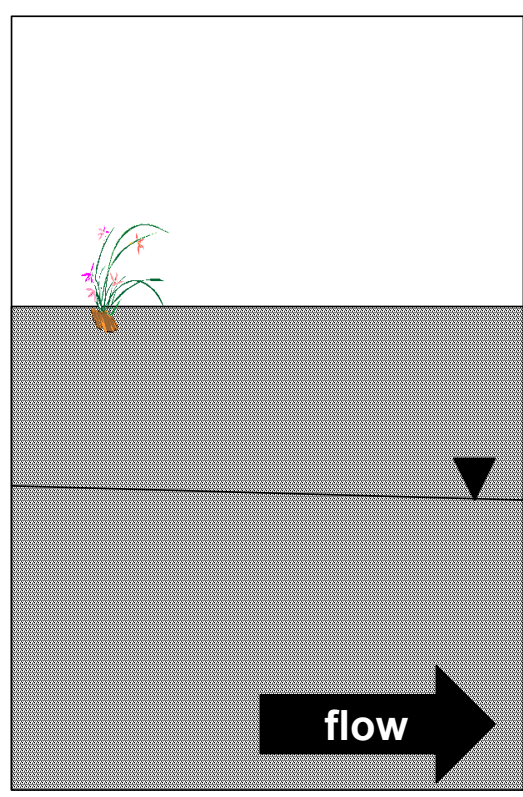

Before

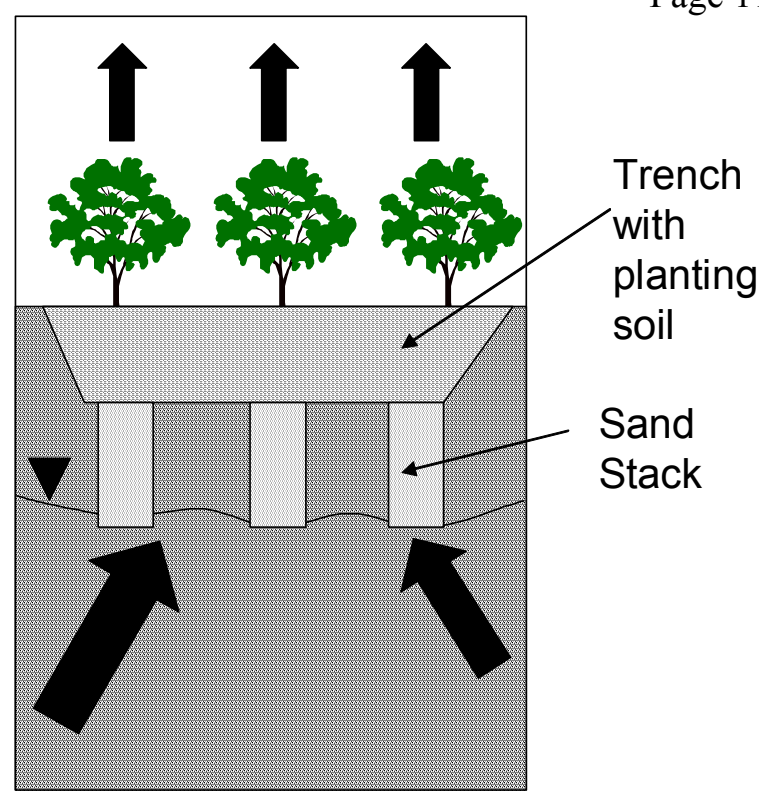

After

Figure A-9. Diagram of Engineered Phytotranspiration System as Implemented by the DOE Portsmouth Site 


\section{SUPPLEMENT TO SECTION 4.1}

Figure A-10 is an example of the Baroball technology. The graphic on the right illustrates how the Baroball operates when the formation vapor pressure $>$ atmospheric pressure. When atmospheric pressure $>$ formation vapor pressure the ping pong ball seats in the valve preventing air flow to the formation. The photo on the left shows an example of the Baroball (http://www.p2pays.org/ref/14/13958.htm).

Features of the Baroball and related devices include the following:

- To support passive soil vapor extraction a barometric check valve prevents the backflow of air into extraction wells, air that would otherwise dilute the contaminants in the subsurface.

- To support in situ processes, the check valve system can be configured to inject air and/or nutrients into the subsurface or to passively transfer solar-heated, water-saturated air into the subsurface as needed to enhance biodegradation or volatilization in the subsurface.
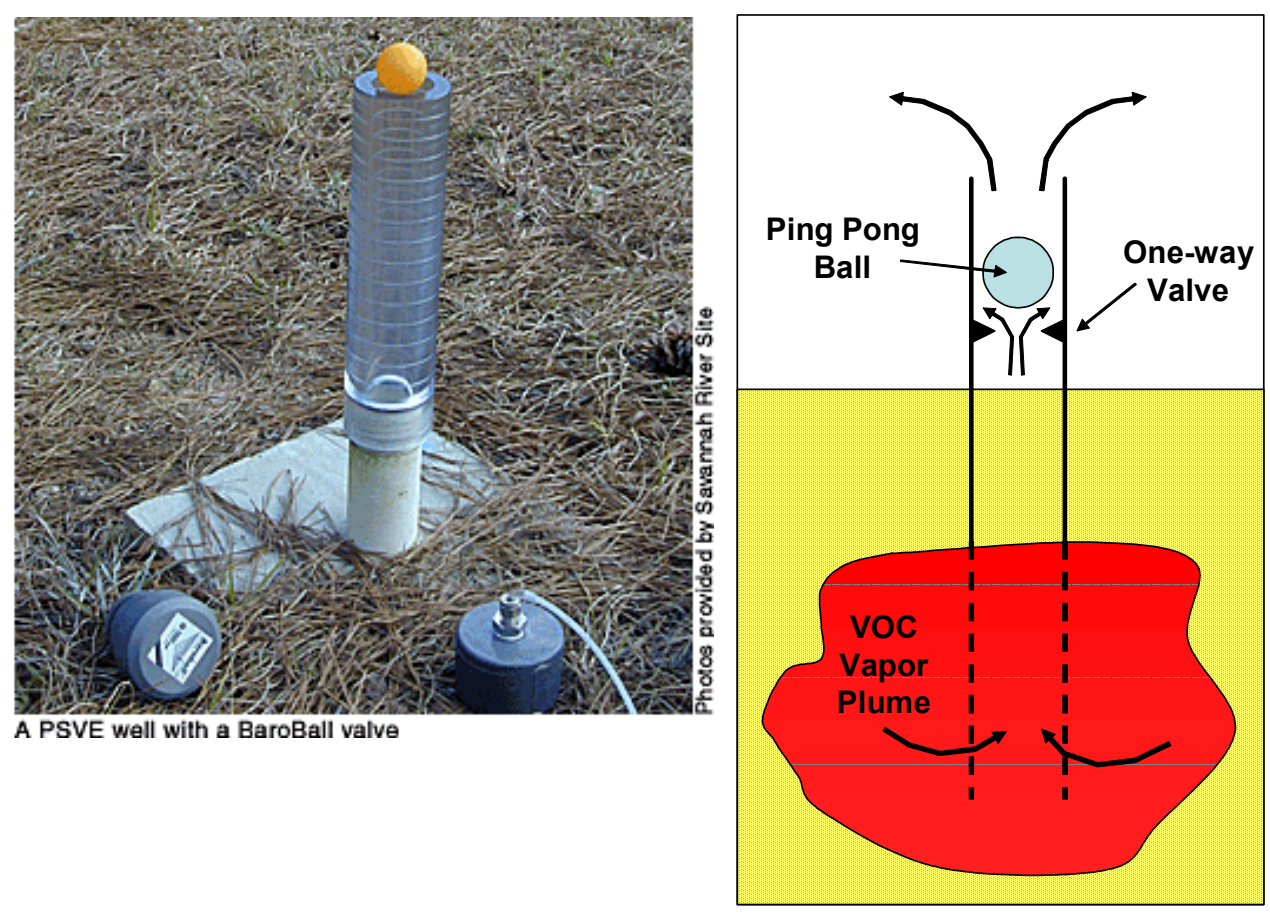

Figure A-10. Baroball Passive Vapor Extraction System. 
Figure A-11 shows a photograph of the Microblower.

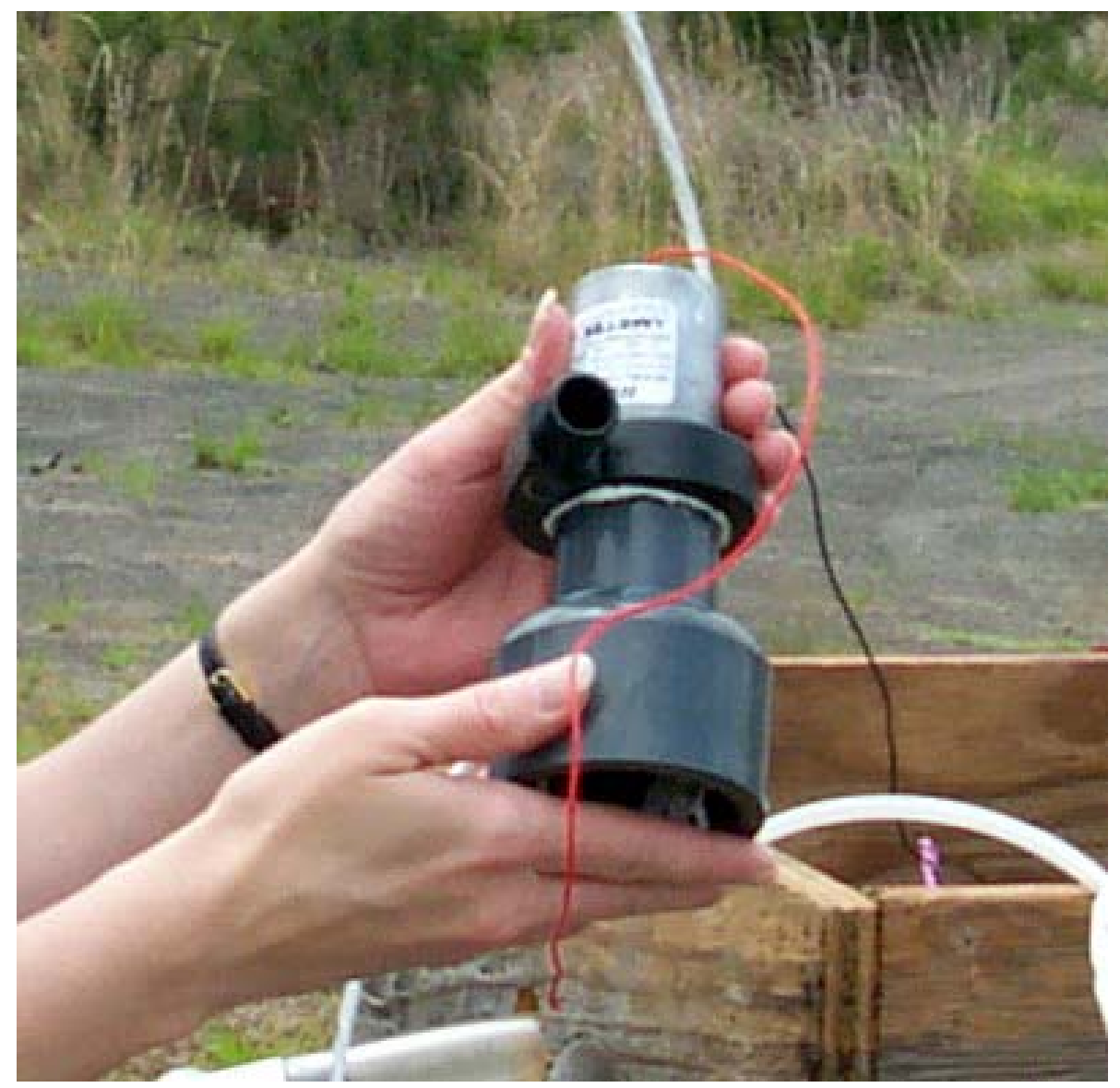

Figure A-11. Microblower Used to Enhance Soil Vapor Extraction (http://www.srs.gov/general/enviro/erd/technology/Pages/h10p.html 


\section{SUPPLEMENT TO SECTION 5.1.1.2}

Solid materials can be easily installed by trenching or soil mixing when the treatment zone is shallow. However at greater depths, solids can only be emplaced by jetting, hydraulic fracturing with solids delivered as a proppant, or similar methods.

Injection of non-toxic NAPLs (e.g., vegetable oil) can be used to provide large volumes of relatively long-lived reagent in the subsurface. As with the other oil injection concepts, all materials used in the process are normally those that are "Generally Recognized As Safe" (GRAS), food-grade materials to aid in gaining regulatory approval for in situ application. The edible oil can be added to the treatment zone through conventional wells or using direct push technology to reduce costs.

Factors such as viscosity, pore entry pressure, media heterogeneities, and vadose vs. saturated zone injection affect the distribution of the NAPL oil. In some applications NAPL may occupy a large amount of pore space, which increases the amount of liquid that must be injected to cover the desired volume. However, these large volumes also may increase the effective lifetime of an injection, reducing the required injection frequency. High NAPL saturations also provide additional oil to sequester chlorinated solvents and reduce the effective permeability of the formation. These effects could be used to advantage to reduce the mass flux of contaminants discharged from a source area. However, NAPLs can move vertically due to density effects, potentially migrating outside the intended treatment zone.

Low solubility reagents can be injected into the subsurface as emulsions (small droplets of liquid 'oil' in water) or dispersions (small particles of solid material in water). For effective transport, the droplets/particles must be smaller than the aquifer pore throat dimensions (typically $10-100$ $\mu \mathrm{m})$. Generating these fine emulsions/dispersions is not a significant problem due to the tremendous practical experience with their preparation in the food, pharmaceutical and chemical industries. Once in the subsurface, transport of droplets/particles smaller than the aquifer pore spaces can be described by colloid transport theory. Extensive research has been conducted on the transport of biocolloids (e.g. bacteria and viruses). However, application of this same theory to distribution of long-lived reagents is less well developed.

Available information indicates that: (1) small droplets / particles can be transported substantial distances and then retained by the aquifer sediments; (2) the amount of reagent retained by the aquifer sediment will be a function of the surface chemistry of the sediment and the particles; (3) sediment and particle surface chemistry can be manipulated using relatively well established techniques; and (4) once particles are captured by sediment surfaces, they are usually retained for long periods. However, much less is known about the relative 'bioavailability' of these materials once they are retained by the sediments. Unpublished data suggests that oil droplets attached to sediment surfaces biodegrade more slowly than oil droplets suspended in an aqueous matrix (Borden, pers. comm.). However, the underlying cause of this phenomenon is not understood.

When compared to NAPL oil injection, emulsified oils have less adverse impact on water phase permeability and provide better distribution of degradation capacity volumetrically throughout 
the target zone. NAPL oil injection, on the other hand, can often deploy larger quantities of oil and potentially create zones that are longer-lived.

High solubility reagents can be injected into the subsurface as an aqueous solution. However, these reagents must then be immobilized by some process or they will be transported out of the treatment zone by flowing groundwater. One approach previously attempted was to mix two soluble reactants (e.g. sodium oleate and calcium chloride) in-situ to form an insoluble precipitate (calcium oleate or 'soap scum'). This approach was very effective in the laboratory for stimulating reductive dechlorination. Initial trials conducted at Kelly AFB were not successful because sufficient mass of oleate was not delivered to the treatment zone. However, trials conducted at a site in Australia have shown that oleate addition is a viable method (D. Major, Pers. Comm.). Immobilization of dissolved reagents is currently the least well developed approach for providing long-lived treatment reagents. However, the tremendous experience in the process chemical industry suggests that in-situ precipitation-immobilization of dissolved reagents has great potential. 


\section{SUPPLEMENT TO SECTION 5.1.3}

The following excerpt is from DOE(2005), a report of a DOE-sponsored technical assistance activity at the East Tennessee Technology Park in Oak Ridge, TN. It was largely prepared for the report by Michelle Lorah (USGS) and John Pardue (Louisiana State University).

\section{Natural Wetland Systems}

The concept of wetland treatment of cVOCs has evolved from observations that these contaminants can be degraded to innocuous byproducts by microbial processes occurring in natural wetland systems. Numerous plumes at Superfund and other sites discharge into natural wetlands of various types. Examples include the Petro-Processors site in Louisiana, Robins Air Force Base in Georgia, and several sites at the Aberdeen Proving Ground in Maryland. At these sites, studies documented order-of-magnitude decreases in contaminant concentrations as groundwater discharged relatively short distances (several feet) upward through the base of these wetlands that are heavily vegetated with Phragmites (Lorah and Olsen, 1999a, 1999b; Pardue et al., 2000a). An example from a site at Aberdeen Proving Ground, Maryland illustrates some key findings of the empirical approach.

At West Branch Canal Creek, Aberdeen Proving Ground, a detailed study of cVOC plumes discharging into a freshwater wetland showed that natural attenuation quantitatively removed the contaminants before groundwater discharged to land surface or a tidal creek (Lorah and Olsen, 1999a, 1999b; Lorah et al., 1997). Along upward flow paths through 1.8- to 3.6-ft thick wetland sediments, total concentrations of chlorinated volatile organic compounds decreased from about $500 \mathrm{ppb}$ at the base of the wetland sediments to less than $5 \mathrm{ppb}$ near the surface. This study showed that biodegradation was a major attenuation process in the anaerobic wetland sediments, with half-lives for trichloroethene and 1,1,2,2-tetrachloroethane of about 2 to 7 days (Lorah et al., 1997; Lorah and Voytek, 2004; Lorah et al., 2003b). These degradation rates in the organic-rich wetland sediments were two to three orders of magnitude higher than those reported previously in sand aquifers, where availability of organic carbon commonly limits the rate and extent of degradation of chlorinated solvents.

Laboratory microcosm experiments showed that most rapid biodegradation occurred by reductive dechlorination under methanogenic conditions. Biodegradation produced lower chlorinated intermediates, and ultimately nonchlorinated end-products of ethene, carbon dioxide, and methane. Some of the anaerobic intermediate products (including cis-DCE and vinyl chloride) also degraded rapidly by methanotrophic degradation under aerobic conditions, which commonly occur near roots (Lorah et al., 2001). Sorption was quantified as another attenuation mechanism for the chlorinated solvents, 
which increased the retention time of the contaminants in the wetland sediments.

The efficiency of natural attenuation at this Aberdeen Proving Ground site indicated that upflow treatment wetlands could be constructed to intercept chlorinated solvent plumes in areas where a wetland is not naturally present. Subsequent laboratory investigations have shown consistent degradation rates for cVOCs in natural wetland sediments and in peat substrate mixtures that can be used reliably in designing treatment wetlands. In addition, a microbial culture has been developed that can be used reliably to bioaugment constructed wetlands for efficient degradation (Lorah et al., 2003a; Lorah et al., 2004).

\section{Constructed wetland treatment systems}

[The previous subsection] establishes the rather short historical background of how observations of degradation of cVOCs occurring in natural wetland settings has evolved into the concept of designing and implementing constructed wetlands to efficiently treat contaminated groundwater. In this section we translate these observations into a better understanding of the underlying processes involved and how constructed wetland treatment systems might be developed.

The rapid attenuation of cVOCs observed in natural wetland systems suggests that a constructed wetland could be designed to effectively eliminate cVOCs based on the presence of reductive dechlorinating and methanotrophic microbial populations known to degrade chlorinated solvents in addition to the action of several other important processes. Specifically, four fate mechanisms contribute to wetland treatment of cVOCs:

- Reductive dechlorination

- Sorption

- Methanotrophic biodegradation

- Plant uptake

Reductive dechlorination, the anaerobic biodegradation process catalyzed by specialized halorespiring bacteria, is the most critical to treatment. Conversion of chlorinated ethenes and ethanes to lower chlorinated daughter products via reductive dechlorination is particularly rapid in wetland peats. For example, rate constants of 30-40 year ${ }^{-1}$ have been observed for reductive dechlorination of TCE in wetlands as opposed to 1-4 year ${ }^{-1}$ typically observed in aquifers (Lorah et al., 1997). Reductive dechlorination occurs throughout the wetland bed. Sorption of cVOCs is another important fate mechanism since it increases the retention time in the wetland peat. Retardation factors of cVOCs in peat can exceed 10, signifying that the cVOC residence time can exceed water residence time by a factor of 10 . Sorption also occurs throughout the wetland bed. Methanotrophic biodegradation, the aerobic biodegradation process catalyzed by methanotrophs, is also important. These bacteria colonize the 
surface of wetland plant roots and have the enzymes necessary to degrade cVOCs to $\mathrm{CO}_{2}$ and $\mathrm{H}_{2} \mathrm{O}$. It is thought that these organisms perform an important polishing step, degrading lower chlorinated daughter products before they reach the overlying water. Methanotrophic biodegradation occurs in the root zone of the wetland plants. Plant uptake and metabolism is thought to be a relatively minor fate process. Some wetland plants have shown the ability to metabolize parent cVOCs (such as TCE), but the robust biodegradation processes that occur in these peats are thought to be more important.

A constructed treatment wetland for cVOC removal can be of two types: it can either passively intercept a groundwater plume or it can be active in that contaminated groundwater can be pumped to a distribution system at the base of the wetland. In both scenarios, the water slowly percolates upward to the surface and treatment occurs as the water is passing through the peat soil and through the root bed of the wetland plants.

A set of design principles for wetland VOC treatment and a design approach has been developed by Pardue et al. (2000b) and Pardue (2002), based on information in the scientific literature. The design approach focuses on predicting wetland bed depth and area required for a given flow rate and plume composition. The design approach uses a simple first-order reactive transport model that incorporates sorption and biodegradation of cVOCs (Kassenga et al., 2003; Kassenga et al., 2004). Dispersion also can be considered using a more complex equation in addition to sequential biodegradation kinetics.

In one example of the application of this design approach, bench-scale soil column experiments were conducted to investigate potential peat substrate mixtures for use in a pilot-scale treatment wetland for a Superfund site in Connecticut (Kassenga et al., 2003; Kassenga et al., 2004). Ten mixtures were evaluated for geotechnical and hydraulic conductivity properties; two substrate mixtures were selected for measurement of sorption and degradation potentials. A mixture of sand, commercial peat, and Bion Soil (a compost derived from dairy waste) was found to have the most suitable hydraulic properties and the highest degradation rates for a mixture of chlorinated ethenes and ethanes compared to a peat-sand mixture (Kassenga et al., 2003; Kassenga et al., 2004). Contaminated groundwater from the site was used in this study to seed the peat substrate mixture with microorganisms capable of degrading the cVOCs. An effective bed depth of about $6 \mathrm{ft}$ was calculated based on this study for a treatment wetland constructed of peat-sand-Bion soil with flow of $15 \mathrm{gpm} / \mathrm{acre}$. For the sites where this design strategy has been applied, required depths have ranged from $2-6 \mathrm{ft}$ and loading rates have ranged from $\sim 10$ to $40 \mathrm{gpm} / \mathrm{acre}$.

Several treatment wetlands have been designed and implemented using this design approach. One pilot project is underway and two additional sites are planning for fullscale implementation in 2005-2006. [Summaries of these projects are presented as 
case studies in Appendix B, Table B-6.] Several other pilot-scale treatment wetlands for $\mathrm{cVOC}$ groundwater plumes have been reported, although bioaugmentation to enhance microbial degradation was not used at these sites. Ferraro et al. (2000) also reported a concept and design process for treatment wetlands for chlorinated alkenes. Summary information on these projects also is found in [the] Appendix....

Building on what has been observed in natural wetlands and more conventional constructed wetland designs, a unique concept for a reactive, flow-through mat has been developed and tested. The mat can be bioaugmented with a culture derived from the wetland sediments where natural biodegradation is known to be effective. The mat was investigated for use in enhanced bioremediation methods to treat cVOCs that were discharging to the tidal wetland along the West Branch Canal Creek through localized seeps (Lorah et al., 2003a; Lorah et al., 2004; Majcher et al., 2003; Majcher et al., 2004). At these seeps, the cVOCs essentially bypass the natural attenuation observed over most of the wetland and discharge at the same high concentrations observed in the aquifer ( 1 to $35 \mathrm{ppm}$ ) to the creek.

The anaerobic culture used in the mat, called "WBC" for the West Branch Consortium, was enriched from the wetland sediments, successfully transferred to culture medium, and grown to large volumes for use in pilot tests of enhanced bioremediation remedies. The culture maintains high degradation rates for a suite of chlorinated ethenes and chlorinated ethanes (Lorah et al., 2003a; Lorah et al., 2004). A wide range of peat-sand-compost mixtures also was tested and a local crab compost was selected for a pilot test of the bioaugmented reactive mat. Field testing was initiated in September 2004 over $\mathrm{a} \sim 12 \mathrm{ft} \times 12 \mathrm{ft}$ seep area, where total cVOC concentrations are as high as 35 ppm. Preliminary results after 3 months of operation show 97 percent mass reduction of the total cVOCs during passive upward flow through the $\sim 1.8 \mathrm{ft}$ thick mat that was constructed over the seep. 


\section{SUPPLEMENT TO SECTION 5.2}

Page 126 of 147

\section{Mechanisms for Enhancements using Plants}

\section{Phytovolatilization}

Because many plants (especially some varieties of trees) transpire water at high rates during the growing season they can be used as a means of managing groundwater. In fact, most attempts at phytoremediation with trees have been to use them to "pump" water and cVOCs from a contaminated aquifer into the atmosphere. Monitoring subsurface water levels in wells indicates that phreatophytic trees such as the hybrid poplars and willows can be effective at lowering groundwater levels and modifying the hydraulic gradient within a plume to reduce flow rates and mass flux. Plants also can help control infiltration of water from precipitation.

Although many plants have the ability to exclude certain types of dissolved contaminants (e.g., metals) in groundwater that is being up-taken by roots, it appears that dissolved cVOC contaminants generally are extracted by trees along with water. This section addresses the process whereby the $\mathrm{cVOCs}$ are discharged to the atmosphere during transpiration (phytovolatilization). Alternatively, trees may have the capacity to metabolize the contaminants and generate a variety of byproducts. Consequently, it is important to recognize that even when trees are used as part of a hydraulic control process for a plume some contaminants will be extracted along with the groundwater and either metabolized or transpired creating an added bonus in reducing mass flux. For example, at Carswell Naval Air Station a MODFLOW groundwater flow model suggests that the planted trees have resulted in a 20-30\% volumetric reduction in groundwater (depressing the water table by $10 \mathrm{~cm}$ ). In addition an $11 \%$ reduction in TCE flux over a three year period was noted (EPA, 2003b).

If trees transpire TCE-contaminated groundwater, most of the TCE is volatilized into the atmosphere where it is ultimately destroyed photochemically. At the Aberdeen Proving Grounds $\mathrm{J}$-Field Site, it is estimated that $85 \%$ of the VOCs would be removed over a 30 -year period via phytovolatilization based on MODFLOW-RT3D calculations (EPA, 2000). Air emission standards for TCE need to be addressed during the design phase of any phytoremediation system. Typically, emissions from phytoremediation plots are minimal, but because standards vary by state and proximity to metropolitan centers the emissions should be documented and appropriate permits obtained if necessary.. The emissions from a small scale demonstration plantation will be very different than the emissions from a full scale phytoremediation plantation. In addition, a phytoremediation plantation may be associated with a soil vapor extraction unit that may limit any additional air emissions.

One of the major limitations to using plants to effectively remediate contaminated groundwater is root access. Surface planted phreatophytic trees typically grow roots to a depth of 8-10 ft. Groundwater plumes located below that depth are not accessible without utilizing alternate planting techniques. There have been several successful attempts to bring contaminated groundwater to trees for phytoremediation. One methodology involves stimulation of root growth to greater depths through the use of "treewells" and engineering the upward flow of contaminated groundwater to plant roots from confined or semi-confined aquifers. 
One interesting variation on the use of treewells is the addition of microbial innoculates to the tree planting medium within the well. This variation was demonstrated at the National Training Center in Orlando Florida. This approach allows for the development of microbial communities that are capable of degrading TCE. This strategy reduces the TCE levels in the root system and may increase the TCE levels at which trees can survive and grow. The trees, in turn, provide root exudates that provide a carbon source for the microbial communities.

A number of factors are critical in designing and implementing systems for plant-mediated phytovolatilization of TCE. They include contaminant levels, position on the landscape, climate, contaminant accessibility, and aquifer properties. Matthews et al. (2003) used models developed from MODFLOW and MODPATH to show that evaporation/transpiration from the plantation area required to completely capture a ground water plume is directly proportional to aquifer horizontal hydraulic conductivity, saturated thickness, and hydraulic gradient. Also, plantation area increased nonlinearly with increasing plume width, aquifer anisotropy, and decreasing growing season. Their model simulations did indicate that phytoremediation plantations can transpire more than three times the groundwater flux if properly designed. They recommend that hydrologic factors be considered and that simply calculating plantation size by dividing the contaminated ground water flux by the ET rate will grossly underestimate the water uptake needed to remediate a plume. Matthews et al (2003) also addressed the issue of seasonality of phytoremediation noting that their model simulations show that plantations can be sized to sufficiently depress the water table during the growing season so that groundwater does not bypass the ET pathway.

\section{Rhizodegradation}

One way plants modify the environment of the soil surrounding the roots is by releasing root exudates and secondary plant metabolites. Root exudates typically are photosynthetic carbon, low molecular weight molecules, and high molecular weight organic acids. This complex mixture modifies and promotes the development of a microbial community in the rhizosphere or soil environment beneath the plant. The low molecular weight secondary plant metabolites are typically considered to be nonessential for the plant metabolism but over evolutionary time have developed a suite of interactions between microorganisms, insects, and plants (Singer et al., 2003). These secondary metabolites have a potential role in the development of naturally occurring contaminant-degrading enzymes. For example, a common class of secondary plant metabolites is terpenoids. Terpenes have been shown to promote the degradation of xenobiotic compounds such as toluene, phenol (Gerhardson, 2002; Hadacek, 2002), and TCE (Kim et al., 2002; Davrock et al., 1992). Plants provide a source of carbon as well as specialized substrates that promote the degradation of some contaminants.

Research at the Aberdeen Proving Ground J-Field Toxic Pit Site suggests that the rhizosphere beneath planted poplar trees supports development of a microbial community capable of degrading TCE. The microbial community appears to develop as the poplar trees grow and mature. With maturation the influence of the trees on the soil continues to increase. Another example of the importance of the rhizosphere is found at the National Training Center site in Orlando, FL where treewells were bored into the underlying aquifer. The soil/media placed in the treewells were designed to enhance the development of a microbial community. 
Media amendments that promote degradation of TCE in the rhizosphere promote tree growth as well. These amendments can include sewage sludge, peat, organic soils, or even soybean oil. One potential drawback to the addition of amendments high in carbon is the reduction of oxygen in the soil/groundwater that might inhibit root growth to desired depths and may reduce transpiration of water from the aquifer.

\section{Phytodegradation}

One of the interesting developments associated with phytovolatilization systems is that some tree species (poplars, Leucaena leucocephala, Salix spp.) also can metabolize TCE (Newman et al., 1997; Doty et al., 2003; Shang et al., 2001; Newman and Reynolds, 2004). Resulting metabolic products include trichloroethanol, trichloroacetic acid, and dichloracetic acid. Experiments with tissue culture labeled with carbon 14 have shown that metabolism is not due to microbial processes, but represents a metabolic pathway in the plant. Mineralization products are probably incorporated into insoluble products such as components of plant cell walls. What proportion of the overall attenuation mechanisms displayed by plants is accounted for by the phytodegradation pathway is unresolved and is a potential direction for future research. 


\section{SUPPLEMENT TO SECTION 6.3}

For the more conventional in situ PRBs, some have been designed using a "funnel and gate" concept in which impermeable walls of various configurations are installed on either side of an opening or gap and function to "funnel" contaminated groundwater into the "gate" where reactive media is located and treatment occurs. Figure A-12 presents examples of different funnel and gate configurations used at field sites at Lowry AFB (CO), Naval Air Station (NAS) Moffet Field (CA), and Dover AFB (DE). Starr and Cherry (1994) have modeled the influence of different funnel and gate designs on plume capture properties. Where shallow conditions permit, the funnel and gate design occasionally has included an excavated treatment gallery in the gate which allows contaminated groundwater to pass through an engineered canister system containing the reactive media. Treatment systems based on this design concept were constructed at both the Portsmouth Gaseous Diffusion Plant and Y-12 (Oak Ridge) facilities and used to test several types of reactive media.

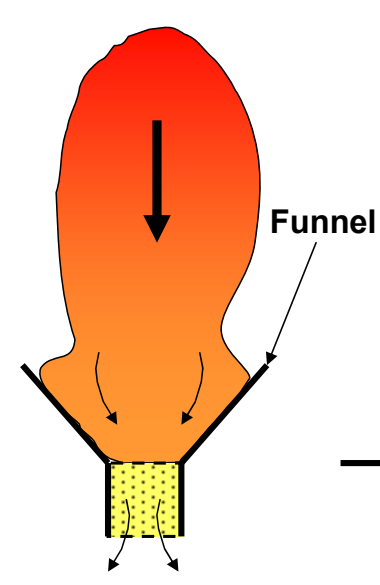

A.

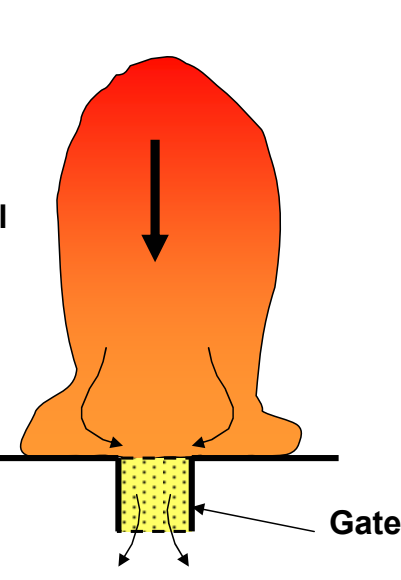

B.

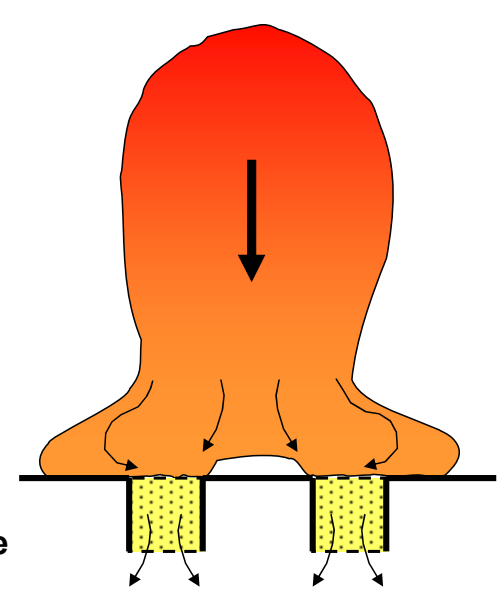

C.

\section{Figure A-12. Different Configurations of the Funnel and Gate Technology. (a). Lowry AFB, CO. (b). NAS Moffet Field, CA. (c). Dover AFB, DE.}

A wide variety of installation techniques have been devised for emplacing reactive barriers. For PRBs that are installed as a vertical wall in a trench excavated into the subsurface, standard construction methods are used (e.g. back hoe, clamshell, continuous trencher). Guar gum frequently is used to keep the trench open during installation of the reactive media. These methods have practical depth limitations of about $50 \mathrm{ft}$. Alternatively, installation with a large soil mixing auger (through which the reactive media is added during mixing) can be used to create a series of overlapping treatment columns to form the wall. Another approach involves driving a hollow mandrel into the ground, filling the space with reactive media, extracting the mandrel, moving over, and repeating the process to produce a continuous wall. The depth limit for these methods depends upon the lithologies encountered, but installation to a depth of $100 \mathrm{ft}$ may be possible at some sites. Hydraulic fracturing methods (where the reactive media is injected as a proppant) and jetting have been used to install PRBs at greater depths than can be 
achieved by other methods and there are several examples where emplacement depths $>100 \mathrm{ft}$. have been achieved. A more detailed discussion of these and other installation methods can be found in AFRL (2000).

Examples of the GeoSiphon approach are found at the Savannah River Site and Site 300 of LLNL (http://www.p2pays.org/ref/14/0_initiatives/init/spring01/geosiphon.htm). Simple gravity feed systems have been implemented at the Oak Ridge Y-12 (D.B. Watson, pers. comm.), Rocky Flats (http:/www.rfets.gov/doe/FactSheet/pdf/REME9E1.pdf), and Portsmouth Ohio (West, et al., 1997) facilities. In addition to avoiding expensive excavation costs, there is ready access to the treatment media in the canisters that simplifies monitoring and rehabilitation or replacement of media should that become necessary during operation. A potential downside of this approach is that there are several sites (e.g., Rocky Flats, Portsmouth Gaseous Diffusion Plant) where the rapid rate of oxidation of the ZVI requires frequent attention to avoid system clogging.

Recent application of solutions using innovative reactive materials (e.g., Na dithionite and nanoscale iron) permit emplacement by standard fluid injection methods where depth constraints are not significant.

Although ZVI is overwhelmingly the most frequently used reactive media, many different types of material have been studied that are applicable to cVOC treatment. Various forms of ZVI with and without amendments (Sivavec and Horney, 1995; Burris et al., 1995; Holser et al., 1995)), granular metals other than Fe (e.g. Cu, Al, Zn - Reynolds et al., 1990; Gillham and O'Hannesin, 1992; Boronina et al., 1995) and bimetallic materials (e.g., Fe - Pd: Muftikian et al., 1995; Korte et al. 1995; Orth and McKenzie, 1995) have been investigated.

In the past 10 years researchers have investigated several innovative approaches to reductive dechlorination of cVOCs with iron. One example involves the injection of a solution of a strong chemical reducing agent (sodium dithionite) which reduces Fe(III) present in aquifer minerals to $\mathrm{Fe}(\mathrm{II})$. Fe (II) has sufficient reducing capacity to degrade some cVOCs to innocuous byproducts (Fruchter et al., 1997).

Another recent example involves the use of nano-scale iron that can be injected as a colloidal suspension. A technical session at the Fourth International Conference on Remediation of Chlorinated and Recalcitrant Compounds (Monterey, CA, May 24-27, 2004) included at least 10 papers focusing on using nano-scale iron or bimetallic materials to treat DNAPLs. Examples included pilot-scale field tests involving injection of nano-particles of Pd-coated iron nanoparticles in an aqueous suspension (Henn and Waddill, 2004) and nano-scale iron suspended in a surfactant-stabilized biodegradable oil-in-water emulsion (O'Hara et al., 2004). In the case of the oil emulsion, both abiotic (due to the iron) and microbial (facilitated by the presence of the oil) degradation occurred. Although the relatively simple injection delivery system is an advantage for this technology, one still must consider how subsurface heterogeneities impact transport of the nano-scale particles to the contaminants. Furthermore, there are cost issues associated with the nano-scale materials, but they may decline in the future if there is more extensive use of this technology. 
Some field tests have been conducted with horizontally emplaced reactive zones where the reactive media is used as a proppant during soil fracturing. Zero valent iron was one type of material used in these studies, although an innovative approach that was investigated involved media composed of strongly oxidizing material (e.g. $\mathrm{KMnO}_{4}$ grouts) where oxidative degradation reactions are used to treat chlorinated ethene contaminants. In contrast to typical PRB applications, these horizontal reaction zones have been applied to low permeability media (e.g., clay) within the vadose zone. Slow infiltration of contaminated water passes into the reactive zone where either reductive (with $\mathrm{ZVI}$ ) or oxidative (e.g., $\mathrm{KMnO}_{4}$ ) degradation occurs thereby preventing contaminants from reaching the underlying aquifer. The $\mathrm{KMnO}_{4}$ grout formulation ensures that the highly soluble $\mathrm{KMnO}_{4}$ is not leached too rapidly. A pilot scale example of such an application was at DOE's Portsmouth Gaseous Diffusion Plant where horizontal treatment zones in the vadose zone intercepted and oxidized TCE leached from the soils (Siegrist et al., 1998; DOE, 2000b).

Another type of reactive wall capable of degrading cVOCs is a biobarrier in which a biological treatment zone is created by filling a trench that intercepts the groundwater plume with an organic material such as mulch, peat, or wood chips. The relatively high sorptive capacity of the media ensures that the residence time of contaminants in the barrier is sufficiently long to result in degradation. The biodegradable components of the organic medium are utilized by microbial consortia and can produce an anaerobic environment which is suitable for the reductive dechlorination of VOCs including TCE (Kao and Lei, 2000). Organic mulch does not inherently contain the correct bacterial assemblage for anaerobic degradation pathways. In separate aerobic and anaerobic micrcosm studies, Kao and Lei (2000) inoculated a peat biobarrier microcosm with activated sludge from a municipal waste water treatment plant and a known TCE/PCE contaminated aquifer as a source of bacteria. Both the aerobic and anaerobic microcosms containing sludge inocula showed higher rates of degradation than those without. Degradation rates for TCE in the aerobic microcosms of $0.277 \mu \mathrm{M} /$ day and $0.419 \mu \mathrm{M} /$ day for PCE in the anaerobic peat microcosms were observed.

In addition to providing a carbon source for the eventual release of hydrogen ions, the organic matter also acts physically to diffuse the groundwater plume. Peat also has the advantage of treating other contaminants such as metals and radionuclides and has been used in an admixture with iron filings for treating groundwater containing a variety of contaminants at DOE's Y-12 facility in Oak Ridge.

An example of a biobarrier is the mulch biowall constructed at Offutt Air Force Base in Nebraska (AFCEE, 2004b). A pilot-scale mulch wall to evaluate the technology was deployed in January 1999 in a trench $100 \mathrm{ft}$ long, $1.0 \mathrm{ft}$ wide, and $23 \mathrm{ft}$ deep. Based on the results from this pilot-wall a full scale wall was constructed with the treatment goal of reducing the ground water levels of TCE originating in Building 301 to MCLs at the base boundary. This new wall was constructed in July 2001 upgradient of the pilot-scale wall using a continuous trenching machine. It is $500 \mathrm{ft}$ long, $1.5 \mathrm{ft}$ wide, and $23 \mathrm{ft}$ deep. An attached hopper allowed for simultaneous filling of the trench with mulch as excavation proceeded. The fill was an equal mix of coarse sand and mulch. Over a two year period, the maximum TCE concentration of $1100 \mu \mathrm{g} / \mathrm{L}$ in groundwater entering the full-scale wall was reduced to $340 \mu \mathrm{g} / \mathrm{L} 15 \mathrm{ft}$ downgradient of the wall, representing a 95 percent removal efficiency (AFCEE, 2004b). Further reduction of TCE concentrations to 
$3.1 \mu \mathrm{g} / \mathrm{L}$ was observed as the treated groundwater subsequently passed through the pilot scale wall.

Another example of a biowall was constructed at Altus AFB, Oklahoma in June 2002. This pilot-scale wall is $455 \mathrm{ft}$ long, $24 \mathrm{ft}$ deep, and $1.5 \mathrm{ft}$ wide. It was filled with a composite of shredded tree mulch, cotton gin compost, and sand. Three months after the biowall was installed, upgradient wells recorded TCE levels at $8,000 \mu \mathrm{g} / \mathrm{L}$ while wells $30 \mathrm{ft}$ downgradient were $120 \mu \mathrm{g} / \mathrm{L}$ (AFCEE, 2003). Within nine months concentrations within and downgradient of the wall were at $5 \mu \mathrm{g} / \mathrm{L}$ (Henry et al., 2004). Within 17 months after installation monitoring data indicated the presence of sulfate reduction and methanogenesis in the wall that have resulted in a $90 \%$ reduction in chlorinated ethenes. A full scale $5000 \mathrm{ft}$ long and $35 \mathrm{ft}$ deep biowall was constructed during spring 2005 at Altus AFB (Borders, 2005).

Similar results were seen for a 100-ft-long, 23-ft-deep pilot wall established at Offutt Air Force Base near Omaha, Nebraska (EPA, 2002). After 31 months of treatment the average TCE removal down-gradient of the wall was $70 \%$ of that observed in the up-gradient influent groundwater (300-21,000 $\mu \mathrm{g} / \mathrm{L}$ up-gradient to $200-600 \mu \mathrm{g} / \mathrm{L}$ down-gradient). Based on this result a $500 \mathrm{ft}$ Biowall was constructed in 2001. As a result of these successful pilot projects the Air Force will be installing up to 5,400 ft of permeable mulch biowalls to treat chlorinated ethenes at Altus Air Force Base (Henry et al, 2004).

Construction costs for a mulch biobarrier wall are estimated at $\$ 140-360$ per linear foot (Henry et al., 2004). Monitoring costs are not included in this estimate. Installation is rapid; the 455-ftlong wall at Altus took less than 5 days to construct. The life expectancy of such walls is expected to be 5-10 years (Parson Corp., 2004), so that mulch biowalls based on current designs may not have sufficient longevity to be a viable enhancement for some systems where EA is under consideration. However, Robertson and others (2000) have shown that reactive mulch barriers designed to treat nitrates have remained effect for over seven years with only a $2-3 \%$ consumption rate of the original biomass. He suggested that these systems may remain effective for at least a decade or longer. Others suggest that, based on seven years of monitoring existing mulch walls, the original mulch in a biobarriers may last 10-15 years (Erica Becvar, AFCEE, pers. comm..). Some techniques such as the use of a perforated pipe to recharge the mulch with a soluble or semi-soluble electron donor or adding vegetable oil to the mulch before placing the mulch in the wall can extend the longevity of a mulch biobarrier. Dependent on site-specific conditions and goals, mulch biobarrier walls may be an appropriate EA technology.

Other types of PRBs where sorption is a primary method for removal of cVOC contaminants from groundwater are possible. For example, surfactant modified zeolites (e.g., Li and Bowman, 1998; Bowman et al., 2001) have been investigated for their ability to sequester a variety of contaminants. PRBs utilizing this type of media generally do not result in formation of secondary phases, but one must consider the loading capacity of the media when assessing the longevity of such PRBs.

Yet another form of barrier to contaminant migration in groundwater involves the use of emulsified oil that can be injected into the subsurface in the form of a series of overlapping treatment zones (see Figure A-13). The emulsified oil barrier both retards the rate of transport of 
cVOCs, but also promotes microbial growth leading to anaerobic degradation of the contaminants.

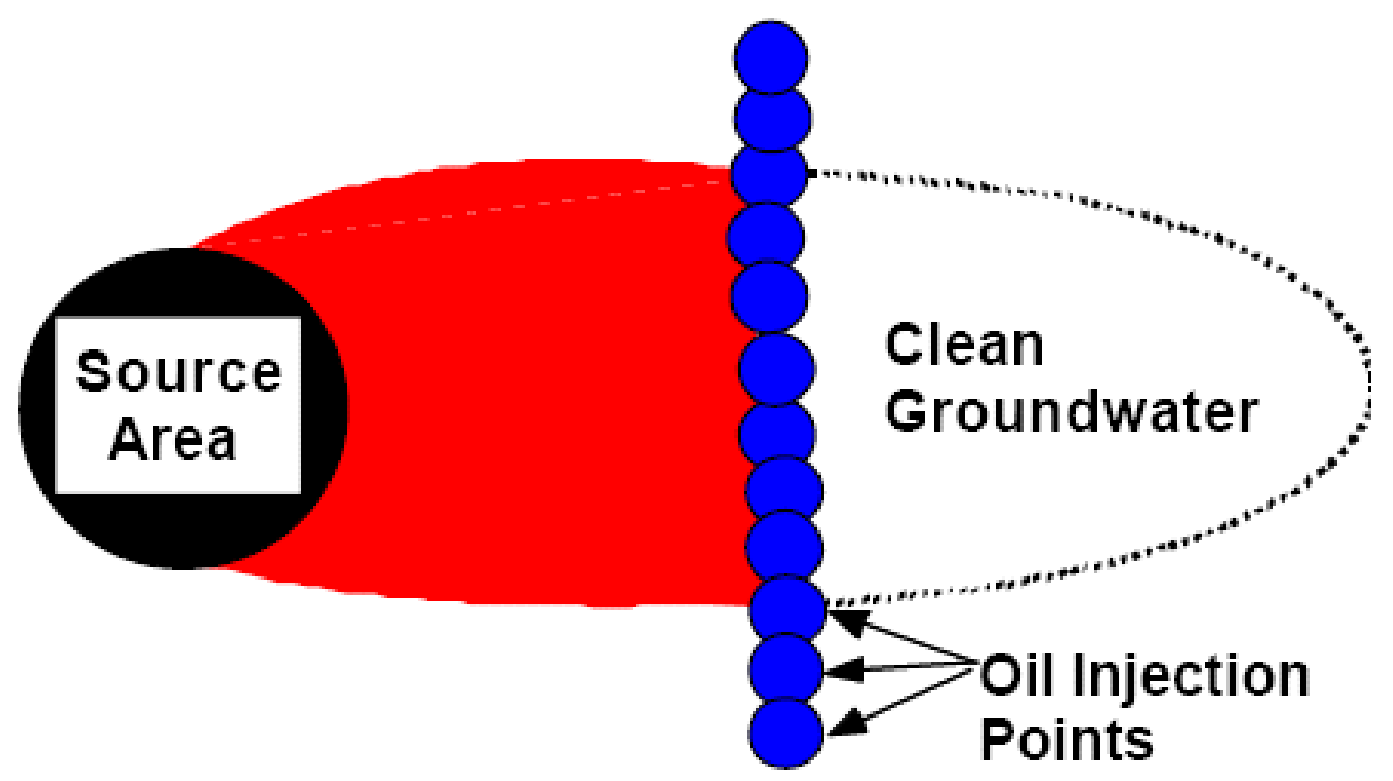

Figure A-13. Concept of a Reactive Barrier Using Emulsified Oil 


\section{APPENDIX B: CASE STUDY SUMMARY TABLES}

Table B-1. Summary case study references: Reduction of infiltration at source......................136

Table B-2. Summary case study references: Source containment. ........................................137

Table B-3. Summary case study references: Lowering the hydraulic gradient. .....................138

Table B-4. Summary case study references: Passive removal of source mass.......................139

Table B-5. Summary case study references: Enhanced destruction of contaminants.

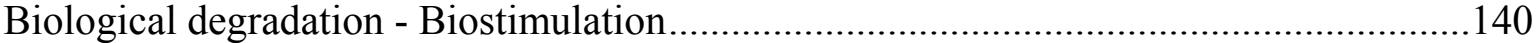

Table B-6. Summary case study references: Enhanced destruction of contaminants.

Biological degradation - Bioaugmentation and Wetland Systems ...................................141

Table B-7. Summary case study references: Enhanced destruction of contaminants.

Plant-Based Methods

Table B-8. Summary case study references: Enhanced destruction of contaminants.

Abiotic Degradation.

Table B-9. Summary case study references: Enhanced destruction of contaminants.

Permeable Reactive Barriers. 
WSRC-STI-2006-00083, Rev. 1

August 1, 2006

Page 135 of 147

This page intentionally left blank. 
Table B-1. Summary case study references: Reduction of infiltration at source.

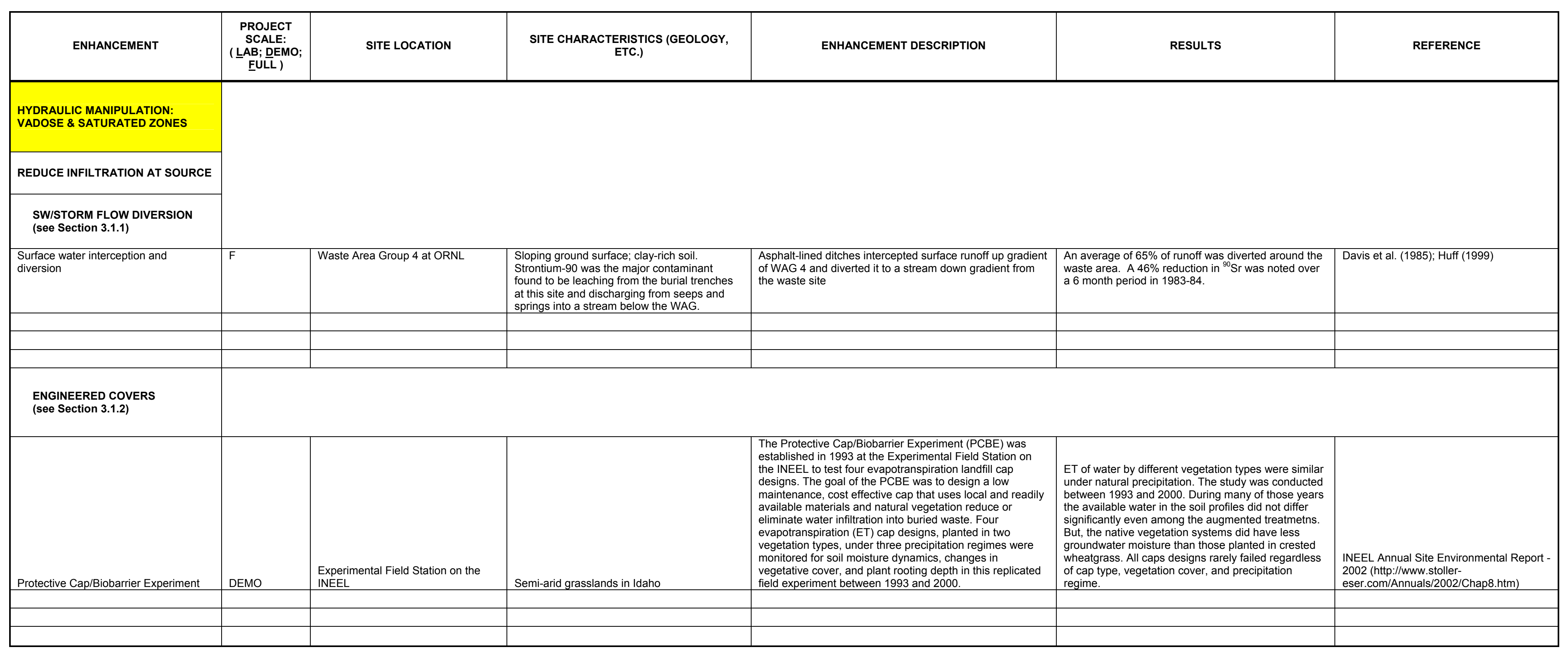


Table B-2. Summary case study references: Source containment.

\begin{tabular}{|c|c|c|c|c|c|c|}
\hline ENHANCEMENT & $\begin{array}{l}\text { PROJECT } \\
\text { SCALE: } \\
\text { (LAB; DEMO; } \\
\text { EULL ) }\end{array}$ & SITE LOCATION & $\begin{array}{l}\text { SITE CHARACTERISTICS (GEOLOGY, } \\
\text { ETC.) }\end{array}$ & ENHANCEMENT DESCRIPTION & RESULTS & REFERENCE \\
\hline \multicolumn{7}{|l|}{$\begin{array}{l}\text { HYDRAULIC MANIPULATION: VADOSE \& SATURATED } \\
\text { ZONES }\end{array}$} \\
\hline \multicolumn{7}{|l|}{ REDUCE MASS TRANSFER } \\
\hline \multicolumn{7}{|l|}{$\begin{array}{l}\text { SOURCE CONTAINMENT } \\
\text { (see Section 3.2.1) }\end{array}$} \\
\hline \multicolumn{7}{|l|}{ BARRIER WALLS } \\
\hline Biobarrier & $\mathrm{F}$ & Butte, MT & Homogeneous test cell; $K_{H}=0.02 \mathrm{~cm} / \mathrm{sec}$ & $\begin{array}{l}\text { Starved bacteria capable of producing a large amount of } \\
\text { biofilm were injected into the subsurface along with nutrient. } \\
\text { Once established, the bacteria clogs the aquifer sediment } \\
\text { pores reducing the permeability. }\end{array}$ & $\begin{array}{l}\text { A reduction of } \mathrm{K}_{\mathrm{H}} \text { by }-99.8 \% \text { was observed in the fast } \\
\text { flowing field test facility. The barrier remained } \\
\text { functional without further nutrient addition, although } \\
\text { the elength of testing is insufficicent to determine the } \\
\text { sustainability of biobarriers, but the Pls believ that } \\
\text { several years without further nutirent addititions is } \\
\text { realistic }\end{array}$ & Hiebert et al., 2001. \\
\hline $\begin{array}{l}\text { An evaluation report of subsurface engineered barriers } \\
\text { containing a number of case studies, some of which involve } \\
\text { CVOC contaminants. }\end{array}$ & $\mathrm{D}$ and $\mathrm{F}$ & Various & Various & $\begin{array}{l}\text { Several different types of engineered barriers including caps } \\
\text { and vertical structures }\end{array}$ & Various & EPA (1998b,c) \\
\hline $\begin{array}{l}\text { Injection of colloidal silica and polysiloxane liquids to form } \\
\text { impereable barriers }\end{array}$ & D & central California & $\begin{array}{l}\text { Heterogeneous fluvial sediments ranging } \\
\text { from coarse sand to large cobbles }\end{array}$ & $\begin{array}{l}\text { The two different grounts were injected at three levels (10, } \\
12 \text {, and } 14 \mathrm{ft} \text { ). }\end{array}$ & $\begin{array}{l}\text { Significant drops in hydraulic conductivity were noted } \\
(\sim-6-8 \text { orders of magnitude depending on the grout } \\
\text { type). Polysiloxane appeared to perform better. }\end{array}$ & Moridis, et al. (1996) \\
\hline Thin diaphragm wall & D & Dover AFB, DE & medium sand & $\begin{array}{l}\text { High-pressure jet grouting of bentonite-cement mixture. } \\
\text { Intersecting panels form barrier wall. }\end{array}$ & $\begin{array}{l}\text { A hydraulic conductivity target of } 2.52 \times 10^{-7} \text { was met, } \\
\text { but a defect was noted. }\end{array}$ & DOE (2000c) \\
\hline \multicolumn{7}{|l|}{ WASTE ENCAPSULATION } \\
\hline Grouting of waste trenches & $\mathrm{F}$ & WAG 4 at ORNL & $\begin{array}{l}\text { Trenches are filled with a variety of waste } \\
\text { materials. Trenches are excavated in the } \\
\text { saprolite derived from the Conasauga } \\
\text { Fm. (shales and interbedded carbonates) }\end{array}$ & $\begin{array}{l}\text { Three types of grout were injected into selected waste } \\
\text { trenches thought to be the source of significant } \mathrm{t}^{\circ} \mathrm{S} \mathrm{s} \text { releases } \\
\text { to seeps and springs: type III portland cement, } \\
\text { cement, and arrylamide grouts. Over } 500 \mathrm{~m}^{3} \text { of cof combined } \\
\text { grout was used }\end{array}$ & $\begin{array}{l}\text { The resultant hydraulic conductivity was } 1 \times 10^{-6} \text {, two } \\
\text { orders of magnitude above the natural soil. A } \\
\text { decrease of } 30 \% \text { in the annual releases of } \\
\text { two } \mathrm{Sr} \text { in the } \\
\text { two years following grouting was observed. }\end{array}$ & Huff (1999); Long et al. (1997) \\
\hline PARTITION BARRIERS & & & & & & \\
\hline
\end{tabular}




\begin{tabular}{|c|c|c|c|c|c|c|}
\hline ENHANCEMENT & $\begin{array}{l}\text { PROJECT } \\
\text { SCALE: } \\
\text { (LAB; DEMO; } \\
\text { FULL) }\end{array}$ & SITE LOCATION & SITE CHARACTERISTICS (GEOLOGY, ETC.) & ENHANCEMENT DESCRIPTION & RESULTS & REFERENCE \\
\hline \multicolumn{7}{|l|}{$\begin{array}{l}\text { HYDRAULIC MANIPULATION: } \\
\text { VADOSE \& SATURATED ZONES }\end{array}$} \\
\hline \multicolumn{7}{|l|}{ REDUCE MASS TRANSFER } \\
\hline \multicolumn{7}{|l|}{$\begin{array}{l}\text { LOWER HYDRAULIC GRADIENT } \\
\text { WITH ENGINEERED } \\
\text { STRUCTURES } \\
\text { (see Section 3.2.2) }\end{array}$} \\
\hline French drain & $\mathrm{F}$ & $\begin{array}{l}\text { Waste Area Group } \\
6 \text { at ORNL }\end{array}$ & $\begin{array}{l}\text { Soil is clay-rich saprolite from weathering of the } \\
\text { underlying Conasauga formation (shale with } \\
\text { some carbonats). WA } 6 \text { surface slopes to the } \\
\text { south and west and groundwater flow generally } \\
\text { follows the topographic gradient. }\end{array}$ & $\begin{array}{l}\text { Two segments of french drain were installed on the north and east side of } \\
\text { the } 49 \text { Trench section (iie. up gradient) where some trenches were } \\
\text { observed to become flooded during periods of high water table. The } \\
\text { french drains were constructed to a maximum depth of } 9 \mathrm{~m} \text { to ensure they } \\
\text { were deeeper than the trench bottoms. The drains discharge into a nearby } \\
\text { stream. }\end{array}$ & $\begin{array}{l}\text { The water table was lowered over } 50 \% \text { of the site to } \\
\text { a point where it no longer intersected the trench } \\
\text { bottoms. }\end{array}$ & $\begin{array}{l}\text { Davis and Stansfield (1984); Davis and } \\
\text { Marshall (1988) }\end{array}$ \\
\hline \multirow[t]{3}{*}{ GeoSiphon } & $\mathrm{F}$ & LLNL: Site 300 & Ex situ & $\begin{array}{l}\text { Geosiphon is a backup system to transport TCE and nitrate contaminated } \\
\text { groundwater to ex situ ZVI treatment canisters }\end{array}$ & System is a backup to natural artesian flow of wells. & $\frac{\text { www.p2pays.org/ref } / 14 / 0 \text { initititives/init }}{\text { Ispring01/geosiphon.htm }}$ \\
\hline & $\mathrm{F}$ & SRS: TNX site & Ex situ & $\begin{array}{l}\text { Geosiphon transports treated water from an ex situ system (treating TCE } \\
\text { and CT) to the point of discharge into a ditch draining to the Savannah } \\
\text { River }\end{array}$ & $\begin{array}{l}7.8-8.3 \mathrm{gpm} \text { could be treated by the system and } \\
\text { lower TCE to below MCLs. The } 1.43 \mathrm{fth} \text { head } \\
\text { difference that drove the GeoSiphon could deliver } \\
\text { only } 2.62 \mathrm{gpm} \text {. }\end{array}$ & $"$ \\
\hline & $\mathrm{D} / \mathrm{F}$ & SRS: D-Area & Ex situ & $\begin{array}{l}\text { GeoSiphon transports metal-contaminated waste water to an ex situ } \\
\text { treatment system. }\end{array}$ & $\begin{array}{l}\text { The GeoSiphon operated with an } \sim 5 \mathrm{ft} \mathrm{head} \\
\text { difference. }\end{array}$ & $"$ \\
\hline \multicolumn{7}{|l|}{$\begin{array}{l}\text { WITH TREES } \\
\text { (see Section 3.2.3) }\end{array}$} \\
\hline $\begin{array}{l}\text { Grand Forks Air Force Base, North } \\
\text { Dakota }\end{array}$ & & $\begin{array}{l}\text { Grand Forks Air } \\
\text { Force Base, North } \\
\text { Dakota }\end{array}$ & $\begin{array}{l}\text { A TCE plume up to } 4900 \mu \mathrm{gg} / \mathrm{L} \text { (and BTEX) in } \\
\text { located in the water table } 4 \text { to } 5 \mathrm{ft} \text { bgs. }\end{array}$ & 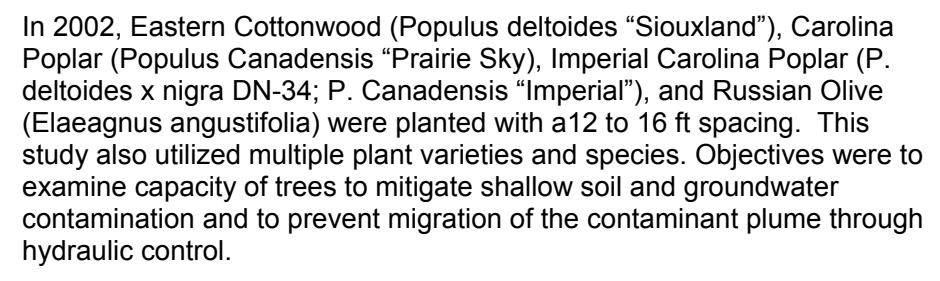 & & \\
\hline $\begin{array}{l}\text { Kauffman \& Minter, Jobstown, New } \\
\text { Jersey }\end{array}$ & & $\begin{array}{l}\text { Kauffman \& Minter, } \\
\text { Jobstown, New } \\
\text { Jersey }\end{array}$ & 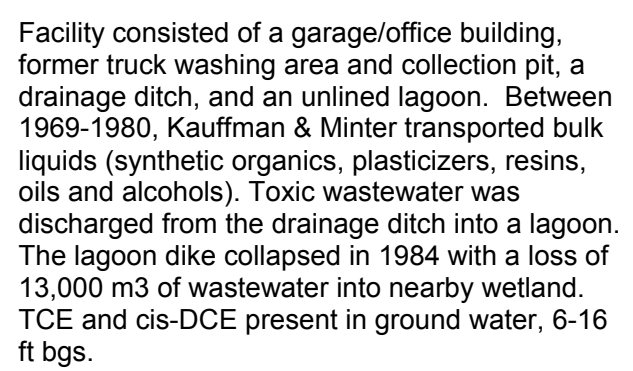 & $\begin{array}{l}\text { Two hundred sixty-five hybrid poplar (P. maximowciczi x trichocarpa) and } \\
\text { black willow (Salix nigra) were planted on a five acre site in } 1998 \text {. Also in } \\
1998,132 \text { new and } 46 \text { replacement poplar and willow trees were addded. } \\
\text { In spring of } 1999,58 \text { additional trees were planted in the former truck } \\
\text { wash bay area. } \\
\text { Presently, trees growing and in good health. Trees mulched and } \\
\text { Miracle-Gro fertilizer spikes installed adjacent to all trees. }\end{array}$ & & \\
\hline
\end{tabular}


Table B-4. Summary case study references: Passive removal of source mass.

\begin{tabular}{|c|c|c|c|c|c|c|}
\hline ENHANCEMENT & $\begin{array}{l}\text { PROJECT SCALE: } \\
\text { (LAB; DEMO; EULL) }\end{array}$ & SITE LOCATION & $\begin{array}{c}\text { SITE CHARACTERISTICS (GEOLOGY, } \\
\text { ETC.) }\end{array}$ & ENHANCEMENT DESCRIPTION & RESULTS & REFERENCE \\
\hline \multicolumn{7}{|c|}{ PASSIVE REMOVAL OF SOURCE MASS } \\
\hline \multicolumn{7}{|l|}{$\begin{array}{l}\text { VAPOR EXTRACTION } \\
\text { (see Section 4.1) }\end{array}$} \\
\hline Passive SVE with Baroballs & $D$ (treatability study)/F & SRS: Metallurgical Laboratory & $\begin{array}{l}\text { Underlain by sands, clayey sands, and } \\
\text { sandy clays; three fine-grained zones at } 15, \\
60, \text { and } 80 \text { th. Water table is at a depth of } \\
\sim 140 \mathrm{ft} \text {. CE, PCE, and Freon-113 are } \\
\text { primary contaminants. }\end{array}$ & $\begin{array}{l}\text { Baroballs were fitted onto PSVE wells within } \\
\text { and bounding subsurface soil gas } \\
\text { contamination. }\end{array}$ & $\begin{array}{l}\text { The PSVE network was conceived and } \\
\text { operated as a treatability study. After two } \\
\text { years there was signififant cleanup of the } \\
\text { subsurface and the PSVE network } \\
\text { transitioned to full-scale cleanup. }\end{array}$ & Riha, et al. (2000) \\
\hline
\end{tabular}


Table B-5. Summary case study references: Enhanced destruction of contaminants. Biological degradation - Biostimulation

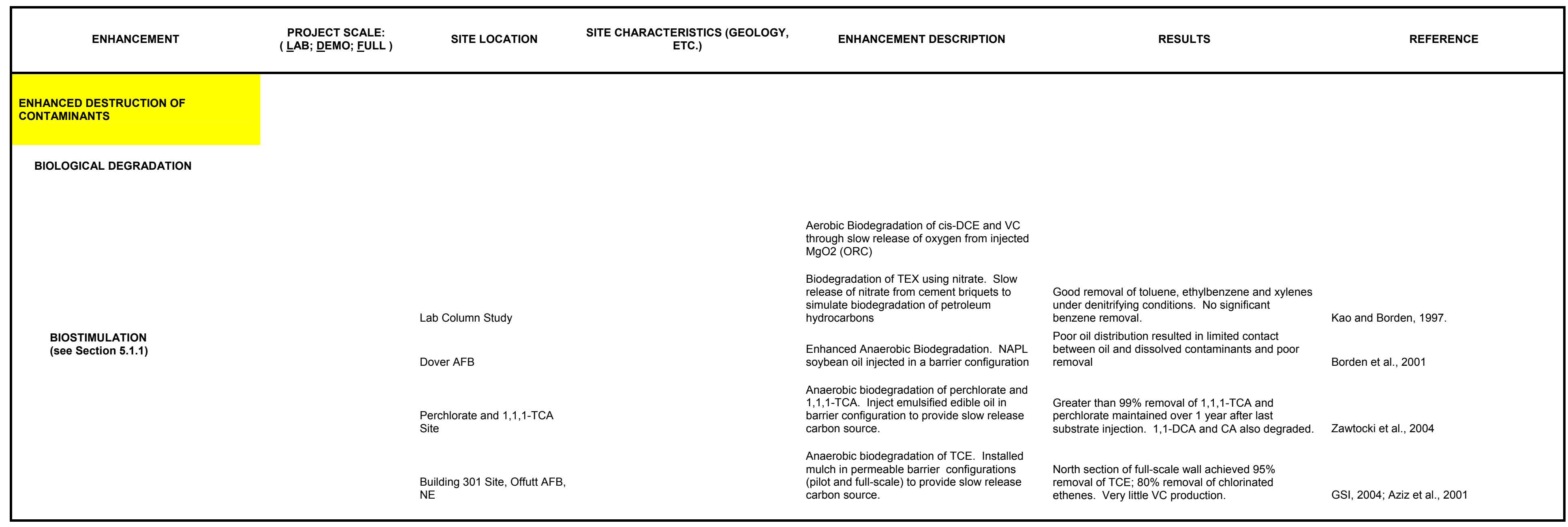


Table B-6. Summary case study references: Enhanced destruction of contaminants. Biological degradation - Bioaugmentation and Wetland Systems

\begin{tabular}{|c|c|c|c|c|c|c|}
\hline ENHANCEMENT & $\begin{array}{l}\text { PROJECT SCALE: } \\
\text { (LAB; DEMO; } \\
\text { EULLL) }\end{array}$ & SITE LOCATION & SITE CHARACTERISTICS (GEOLOGY, ETC.) & ENHANCEMENT DESCRIPTION & RESULTS & REFERENCE \\
\hline \multicolumn{7}{|l|}{$\begin{array}{l}\text { ENHANCED DESTRUCTION OF } \\
\text { CONTAMINANTS } \\
\text { BIOLOGICAL DEGRADATION } \\
\text { BIOAUGMENTATION } \\
\text { (see Section 5.1.2) }\end{array}$} \\
\hline $\begin{array}{l}\text { WETLAND SYSTEMS } \\
\text { (see Section 5.1.3) }\end{array}$ & Full-scale & $\begin{array}{l}\text { Superfund site, North } \\
\text { Dartmouth, } \\
\text { Massachusetts } \\
\\
\text { Superfund Site at } \\
\text { Aberdeen Proving } \\
\text { Ground, Edgewood, } \\
\text { Maryland. The specific } \\
\text { site is the 22nd Street } \\
\text { Landfilirea adjacent to } \\
\text { the southern Bush River. } \\
\text { Chemical Landfill Site, } \\
\text { High Point, North } \\
\text { Carolina adjacent to a } \\
\text { planned drinking water } \\
\text { reservoir. }\end{array}$ & $\begin{array}{l}\text { A plume with 1,1,2,2-tetrachloroethane and } \\
\text { trichloroethene and associated daughter products } \\
\text { underlies the landfill and is discharging into the } \\
\text { Bush River (Chesapeake Bay). } \\
\text { The site encompasses the old city landfill and an } \\
\text { adjacent chemical reprocessing facility. }\end{array}$ & 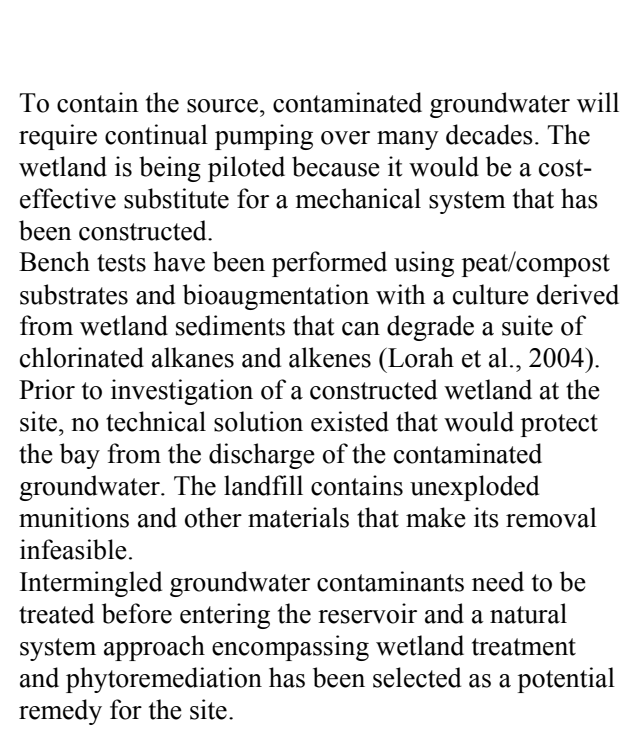 & $\begin{array}{l}\text { The wetland system is currently being designed } \\
\text { and regulatory activity is inititating. } \\
\text { Although awaiting final approval in Spring, } 2005 \text {, } \\
\text { the wetland system is planned for construction in } \\
\text { Fall } 2005 \text {. }\end{array}$ & 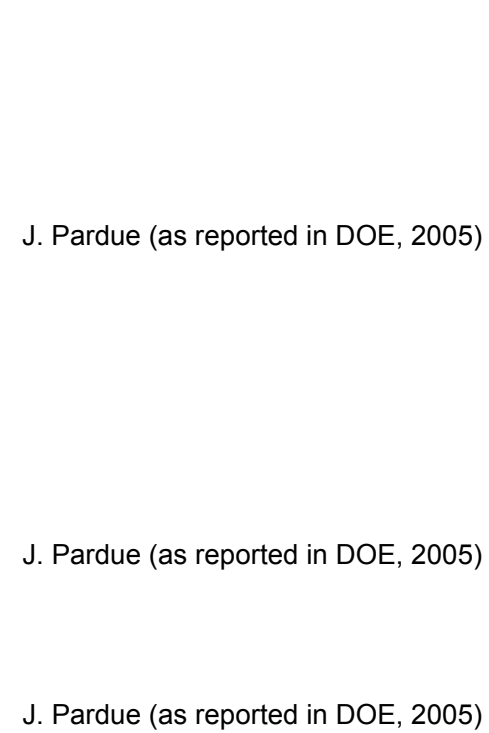 \\
\hline & $\begin{array}{l}\text { Full-scale; pilot- } \\
\text { scale } \\
\text { Pilot }\end{array}$ & $\begin{array}{l}\text { Hillsdale Michigan } \\
\text { Tow constructed } \\
\text { wetlands (one full-scale) } \\
\text { in Fort Edward, New } \\
\text { York } \\
\text { Offutt Air Force Base in } \\
\text { Nebraska }\end{array}$ & $\begin{array}{l}\text { groundwater contaminated with metal cleaning } \\
\text { solvents (Haberl et al., 2003) } \\
\text { Treatment of landfill leachate that contained } \\
\text { chlorinated VOCs. }\end{array}$ & $\begin{array}{l}\text { A passive upflow wetland system with four parallel } \\
\text { treatment cells has been operating since October } \\
1999 \text {. Trichloroethene and dichloroethene enter the } \\
\text { cells at 1-3 ppm. }\end{array}$ & 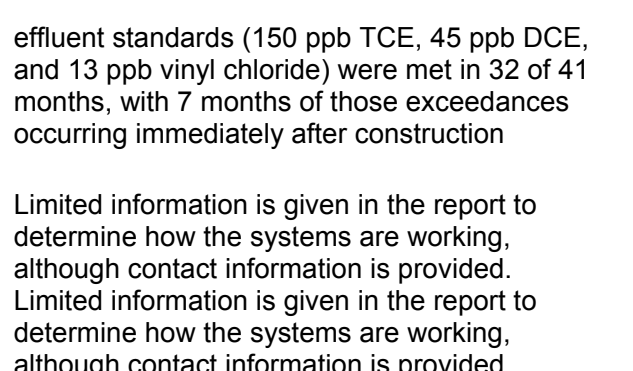 & ITRC (2003) \\
\hline & $\begin{array}{l}\text { full-scale } \\
\text { reconstruction }\end{array}$ & $\begin{array}{l}\text { along the shore of a lake } \\
\text { in Minnesota }\end{array}$ & $\begin{array}{l}\text { groundwater discharge that contained low } \\
\text { concentrations of chlorinated VOCs }\end{array}$ & 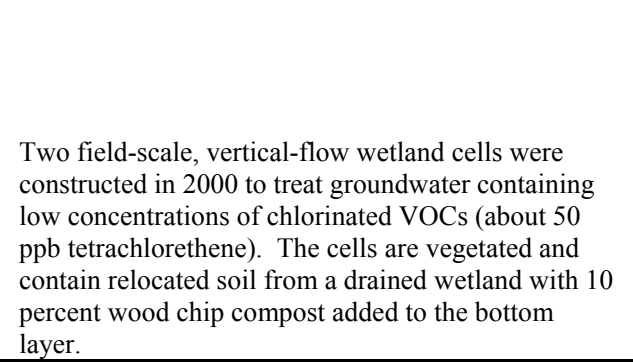 & 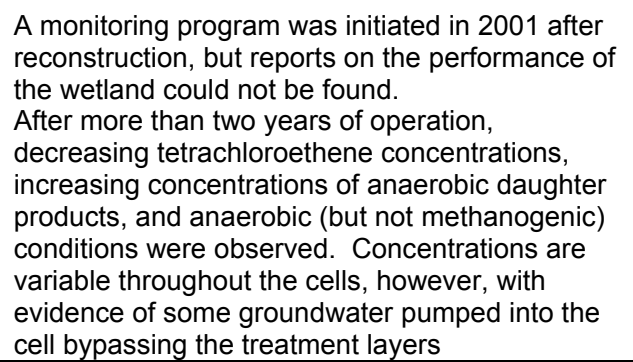 & BonDurant, 2004; Clemmer, 2003 \\
\hline
\end{tabular}


Table B-7. Summary case study references: Enhanced destruction of contaminants. Plant-Based Methods

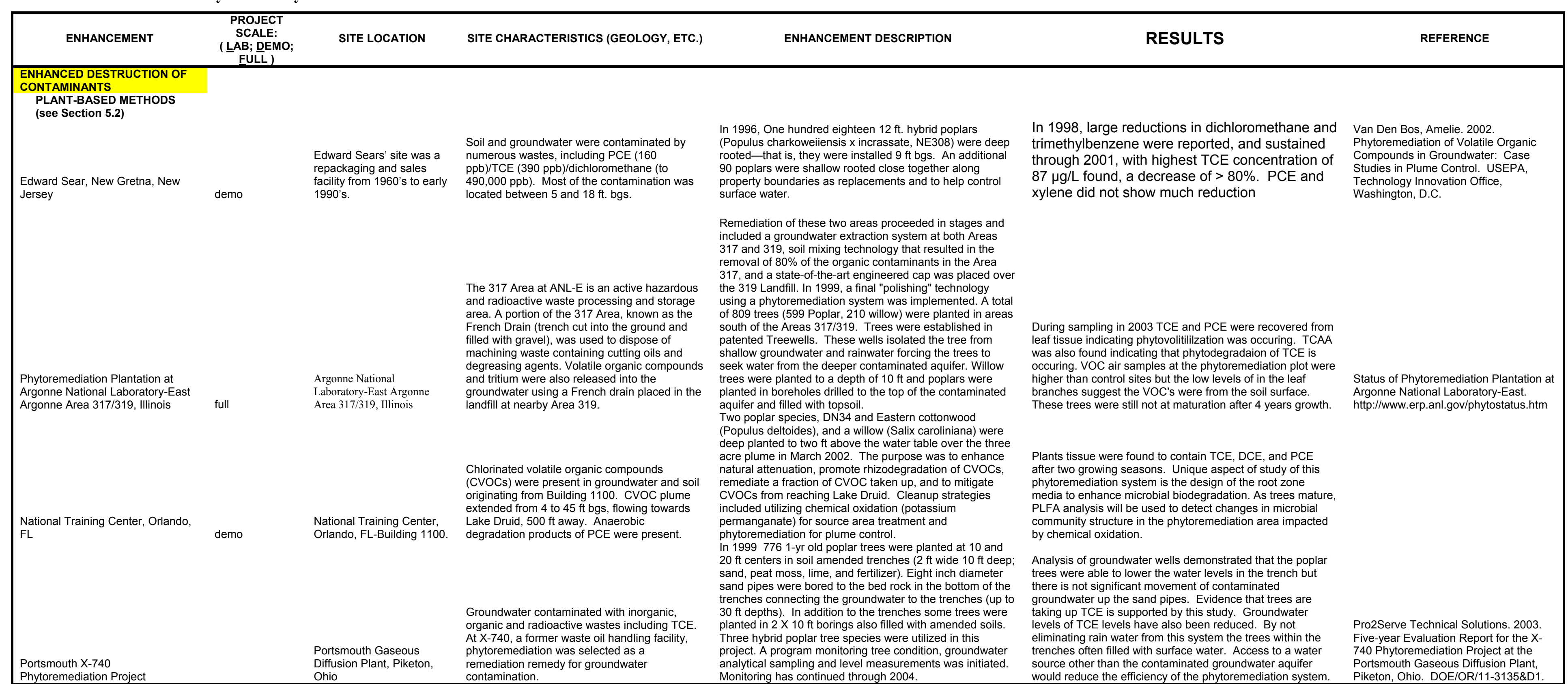


Aberdeen Proving Grounds-
Edgewood Area J-Field Site Edgewood Area
Edgewood, MD

Aberdeen Proving Grounds-Edgewood Area MD arswell Naval Air Statio ad by phytoremediation using native trees, a permeable
(PRB), and natural attenuation
The J-Field Toxic Pit Site was used as an open
pit burning facility for munitions and chemical agents including chlorinated solvent

tetrachloroethane at $20,000-220,200$ ag/ in

groundwater) from 1940 through the 1970s. This site is located in the Edgewood area of Maryland.

In 1996, 660 of Eastern Cottonwoods (Populus deltoids; 列 5 gallon bucket trees and whips) native to the region were planted to hydraulically contain and remove
TCE from underlying grordwater A mature 19 yr old TCE from underlying groundwater. A mature $19 \mathrm{yr}$ o comparisons of groundwater.
March/April, 1996, a phytoremediation study was Field could be removed through phytoremediation using . from the surface to the deeper roots to provide oxygen and promole deeper root growh. In adalition a drainage system high transpiration rates, 183 hybbrid popplar trees (Popullus

VOCs and their degradation products have been defected in

the leaf tissue and gas and water vapor expelled by the

and releaing the contamipans of concong, degradion

products included trichloroacetic acid (TCCA) that are dire

indicators that the poplar trees are not only transpiring TCE

flow rates and shallow ground water levels also indicate that

the trees are intercepting and removing the contaminants

from the site. Finally, it is possible that the trees may also be

needed to determine this, It is estimated that within 30

percent. Innovative planting techniques to isolate trees from

.

Monitoring was performed by studying tree cores and local

geochentistry and microbiology (29 moniloring wells) to

years, monitoring showed that young trees begn geochemistry and microbiology of nearby ground water,

Jansitioning to an increasingly anaerobic system. Constant volatilization and transpiration accounted for majority of loss of TCE mass. Transpiration rates were generallly higher in .

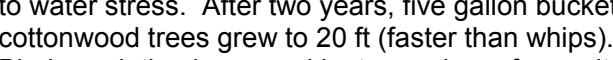

Biodegradation increased by two orders of magnitude and

magnitude. Evapotranspiration rates detemined, though

none available for this report. Three growing seasons resulted in $11 \%$ reduction of TCE flux. Estimated decrease rates for 660 trees was only 20 to 30 percent. ological degradation occurred naturally from abiof

generation of acetate from production of 1,1,1-TCA and source area, a PRB of zero valent iron (ZVI) was installed to teat a detached plume prior to its entering a fresh water marsh. Existing mature lowland forest situated beyond the phytovolatilization, so it was not necessary to cut trees.
Lower chlorinated ethenes appear to be attenuating at the most downgradient fringe of the plume through aerobic and
possibly anaerobic (iron reducing) microbial oxidation. There was minimal damage to environment and long term costs primarily were primarily for performance monitorimg. 
Table B-8. Summary case study references: Enhanced destruction of contaminants. Abiotic Degradation

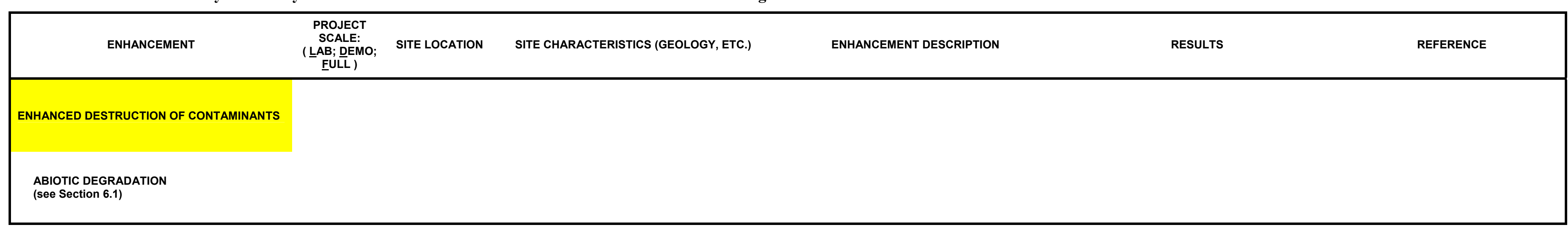


Table B-9. Summary case study references: Enhanced destruction of contaminants. Permeable Reactive Barriers

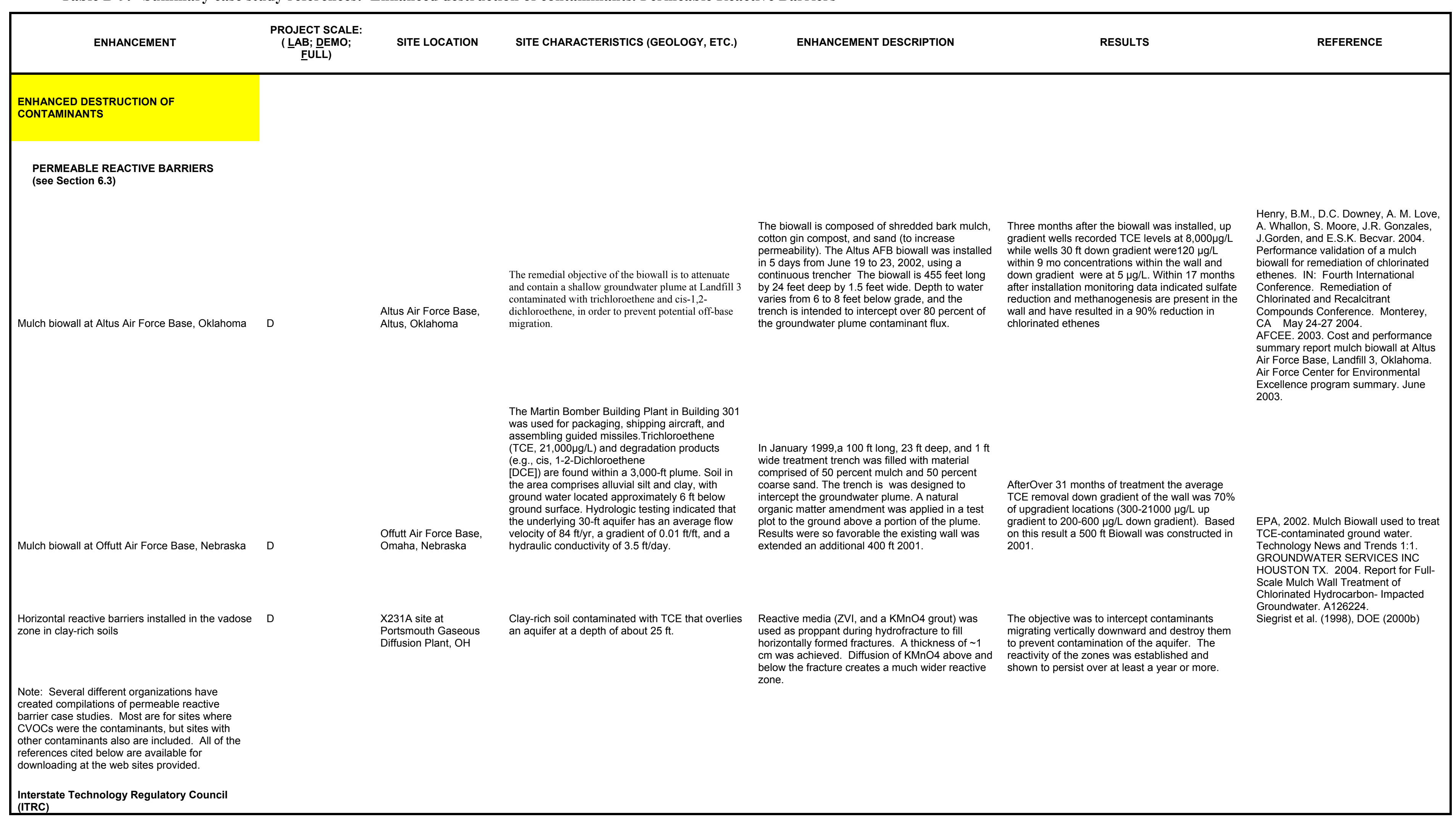


WSRC-STI-2006-00083, Rev. 1

August 1, 2006

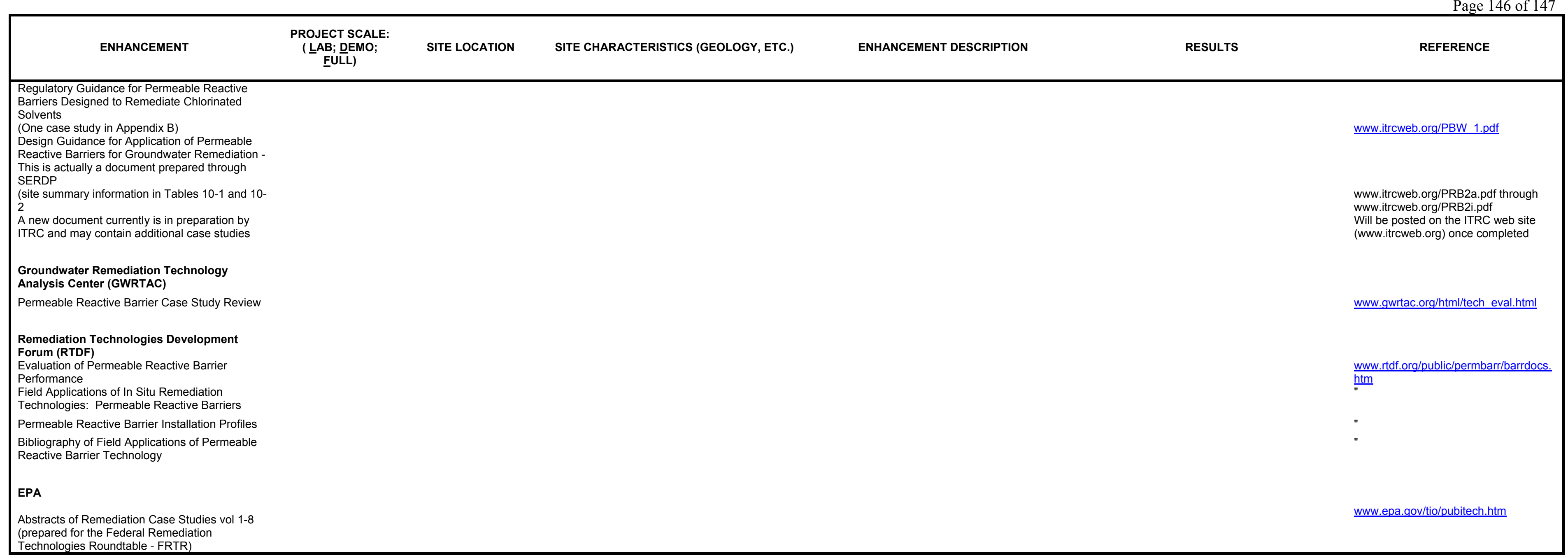


WSRC-STI-2006-00083, Rev.

August 1, 2006

Page 147 of 147

This page intentionally left blank. 